MARCIO AURELIO FURTADO MONTEZUMA

\title{
METODOLOGIA PARA IDENTIFICAÇÃO E CONTROLE DE UM PROTÓTIPO DE UMA PLATAFORMA DE MOVIMENTO COM 2 G.D.L.
}

Tese apresentada à Escola de Engenharia de São Carlos da Universidade de São Paulo para obtenção do título de Doutor em Engenharia Mecânica.

Área de Concentração: Aeronáutica Orientador: Prof. Dr. Eduardo Morgado Belo

São Carlos 

Candidato(a): Engenheiro MARCIO AURELIO FURTADO MONTEZUMA.

Tese defendida e julgada em 29/06/2010 perante a Comissão Julgadora:
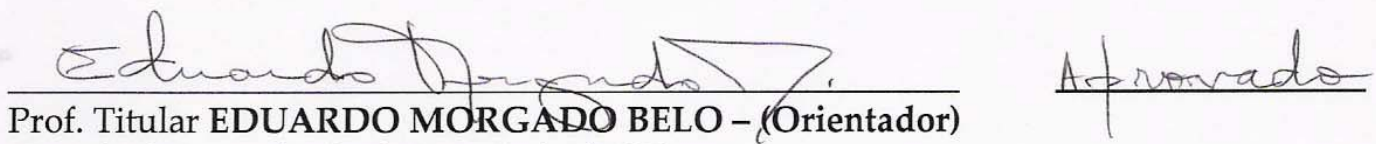

(Escola de Engenharia de São Carlos/USP)

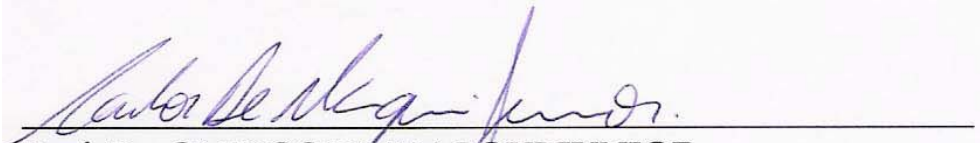

Prof. Dr. CARLOS DE MARQUI JUNIOR

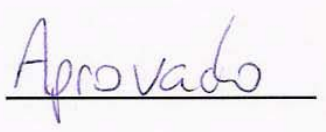

(Escola de Engenharia de Săo Carlos/USP)

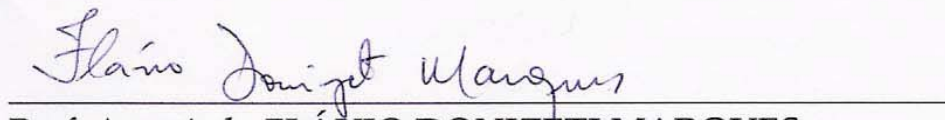

APROVADO

Prof. Associado FLÁVIO DONIZETI MARQUES

(Escola de Engenharia de São Carlos/USP)

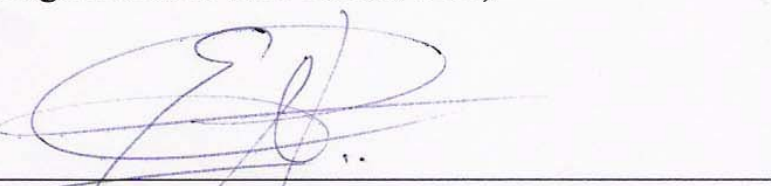

MPROVADO

Prof. Dr. EDSON ANTONIO CAPELLO SOUZA

(Universidade Estadual Paulista "Julio de Mesquita Filho"/UNESP/Campus de Bauru)

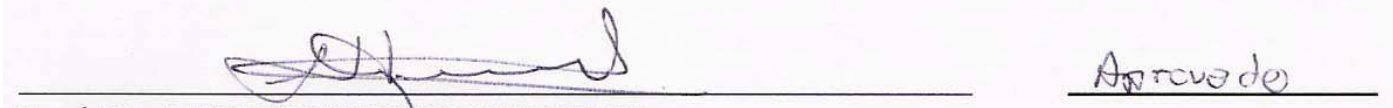

Prof. Dr. LUIZ HENRIQUE GEROMEL

(Universidade Tecnológica Federal do Paraná/UTFPR)

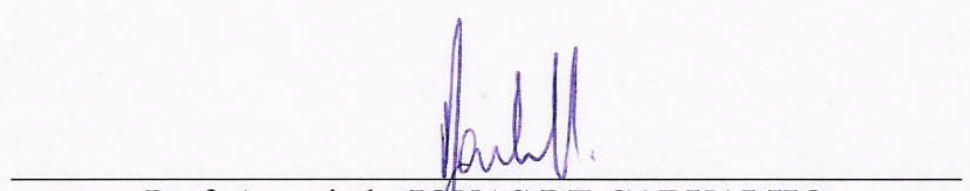

Prof. Associado JONAS DE CARVALHO

Coordenador do Programa de Pós-Graduação em

Engenharia Mecânica

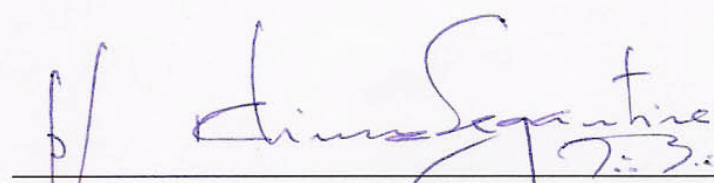

Prof. Titular GERALDO ROBERTO MARTINS DA COSTA

Presidente da Comissão da Pós-Graduação da EESC 
Dedico este trabalho à minha querida Tia Maninha (in memoriun). 


\section{AGRADECIMENTOS}

Ao Prof. Dr. Eduardo Morgado Belo pela orientação, discussão durante a elaboração deste trabalho, pela oportunidade que me foi dada e pela contribuição para minha formação como professor.

Ao Prof. Dr. Flávio D. Marques pelos conhecimentos adquiridos na sua disciplina, pelas conversas, comentários, discussões e principalmente pelos passeios.

Ao Prof. Dr. Álvaro Costa Neto pelos conhecimentos adquiridos nas suas disciplinas, pelas dicas sobre o $A D A M S^{\circledR}$, pelas discussões e comentários que me pouparam tempo e contribuíram para melhorar o trabalho.

Ao Prof. Dr. Carlos De Marqui Junior pela amizade durante todos esses anos.

Ao Prof. Dr. Glauco Augusto de Paula Caurin e Prof. Dr. Luiz Carlos Sandoval Góes do ITA/CTA pelos comentários e discussões que contribuíram para enriquecer o trabalho.

Aos Professores Passarini, Mucheroni, Pinotti, Seleguim, Durval, Evandro, Vilma, Varoto pelos conhecimentos adquiridos nas suas disciplinas.

Aos colegas de laboratório Caixeta, Daniela, Edson, Elizangela, Fabião, Gasparini, Júlio, Luciane, Nagamine e Maurício pelo companheirismo e amizade demonstrado nesse período de convívio.

Aos colegas da pós-graduação pelo companheirismo e amizade.

Ao amigo Vicente por toda a colaboração durante as disciplinas, pelos almoços divertidos e pela grande amizade que construímos nestes anos.

Ao amigo André Lins pelas discussões e sugestões que me ajudaram a realizar este trabalho.

Ao amigo Ricardo Breganon, pela colaboração durante as realizações dos experimentos e nas horas de aflição sempre um companheiro fiel. E, também, pelo rango da republica.

Aos amigos de Uraí Rogério, Solange, Adriana, Aguinaldo, Joãozinho, Pedrinho, Bento, Dona Nice pela amizade e companheirismo durante todos esses anos.

À amiga Luciana Abdo pela amizade e pelas idas aos barzinhos. 
Às secretárias Ana Paula, Cristina, Gisele pela ajuda e suporte.

Aos técnicos do Laboratório de Aeronaves Carlos, Osnam e Claudio.

Aos meus pais e a toda a minha família pelo carinho, incentivo e apoio.

A Universidade Tecnológica Federal do Paraná - UTFPR/Campus Cornélio Procópio por ter me concedido o afastamento das minhas atividades para realização deste trabalho.

Aos amigos da Universidade Tecnológica Federal do Paraná - UTFPR/Campus Cornélio Procópio.

Ao Prof. Devanil Antonio Franscisco, diretor do campus da UTFPR de Cornélio Procópio, uma das pessoas que mais me incentivaram a começar e a terminar este trabalho.

À Prof $f^{a}$ Dra. Marilu Martens pela correção de português da revisão bibliográfica.

Ao pessoal da Ca And Ma Vera, Sebastião, Coxinha e André por todos esses anos de amizade e diversão.

Ao amigo Conrado Di Raimo pela amizade e por me agüentar durante esse período complicado.

Ao amigo Luiz Henrique Geromel pelo incentivo e amizade.

Aos amigos Rogério e Lígia Ikegame pelos churrascos e pela amizade.

Ao amigo Jorge pelas ajudas com o LabVIE $W^{\mathrm{TM}}$.

Ao pessoal da Eletrônica Pinhé Caetano e Paco pelo atendimento e a amizade ao longo desses anos.

Ao instrutor do SENAI de São Carlos David Nacur por ter me ensinado eletrônica e pela amizade que fizemos durantes esses anos.

Aos amigos Reginaldo, Rafaela e Leandro companhia sempre muito agradável nas aulas do SENAI.

Ao pessoal da GJR Godoy, Rene, Jorge, Zé Paulo, Joãozinho pela colaboração nos trabalhos de usinagem e soldagem que tornaram este trabalho possível. 
Ao pessoal da república Gawa, Roy, Dinão, Ivan, Lucas, Brega, Gianlucca e Moselli pela amizade e pelas horas descontraídas e divertidas que passamos juntos.

A Marcia Marques da Silva Carvalho bibliotecária do Centro de Ciências da Saúde da Universidade Estadual de Londrina pela revisão deste trabalho segundo as normas da ABNT. 
"Combati o bom combate, completei a corrida, guardei a fé." São Paulo Apóstolo 


\section{RESUMO}

MONTEZUMA, Marcio Aurelio Furtado. Metodologia para Identificação e Controle de um Protótipo de uma Plataforma de Movimento com 2 G.D.L. 2010. 167 p. Tese (Doutorado em Engenharia Mecânica) - Escola de Engenharia de São Carlos, Universidade de São Paulo, São Carlos, 2010.

Devido à dificuldade em se desenvolver um sistema de controle baseado no modelo da planta, principalmente quando a mesma possui diversos graus de liberdade, busca-se uma metodologia a fim de minimizar o tempo e os esforços para projetar o sistema de controle. A metodologia consiste na utilização de um software de sistemas multicorpos, para a geração do conjunto de equações que descrevem o comportamento dinâmico, a partir de características físicas do sistema, tais como: massa, centro de massa, momentos principais de inércia, dimensões dos elos e juntas com determinados graus de liberdade. Para determinação das características físicas, são utilizadas técnicas experimentais, procedimentos e instrumentação para identificação com acuracidade controlada dos centros de massa e dos momentos principais de inércia dos elos. Estes são considerados corpos rígidos não homogêneos, algumas vezes acoplados por juntas de movimento, não sendo possível desacoplá-los. $\mathrm{O}$ sistema de controle utiliza um sistema com realimentação de estados com observador, capaz de fornecer resultados satisfatórios. O observador é utilizado para diminuir o número de estados medidos, facilitando a instrumentação do mecanismo. Esses procedimentos podem ser aplicados à maioria dos sistemas multicorpos, com muitos graus de liberdade, a fim de se obter um sistema de controle com desempenho e acuracidade predefinidos, para serem implementados em sistemas de aquisição e controle flexíveis, ou através de hardwares dedicados. Para validar essa metodologia, esta será aplicada ao protótipo de uma plataforma de movimento que, por conveniência de projeto, teve seus graus de liberdade controlados limitados a dois. Seu acionamento dá-se por servomotores brushless, atuadores de fusos de esferas, utilizando-se sensores de posição linear por magnetostrição e angular ópticos. $\mathrm{O}$ fato do número de graus de liberdade ter sido reduzido a dois não invalida a metodologia, caso seja necessário aplicá-la a sistemas com qualquer número de graus de liberdade.

Palavras-chave: Prototipagem Virtual. Identificação de Características Inerciais. Controle Seguidor. Plataforma de Stewart. Simulador de Vôo. 


\begin{abstract}
MONTEZUMA, Marcio Aurelio Furtado. Methodology for identification and control of a movement platform prototype with 2 D.O.F. 2010. 167 p. Thesis (Doctoral in Mechanical Engineering) - Escola de Engenharia de São Carlos, Universidade de São Paulo, São Carlos, 2010 .

The difficulty to develop a control system based in the model of the plant, mainly when the plant has many degrees of freedom, motivated this work which presents a methodology to minimize the time and effort in developing the control system. The methodology consists on the use of a multibody systems software for generating the set of equations that describes the system dynamic behavior, starting from its physical characteristics such as mass, center of mass, principal moments of inertia, dimensions of the links and joints with certain degrees of freedom coupling the links. For the physical characteristics determination, experimental techniques, procedures and instrumentation are used to identify, with controlled accuracy, the links centers of mass and principal moments of inertia, being the plant considered formed by non homogeneous rigid bodies, sometimes coupled by joints of movement and not being possible to uncouple them. For the control system a state feedback control system with estimator is used, capable of suppling satisfactory results. An estimator is used to reduce the number of measured states facilitating the mechanism instrumentation. Those procedures can be applied to most of multibody systems with several degrees of freedom to obtain a control system with performance and accuracy previously defined to be implemented in a flexible acquisition and control board or dedicated hardware. To validate this methodology, it will be applied to a prototype of a movement platform, which, for project convenience had their controlled degrees of freedom limited to two. The platform is driven by brushless servomotors, has actuators with spindle bearings, using sensors of linear position by magnetostriction and angular by optical principle. The fact of the number of degrees of freedom being reduced to two doesn't invalidate the methodology in case it is necessary to apply it to systems with any number of degrees of freedom.
\end{abstract}

Keywords: Virtual Prototyping. Identification of Inertial Characteristics. Tracking System. Stewart Platform. Flight Simulator. 


\section{LISTA DE FIGURAS}

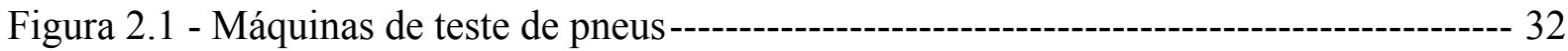

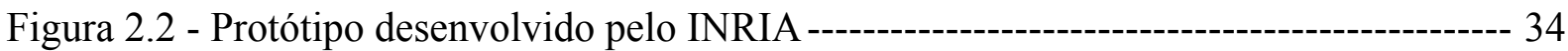

Figura 2.3 - Robô manipulador baseado em uma plataforma de Stewart------------------------ 35

Figura 2.4 - Robô Puma 260 montado no Sistema Emulador de Veículo ----------------------- 36

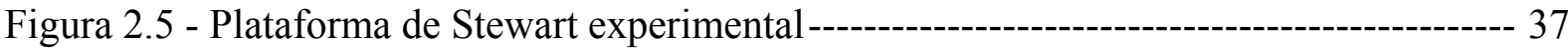

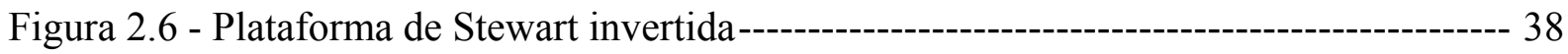

Figura 2.7 - (a) Plataforma de Stewart SPIKE, (b) Sistema de coordenadas do robô móvel

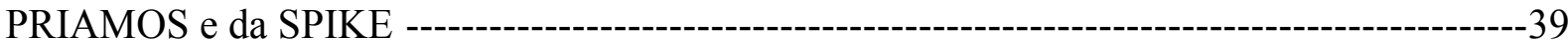

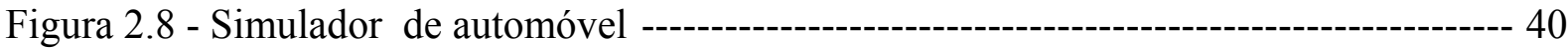

Figura 2.9 - (a) Sistema de movimento experimental, (b) Simulador de vôo ----------------- 41

Figura 2.10 - Controle do sistema de movimento do simulador de vôo em vários níveis ----- 41

Figura 2.11 - (a) Arranjo experimental da plataforma de Stewart, (b) Processo de usinagem

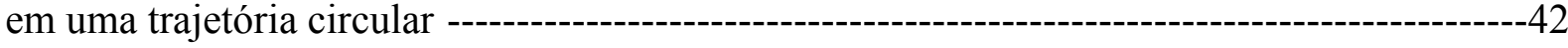

Figura 2.12 - Diagrama esquemático do controlador da plataforma de Stewart----------------- 42

Figura 2.13 - Plataforma de Stewart equipada com um difratômetro de raio X ----------------- 43

Figura 2.14 - Plataforma cinestática aplicada a fresagem de contorno --------------------------- 44

Figura 2.15 - Resposta a uma entrada degrau usando um controlador PID --------------------- 44

Figura 2.16 - Hexabot Serie 1 fabricado pela Hexel Corporation---------------------------- 45

Figura 2.17 - (a) Plataforma de Stewart e (b) Ambiente virtual de dirigibilidade--------------- 46

Figura 2.18 - (a) R Series Rotopod, (b) P 2000 Hexapod fabricados pela PRSCO ----------- 46

Figura 2.19 - Robô PAROS da fabricante Micos-------------------------------------------------- 47

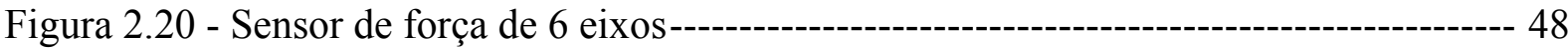

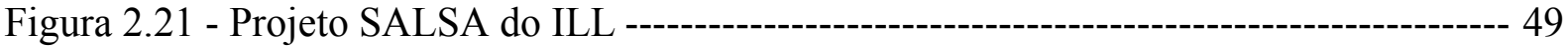

Figura 2.22 - Simulador mini-van-sized da universidade McMaster----------------------------- 49

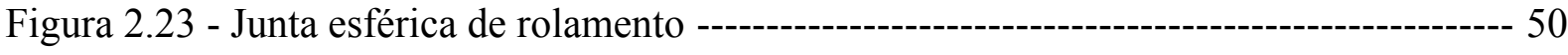

Figura 2.24 - FlexPLP sendo utilizado para posicionar um automóvel em fabricação. ------- 51 
Figura 2.25 - Esquema do robô Delta, patente US No. 4.976.582--------------------------------- 52

Figura 3.1 - Configurações da plataforma de Stewart---------------------------------------------- 53

Figura 3.2 - Configuração cúbica da plataforma de Stewart ---------------------------------------- 54

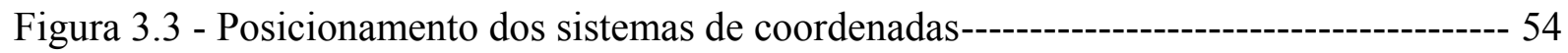

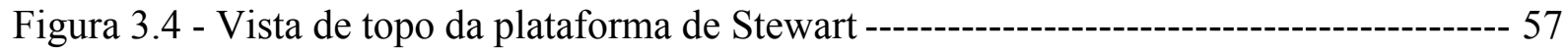

Figura 3.5 - Distância do vértice do cubo ao centro de massa da plataforma móvel------------ 57

Figura 3.6 - Ângulo dos atuadores com a horizontal --------------------------------------------------- 59

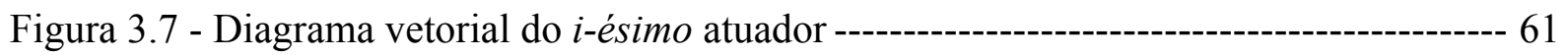

Figura 4.1 - Determinação experimental do centro de massa --------------------------------------- 66

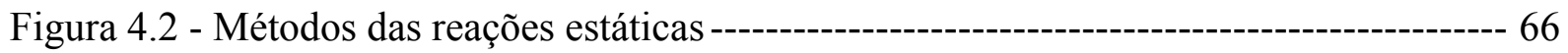

Figura 4.3 - Curva de calibração do sistema de aquisição e da célula de carga ---------------- 68

Figura 4.4 - Determinação do centro de massa utilizando reações estáticas -------------------- 69

Figura 4.5 - Movimento relativo entre os elos ---

Figura 4.6 - Solução para determinação do centro de massa para três reações estáticas ------ 73

Figura 4.7 - Método da pendulação --------------------------------------------------------------- 74

Figura 4.8 - Método da vibração----------------------------------------------------------------------- 74

Figura 4.9 - Etapas do ensaio de identificação de momento de inércia-------------------------- 75

Figura 4.10 - Cavalete para determinação experimental de centro de gravidade e momentos

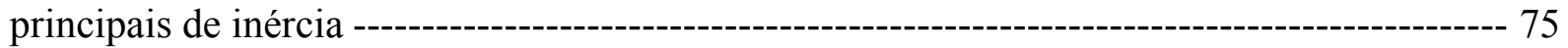

Figura 4.11 - Peça sobre suporte oscilatório ---------------------------------------------------- 78

Figura 4.12 - Eixo $O L$ e sua direção representada pelo versor $\lambda$. ------------------------------- 81

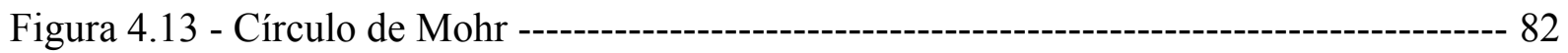

Figura 4.14 - Encoder HEDS-5540\#A02, Avago Technologies ---------------------------------- 90

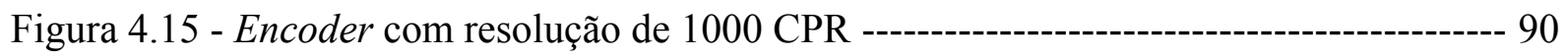

Figura 4.16 - Dispositivo em inox para fixação do encoder HEDS-5540\#A02 ---------------- 91

Figura 4.17 - Dispositivo para proteção, alinhamento e fixação do encoder--------------------- 91

Figura 4.18 - Encoder AEAS-7000-1GSG0, Avago Technologies ---

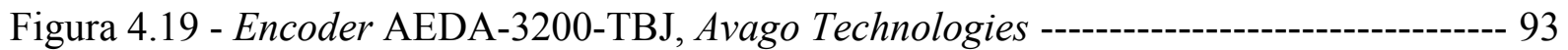




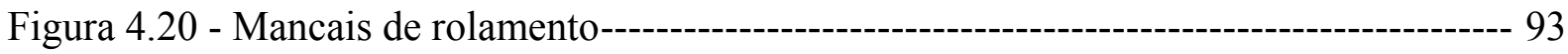

Figura 4.21 - Acoplamento rígido para compensação de desalinhamento ---------------------- 94

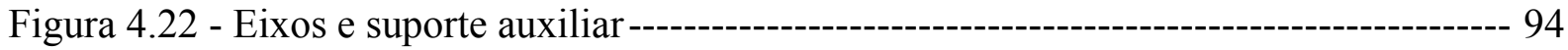

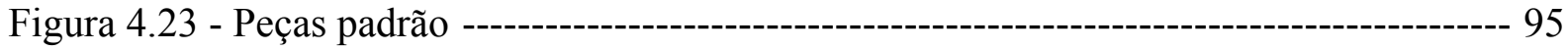

Figura 4.24 - Eixo principal de inércia da peça paralelo ao eixo de rotação -------------------- 96

Figura 4.25 - Medidor de Inclinação PRO 3600, Mitutoyo----------------------------------- 96

Figura 4.26 - Eixo principal de inércia da peça paralelo ao eixo de rotação --------------------- 97

Figura 4.27 - Protótipo de uma plataforma de movimento com 2 G.D.L. ---------------------- 102

Figura 4.28 - Conectores da placa de aquisição e controle DS1103, dSPACE, Inc ----------- 103

Figura 4.29 - Exemplo de painel de controle elaborado utilizando o control desk

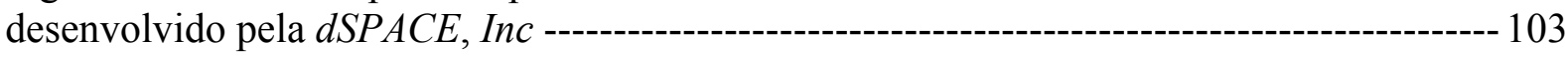

Figura 5.1 - Ensaio para determinação do centro de massa da haste, coordenada $y$, através de reações estáticas ----------------------------------------------------------------------------------- 105

Figura 5.2 - Ensaio da haste do atuador para determinação do momento de inércia em $x$--- 106 Figura 5.3 - Ensaio da haste do atuador para determinação do momento de inércia em y --- 106 Figura 5.4 - Gráfico do erro quadrático mínimo para determinação do momento de inércia

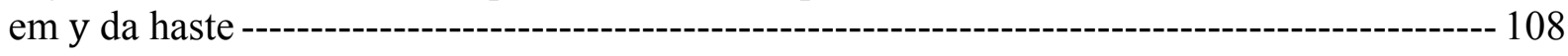

Figura 5.5 - Posicionamento do centro de massa e dos eixos principais de inércia da haste

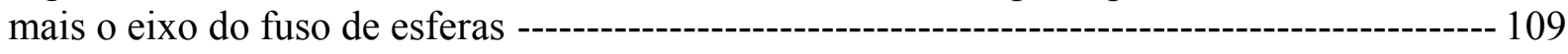

Figura 5.6 - Posicionamento do centro de massa e dos eixos principais de inércia do eixo

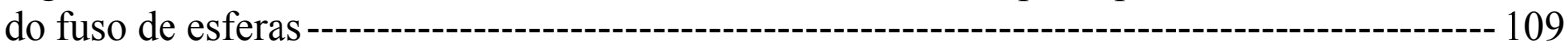

Figura 5.7 - Posicionamento do centro de massa e dos eixos principais de inércia do garfo

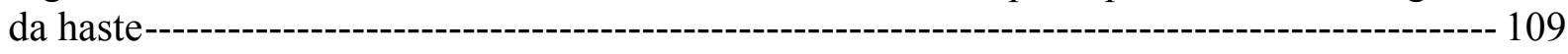

Figura 5.8 - Ensaio para determinação do centro de massa do atuador, coordenada $\mathrm{x}$,

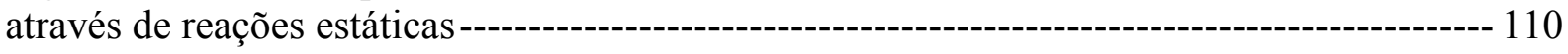

Figura 5.9 - Ensaio do atuador (a) para determinação do momento de inércia em x, (b) para determinação do momento de inércia em $z$ -

Figura 5.10 - Ensaio do atuador para determinação do momento de inércia em $y$------------- 111

Figura 5.11 - Ensaio do atuador para determinação do momento de inércia para o eixo OL 112

Figura 5.12 - Gráfico do erro quadrático mínimo para determinação do momento de inércia em $y$ do atuador ------------------------------------------------------------------ 113 
Figura 5.13 - Posicionamento do centro de massa e dos eixos principais de inércia do atuador para o curso utilizado nos ensaios----------------------------------------------------- 114

Figura 5.14 - Plataforma: (a) modelada no $A D A M S^{\circledR}$ (b) real----------------------------------- 114

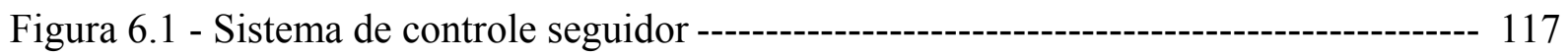

Figura 6.2 - Planta física e um observador para reconstruir os estados ------------------------- 121

Figura 7.1 - Modelo dinâmico da plataforma de movimento desenvolvida no $A D A M S^{\circledR}$---- 123

Figura 7.2 - Sistema de controle seguidor com observador --------------------------------------- 125

Figura 7.3 - Deslocamento dos atuadores para uma entrada degrau ----------------------------- 129

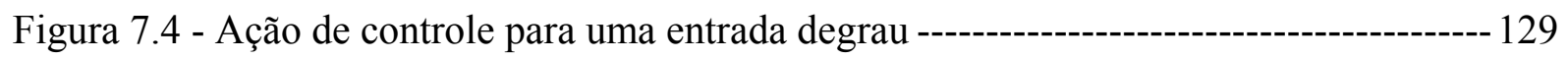

Figura 7.5 - Deslocamentos dos atuadores para uma entrada senoidal de $1 \mathrm{rad} / \mathrm{s}$,

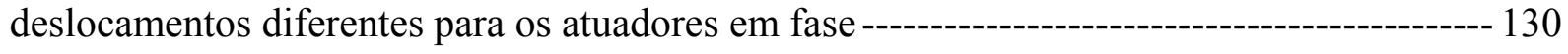

Figura 7.6 - Ação de controle para uma entrada senoidal de $1 \mathrm{rad} / \mathrm{s}$, deslocamentos

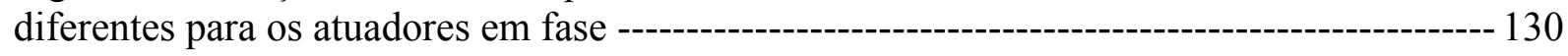

Figura 7.7 - Deslocamentos dos atuadores para uma entrada senoidal de $1 \mathrm{rad} / \mathrm{s}$,

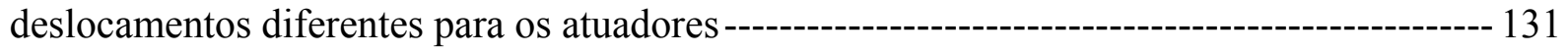

Figura 7.8 - Ação de controle para uma entrada senoidal de $1 \mathrm{rad} / \mathrm{s}$, deslocamentos

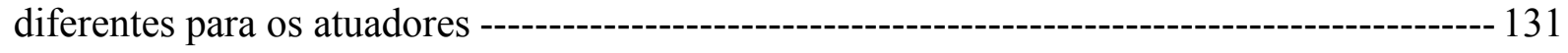

Figura 7.9 - Deslocamentos dos atuadores para uma entrada trapezoidal ---------------------- 132

Figura 7.10 - Ação de controle para uma entrada trapezoidal ------------------------------------ 132

Figura 7.11 - Protótipo virtual dos atuadores na configuração que estariam na plataforma de movimento modelados no $A D A M S^{\circledR}$----------------------------------------------------------- 134

Figura 7.12 - Deslocamento dos atuadores para uma entrada degrau. --------------------------- 136

Figura 7.13 - Ação de controle para uma entrada degrau. ---------------------------------------- 136

Figura 7.14 - Deslocamentos dos atuadores para uma entrada senoidal de $1 \mathrm{rad} / \mathrm{s}$, deslocamentos diferentes para os atuadores em fase

Figura 7.15 - Ação de controle para uma entrada senoidal de $1 \mathrm{rad} / \mathrm{s}$, deslocamentos diferentes para os atuadores em fase

Figura 7.16 - Deslocamentos dos atuadores para uma entrada senoidal de $1 \mathrm{rad} / \mathrm{s}$,

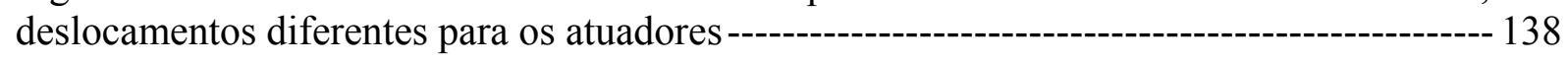

Figura 7.17 - Ação de controle para uma entrada senoidal de $1 \mathrm{rad} / \mathrm{s}$, deslocamentos

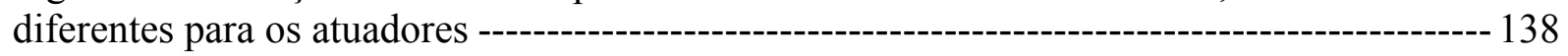

Figura 7.18 - Deslocamentos dos atuadores para uma entrada trapezoidal---------------------- 139 
Figura 7.19 - Deslocamento dos atuadores para uma entrada trapezoidal-

Figura 7.20 - Deslocamentos dos atuadores para uma entrada degrau-

Figura 7.21 - Ação de controle para uma entrada degrau-

Figura 7.22 - Deslocamentos dos atuadores para uma entrada senoidal de $1 \mathrm{rad} / \mathrm{s}$, deslocamentos diferentes para os atuadores em fase

Figura 7.23 - Ação de controle para uma entrada senoidal de $1 \mathrm{rad} / \mathrm{s}$, deslocamentos diferentes para os atuadores em fase

Figura 7.24 - Deslocamentos dos atuadores para uma entrada senoidal de $1 \mathrm{rad} / \mathrm{s}$, deslocamentos diferentes para os atuadores

Figura 7.25 - Deslocamentos dos atuadores para uma entrada senoidal de $1 \mathrm{rad} / \mathrm{s}$, deslocamentos diferentes para os atuadores -------------------------------------------- 143

Figura 7.26 - Deslocamentos dos atuadores para uma entrada trapezoidal --------------------- 144

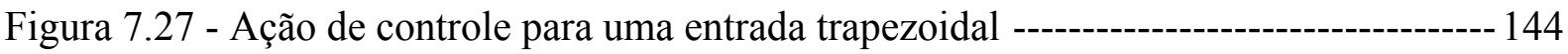

Figura 8.1 - Imagem ilustrativa do sistema hardware-in-the-loop do experimento ---------- 145

Figura 8.2 - Experimento montado para validação da metodologia------------------------------ 146

Figura 8.3 - Deslocamentos dos atuadores para uma entrada senoidal de $1 \mathrm{rad} / \mathrm{s}$-------------- 147

Figura 8.4 - Ação de controle para uma entrada senoidal de $1 \mathrm{rad} / \mathrm{s}$----------------------------- 147

Figura 8.5 - Deslocamentos dos atuadores para uma entrada senoidal de $1 \mathrm{rad} / \mathrm{s}$ com o atuador 2 defasado em $180^{\circ}$ do atuador 1-------------------------------------------------- 148

Figura 8.6 - Ação de controle para uma entrada senoidal de $1 \mathrm{rad} / \mathrm{s}$ com o atuador 2

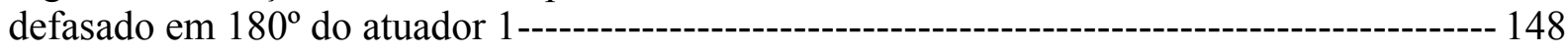

Figura 8.7 - Deslocamentos dos atuadores para uma entrada senoidal de $0,1 \mathrm{rad} / \mathrm{s}$

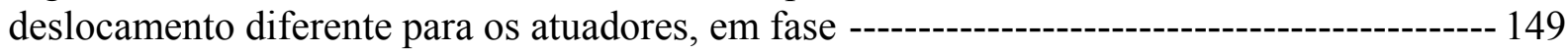

Figura 8.8 - Ação de controle para uma entrada senoidal de $0,1 \mathrm{rad} / \mathrm{s}$ deslocamento diferente para os atuadores em fase --------------------------------------------------- 149

Figura 8.9 - Deslocamentos dos atuadores para uma entrada senoidal de $2 \mathrm{rad} / \mathrm{s}$ com o

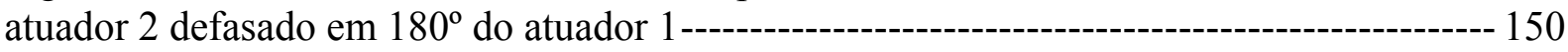

Figura 8.10 - Ação de controle para uma entrada senoidal de $2 \mathrm{rad} / \mathrm{s}$ com o atuador 2 defasado em $180^{\circ}$ do atuador 1 --- 150

Figura 8.11 - Deslocamentos dos atuadores para uma entrada senoidal de $1 \mathrm{rad} / \mathrm{s}$----------- 151

Figura 8.12 - Ação de controle para uma entrada senoidal de $1 \mathrm{rad} / \mathrm{s}$------------------------ 151

Figura 8.13 - Deslocamentos dos atuadores para uma entrada senoidal de $2 \mathrm{rad} / \mathrm{s}$----------- 152 
Figura 8.14 - Ação de controle para uma entrada senoidal de $2 \mathrm{rad} / \mathrm{s}$

Figura 8.15 - Deslocamentos dos atuadores para uma entrada senoidal de $1 \mathrm{rad} / \mathrm{s}$ deslocamentos diferentes para os atuadores em fase $(2 x[-19$ rads,-20 rads,-21 rads $])$

Figura 8.16 - Ação de controle para uma entrada senoidal de $1 \mathrm{rad} / \mathrm{s}$ deslocamentos diferentes para os atuadores em fase $(2 x[-19 \mathrm{rads},-20 \mathrm{rads},-21 \mathrm{rads}])$

Figura 8.17 - Deslocamentos dos atuadores para uma entrada senoidal de $1 \mathrm{rad} / \mathrm{s}$, deslocamentos diferentes para os atuadores em fase

Figura 8.18 - Ação de controle para uma entrada senoidal de $2 \mathrm{rad} / \mathrm{s}$, deslocamentos diferentes para os atuadores em fase

Figura 8.19 - Detalhe do atraso na resposta do controle, na simulação, para deslocamentos máximos de $40 \mathrm{~mm}$ e $30 \mathrm{~mm}$ para os atuadores em fase (2x [-19rads, -20 rads, -21 rads $])$

Figura 8.20 - Detalhe do atraso na resposta real do controle para deslocamentos máximos de $40 \mathrm{~mm}$ e $30 \mathrm{~mm}$ para os atuadores em fase (2x [-19rads, $-20 \mathrm{rads},-21 \mathrm{rads}])$------ 155

Figura 8.21 - Detalhe do atraso na resposta do controle, na simulação, para deslocamentos máximos de $40 \mathrm{~mm}$ e $60 \mathrm{~mm}$ para os atuadores em fase

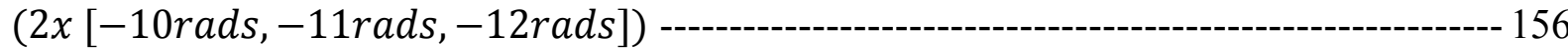

Figura 8.22 - Detalhe do atraso na resposta real do controle para deslocamentos máximos de $40 \mathrm{~mm}$ e $60 \mathrm{mmpara}$ os atuadores em fase (2x [-10rads, $-11 \mathrm{rads},-12 \mathrm{rads}])$------- 156

Figura 8.23 - Deslocamento dos atuadores para uma entrada trapezoidal----------------------- 157

Figura 8.24 - Ação de controle para uma entrada trapezoidal ------------------------------------ 157

Figura 8.25 - Deslocamento dos atuadores para uma entrada senoidal de $2 \mathrm{rad} / \mathrm{s}$------------- 158

Figura 8.26 - Ação de controle para uma entrada senoidal de $2 \mathrm{rad} / \mathrm{s}$-------------------------- 159

Figura 9.1- Atuador da linha Electrak 2000, Warner Electric ---------------------------------- 162 


\section{LISTA DE TABELAS}

Tabela 2.1 - Amplitude de movimento do protótipo

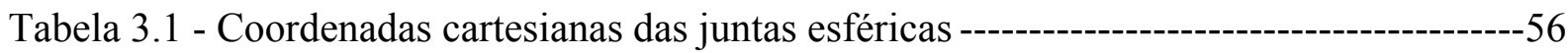

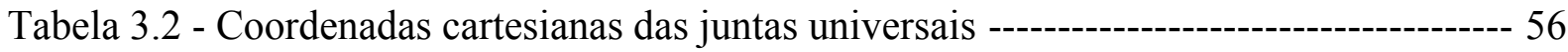

Tabela 3.3 - Posição e orientação dos atuadores--------------------------------------------------- 59

Tabela 3.4 - Cálculo das parcelas da Fórmula de Grübler a partir dos componentes da plataforma de Stewart ------------------------------------------------------------------------60

Tabela 4.1 - Dados do primeiro experimento para determinação do centro de massa -----------85

Tabela 4.2 - Dados do segundo experimento para determinação do centro de massa --------- 85

Tabela 4.3 - Comparação dos momentos de inércia obtidos de forma experimental e analítica para peças padrão com dois planos de simetria --------------------------------------98

Tabela 4.4 - Comparação dos momentos de inércia obtidos de forma experimental e analítica, para peças padrão com dois planos de simetria, com análise de repetibilidade------99

Tabela 4.5 - Comparação dos momentos de inércia obtidos de forma experimental e analítica, para peças padrão com um plano de simetria, com análise de repetibilidade ------ 100

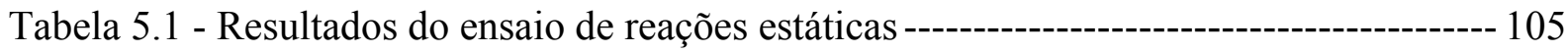

Tabela 5.2 - Resultados dos ensaios de momento de inércia---------------------------------- 107

Tabela 5.3 - Resultados dos ensaios de momentos de inércia, da haste, em relação a um ângulo

Tabela 5.4 - Resultados dos ensaios de momentos de inércia, da haste, em relação a um

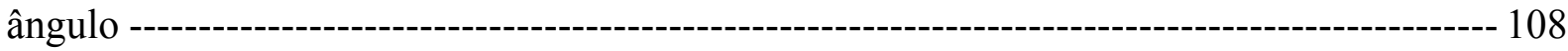

Tabela 5.5 - Características inerciais da haste no plano $x y$-------------------------------------- 108

Tabela 5.6 - Características inerciais do eixo do fuso de esferas obtidas através do

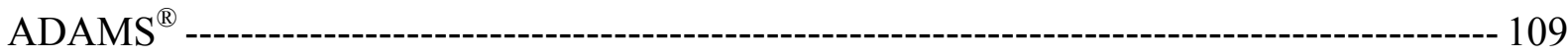

Tabela 5.7 - Características inerciais do eixo do fuso de esferas obtidas através do

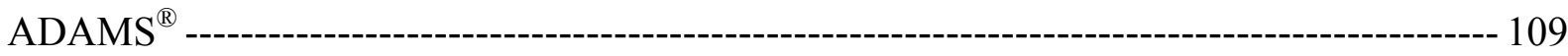

Tabela 5.8 - Resultados dos ensaios de reações estáticas--------------------------------------- 110

Tabela 5.9 - Resultados dos ensaios de momento de inércia----------------------------------- 112

Tabela 5.10 - Resultados dos ensaios de momentos de inércia em relação a um ângulo----- 112 
Tabela 5.11 - Resultados dos ensaios de momentos de inércia em relação a um ângulo ----- 113

Tabela 5.12 - Características inerciais do atuador no plano $x y$---------------------------------- 113

Tabela 5.13 - Momentos e produtos de inércia da plataforma móvel, obtidos através do

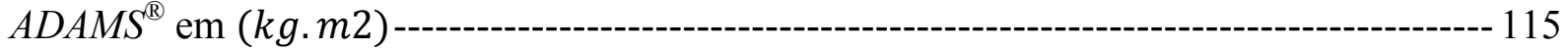

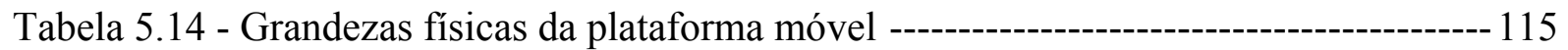




\section{LISTA DE SÍMBOLOS}

$\boldsymbol{A}$

$A A_{i}$

${ }^{A} \boldsymbol{a}_{i}$

$a_{i x}, a_{i y}, a_{i z}$

$\boldsymbol{B}$

$B B_{i}$

${ }^{B} \boldsymbol{b}_{i}$

${ }^{B} \boldsymbol{b}_{o}$

$b_{i x}, b_{i y}, b_{i z}$

C

D

$d$

$d_{c}$

${ }^{B} \boldsymbol{d}_{\boldsymbol{i}}$

$d_{x 1-2}$

$d_{y 1-2}$

$d_{N x}$

Matriz de estados.

Posição do vértice $i$ da plataforma móvel.

Posição de fixação da junta esférica no ponto $A i$ na plataforma móvel em relação ao sistema de coordenadas $\{\mathrm{A}\}$.

Coordenadas em $x, y$ e $z$ da posição de fixação da $i$-ésima junta esférica.

Matriz de entrada ou de controle.

Posição do vértice $i$ da plataforma fixa.

Posição de fixação da junta esférica no ponto $B i$ na plataforma móvel em relação ao sistema de coordenadas $\{\mathrm{B}\}$.

Vetor posição da origem de $\{A\}$ em relação a $\{B\}$.

Coordenadas em $x, y$ e $z$ da posição de fixação da $i$-ésima junta universal.

Matriz de saída.

Matriz de transmissão direta.

Distância entre as posições 1 e 2 nos ensaios de reações estáticas.

Diagonal do cubo formada pelos cilindros da plataforma de Stewart.

Vetor posição do i-ésimo atuador, cujo módulo é igual ao comprimento do atuador.

Distância entre as coordenadas em $x$ da posição 1 e 2 do centro de massa.

Distância entre as coordenadas em $y$ da posição 1 e 2 do centro de massa.

Diferença de posição do centro de massa na direção $x$ da posição 1 para 2 da parte $N$. 


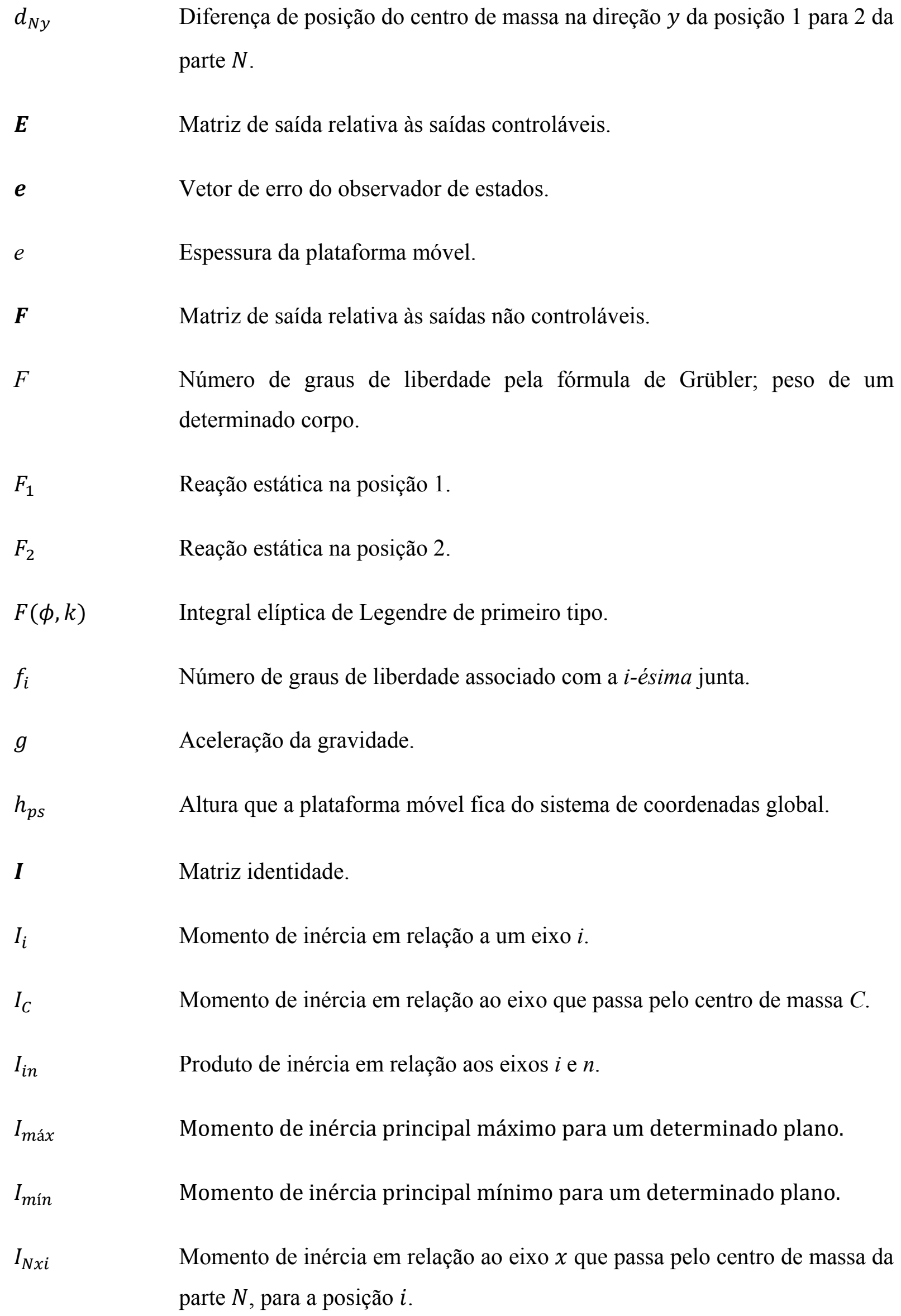

Matriz de saída relativa às saídas controláveis.

Vetor de erro do observador de estados.

Espessura da plataforma móvel.

$\boldsymbol{F}$

Matriz de saída relativa às saídas não controláveis.

F

Número de graus de liberdade pela fórmula de Grübler; peso de um determinado corpo.

$F_{1} \quad$ Reação estática na posição 1 .

$F_{2}$

Reação estática na posição 2 .

$F(\phi, k) \quad$ Integral elíptica de Legendre de primeiro tipo.

$f_{i}$

Número de graus de liberdade associado com a $i$-ésima junta.

$g$

Aceleração da gravidade.

$h_{p s}$

Altura que a plataforma móvel fica do sistema de coordenadas global.

Matriz identidade.

$I_{i}$

Momento de inércia em relação a um eixo $i$.

$I_{C}$

Momento de inércia em relação ao eixo que passa pelo centro de massa $C$.

$I_{\text {in }}$

Produto de inércia em relação aos eixos $i$ e $n$.

$I_{\text {máx }}$

Momento de inércia principal máximo para um determinado plano.

$I_{m i ́ n}$

Momento de inércia principal mínimo para um determinado plano.

$I_{N x i}$

Momento de inércia em relação ao eixo $x$ que passa pelo centro de massa da parte $N$, para a posição $i$. 

$I_{N y i}$
Momento de inércia em relação ao eixo $y$ que passa pelo centro de massa da parte $N$, para a posição $i$.
$I_{N x y i}$
Produto de inércia em relação ao eixo y que passa pelo centro de massa da parte $N$, para a posição $i$.
$I_{O}$
Momento de inércia em relação ao eixo $z$ que passa por $O$.
$I_{O L}$
Momento de inércia em relação a um eixo $O L$.
$I_{p c}$
Momento de inércia da peça em relação ao eixo de rotação que passa pelo centro de massa.
$I_{P O}$
Momento de inércia da peça em relação ao eixo de rotação.
$I_{S O}$
Momento de inércia do suporte em relação ao eixo de rotação.
$I_{x i}$
Momento de inércia em relação ao eixo $x$ que passa pelo centro de massa, para a posição $i$.
$I_{y i}$
Momento de inércia em relação ao eixo y que passa pelo centro de massa, para a posição $i$.
$I_{x y i}$
Produto de inércia em relação ao eixo y que passa pelo centro de massa, para a posição $i$.
$\boldsymbol{K}_{1}, \boldsymbol{K}_{2} \quad$ Matrizes de ganhos do controle seguidor.
$\boldsymbol{L}$
Matriz de ganho do observador de estados.
$L \quad$ Distância entre o ponto $O$ e o centro de massa $C$.
$L_{P} \quad$ Distância entre o eixo de rotação e o centro de massa da peça.
$L_{S} \quad$ Distância entre o eixo de rotação e o centro de massa do suporte.
$L_{S P} \quad$ Distância entre o eixo de rotação e o centro de massa da peça mais suporte.
$l \quad$ Comprimento do atuador na posição neutra. 


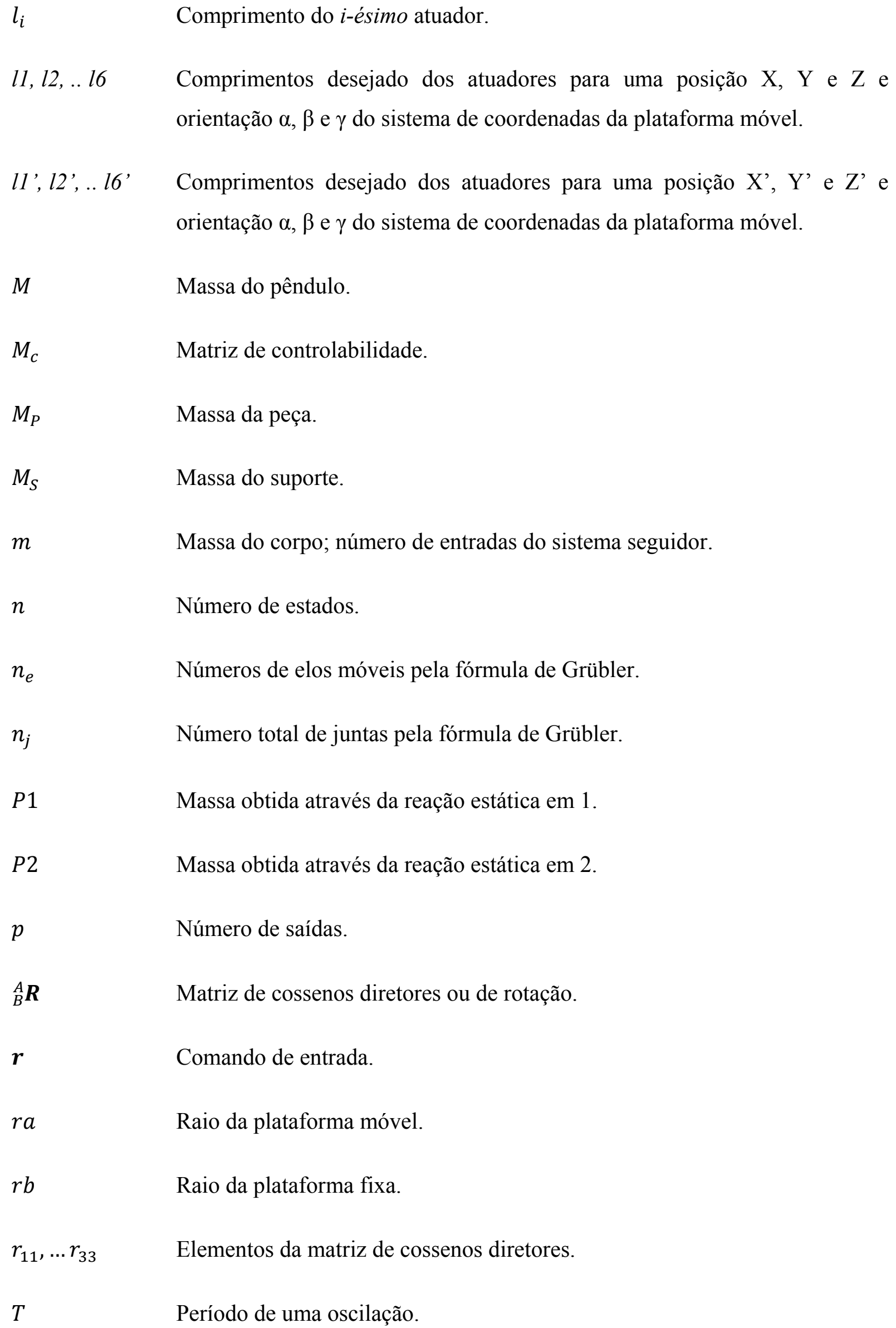




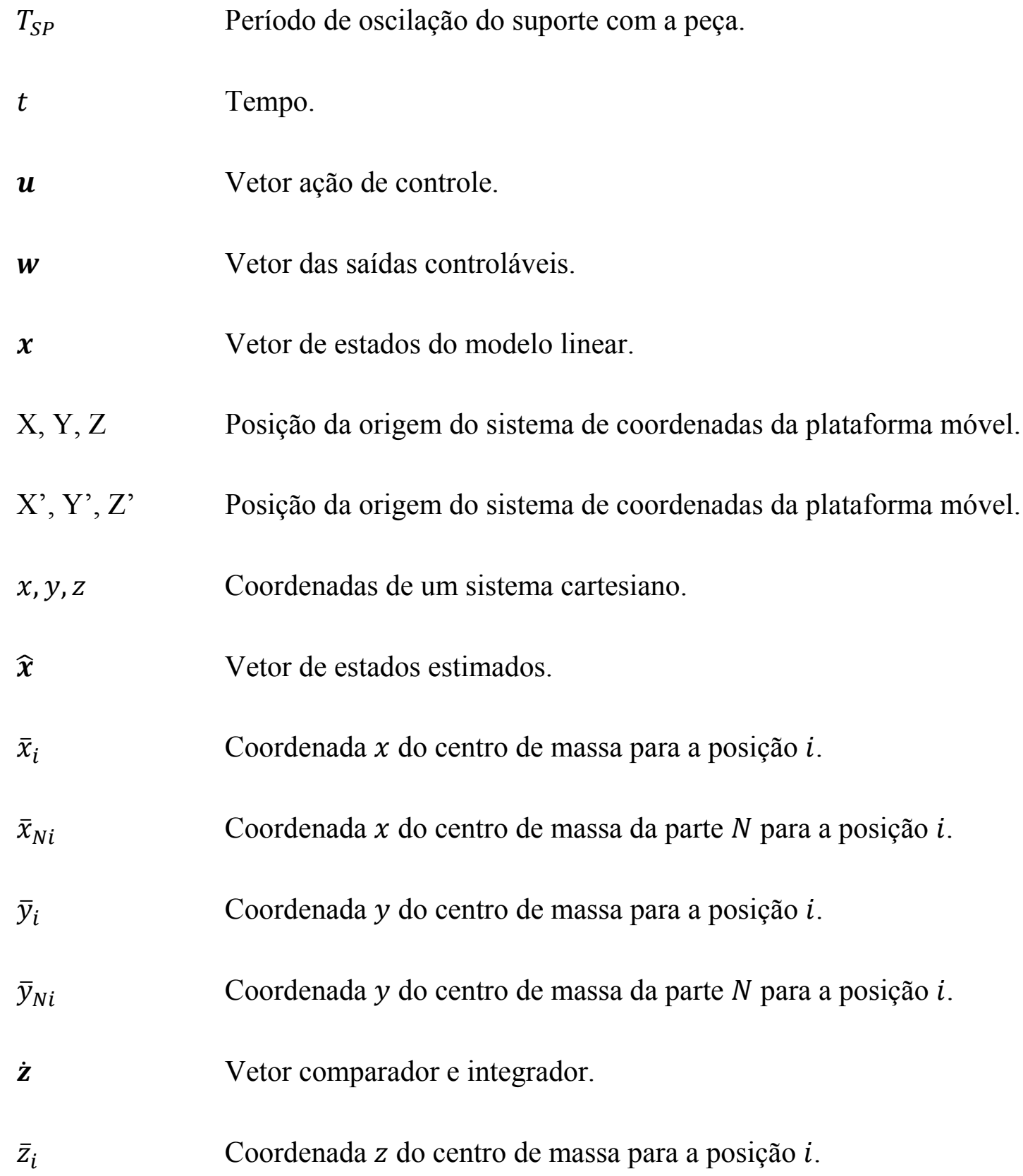

Tempo.

Vetor ação de controle.

Vetor das saídas controláveis.

Vetor de estados do modelo linear.

Posição da origem do sistema de coordenadas da plataforma móvel.

Posição da origem do sistema de coordenadas da plataforma móvel.

Coordenadas de um sistema cartesiano.

Vetor de estados estimados.

Coordenada $x$ do centro de massa para a posição $i$.

Coordenada $x$ do centro de massa da parte $N$ para a posição $i$.

Coordenada $y$ do centro de massa para a posição $i$.

Coordenada $y$ do centro de massa da parte $N$ para a posição $i$.

Vetor comparador e integrador.

Coordenada $z$ do centro de massa para a posição $i$.

Sistema de coordenadas A.

Sistema de coordenadas B.

Ângulos de orientação do sistema de coordenadas da plataforma móvel utilizando ângulos de Euler.

Ângulo de rotação para obtenção do eixo principal de inércia.

Entrada função do tempo.

Ângulo de rotação da peça em relação à posição vertical. 
Ângulo de rotação da peça em relação à posição horizontal.

$\Lambda_{i} \quad$ Ângulo entre $A A_{i}$ e $z_{A}$.

$\lambda \quad$ Versor da direção $O L$.

$\lambda_{i} \quad$ Ângulo entre $B B_{i}$ e $z_{B}$.

$\lambda_{1}, \lambda_{2}, \ldots \lambda_{n+m} \quad$ Autovalores.

$\lambda_{x}, \lambda_{y}, \lambda_{z} \quad$ Cossenos diretores.

$\boldsymbol{v} \quad$ Conjunto de autovetores.

$\boldsymbol{v}_{1}, \boldsymbol{v}_{2}, \ldots \boldsymbol{v}_{n+m}$ Autovetores.

$\rho \quad$ Massa específica.

$\sigma \quad$ Conjunto de autovalores.

$\omega \quad$ Freqüência de oscilação. 


\section{SUMÁRIO}

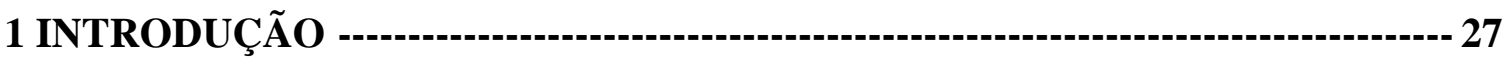

2 REVISÃO DA LITERATURA--- 32

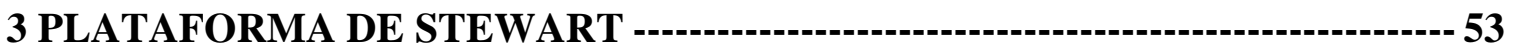

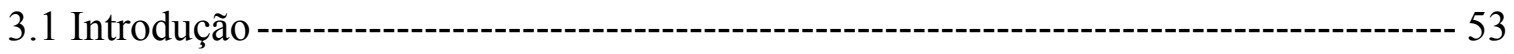

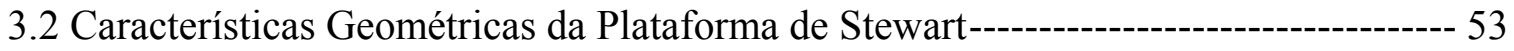

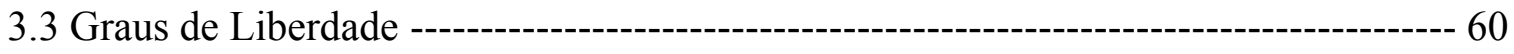

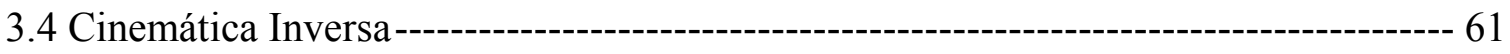

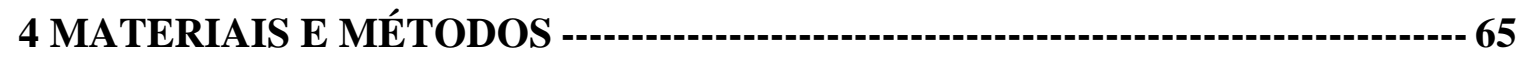

4.1 Determinação das Características Inerciais de Corpos Rígidos ------------------------- 65

4.1.1 Experimentos para Determinação do Centro de Massa e dos Momentos de

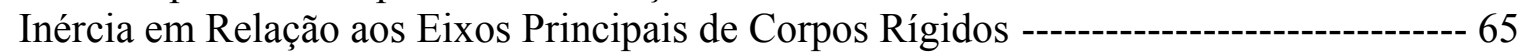

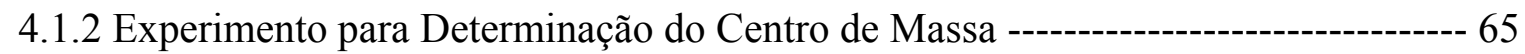

4.1.3 Experimento para Determinação dos Momentos de Inércia em Relação aos Eixos Principais de Corpos Rígidos ------------------------------------------------------- 74

4.2 Validação dos Experimentos para Determinação do Centro de Massa e dos Momentos de Inércia em Relação aos Eixos Principais de Corpos Rígidos --------------- 84

4.2.1 Validação dos Experimentos para Determinação do Centro de Massa -------------- 84

4.2.2 Validação do Experimento para Determinação dos Momentos de Inércia em Relação aos Eixos Principais de Corpos Rígidos ------------------------------------------- 85

4.2.3 Protótipo Real de uma Plataforma de Movimento com 2 G.D.L.-------------------- 100

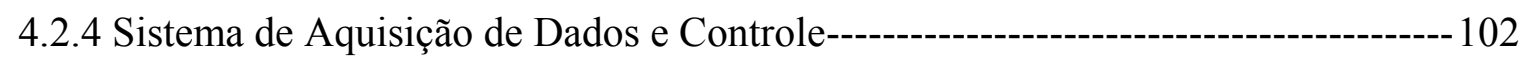

\section{IDENTIFICAÇÃO DAS CARACTERÍSTICAS INERCIAIS DOS ELOS DA}

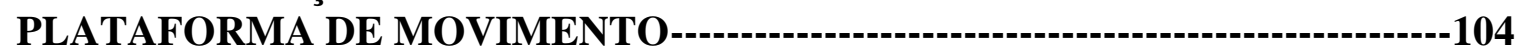

5.1 Identificação das Características Inerciais dos Elos que Compõem o Atuador ------ 104

5.1.1 Identificação das Características Inerciais da Haste do Atuador--------------------- 105

5.1.2 Identificação das Características Inerciais do Atuador------------------------------ 110

5.1.3 Identificação das Características Inerciais da Plataforma Móvel --------------------- 114

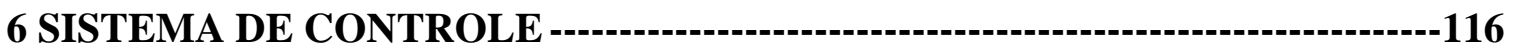

6.1 Sistema de Controle Seguidor com Realimentação de Estados ------------------------116

7 SIMULAÇÃO USANDO SIMULINK/ADAMS ${ }^{\circledR}$

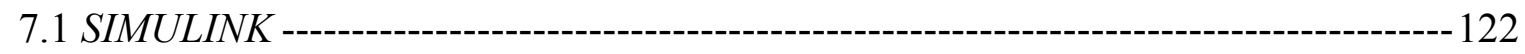

7.2 Ambiente de Sistemas Multicorpos $A D A M S^{\circledR}$--------------------------------------------122 
7.3 Simulação e Controle Usando SIMULINK/ADAMS ${ }^{\circledR}$

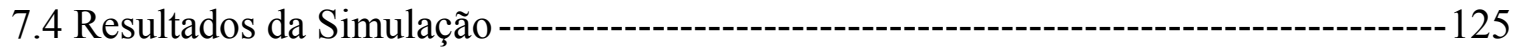

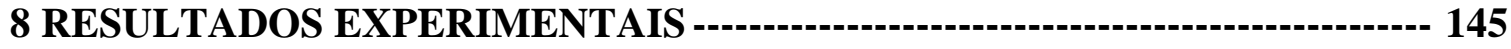

9 CONCLUSÕES E PROPOSTAS PARA TRABALHOS FUTUROS------------- 160

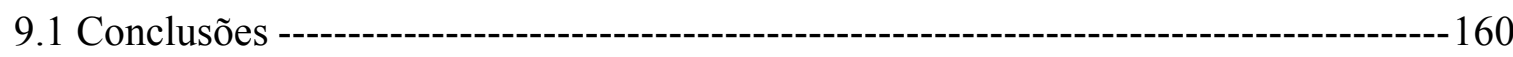

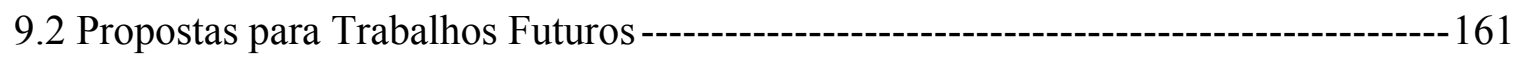

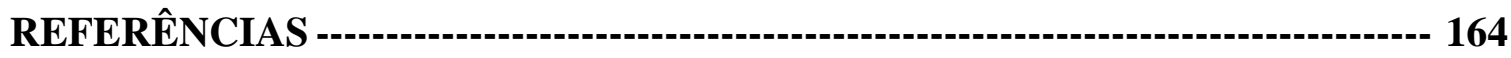




\section{INTRODUÇÃO}

Manipuladores de cadeia cinemática fechada que incluem duas plataformas acopladas por seis atuadores lineares em paralelo, cuja variação de comprimento produz o movimento de uma plataforma em relação à outra, são classificados como manipuladores baseados na plataforma de Stewart (NGUYEN et al., 1993). O desenvolvimento do mecanismo acima, proposto por Stewart (1965) no projeto de um simulador de vôo, foi motivado por desvantagens apresentadas pelo manipulador de cadeia cinemática aberta cujos elos e juntas são acionados em série (NGUYEN et al., 1993). A variação do comprimento dos atuadores altera um efetuador unido à plataforma móvel, que pode-se movimentar com seis graus de liberdade, obtendo a configuração desejada (posição e orientação) (GENG et al., 1992). Além de possuir alta rigidez mecânica, alcança-se uma maior acuracidade na posição e no movimento devido aos erros nos atuadores não serem cumulativos (GENG et al., 1992; LEBRET; LIU; LEWIS, 1993). Muitas variantes da plataforma de Stewart têm sido investigadas; a maioria delas possui seis atuadores lineares, com diferentes combinações de fixação dos atuadores nas plataformas (BEN-HORIN; SHOHAM; DJERASSI, 1998).

Uma das configurações de uma plataforma de Stewart é quando há duas plataformas triangulares iguais, sendo os atuadores ligados à plataforma móvel através de seis juntas esféricas, e à estacionária, por seis juntas universais. A configuração utilizada é conhecida como plataforma cúbica, pois os atuadores ficam posicionados como arestas de um cubo.

Como apresentado no trabalho de Geng e Haynes (1994), a Plataforma de Stewart tem vantagens únicas, e o comportamento cinemático e dinâmico da Plataforma é bastante complexo. A dificuldade primária é que os movimentos ao longo dos eixos são fortemente acoplados e o movimento em alguma direção necessita do movimento de todos os atuadores, resultando em complexidade matemática no projeto do sistema de controle. Como resultado de seu estudo, a configuração cúbica da Plataforma de Stewart, elimina muito desses problemas.

O objetivo deste trabalho é modelar o protótipo de uma plataforma de movimento, baseada em uma plataforma de Stewart usando-se um software de modelagem de Sistemas Multicorpos (MBS - Multibody Systems). Procurar-se-á identificá-lo experimentalmente, para gerar o modelo dinâmico e aplicar a este um controle de posição e orientação, utilizando 
realimentação de estados, além de implementá-lo através de um sistema de aquisição de dados e controle, verificando a eficiência da metodologia no protótipo real instrumentado.

Em estudos de engenharia, a palavra modelo possui dois significados principais: um está associado aos modelos físicos, construídos em escala, e o outro está associado aos modelos matemáticos, utilizados na descrição das relações e leis físicas que regem o comportamento de um dado sistema. O modelo físico apresenta-se como um arranjo similar à situação real, construído de acordo com leis e escalas apropriadas, tal que o modelo funcione de forma similar ao objeto real em estudo. Por modelo matemático entende-se o processo de descrever o sistema real em termos matemáticos, isto é, equações matemáticas que correspondam aos princípios e às leis físicas que regem o comportamento do sistema que se deseja analisar (SILVA, 1999).

Implementações computacionais no campo de simulação de sistemas multicorpos, permitindo desenvolver, testar, alterar e otimizar o desempenho de sistemas mecânicos submetidos a grandes deslocamentos, são conhecidas como “prototipagem virtual”. Mas esta poderosa técnica não elimina a necessidade de construção de protótipos reais. O uso desta tecnologia reduz o tempo e os custos nos inúmeros testes realizados nos protótipos reais. Constrói-se o protótipo real com o intuito de validar os resultados da simulação.

Em geral, a validação de modelos matemáticos é realizada pela comparação direta com valores experimentais, obtidos através de medição sobre os sistemas cujo comportamento se deseja prever.

No procedimento experimental, pretende-se levantar grandezas tais como aceleração, deformação e tensão na estrutura quando submetida a determinadas excitações. No procedimento experimental, neste caso, pretende-se levantar apenas características como aceleração, velocidade e deslocamento, pois considera-se o modelo como um Sistema Multicorpo (MBS - Multibody Systems) onde as partes são consideradas corpos rígidos interligados por juntas móveis. Para isso pode-se instalar acelerômetros do tipo massa mola ou capacitivos em determinados pontos e submeter o protótipo real a entradas conhecidas e comparar as respostas às obtidas através do modelo matemático e com isso conseguir levantar os parâmetros principais do modelo matemático. Esta técnica é conhecida como identificação do modelo. Pode-se, também, utilizar encoders lineares e angulares e tacômetros para obtenção das posições e velocidades de determinados pontos da plataforma de movimento. 
Para facilitar a análise dos dados, opta-se por ensaiar e determinar as características de centro de gravidade e momento de inércia de cada elo que compõe a plataforma de Stewart. Para isso foi desenvolvido um cavalete provido de vários dispositivos de fixação, para através de encoder, células de carga, medidor de inclinação, trena digital, placa de aquisição de dados, além de outros equipamentos; determinar as características inerciais dos elos. Após essa etapa, os dados obtidos deverão ser inseridos no modelo virtual desenvolvido no ambiente multicorpos, de onde se obtém, através de uma linearização em um determinado ponto, o modelo linear para elaboração do sistema de controle.

Após se obter o modelo matemático identificado, parte-se para o projeto do sistema de controle, levando-se em consideração os estados que serão realimentados, já que as matrizes de estado, que são a representação matemática do modelo real, não são únicas como no caso das funções transferências.

Com base nas características de observabilidade e controlabilidade dos estados e das saídas, deve-se procurar uma lei de controle com a qual se possam atribuir determinados autovalores e autovetores, ou seja, atribuição de auto-estrutura completa, de forma que o sistema final formado pela planta e pelo controle possua características dinâmicas que satisfaçam às condições mínimas para a aplicação, seja para utilização como simuladores de vôo, usinagem através de comando numérico, posicionador de antenas parabólicas, simulador de desgaste de pneus e etc.

Após se obter o sistema de controle que satisfaça as condições da aplicação em termos de rapidez e acuracidade, testado e utilizando-se o modelo linear, deve-se aplicar o controle ao modelo matemático não linear, verificando-se as características de resposta do sistema através de simulação, principalmente para grandes deslocamentos, onde o mesmo se afasta do ponto de linearização para, então, aplicar-se o controle ao protótipo real instrumentado. No presente caso aplicar-se-á diretamente o sistema de controle obtido à plataforma real.

Antes de se construir a plataforma de movimento com as dimensões finais e a potência de acionamento desejada, será construído um protótipo para se analisar os problemas relativos a desalinhamentos, tolerâncias de forma e posição, diferenças entre o protótipo virtual e o protótipo real, como soldas, chanfros, arredondamentos que acabam por interferir na posição final dos centros geométricos e nos volumes das partes, sem falar no atrito, dos problemas relacionados à medição dos estados a serem realimentados e das saídas, onde se podem 
encontrar alguns problemas como: acesso aos estados, condicionamento como no caso dos acelerômetros, alto nível de ruídos nos sistemas de amplificação de sinal e de potência, interferência eletromagnética, dentre outros. Este protótipo terá apenas dois graus de liberdade, ou seja, terá apenas rotação em dois eixos X-Y (arfagem e rolagem) e não terá nenhuma translação. Como a orientação e a posição final da plataforma móvel dependem da posição final dos atuadores lineares, o fato de se retirar quatro graus de liberdade não afetaria significativamente a precisão mecânica do sistema, que depende principalmente das folgas, imprecisão na montagem e, sobretudo, das posições finais dos atuadores lineares. Para exemplificar: deseja-se posicionar a plataforma móvel na posição X, Y e Z e a orientação $\alpha, \beta$ e $\gamma$ os valores obtidos para os atuadores, através da cinemática inversa, seriam $l 1, l 2, . . l 6 \mathrm{e}$ para posicionar a plataforma móvel na posição X', Y' e Z' e a orientação $\alpha, \beta$ e $\gamma$ os valores obtidos para os atuadores, através da cinemática inversa, seriam $l 1^{\prime}, l 2^{\prime}$, .. l6'. Sabe-se que existe uma relação trigonométrica entre os resultados obtidos para os dois casos, mas ao se olhar para cada atuador independentemente, pode-se verificar que é interessante obter precisão no posicionamento dos atuadores lineares, o que levariam a uma precisão maior ainda no posicionamento da plataforma móvel, uma vez que os erros nos atuadores não são acumulativos e não há uma medição direta da posição da plataforma móvel.

Embora a retirada dos graus de liberdade, de translação e rotação, não afete significativamente a precisão mecânica da plataforma, esta pode afetar a precisão do sistema de controle devido à variação de esforços inerciais e da carga nos atuadores.

A seguir estão listados os objetivos específicos deste trabalho:

- modelar o protótipo de uma plataforma de movimento, baseada em uma plataforma de Stewart usando-se um software de modelagem de Sistemas Multicorpos (MBS - Multibody Systems);

- definir uma metodologia para identificar a plataforma real para obter as características inerciais que serão utilizadas na geração do modelo matemático linear, utilizando variáveis de estado, através de um software de modelagem de Sistemas Multicorpos (MBS - Multibody Systems);

- definir um sistema de controle baseado em modelo com atribuição de autovalores, ou seja, das características de resposta no tempo de forma que o sistema final, formado pela 
planta e pelo controle possua características dinâmicas que satisfaçam às condições mínimas para a aplicação;

- testar a eficiência do controle utilizado, isto é, verificar se o controle gerado a partir do modelo linear é capaz de controlar o modelo não linear de forma adequada em torno do ponto de linearização. Nesta aplicação utilizaremos a planta real instrumentada e a técnica hardware-in-the-loop para verificar se o controle obtido através do modelo linear é capaz de controlar a plataforma real;

- elaborar uma metodologia, baseada nas etapas anteriores, para identificação e controle de uma plataforma de movimento, com características de acuracidade e de desempenho pré-definidas desde que não haja pontos de singularidades dentro do volume de trabalho e garantindo que o sistema de acionamento seja capaz de fornecer a ação de controle desejada. Está metodologia deve, através de procedimentos técnicos, ser capaz de gerar um sistema de controle de forma rápida e eficiente, ou seja, gastando menos tempo que as técnicas tradicionais que são menos específicas em relação aos procedimentos e instrumental a ser utilizado nas etapas de modelagem, identificação e controle. 


\section{REVISÃO DA LITERATURA}

Apresentam-se, a seguir, através de uma revisão analítica, os diversos desenvolvimentos relativos a sistemas de controle aplicados à plataforma de Stewart e às diversas aplicações da plataforma. Os relatos dos artigos até o ano de 2000 têm a colaboração de Alexandre Simião Caporali, através de discussão, pesquisa e análise conjunta dos trabalhos, apresentadas em sua tese de doutorado (CAPORALI, 2003).

O primeiro a utilizar um mecanismo com seis graus de liberdade, com a configuração hoje conhecida como plataforma de Stewart, foi Gough em 1962 (STEWART, 1965), para teste em pneus (Figura 2.1). Stewart depois modificou este mecanismo e aplicou-o em um simulador de vôo, em 1965. Devido à complexidade da dinâmica e da cinemática da plataforma de Stewart, o seu uso ficou restrito aos simuladores de vôo por muito tempo. O esforço computacional envolvido no controle é grande, graças às não-linearidades e acoplamentos apresentados pela estrutura da plataforma. Devido aos recentes avanços na tecnologia de microcomputadores, microcontroladores e softwares, as dificuldades computacionais têm sido superadas. Agora é possível controlar estruturas paralelas em tempo real por equipamentos relativamente baratos (SILFHOUT, 1999).

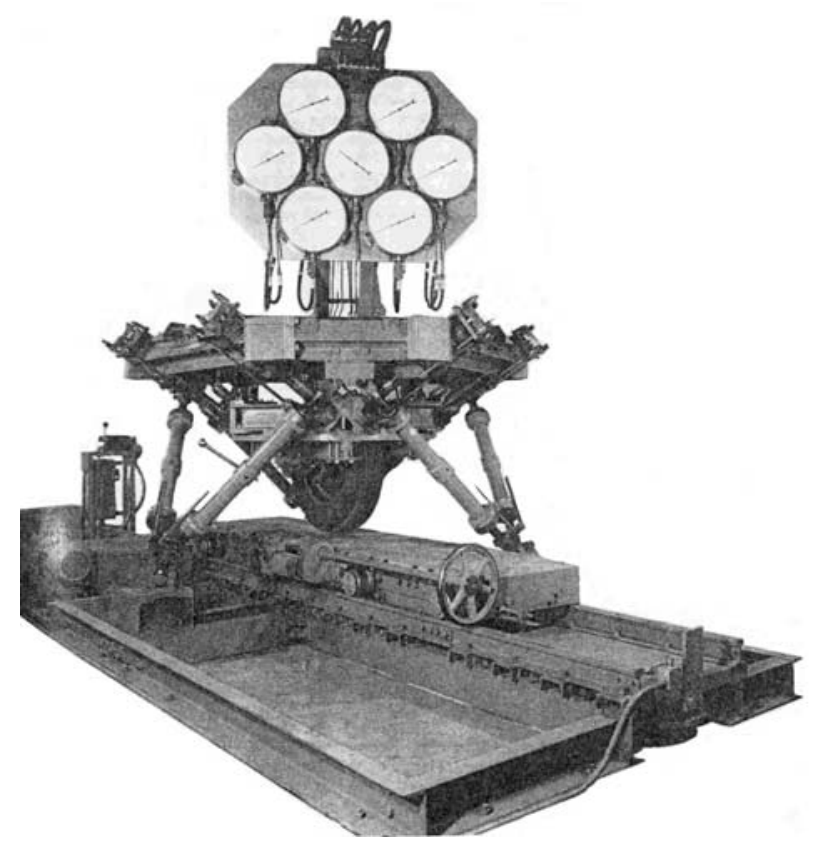

Figura 2.1 - Máquinas de teste de pneus (STEWART, 1965). 
Importantes trabalhos na área de cinemática e dinâmica de manipuladores de cadeia cinemática fechada foram publicados no final dos anos 80 e durante os anos 90, como se pode observar na literatura em geral e nos trabalhos de Advani e Baarspul (1992); Do e Yang (1988); Fichter (1986); Geng e Haynes (1991); Geng et al. (1992); Ji (1994); Koekebakker, Teerhuis e Van der Weiswn (1996); Kosuge et al. (1993); Nanua, Waldron e Murthy (1990); Nguyen e Pooran (1989); Nguyen et al. (1991a); Nguyen et al. (1991b); Zang e Song (1991) e também nos artigos atuais que continuam a referenciar publicações desse período. No final do século XX, Dasgupta e Mruthyunjaya (2000) publicam uma revisão que descreve a busca por modelos dinâmicos para manipuladores paralelos.

Acredita-se não ser uma tarefa simples apresentar de forma, cronológica e progressiva, os avanços na área de aplicações da plataforma de Stewart. Na verdade, o que tem ocorrido nos últimos anos é a popularização das aplicações utilizando este tipo de manipulador, devido aos avanços na área da eletrônica e computação, além da produção em maior escala, que tem possibilitado e viabilizado as implementações dos sistemas de controle para as mesmas. Portanto, o capítulo se restringe a apresentar algumas aplicações realizadas e julgadas importantes, para exemplificar a difusão da plataforma de Stewart como um mecanismo de alta rigidez, alta capacidade de carga, alta velocidade de posicionamento e com grande acuracidade.

Fichter (1986) mostrou em seu trabalho, um estudo teórico das equações necessárias na formulação cinemática e dinâmica, para serem usadas em uma plataforma de Stewart como um robô manipulador e também considerações práticas na construção de uma plataforma alocada na Oregon State University.

Merlet (1988) implementou um controle em um protótipo de um manipulador paralelo, desenvolvido pelo INRIA (Institut National de Recherche en Informatique et en Automatique), possuindo uma configuração de plataforma de Stewart (Figura 2.2). Esta estrutura permite obter alta capacidade de posicionamento e é adequada para controle por realimentação de força. Os atuadores possuem acionamento elétrico, os deslocamentos das pernas são medidos com um potenciômetro linear preciso e extensômetros são usados para medir a força axial em cada perna. A amplitude do movimento do protótipo é apresentada na Tabela 2.1. 
Tabela 2.1 - Amplitude de movimento do protótipo.

\begin{tabular}{c|c|c|c|c|c}
\hline$x$ & $y$ & $z$ & $\psi$ & $\theta$ & $\varnothing$ \\
\hline $\pm 6 \mathrm{~cm}$ & $\pm 6 \mathrm{~cm}$ & $0-2 \mathrm{~cm}$ & $\pm 55^{\circ}$ & $\pm 15^{\circ}$ & $\pm 55^{\circ}$ \\
\hline
\end{tabular}

onde $x, y$ e $z$ são posições do centro de massa da plataforma móvel e $\psi, \theta$ e $\phi$ os seus ângulos de Euler de orientação. No controle foi utilizado um sistema híbrido de força e posição e conseguiu-se uma acuracidade de $10 \mu \mathrm{m}$ sem carga e $60 \mu \mathrm{m}$ com uma carga de 6 $\mathrm{kg}$, sendo a capacidade máxima de $100 \mathrm{~kg}$ (MERLET, 2000). A altura do protótipo é de 51 $\mathrm{cm}$ e o peso é de $11 \mathrm{~kg}$.
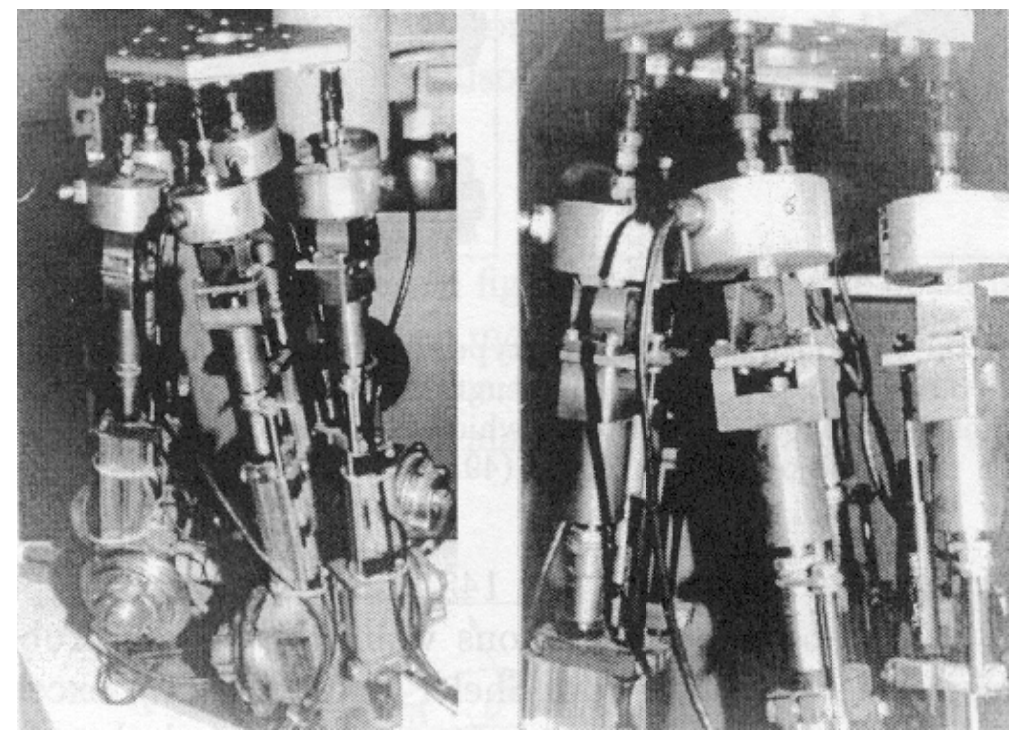

Figura 2.2 - Protótipo desenvolvido pelo INRIA (MERLET, 2000).

Um robô manipulador, baseado em duas plataformas de Stewart acionadas por motores de passo acoplados a fusos, foi desenvolvido por Nguyen et al. (1991b) (Figura 2.3), sendo acoplada à plataforma escrava uma garra manipuladora. Os dados experimentais do trabalho mostram a capacidade da plataforma escrava de descrever uma trajetória planejada, em linha reta, com um erro de regime insignificante, segundo os autores. 


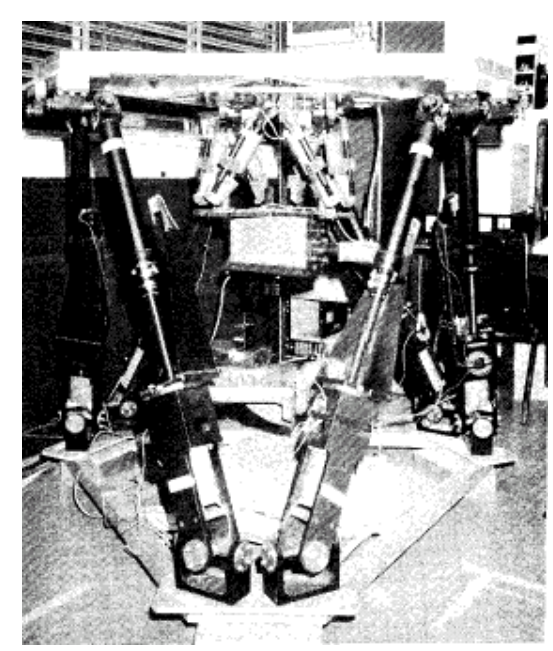

Figura 2.3 - Robô manipulador baseado em uma plataforma de Stewart (NGUYEN et al., 1991b).

O Sistema de Emulação de Veículos (Vehicle Emulation System - VES) desenvolvido pelo MIT (Massachusetts Institute of Tecnology), segundo Durfee, Idris e Dubowsky (1991), é um equipamento projetado para facilitar o estudo de controle de robôs fixados em bases móveis. O controle de força e posicionamento do efetuador para manipuladores, sob estas condições, necessitava do desenvolvimento de uma nova teoria e de testes para verificação dos resultados teóricos através de experimentação. O VES é uma plataforma com seis graus de liberdade, com controle de posicionamento, que simula os movimentos de um veículo. $\mathrm{Na}$ segunda versão do sistema VES (VES I), um manipulador é fixado no topo da plataforma em série, com um sensor de força de seis graus de liberdade (Figura 2.4). O posicionamento dos atuadores é realizado através de um sistema de controle PD, que tem como entrada de referência a posição desejada do atuador. Hootsmans, Dubowsky e Mo (1992) mostram que várias formas de aprimoramento foram realizadas nesse sistema, tanto na parte de sensoriamento, quanto em termos de algoritmo de controle. Na prática, seria difícil o sensoriamento do efetuador em todos os seis graus de liberdade da trajetória com grandes movimentos em todo o campo de ação. Então, dois algoritmos de controle, o Mobile Manipulator Jacobian Transpose (MMJT) e o Mobile Manipulator Resolved Rate (MMRR) foram desenvolvidos, não confiando no sensoriamento do end-point, mas utilizando sensores de movimento no veículo. Um sensor ultrasônico mede o movimento vertical e dois sensores de inclinação (inclinometers) medem os ângulos de arfagem e rolagem. Esses algoritmos mostraram bom desempenho na simulação, sendo superiores aos controladores PD. O MIT ainda criou mais uma versão deste sistema e deu o nome de VES II. 


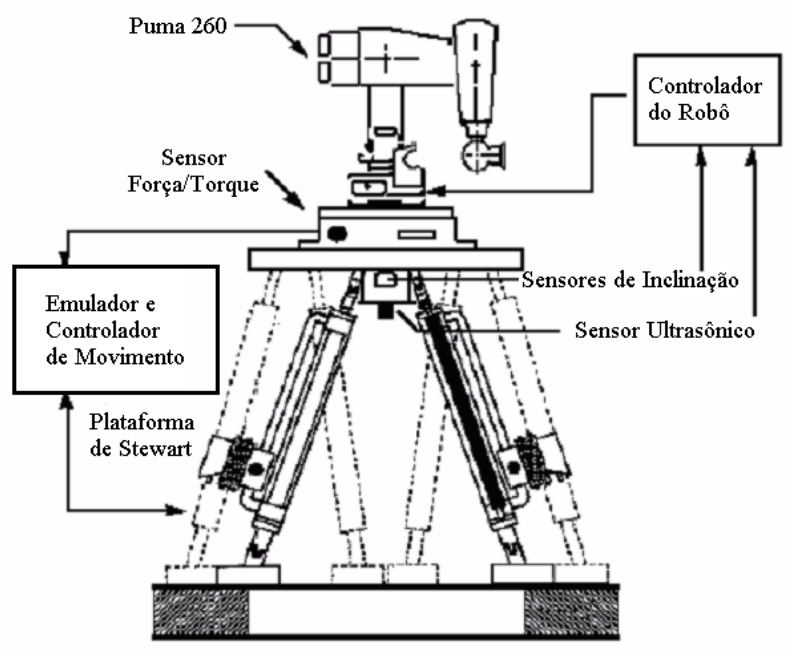

Figura 2.4 - Robô Puma 260 montado no Sistema Emulador de Veículo (HOOTSMANS;

DUBOWSKY; MO, 1992).

No trabalho de Nguyen et al. (1993), é apresentado o projeto de um controle adaptativo para um manipulador baseado na plataforma de Stewart, instalado em um robô para simular operações no espaço. Este mecanismo está montado no Goddard Space Fight Center-NASA, sendo a plataforma acionada por motores elétricos de corrente contínua. $\mathrm{O}$ esquema de controle é composto basicamente por controladores PD (Proporcional Derivativo), cujos ganhos são ajustados por uma lei de adaptação. Este acionamento é realizado com os sinais de erro gerados pela comparação entre a trajetória desejada do manipulador e o comprimento dos atuadores. O projeto do controle adaptativo é motivado por não linearidades na dinâmica do manipulador, erros na modelagem e mudanças bruscas nos carregamentos aos quais o robô está submetido. A lei de adaptação é baseada no conceito de controle adaptativo por modelo de referência e método direto de Lyapunov. Um estudo experimental é realizado para avaliar o desempenho do esquema da lei de controle adaptativa implementada para o manipulador. Segundo o autor, os resultados apresentados mostram que o esquema de controle proporciona capacidade de seguir a trajetória desejada com desempenho melhor do que esquemas de controle com ganhos fixos, apesar do erro de regime apresentado nos ensaios.

O esquema de controle seguidor robusto (Robust Tracking), usado no trabalho de Kang, Kim e Lee (1996), apresenta duas classes de controle robusto na presença de distúrbios para a plataforma de Stewart. Os autores consideram o esquema de controle nas coordenadas da plataforma e outro esquema de controle nas coordenadas dos atuadores. Os esquemas mostraram características distintas um em relação ao outro. O erro de regime, mostrado pelo 
autor, pode ser ajustado, por uma escolha apropriada, nos parâmetros do esquema de controle proposto. Também é discutida uma "estabilidade prática" alcançada pelo controlador.

No trabalho de Kosuge et al. (1996), é mostrado um esquema de controle, de uma plataforma de Stewart acionada hidraulicamente (Figura 2.5), usando um algoritmo de controle de força baseado na velocidade dos atuadores da plataforma. O esquema proposto é aplicado em uma plataforma experimental e o controle é implementado em um sistema de operação em tempo real. Os dados experimentais apresentados pelos autores são bons, alcançando-se as posição e força desejadas sem erro de regime, mas com overshoot.

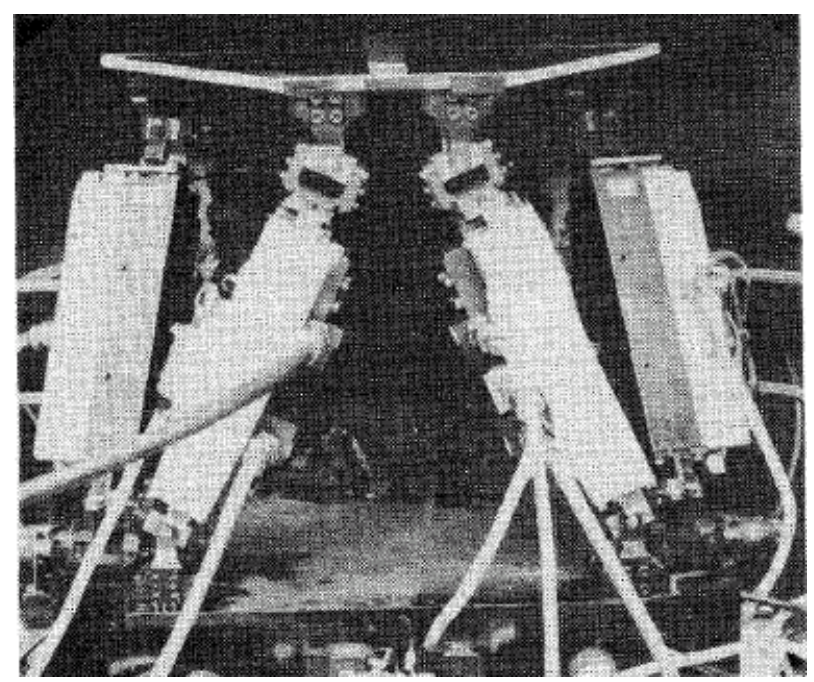

Figura 2.5 - Plataforma de Stewart experimental (KOSUGE et al., 1996).

Li e Salcudean (1997) desenvolveram uma plataforma de Stewart invertida, acionada hidraulicamente (Figura 2.6), para simulação de movimento em uma pessoa apenas. Uma realimentação de pressão (link-space pressure feedback controller) é usada para controle de força e os resultados de simulação mostram que o esquema de controle adotado apresenta bom comportamento, seguindo uma trajetória desejada com pequeno erro. Os autores discutem que os resultados experimentais alcançados são bons. 


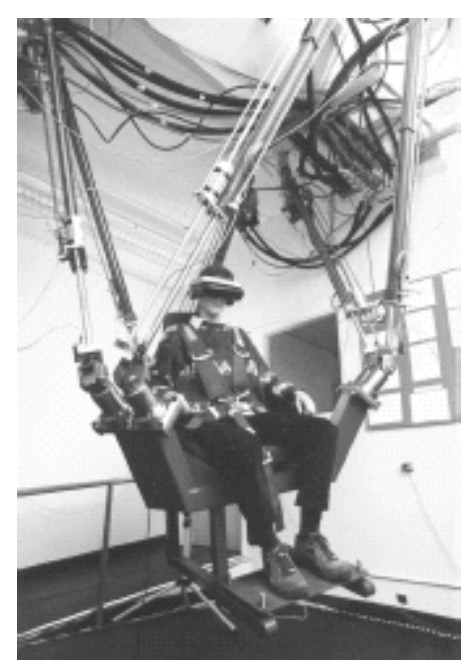

Figura 2.6 - Plataforma de Stewart invertida (LI; SALCUDEAN, 1997).

O transporte de um objeto em uma plataforma móvel sempre transfere acelerações para o mesmo. Em muitos casos isso é indesejável, sendo útil a compensação. Há sistemas passivos que podem amenizar os efeitos das acelerações, no entanto, Graf, Vierling e Dillman (1997, 1999) apresentam um sistema ativo tanto para a compensação da aceleração quanto para a rápida e precisa movimentação. Para se alcançar o objetivo, uma plataforma de Stewart foi montada sobre um robô móvel (Figura 2.7). Usualmente uma plataforma de Stewart é usada para gerar uma aceleração, como no caso dos simuladores de vôo e dos simuladores de automóveis. Nesta aplicação, o vetor aceleração do robô é invertido e mandado para um filtro washout que determina os deslocamentos da plataforma, dependendo do movimento do robô. Este filtro tem capacidade de manipular seis graus de liberdade. Então, todo movimento pode ser levado em conta se for captado pelos sensores de aceleração e inclinação. Segundo Graf Vierling e Dillman (1997), a plataforma de Stewart utilizada possui dimensão 1:4 comparada com o modelo original (WILLSSER $1997^{1}$ apud GRAF; VIERLING; DILLMAN, 1997) e é acionada por motores elétricos e fusos, ao invés de cilindros hidráulicos. Segundo os autores, a plataforma alcança uma acuracidade de $10 \mu \mathrm{m}$ e é controlada por microprocessador.

\footnotetext{
${ }^{1}$ WILSSER, J. U. Construction of a model of a Stewart-platform. 1997. (Master's Thesis) - Institute for Real-Time Systems and Robotics, University of Karlsruhe, Karlsruhe, 1997.
} 


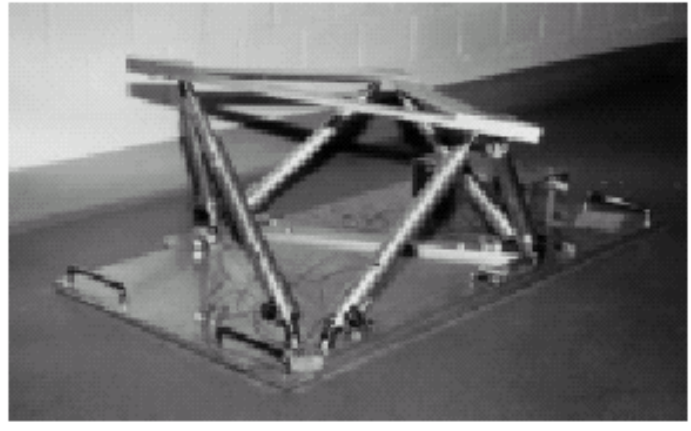

(a)

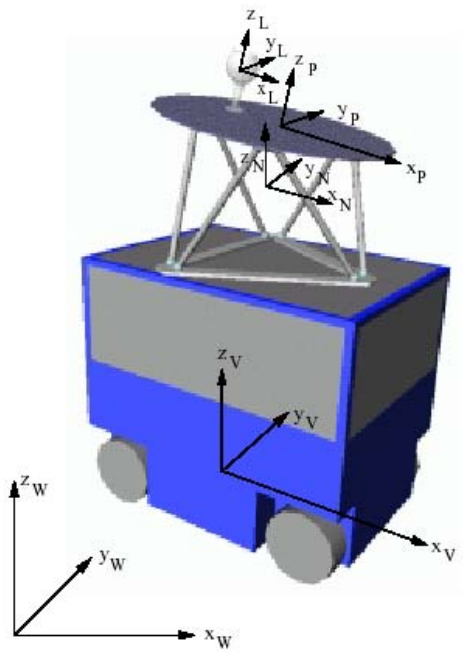

(b)

Figura 2.7 - (a) Plataforma de Stewart SPIKE, (b) Sistema de coordenadas do robô móvel PRIAMOS e da SPIKE (GRAF; VIERLING; DILLMAN, 1999).

Kim et al. (1997) desenvolveram uma plataforma de Stewart acionada hidraulicamente para simulação de movimentos de um automóvel como mostrado na Figura 2.8. O esquema de controle para acionamento da plataforma usa o algoritmo chamado de washout, que é uma espécie de filtro. Os sinais provenientes do modelo dinâmico do veículo e da interação com a parte gráfica de um cenário são enviados para o filtro. Nos sinais de saída do filtro, estão contidas as informações de velocidades angulares e acelerações lineares necessárias à simulação do movimento do veículo. Portanto, estes sinais são enviados à plataforma para acionamento dos atuadores hidráulicos. Os dados de simulação dos movimentos da plataforma mostrados pelos autores apresentam bons resultados. 


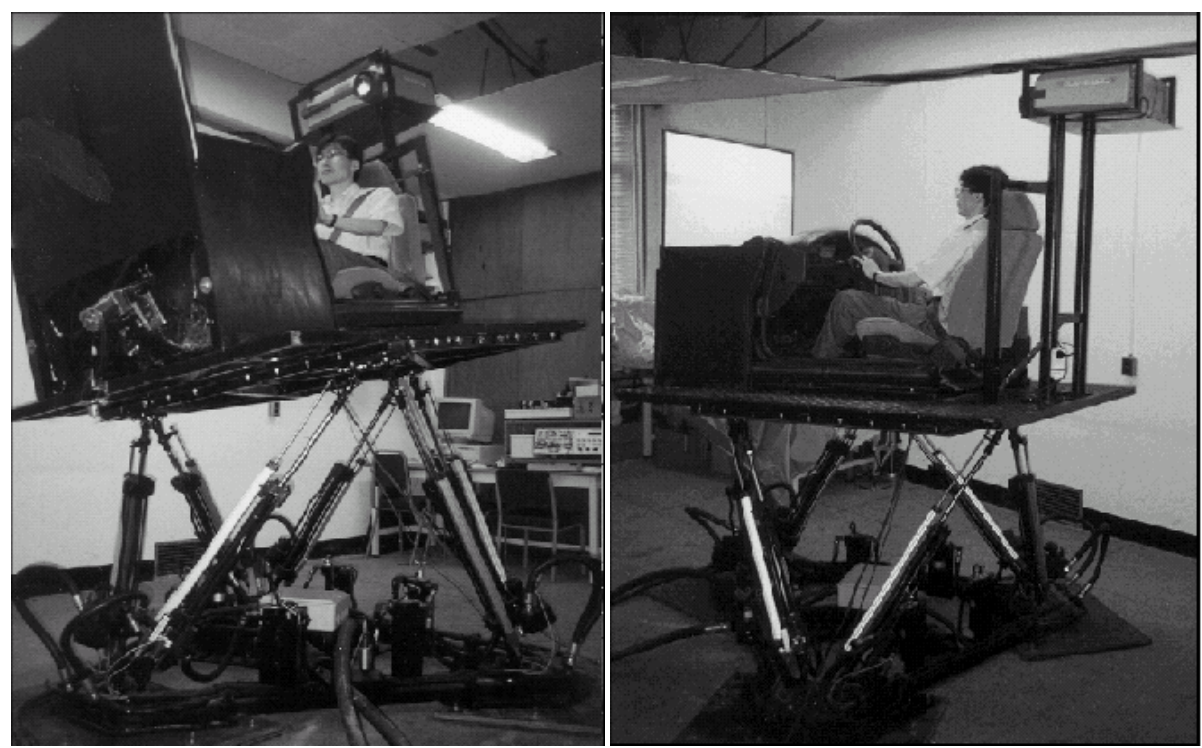

Figura 2.8 - Simulador de automóvel (KIM et al, 1997).

No trabalho de Graf, Vierling e Dillman (1998) é descrita uma plataforma de Stewart para aplicações de movimento em ambientes de realidade virtual, que foi desenvolvida no Centro para Arte e Mídia (ZKM) em Karlsruhe, na Alemanha, destinada a diversas aplicações. O esquema de controle é divido em 3 partes: a primeira parte usa filtros para calcular as acelerações exigidas para a simulação de movimento; a segunda parte consiste de um regulador para o controle de posição dos atuadores, onde é calculada a cinemática inversa e direta; na terceira, é usado regulador para as juntas, sendo que nesta parte os comprimentos de cada atuador são transformados em tensão. $\mathrm{O}$ autor conclui que o controle proposto tem várias vantagens para aplicações em ambiente de multimídia, mostrando que os filtros usados têm robustez e flexibilidade.

Koekebakker, Teerhuis e Van der Weiden (1998), do International Research Institute for Simulation, Motion and Navigation, em Delft, Holanda, mostram uma plataforma de Stewart, acionada hidraulicamente, aplicada a um simulador de vôo (Figura 2.9). Os autores apresentaram uma estrutura de controle baseada em quatro níveis (Figura 2.10), cada qual com sua especificação e relação fechada com os outros níveis, evitando um processamento pesado de informações em apenas um nível de controle ou malha de realimentação. No nível 1 está a malha de controle do sistema hidráulico. No nível 2 está o algoritmo de Multivariable Feedback Linearization. No nível 3 está a malha externa de estabilização de posição e, no nível 4, está o controle baseado na referência do modelo (Reference Model Based Control). Os sistemas de controle foram implementados sobre um placa processadora em tempo real DSP (Digital Signal Processing) da $d S P A C E$ que foi conectada a um protótipo de sistema de 
movimento usado para ensaios (Figura 2.9a). A estrutura de controle foi implementada em ambiente MATLAB/SIMULINK e compilada na placa DSP em código C. O desempenho do sistema de controle é discutido pelos autores. Dados experimentais colhidos da plataforma protótipo são comparados com dados gravados de uma aeronave real em vôo, e o autor conclui que o esquema de controle implementado obteve bom desempenho.

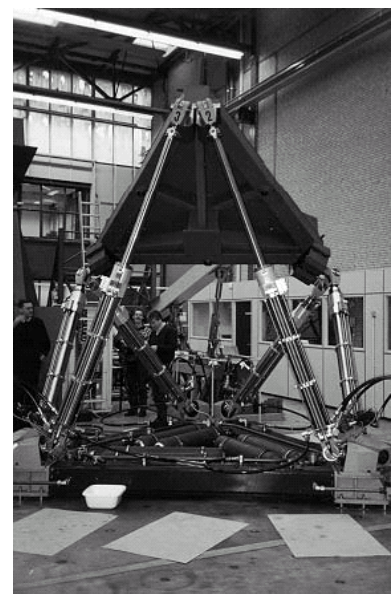

(a)

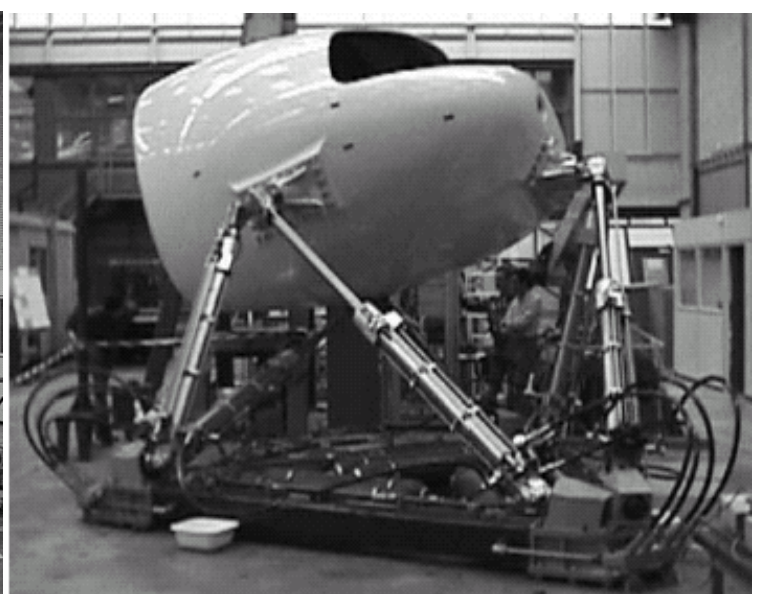

(b)

Figura 2.9 - (a) Sistema de movimento experimental, (b) Simulador de vôo (KOEKEBAKKER; TEERHUIS; Van der WEIDEN, 1998).

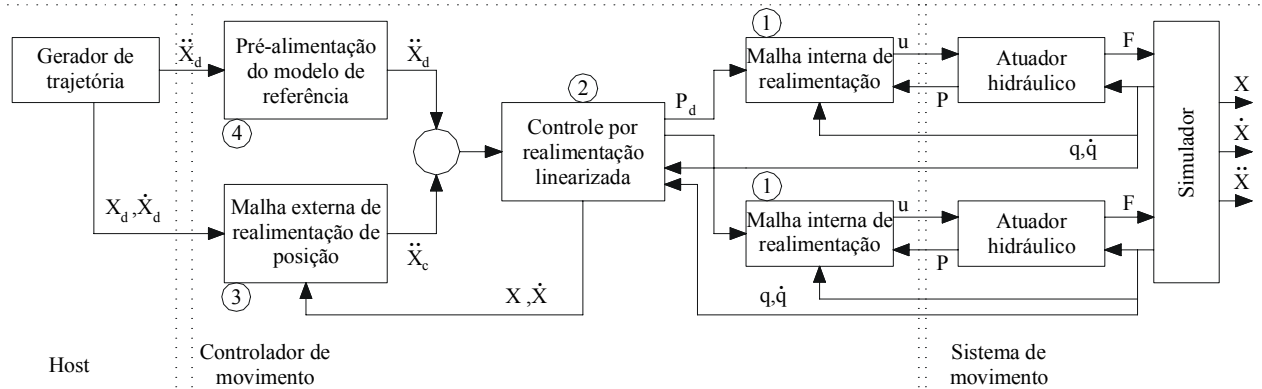

Figura 2.10 - Controle do sistema de movimento do simulador de vôo em vários níveis proposto por Koekebakker, Teerhuis, Van der Weiden (1998)

O esquema de controle adaptativo do modelo de referência (MRAC-Model Reference Adaptive Control) é abordado no trabalho de Chae et al. (1998) para um protótipo de máquina ferramenta baseada em uma plataforma de Stewart (Figura 2.11). O controle adaptativo (Figura 2.12) é projetado para que a plataforma siga uma determinada trajetória de usinagem com robustez, ou seja, o sistema deve ser imune às imprecisões de modelagem e aos distúrbios externos. Para cada condição de trabalho, o controlador executa uma adaptação dos parâmetros. Os autores executaram dois tipos de testes na plataforma. No primeiro teste, a plataforma é levada a seguir uma trajetória circular, em um modo livre, ou seja, a plataforma 
não está executando uma usinagem. Os dados obtidos neste teste mostram robustez do controlador, pois a plataforma segue a trajetória desejada com erros muito pequenos. No segundo teste, a plataforma é levada a executar uma usinagem em peça de Teflon, com uma trajetória circular. Os dados demonstram que o controlador mostrou-se estável mesmo na presença de distúrbios provocados pelo processo de usinagem e alcançou bons resultados.

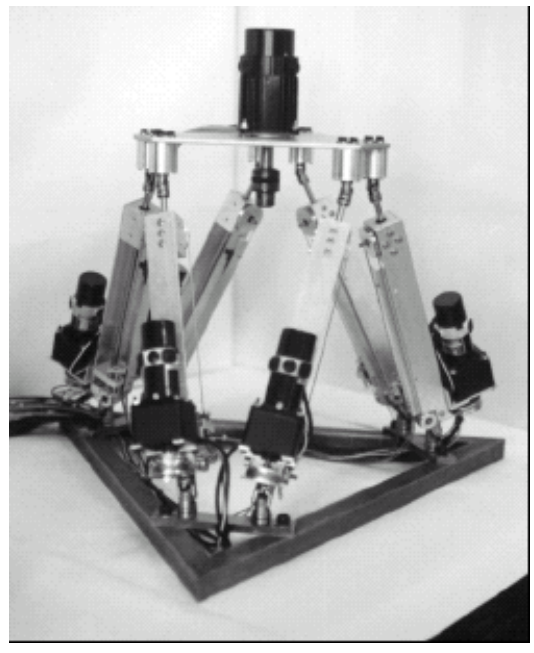

(a)

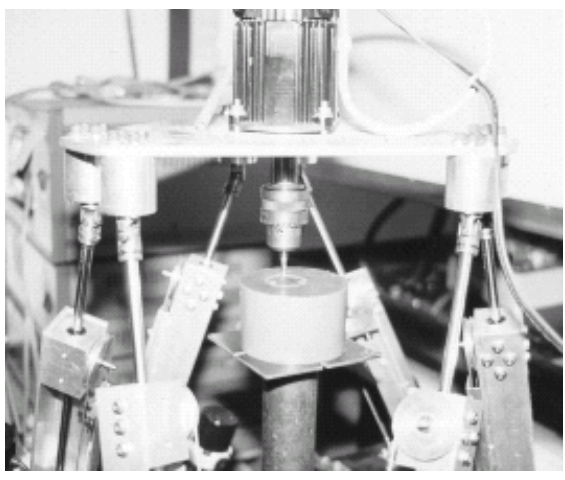

(b)

Figura 2.11 - (a) Arranjo experimental da plataforma de Stewart, (b) Processo de usinagem em uma trajetória circular (CHAE et al., 1998).

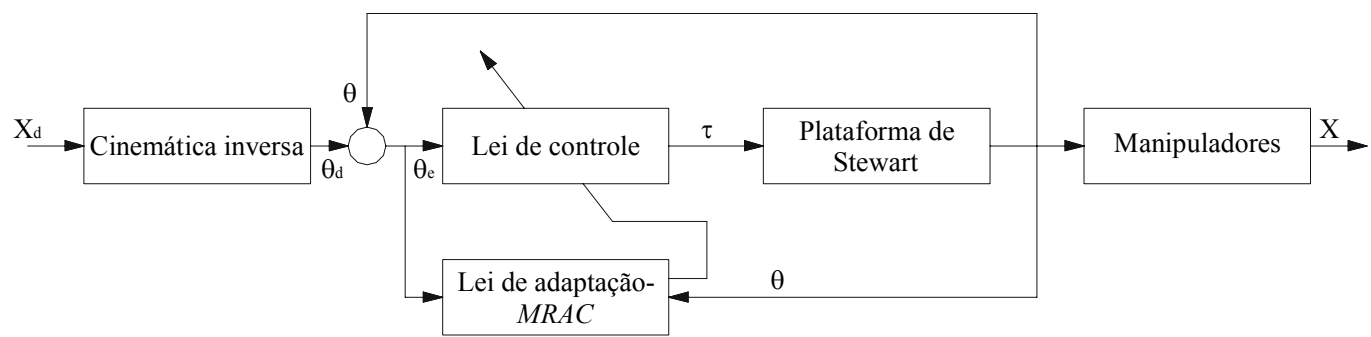

Figura 2.12 - Diagrama esquemático do controlador da plataforma de Stewart proposto por Chae et al. (1998).

Silfhout (1999) apresenta um projeto de plataforma de Stewart atuada hidraulicamente para posicionamento com alto grau de acuracidade. A plataforma é usada como suporte para uma grande variedade de instrumentos científicos que necessitam de um alinhamento estável, com movimento acurado como mostra a Figura 2.13. O esquema de controle adotado para o acionamento dos atuadores hidráulicos foi o PID (Proporcional Integral Derivativo). A plataforma também funciona como um isolador de vibrações com atuação ativa. Os dados abordados pelo autor, realmente, mostram uma grande acuracidade no posicionamento da 
plataforma com relativa rapidez. É também discutido, no trabalho, o excelente desempenho realizado pela plataforma como suporte para um difratômetro de raios X.

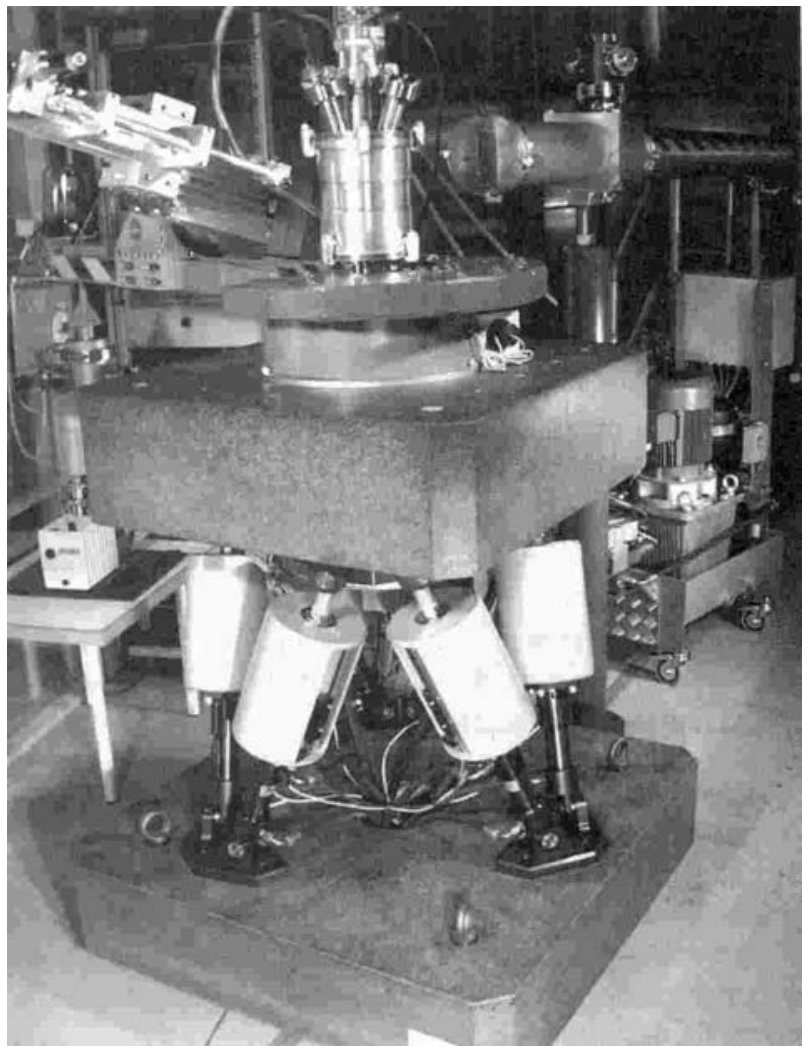

Figura 2.13 - Plataforma de Stewart equipada com um difratômetro de raio X (SILFHOUT, 1999).

Algumas empresas têm experimentado sistemas baseados em manipuladores paralelos aplicados a fresadoras. A pesquisa de Abbasi et al. (2000) apresenta o desenvolvimento de um mecanismo paralelo especial aplicado à fresagem de contorno, conforme mostra a Figura 2.14. A idéia principal do trabalho é aumentar a capacidade de um equipamento de usinagem não $\mathrm{CNC}$, a um custo menor do que a compra de um tradicional centro de usinagem com cinco eixos. Assim, utilizando uma metodologia de projeto cinestática paramétrica (parametric kinestatic design methodology), para um mecanismo paralelo especial (plataforma cinestática), capacita-se uma fresadora de 3 eixos não $\mathrm{CNC}$ a realizar operações de fresagem de contorno semelhantes às de uma de cinco eixos. A vantagem de se utilizar uma plataforma cinestática é a possibilidade de realizar, simultaneamente, um controle preciso de força de contato e deslocamento na fresagem. 


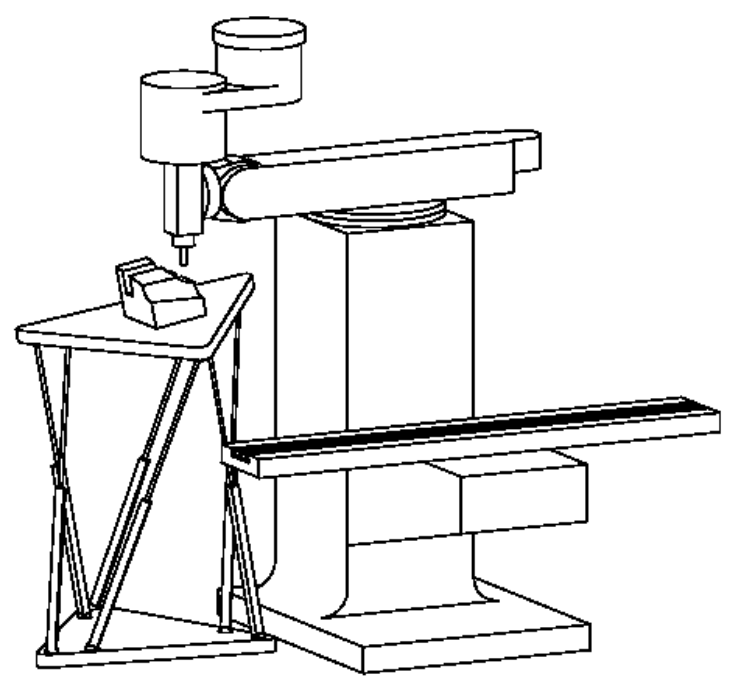

Figura 2.14 - Plataforma cinestática aplicada a fresagem de contorno (ABASSI et al., 2000).

Para controlar a plataforma, utilizou-se um controle PID no qual os resultados obtidos para uma entrada degrau de 0,0102 mm estão mostrados na Figura 2.15. Para este teste, os ganhos do controlador foram obtidos usando-se as regras de Ziegler-Nichols para os valores iniciais. Overshoot e erro de regime foram reduzidos, ajustando-se o controle, porém houve um aumento no tempo de resposta. Para corrigir tal fato, Abbasi et al. (2000) sugerem uma estratégia de controle adaptativa. Conclui-se, então, que o controlador PID mostrou suficiente precisão no posicionamento e, a partir dos dados de simulação de movimentos, mostrou que é possível seguir a trajetória com um atraso.

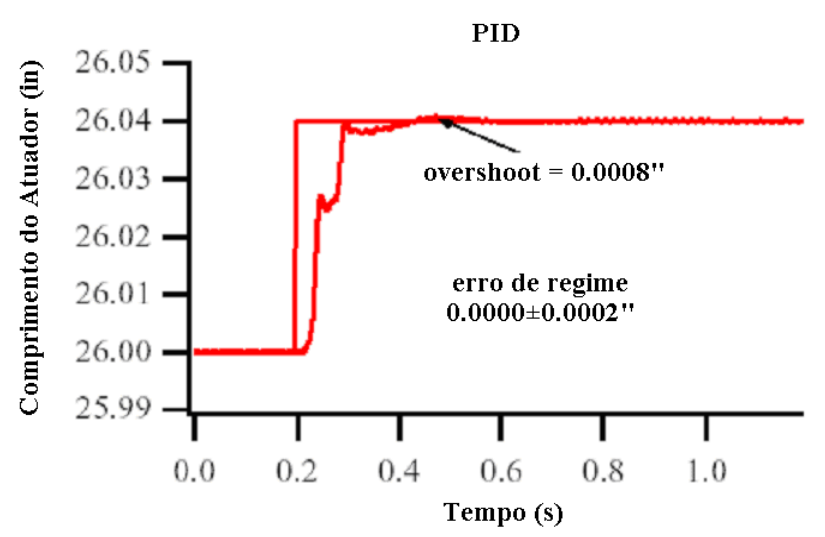

Figura 2.15 - Resposta a uma entrada degrau usando um controlador PID (ABASSI et al., 2000).

Segundo o publicado no site da revista MMS (Modern Machine Shop), MMS Online ${ }^{2}$, pelo editor Chis Koepfer, no ano de 2000, a Hexel Corporation havia lançado o Hexabot

\footnotetext{
${ }^{2}<$ http://www.mmsonline.com/articles/this-hexapod-you-can-work-with.aspx>. Acesso em: 12 ago. 2009.
} 
Series 1, que era um hexapod para ser adaptado em fresadoras convencionais para transformálas em uma fresadora CNC de cinco eixos. A aceitação comercial do hexapod foi lenta devido ao receio de se investir em uma tecnologia relativamente nova. A mesa Hexabot é acionada por comando numérico computadorizado, usa uma interface baseada em PC e software que permite implementar a produção em cinco eixos a partir de um software CNC padrão (Figura 2.16).

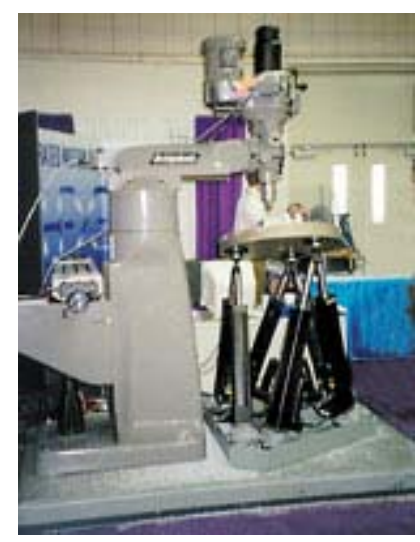

Figura 2.16 - Hexabot Serie 1 fabricado pela Hexel Corporation.

Relativamente a simuladores, segundo Son et al. (2001) simuladores de dirigibilidade de veículos têm sido utilizados para desenvolvimento e alteração de modelos. Um simulador pode reduzir custo e tempo através de uma grande variedade de simulações em laboratório. Recentemente, simuladores de dirigibilidade têm se proliferado na indústria automobilística e na comunidade de pesquisa a ela ligada. No artigo, são apresentados o hardware e o software para um simulador de dirigibilidade de um veículo de construção. Para tanto foi necessário despender esforço para realizar uma análise dinâmica, em tempo real da máquina escavadeira, projeto e desenvolvimento de uma plataforma de Stewart, um sistema de controle integrado da plataforma e um modelo gráfico tridimensional de um ambiente de dirigibilidade (Figura 2.17). 


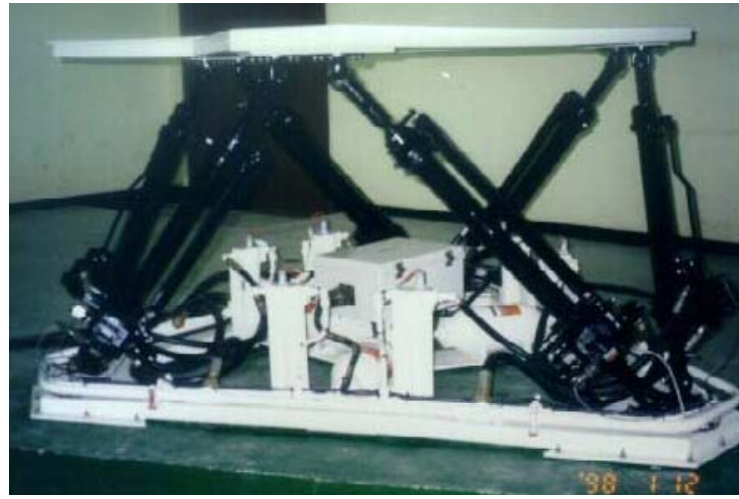

(a)

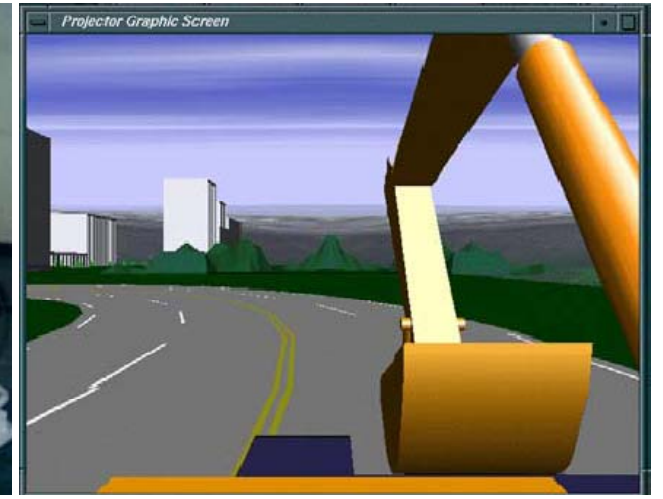

(b)

Figura 2.17 - (a) Plataforma de Stewart e (b) Ambiente virtual de dirigibilidade (SON et al, 2001).

Com a possibilidade de robôs paralelos competirem com robôs convencionais, com algumas vantagens em algumas áreas, surgiu, em 2002, uma empresa chamada Parallel Robotics Systems Corporation (PRSCO) ${ }^{3}$ que é dedicada ao projeto, manufatura e aplicação de robôs paralelos. A PRSCO tem, desde a sua fundação, desenvolvido novas aplicações robóticas, usando a licença de patente da Hexel Corporation. Esses dispositivos têm sido usados para eliminar erros em linhas automatizadas de solda, em processos de alta precisão e em outras aplicações nas quais seja necessário o uso de hexapods ou plataformas de Stewart. Um equipamento similar ao Hexabot da Hexel Corporation, é atualmente fabricado pela PRSCO com o nome de $P 2000$ Hexapod (Figura 2.18b).

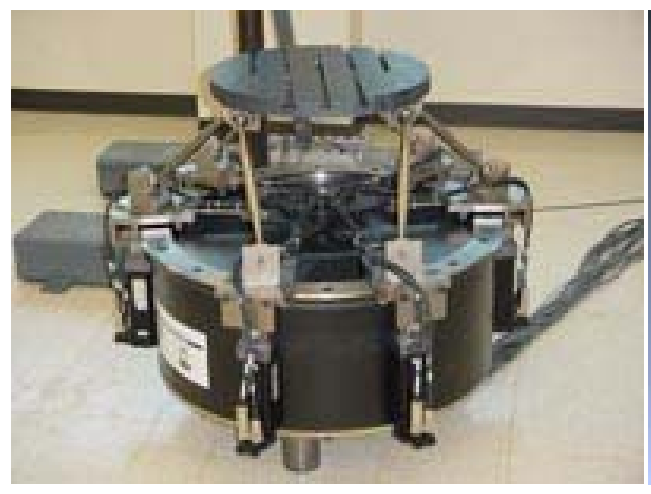

(a)

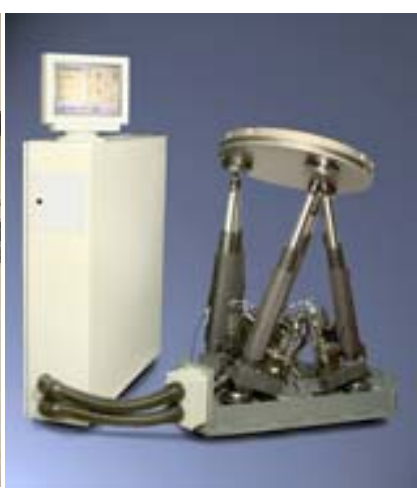

(b)

Figura 2.18 - (a) R Series Rotopod, (b) P 2000 Hexapod fabricados pela PRSCO.

\footnotetext{
${ }^{3}<$ http://prsco.com/about.html $>$. Acesso em: 12 ago. 2009.
} 
Segundo Rowe, apresentado no relatório anual de 2002 do ILL (Institut LaueLangenvin $)^{4}$, historicamente o design, além da manufatura de robôs paralelos, havia permanecido dentro do ambiente acadêmico e de companhias de alta tecnologia que têm necessidades de soluções para problemas específicos, como simuladores de vôo. Entretanto, como resultado da diminuição dos custos e aumento da velocidade de processamento computacional disponível, a indústria começou a atuar em áreas tradicionalmente restritas a mecanismos com configuração padrão, como posicionamento de alta precisão requerido para a fabricação de circuitos integrados. O aumento do volume do mercado resultou num número de dispositivos disponíveis comercialmente. As plataformas de Stewart tiveram um destaque especial, sendo a última palavra em termos de graus de liberdade e em termos de custo, sendo comercializadas por algumas empresas, como a Physik Instrumente que oferece o M-850, Micos que produz o PAROS (Figura 2.19) e outros, que oferece equipamentos com capacidade de carga e posicionamento que ultrapassam os $50 \mathrm{~kg}$, com uma resolução superior a $2 \mu \mathrm{m}$ e $5 \mu \mathrm{rad}$.

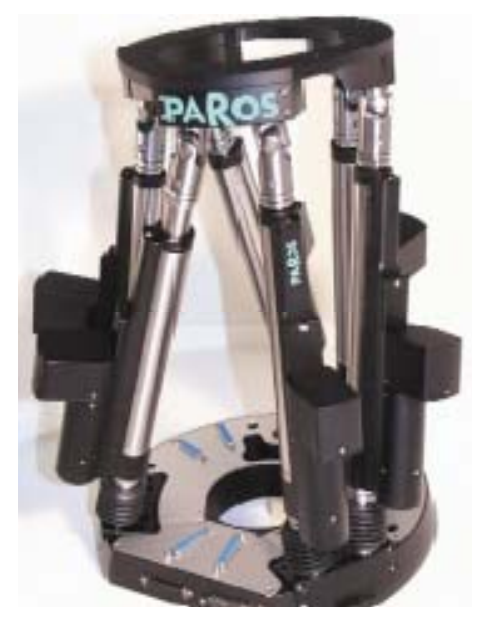

Figura 2.19 - Robô PAROS da fabricante Micos.

Luo (2005) descreve o desenvolvimento de um robô sensor de força baseado em uma plataforma de Stewart, com estrutura de juntas móveis característica. O número de juntas móveis é, nesse caso, a metade dos sensores similares a este que não se utilizam a configuração de plataforma de Stewart; e com isso é possível reduzir o tamanho e o peso do sensor. Em vez de se utilizar vigas, foram utilizados tubos com extensômetros, no qual a utilização de juntas flexíveis e tubos, efetivamente reduziram o erro do sensor.

\footnotetext{
${ }^{4}<$ http://www.ill.eu/fileadmin/users_files/Annual_Report/AR-02/site/areport/fset_96.htm>. Acesso em: 12 ago. 2009.
} 


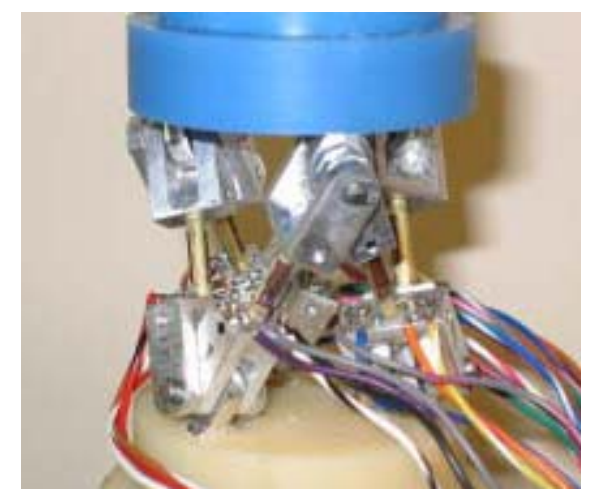

Figura 2.20 - Sensor de força de 6 eixos (LOU et al, 2005).

Uma das iniciativas do programa do milênio do ILL (Institut Laue-Langenvin) é o SALSA (Strain Analyser for Large and Small scale engineering Applications). Segundo o sítio do instituto ${ }^{5}$ e Pirling et al. (2006), a SALSA é utilizada para determinação de stress residual numa grande faixa de aplicações em termos de componentes e de materiais. É projetado para realizar medições por difração em componentes "reais" de engenharia e é otimizado para determinação de stress em componentes metálicos. Uma das principais vantagens, durante o experimento de esforço, é o movimento da amostra em relação ao feixe de nêutrons. O SALSA usa um hexapod que tem vantagens significativas sobre uma mesa $\mathrm{X}$, $\mathrm{Y}$ e $\mathrm{Z}$ tradicional. O hexapod possui seis atuadores, de forma independentemente acionados hidraulicamente que podem mover cargas de $90 \mathrm{~kg}$ com uma precisão da ordem de microns (Figura 2.21). Esse experimento demonstra algumas das características principais de uma plataforma de Stewart que são: alta rigidez, grande capacidade de carga, grande acuracidade, além de possuir 6 graus de liberdade.

${ }^{5}<$ http://www.ill.eu>. Acesso em: 12 ago. 2009. 


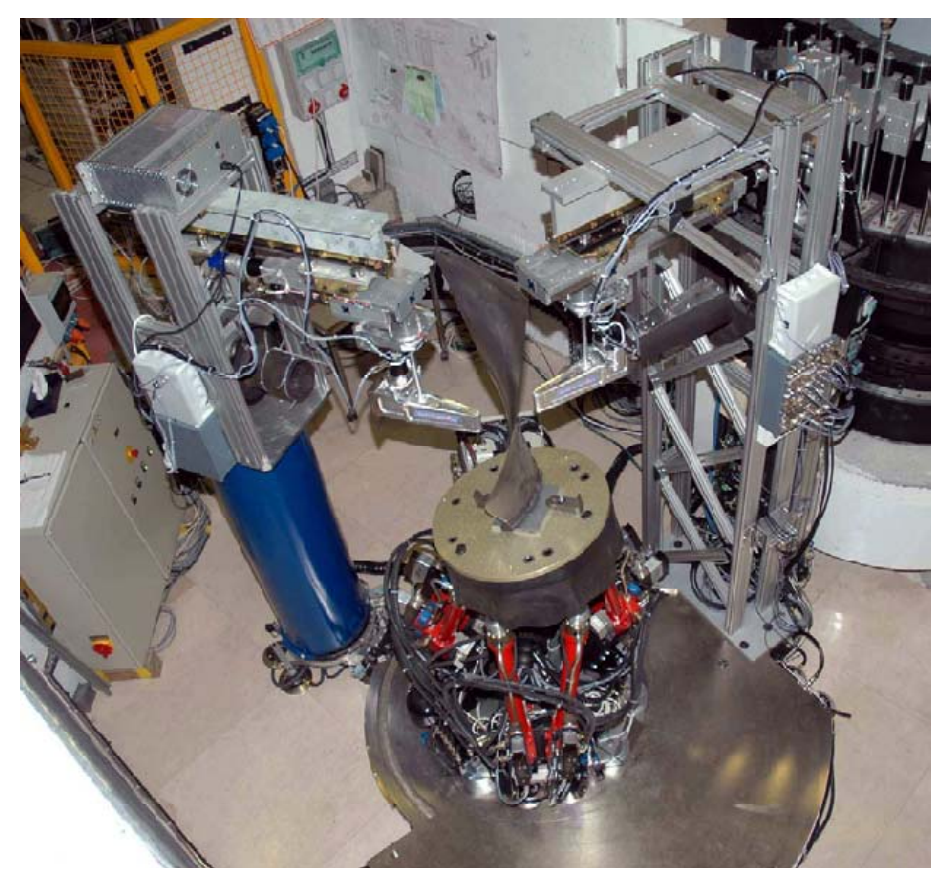

Figura 2.21 - Projeto SALSA do ILL (PIRLING et al., 2006).

O simulador de vôo desenvolvido pela universidade McMaster $^{6}$, no Canadá, apresenta forma e cor futurísticas com capacidade para até cinco pessoas. Construído em fibra de vidro, com sistema de projeção no interior e sistema de som Dolby digital surround, esta estrutura é movimentada por uma plataforma de Stewart fabricada pela $M O O G$, Inc. com seis graus de liberdade, e capacidade para $1000 \mathrm{~kg}$ e 0,6 Gs de aceleração, o que corresponde a um carro esportivo de grande desempenho. Este simulador é utilizado por estudantes para desenvolvimento de técnicas de realidade virtual em 4D, sistemas de tempo real, controle, ferramentas de animação, interfaces para usuários. O equipamento tem como objetivo estimular e suprir a demanda crescente por tecnologia da informação para os cursos de Ciência da Computação e Engenharia de Software.

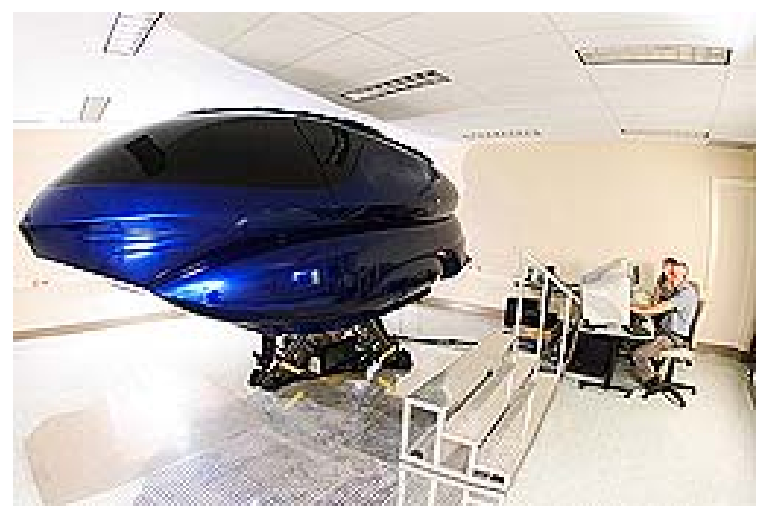

Figura 2.22 - Simulador mini-van-sized da universidade McMaster.

\footnotetext{
${ }^{6}<$ http://dailynews.macmaster.ca $/$ story.cfm?id=4233>. Acesso em: 11 ago. 2008.
} 
Um dos problemas recorrentes em plataformas de Stewart é a construção de juntas esféricas, nas quais o objetivo é a obtenção de uma junta com 3 D.G.L., onde todos são de rotação em torno dos eixos $\mathrm{X}, \mathrm{Y}$ e Z, ocupando o menor espaço possível. Lee (2003) apresenta um modelo de junta esférica conectando dois atuadores, que seja funcional, a solução demanda um espaço maior do que o modelo ideal de uma junta esférica que é formada por uma esfera e um assento esférico. Ainda que a construção dessa junta ideal seja possível, é trabalhosa e precisa de processos especiais para garantir precisão e baixo atrito. Pensando nesse mercado, a empresa japonesa Hephaist Seiko ${ }^{7}$ é a única a apresentar uma solução de alta precisão de posicionamento, alinhamento, sem folgas, com grande rigidez, baixo atrito e ocupando pouco espaço para juntas esféricas, sendo seu projeto baseado nos rolamentos de esferas tradicionais adaptado para juntas com 3 graus de liberdade. O objetivo é apresentar uma solução com baixo custo, devido ao volume de fabricação que pouparia trabalho e tempo nos projetos de manipuladores paralelos que necessitem de juntas esféricas de baixo atrito e alta precisão. Lançado em $2007^{8}$, a empresa chamou o produto de "juntas esféricas de rolamento" e as juntas esféricas tradicionais de "juntas esféricas deslizantes" (Figura 2.23).

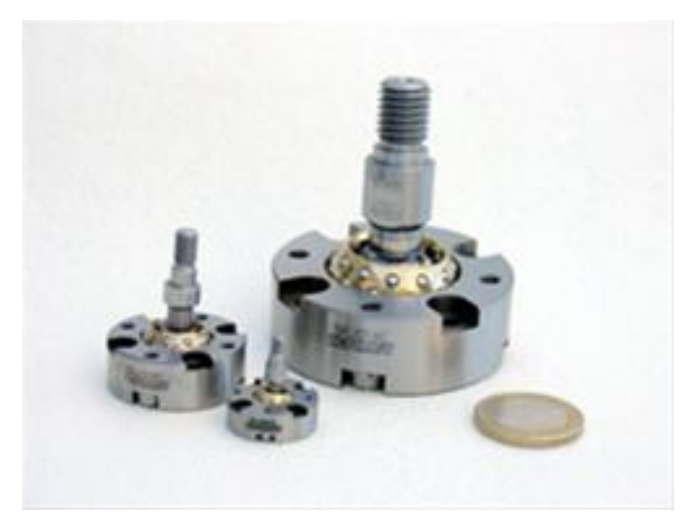

Figura 2.23 - Junta esférica de rolamento.

A fabricante de robôs ABB desenvolveu um novo tipo de PKM (Parallel Kinematic Machine), denominado de FlexPLP (Flexible Principle Locator Points) ${ }^{9}$, projetado para tarefas de fixação de forma flexível. A idéia do FlexPLP é substituir os dispositivos de fixação que utilizam pontos fixos, definidos de acordo com a geometria das partes, os quais formam o corpo do carro durante a fabricação e a soldagem. O FlexPLP controla, através de um sistema computadorizado, os pontos de fixação (Figura 2.24).

\footnotetext{
${ }^{7}<$ http://www.hephaist.co.jp/e/>. Acesso em: 12 ago. 2009.

${ }^{8}<$ http://www.heason.com/news/2/35/hephaist-spherical-rolling-joints.html>. Acesso em: 12 ago. 2009.

${ }^{9}<$ http://www.parallemic.org/Reviews/Review015.html $>$. Acesso em: 12 ago. 2009.
} 


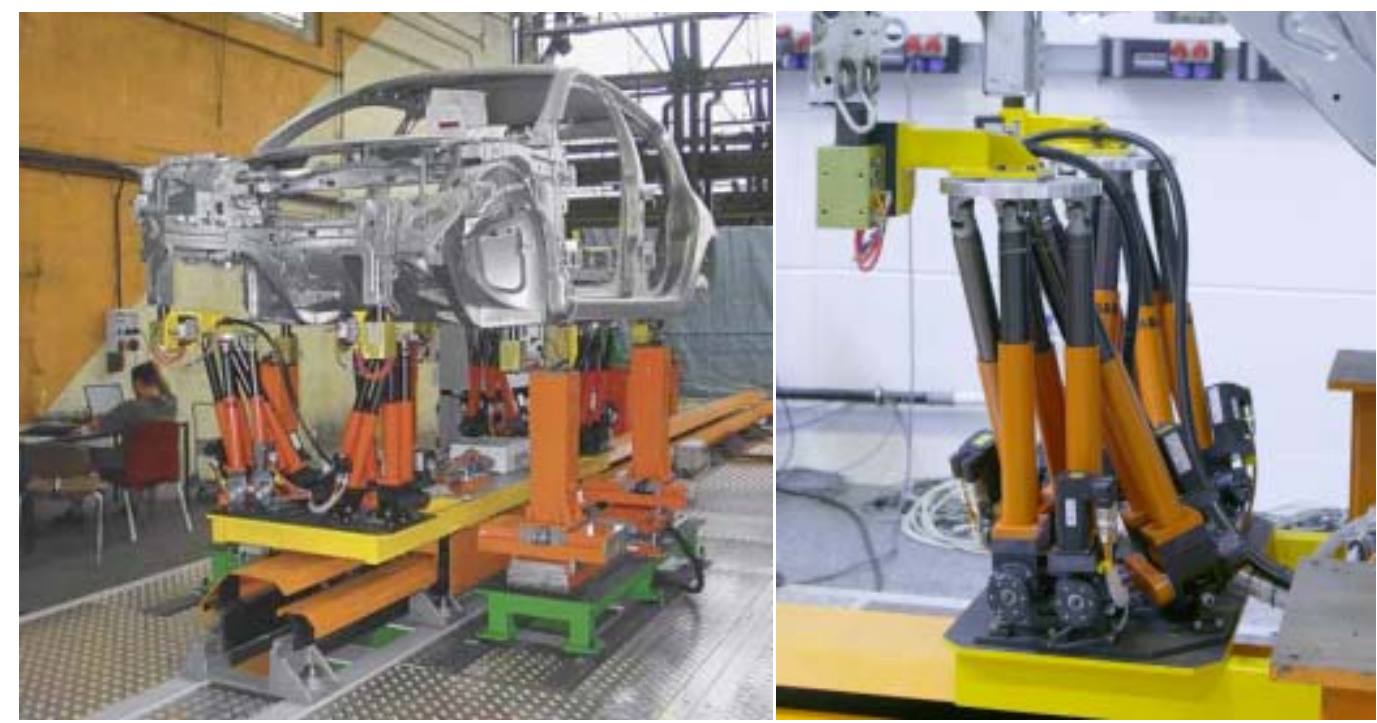

Figura 2.24 - FlexPLP sendo utilizado para posicionar um automóvel em fabricação.

Esta configuração de robô com cadeia cinemática paralela, denominada de deltapod, foi desenvolvida para que os pontos de fixação possam ter suas posições variáveis. O deltapod representa a junção de dois princípios de robôs paralelos bem conhecidos, que são o delta e o hexapod. O robô de cadeia cinemática paralela conhecido como robô delta foi criado nos anos 80, pelo professor Reymond Clavel, da École Polytechnique Fédérale de Lausanne, através da idéia de utilizar paralelogramos para construir um robô com 3 graus de liberdade de translação e um de rotação. Com o tempo, o robô delta se tornou um sucesso. Sendo o Dr. Clavel presenteado com o prêmio Golden Robot Award em 1999, pela fabricante de robôs ABB, por seu trabalho inovador. Segundo Ilian Bonev ${ }^{10}$, do Parallel Mechanisms Information Center (ParalleMIC), da Universidade de Laval, na cidade canadense de Quebec, o robô delta é utilizado para tarefas de pegar e posicionar, embora haja aplicações com máquinas ferramentas. O robô delta foi licenciado para várias companhias, incluindo alguns fabricantes de máquinas ferramentas que conseguiram suas próprias patentes e construíram PKMs baseados na arquitetura dos robôs delta.

\footnotetext{
${ }^{10}<$ http://www.parallemic.org/Reviews/Review002.html>. Acesso em: 12 ago. 2009.
} 


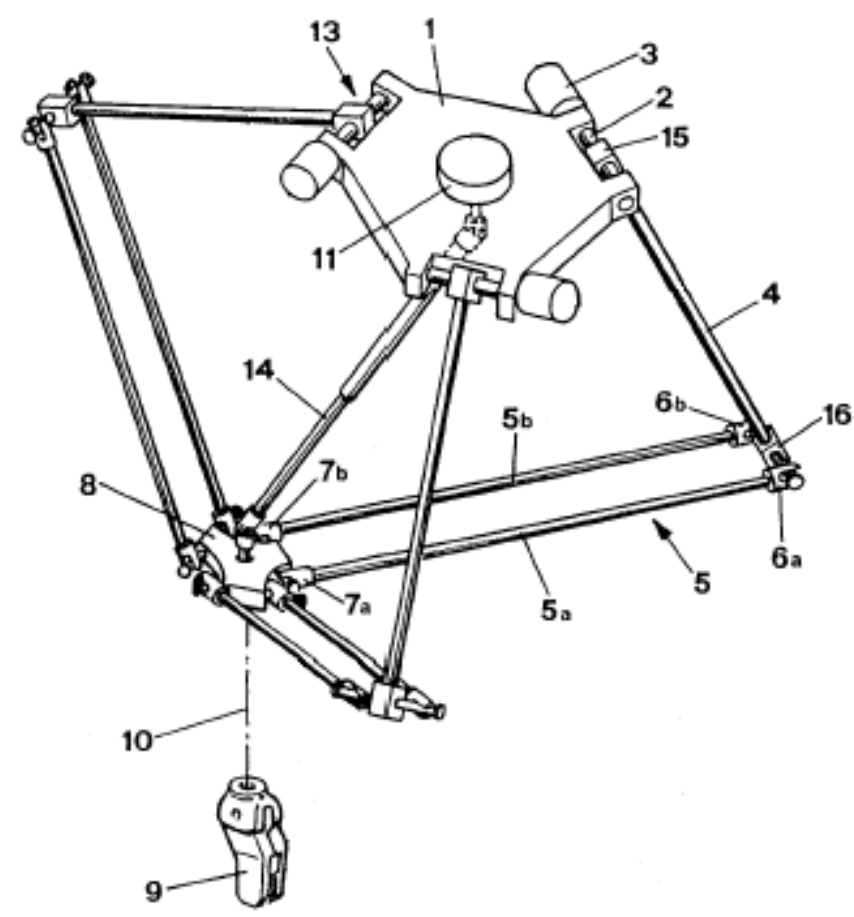

Figura 2.25 - Esquema do robô Delta, patente US No. 4.976.582.

Devido aos avanços tecnológicos dessa última década, as plataformas de Stewart tiveram um significativo aumento na sua utilização. Isso se deve em parte devido a sua precisão e a sua capacidade de carga, sendo amplamente utilizadas em simuladores de veículos ou de vôo e posicionadores. Até o início dessa década alguns livros publicados sobre robôs traziam capítulos sobre manipuladores paralelos: em 2000, J. P. Merlet ${ }^{11}$ publicou o livro intitulado Paralle Robots, versando exclusivamente sobre manipuladores paralelos e que foi reeditado em 2006. Hoje isso já está mudando, e é possível encontrar na internet sítios comerciais de manipuladores paralelos que possuem diversos modelos de plataforma de Stewart, para diversas aplicações, como já apresentado nesse capítulo, assim como alguns livros exclusivos sobre manipuladores paralelos, como os de Gogu (2008) e Zang (2010).

\footnotetext{
${ }^{11}<$ http://www-sop.inria.fr/members/Jean-Pierre.Merlet/merlet.html>. Acesso em: 12 ago. 2009.
} 


\section{PLATAFORMA DE STEWART}

\subsection{Introdução}

Sistemas mecânicos que permitem um corpo rígido (aqui chamado efetuador) se mover em relação a uma base fixa, desempenham um papel muito importante em inúmeras aplicações. Um corpo rígido no espaço pode se mover de várias formas, em movimentos de translação e/ou rotação. Esses são chamados graus de liberdade. O número total de graus de liberdade de um corpo rígido, no espaço, não pode exceder a seis (por exemplo, três movimentos de translação ao longo de eixos perpendiculares entre si e três movimentos de rotação em torno desses eixos). A posição e a orientação do efetuador pode ser descrita por coordenadas generalizadas; essas são usualmente as coordenadas de um ponto específico do efetuador e os ângulos que definem a sua orientação. Sendo possível controlar vários graus de liberdade via um sistema mecânico, esse sistema pode ser chamado de robô. Em particular, um desses sistemas é chamado de plataforma de Stewart.

\subsection{Características Geométricas da Plataforma de Stewart}

Muitas variantes da plataforma de Stewart têm sido investigadas; a maioria delas possui seis atuadores lineares com diferentes combinações de fixação dos atuadores nas plataformas como 3-3, 3-6 e a mais geral 6-6 (Figura 3.1) (BEN-HORIN; SHOHAM; DJERASSI, 1998).

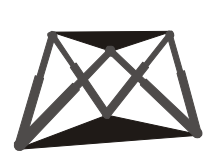

tipo 3-3

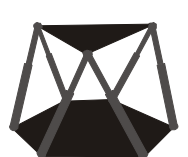

tipo 3-6

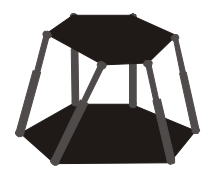

tipo 6-6

Figura 3.1 - Configurações da plataforma de Stewart (BEN-HORIN; SHOHAM; DJERASSI, 1998).

A configuração 3-3, com duas plataformas triangulares iguais, tem os atuadores ligados à plataforma móvel através de seis juntas esféricas e à estacionária por seis juntas 
universais. Esta configuração é conhecida como plataforma cúbica, pois os atuadores ficam posicionados como arestas de um cubo, como mostra a Figura 3.2. As dimensões da plataforma e os pontos de fixação das juntas dependem do comprimento dos atuadores na posição neutra e podem ser determinados por trigonometria.
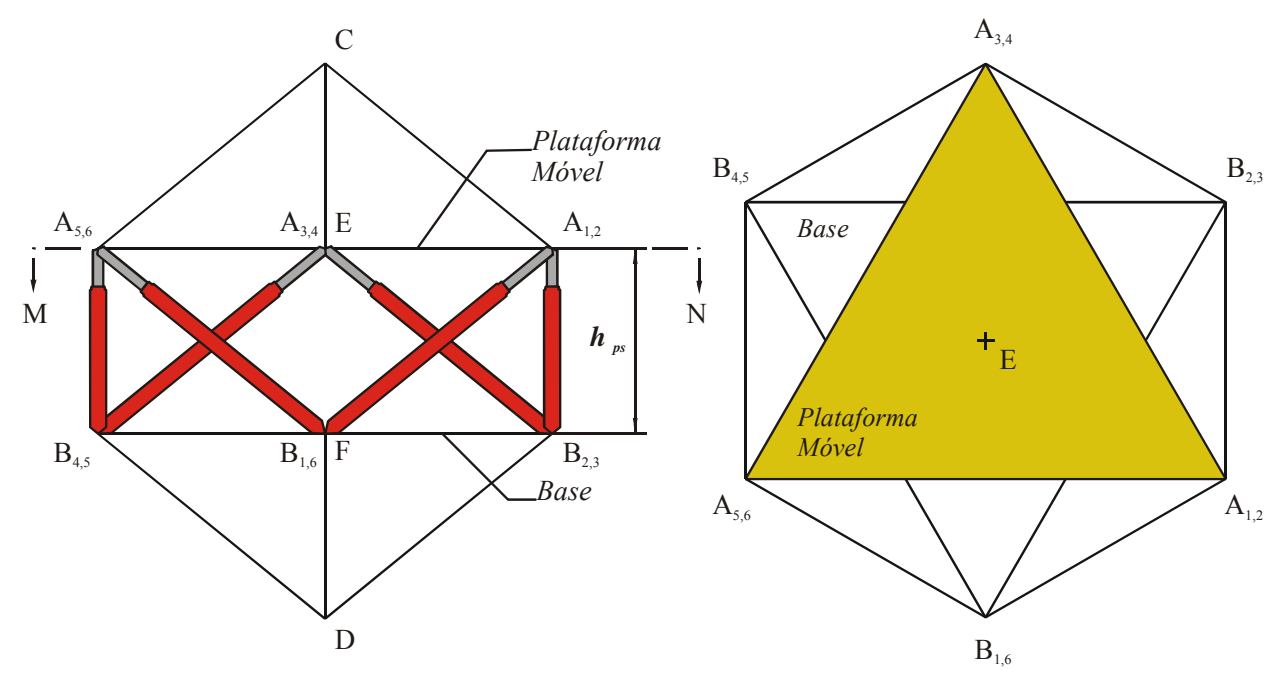

Figura 3.2 - Configuração cúbica da plataforma de Stewart.

Define-se, então, um sistema de coordenada global $\{\mathrm{B}\}$ com o eixo $y_{B}$ normal ao plano da plataforma estacionária e um sistema de coordenada local $\{\mathrm{A}\}$ com o eixo $y_{A}$ normal ao plano da plataforma móvel e a origem no centro de massa, Figura 3.3.

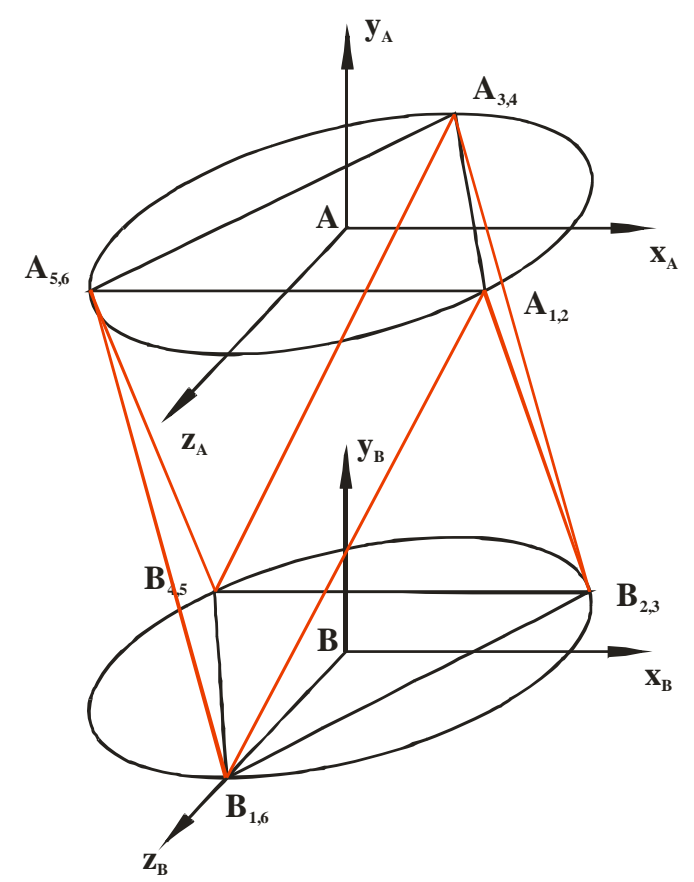

Figura 3.3 - Posicionamento dos sistemas de coordenadas. 
Se for adotado o ângulo entre $A A_{i}$ e $z_{A}$ por $\Lambda_{i}$ e o ângulo entre $B B_{i}$ e $z_{B}$ por $\lambda_{i}$ para $i=1,2, \ldots 6$, então por observação consegue-se obter

$$
\begin{aligned}
& \Lambda_{\mathrm{i}}=60^{\circ}+60(\mathrm{i}-1)^{\circ} ; \lambda_{\mathrm{i}}=60(\mathrm{i}-1)^{\circ} \text { para } \mathrm{i}=1,3,5 \\
& \Lambda_{\mathrm{i}}=\Lambda_{\mathrm{i}-1} ; \lambda_{\mathrm{i}}=\lambda_{\mathrm{i}-1}+120^{\circ} \text { para } \mathrm{i}=2,4,6 .
\end{aligned}
$$

Se ${ }^{A} \boldsymbol{a}_{i}=\left(\begin{array}{lll}a_{i x} & a_{i y} & a_{i z}\end{array}\right)^{T}$ é a posição de fixação da junta esférica no ponto $A_{i}$ na plataforma móvel em relação ao sistema de coordenadas $\{\mathrm{A}\}$ e ${ }^{B} \boldsymbol{b}_{i}=\left(b_{i x} b_{i y} b_{i z}\right)^{T}$ é a posição da fixação da junta universal no ponto $B_{i}$ na plataforma estacionária em relação ao sistema de coordenadas $\{B\}$, então pode se escrever

$$
{ }^{A} \boldsymbol{a}_{i}=\left[\begin{array}{lll}
r_{A} \operatorname{sen}\left(\Lambda_{i}\right) & -\frac{e}{2} & r_{A} \cos \left(\Lambda_{i}\right)
\end{array}\right]
$$

e

$$
{ }^{A} \boldsymbol{b}_{i}=\left[\begin{array}{lll}
r_{B} \operatorname{sen}\left(\lambda_{i}\right) & -\frac{e}{2} & r_{B} \cos \left(\lambda_{i}\right)
\end{array}\right]
$$

para $i=1,2, \ldots 6$ onde $r_{A}$ e $r_{B}$ representam os raios das plataformas móvel e estacionária respectivamente e $e$ é a espessura da plataforma móvel.

Para a configuração cúbica da Plataforma de Stewart os pontos de fixação das juntas esféricas na plataforma móvel em função do comprimento dos atuadores na posição neutra $l$, em relação ao sistema de coordenadas local, dado pelo vetor ${ }^{A} \boldsymbol{a}_{i}=\left(a_{i x} a_{i y} a_{i z}\right)^{T}$ são mostrados na Tabela 3.1. 
Tabela 3.1 - Coordenadas cartesianas das juntas esféricas.

\begin{tabular}{c|c|c}
\hline Juntas esféricas 1 e 2 & Juntas esféricas 3 e 4 & Juntas esféricas 5 e 6 \\
\hline$a_{1,2 x}=\frac{l \sqrt{2}}{2}$ & $a_{3,4 x}=0$ & $a_{5,6 x}=-\frac{l \sqrt{2}}{2}$ \\
$a_{1,2 y}=\frac{l \sqrt{3}}{3}$ & $a_{3,4 y}=\frac{l \sqrt{3}}{3}$ & $a_{5,6 y}=\frac{l \sqrt{3}}{3}$ \\
$a_{1,2 z}=\frac{l \sqrt{6}}{3}$ & $a_{3,4 z}=-\frac{l \sqrt{6}}{6}$ & $a_{5,6 z}=\frac{l \sqrt{6}}{6}$ \\
\hline
\end{tabular}

Para as juntas universais, quem representa o posicionamento das mesmas em relação ao sistema de coordenadas global, é o vetor ${ }^{B} \boldsymbol{b}_{i}=\left(b_{i x} b_{i y} b_{i z}\right)^{T}$, mostrado na Tabela 3.2.

Tabela 3.2 - Coordenadas cartesianas das juntas universais.

\begin{tabular}{c|c|c}
\hline Juntas universais 1 e 6 & Juntas universais 2 e 3 & Juntas universais 4 e 5 \\
\hline$b_{1,6 x}=0$ & $b_{2,3 x}=\frac{l \sqrt{2}}{2}$ & $b_{4,5 x}=-\frac{l \sqrt{2}}{2}$ \\
$b_{1,6 y}=0$ & $b_{2,3 y}=0$ & $b_{4,5 y}=0$ \\
$b_{1,6 z}=\frac{l \sqrt{6}}{3}$ & $b_{2,3 z}=-\frac{l \sqrt{6}}{6}$ & $b_{4,5 z}=-\frac{l \sqrt{6}}{3}$ \\
\hline
\end{tabular}

Os valores mostrados nas Tabelas 3.1 e 3.2 foram obtidos através das equações (3.3) e (3.4).

Determinar o versor direcional de cada atuador e seu ponto de aplicação é de grande importância para a montagem do protótipo virtual. Isso será feito considerando a plataforma de Stewart na posição neutra. Através das Figuras 3.4 e 3.5 os ângulos necessários podem ser determinados utilizando as propriedades de triângulo. 


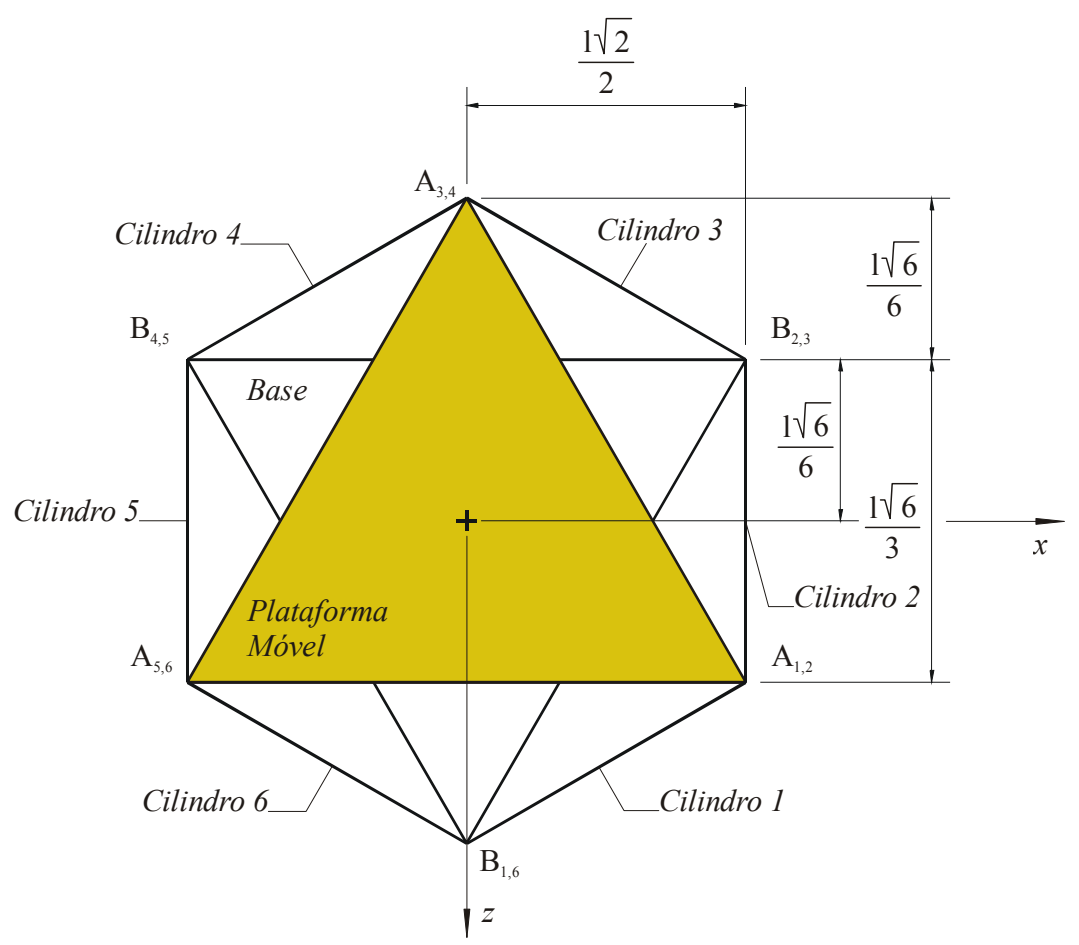

Figura 3.4 - Vista de topo da plataforma de Stewart.

Observando a Figura 3.6b e aplicando a lei dos cossenos podemos determinar o ângulo $\beta$.

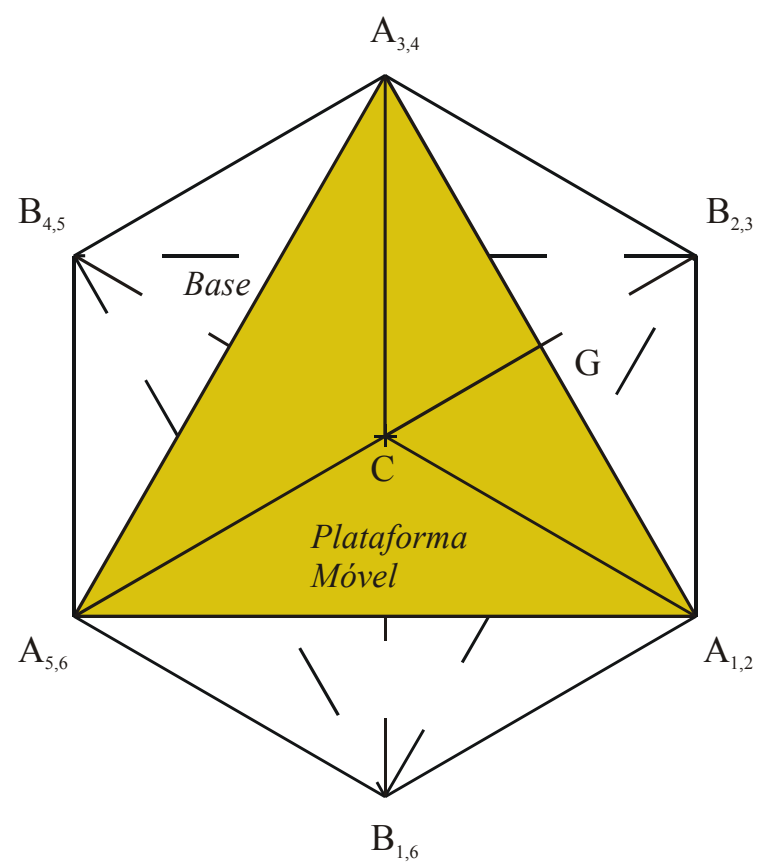

(a)

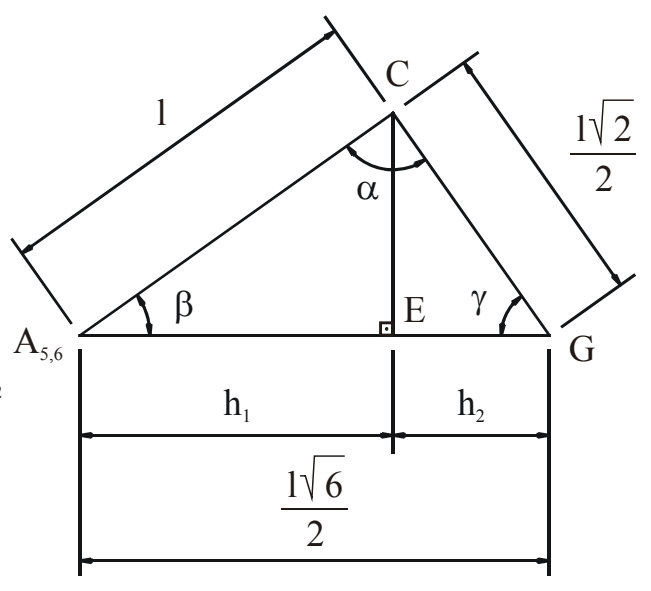

(b)

Figura 3.5 - Distância do vértice do cubo ao centro de massa da plataforma móvel. 
$\frac{l^{2}}{2}=l^{2}+\frac{6 l^{2}}{4}-2 \frac{\sqrt{6} l}{2} l \cos \beta$

$\frac{l^{2}}{2}=\frac{10 l^{2}}{4}-\sqrt{6} l^{2} \cos \beta$

$\frac{l^{2}}{2}-\frac{10 l^{2}}{4}=-\sqrt{6} l^{2} \cos \beta$

$-\frac{8 l^{2}}{4}=-\sqrt{6} l^{2} \cos \beta$

$\cos \beta=\frac{8}{4 \sqrt{6}}=\frac{\sqrt{6}}{3}$

Como, $\alpha=90^{\circ}$ e $\alpha+\beta+\gamma=180^{\circ}$, sabe-se que $\gamma$ é igual ao complemento de $\beta$, portanto

$\cos \gamma=\operatorname{sen} \beta$

$\operatorname{sen}^{2} \beta=1-\cos ^{2} \beta$

$\operatorname{sen} \beta=\frac{\sqrt{3}}{3}$

$\operatorname{sen} \gamma=\frac{\sqrt{6}}{3}$

Precisa ser determinada a altura que a parte inferior da plataforma móvel fica do sistema de coordenadas da base $\left(h_{p s}\right)$ (Figura 3.2) e para isso, a diagonal do cubo que possui as arestas com o mesmo comprimento dos atuadores na posição neutra deve ser calculada, assim

$d_{c}^{2}=l^{2}+l^{2}+l^{2}$

$h_{p s}=d_{c}-\overline{C E}-\overline{D F}$

$\overline{C E}=\overline{D F}=l \operatorname{sen} \beta=l \frac{\sqrt{3}}{3}$

$h_{p s}=l \frac{\sqrt{3}}{3}$. 
Calcula-se o ângulo $\theta$ que cada cilindro forma com a horizontal a partir da Figura 3.6.

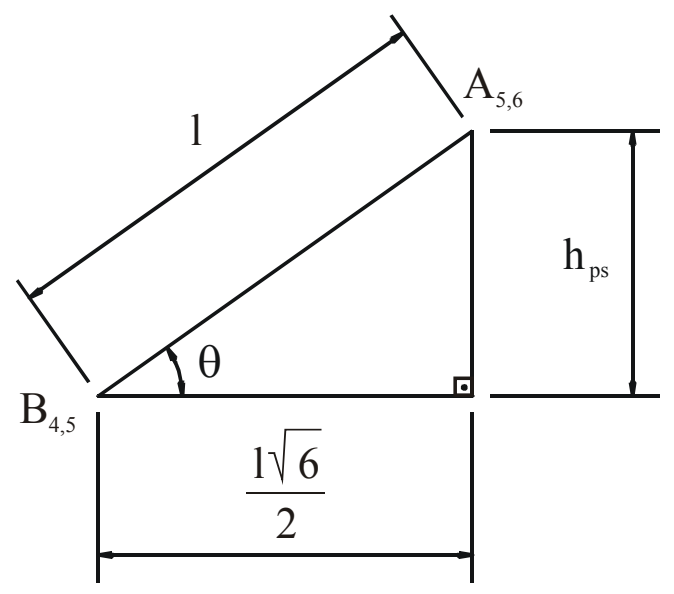

Figura 3.6 - Ângulo dos atuadores com a horizontal.

$\operatorname{sen} \theta=\frac{h_{p s}}{l}=\frac{\sqrt{3}}{3}$

Com os ângulos calculados até aqui e os obtidos da Figura 3.5 pode-se montar a Tabela 3.3 abaixo com todas as posições e orientações dos atuadores em relação ao sistema de coordenadas global $\{\mathrm{B}\}$.

Tabela 3.3 - Posição e orientação dos atuadores.

\begin{tabular}{c|c|c}
\hline Atuador & Posição $(x y z)$ & Direção $(\vec{\imath} \vec{\jmath} \vec{k})$ \\
\hline 1 & $\left(00 \frac{l \sqrt{6}}{3}\right)$ & $\left(\frac{\sqrt{2}}{2} \frac{\sqrt{3}}{3} \frac{\sqrt{6}}{6}\right)$ \\
\hline 2 & $\left(\frac{l \sqrt{2}}{2} 0-\frac{l \sqrt{6}}{6}\right)$ & $\left(0 \frac{\sqrt{3}}{3} \frac{\sqrt{6}}{3}\right)$ \\
\hline 3 & $\left(\frac{l \sqrt{2}}{2} 0-\frac{l \sqrt{6}}{6}\right)$ & $\left(\frac{\sqrt{2}}{2} \frac{\sqrt{3}}{3} \frac{\sqrt{6}}{6}\right)$ \\
\hline
\end{tabular}

"continua" 


\begin{tabular}{c|c|c}
\multicolumn{2}{c|}{ “conclusão" } \\
\hline Atuador & Posição $(x$ y $z)$ & Direção $(\vec{\imath} \vec{\jmath} \vec{k})$ \\
\hline 4 & $\left(-\frac{l \sqrt{2}}{2} 0-\frac{l \sqrt{6}}{6}\right)$ & $\left(\frac{\sqrt{2}}{2} \frac{\sqrt{3}}{3}-\frac{\sqrt{6}}{6}\right)$ \\
\hline 5 & $\left(-\frac{l \sqrt{2}}{2} 0-\frac{l \sqrt{6}}{6}\right)$ & $\left(0 \frac{\sqrt{3}}{3} \frac{\sqrt{6}}{3}\right)$ \\
\hline 6 & $\left(00 \frac{l \sqrt{6}}{3}\right)$ & $\left(\frac{\sqrt{2}}{2} \frac{\sqrt{3}}{3} \frac{\sqrt{6}}{6}\right)$ \\
\hline
\end{tabular}

\subsection{Graus de Liberdade}

O número de graus de liberdade de um mecanismo de cadeia cinemática fechada pode não ser óbvio. O número total de graus de liberdade pode ser calculado pela fórmula de Grübler, (CRAIG, 1989)

$F=6\left(n_{e}-n_{j}\right)+\sum_{i=1}^{n} f_{i}$

onde $F$ é o número total de graus de liberdade do mecanismo, $n_{e}$ é o número de elos móveis, $n_{j}$ é o número total de juntas e $f_{i}$ é o número de graus de liberdade associado com a $i$-ésima junta. A versão planar da fórmula de Grübler é obtida substituindo-se o 6 na equação por 3 (CRAIG, 1989).

Tabela 3.4 - Cálculo das parcelas da fórmula de Grübler a partir dos componentes da plataforma de Stewart.

\begin{tabular}{l|c|c|c|c}
\hline Componentes & $\mathrm{N}^{\mathrm{o}}$ de elos & $\mathrm{N}^{\mathrm{o}}$ de juntas & $\begin{array}{c}\text { Graus de } \\
\text { liberdade }\end{array}$ & $f_{i}$ \\
\hline Plataforma móvel & 1 & & & \\
\hline Haste dos atuadores & 6 & & & \\
\hline Corpo dos atuadores & 6 & & & 18 \\
\hline Juntas esféricas & & 6 & 3 & 12 \\
\hline Juntas universais & & 6 & 2 & 2 \\
\hline Juntas de translação & & 6 & 1 & $\sum f_{i}=36$ \\
\hline Total & $n_{e}=13$ & $n_{j}=18$ & &
\end{tabular}


A partir dos valores obtidos na Tabela 3.4 e da equação (3.5), tem-se

$F=6(13-18)+36=6$

conclui-se que a configuração da plataforma de Stewart analisada possui seis graus de liberdade.

\subsection{Cinemática Inversa}

As tarefas são usualmente dadas como um conjunto de posições e orientações no sistema de coordenadas global da ferramenta do robô. Para realizar esta tarefa é necessário transformar a trajetória da ferramenta em movimentos das juntas. Esta transformação, também conhecida como problema de cinemática inversa, é no caso, o cálculo do comprimento dos seis cilindros dada a posição e a orientação desejadas da plataforma móvel (BEN-HORIN; SHOHAM; DJERASSI, 1998).

Define-se, então, um sistema de coordenadas global $\{\mathrm{B}\}$ com o eixo $y_{B}$ normal ao plano da plataforma estacionária (base) e um sistema de coordenadas local $\{\mathrm{A}\}$ com o eixo $y_{A}$ normal ao plano da plataforma móvel e a origem no centro de massa (Figura 3.7).

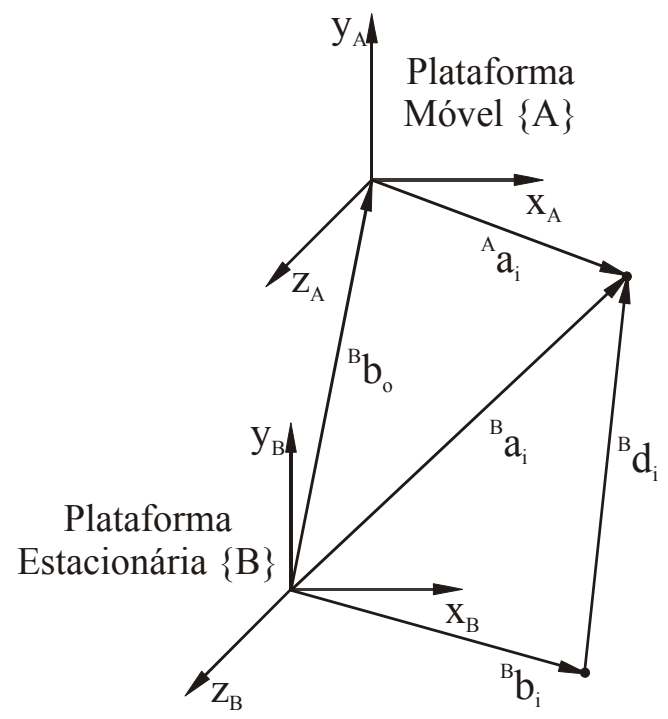

Figura 3.7 - Diagrama vetorial do i-ésimo atuador.

Se ${ }^{B} \boldsymbol{b}_{i}=\left(b_{i x} b_{i y} b_{i z}\right)^{T}$ é a posição da fixação da junta universal na plataforma estacionária no sistema de coordenadas $\{\mathrm{B}\} ;{ }^{A} \boldsymbol{a}_{i}=\left(a_{i x} a_{i y} a_{i z}\right)^{T}$ é a posição do ponto de 
fixação da junta esférica na plataforma móvel no sistema de coordenadas $\{\mathrm{A}\}$ e ${ }^{B} \boldsymbol{b}_{0}=$ $(x y z)$ é a posição da origem de $\{\mathrm{A}\}$ em relação a $\{\mathrm{B}\}$, então pode-se dizer que

$$
{ }^{B} \boldsymbol{a}_{i}={ }^{B} \boldsymbol{b}_{0}+{ }_{A}^{B} \boldsymbol{R}{ }^{A} \boldsymbol{a}_{i}
$$

onde ${ }_{A}^{B} \boldsymbol{R}$ é a matriz de orientação.

O comprimento do atuador dado pelo módulo do vetor ${ }^{B} \boldsymbol{d}_{i}=\left(d_{i x} d_{i y} d_{i z}\right)^{T}$ em relação ao sistema de coordenadas global pode ser calculado por

$$
{ }^{B} \boldsymbol{d}_{i}={ }^{B} \boldsymbol{a}_{i}-{ }^{B} \boldsymbol{b}_{i}
$$

Há várias maneiras de representar uma orientação por três variáveis, sendo a mais utilizada a dos Ângulos de Euler Z-Y-X (NGUYEN; POORAN, 1989), que representa a orientação de $\{A\}$, obtida depois da seguinte seqüência de rotações em relação a $\{B\}$ :

- rotação de um ângulo $\alpha$ em torno do eixo $z_{B}$,

- rotação de um ângulo $\beta$ em torno de um novo eixo $y_{B}^{\prime}$,

- rotação de um ângulo $\gamma$ em torno de um novo eixo $x_{B}^{\prime \prime}$.

A orientação representada por $\alpha, \beta$ e $\gamma$ é dada por

$$
\begin{aligned}
\boldsymbol{R}_{z y x}(\alpha, \beta, \gamma) & =\left[\begin{array}{ccc}
c \alpha c \beta & c \alpha s \beta s \gamma-s \alpha c \gamma & c \alpha s \beta c \gamma+s \alpha s \gamma \\
s \alpha c \beta & s \alpha s \beta s \gamma+c \alpha c \gamma & s \alpha s \beta c \gamma-c \alpha s \gamma \\
-s \beta & c \beta s \gamma & c \beta c \gamma
\end{array}\right] \\
& =\left[\begin{array}{lll}
r_{11} & r_{12} & r_{13} \\
r_{21} & r_{22} & r_{23} \\
r_{31} & r_{32} & r_{33}
\end{array}\right]={ }_{A}^{B} \boldsymbol{R} \therefore c=\cos () \text { e } s=\operatorname{sen}() .
\end{aligned}
$$

Substituindo a equação (3.7) na equação (3.8), tem-se

$$
{ }^{B} \boldsymbol{d}_{i}={ }_{A}^{B} \boldsymbol{R}^{A} \boldsymbol{a}_{i}+{ }^{B} \boldsymbol{b}_{0}-{ }^{B} \boldsymbol{b}_{i} \quad \text { para i }=1,2, \ldots 6,
$$


${ }^{B} \boldsymbol{d}_{i}=\left[\begin{array}{l}d_{i x} \\ d_{i y} \\ d_{i z}\end{array}\right]=\left[\begin{array}{l}r_{11} a_{i x}+r_{12} a_{i y}+r_{13} a_{i z}+x-b_{i x} \\ r_{21} a_{i x}+r_{22} a_{i y}+r_{23} a_{i z}+y-b_{i y} \\ r_{31} a_{i x}+r_{32} a_{i y}+r_{33} a_{i z}+z-b_{i z}\end{array}\right]$.

Além disso o comprimento do vetor ${ }^{B} \boldsymbol{d}_{i}$, chamado de $l_{i}$ pode ser colocado como função das componentes do mesmo por

$l_{i}=\left(d_{i x}^{2}+d_{i y}^{2}+d_{i z}^{2}\right)^{\frac{1}{2}}$

Usando o resultado da equação (3.11), a equação (3.12) pode ser reescrita como

$$
\begin{aligned}
l_{i}^{2}=x^{2}+y^{2}+ & z^{2}+a_{i x}^{2}\left(r_{11}^{2}+r_{21}^{2}+r_{31}^{2}\right)+a_{i y}^{2}\left(r_{12}^{2}+r_{22}^{2}+r_{32}^{2}\right) \\
& +a_{i z}^{2}\left(r_{13}^{2}+r_{23}^{2}+r_{33}^{2}\right)+b_{i x}^{2}+b_{i y}^{2}+b_{i z}^{2} \\
& +2 a_{i x} a_{i y}\left(r_{11} r_{12}+r_{21} r_{22}+r_{31} r_{32}\right) \\
& +2 a_{i x} a_{i z}\left(r_{11} r_{13}+r_{21} r_{23}+r_{31} r_{33}\right) \\
& +2 a_{i y} a_{i z}\left(r_{12} r_{13}+r_{22} r_{23}+r_{32} r_{33}\right) \\
& +2\left(r_{11} a_{i x}+r_{12} a_{i y}+r_{13} a_{i z}\right)\left(x-b_{i x}\right) \\
& +2\left(r_{21} a_{i x}+r_{22} a_{i y}+r_{23} a_{i z}\right)\left(y-b_{i y}\right) \\
& +2\left(r_{31} a_{i x}+r_{32} a_{i y}+r_{33} a_{i z}\right)\left(z-b_{i z}\right) \\
& -2\left(x b_{i x}+y b_{i y}+z b_{i z}\right) \quad \text { parai } i=1, \ldots 6 .
\end{aligned}
$$

Como a matriz de orientação é ortonormal (NGUYEN; POORAN, 1989), tem-se que

$$
\begin{aligned}
& r_{11}^{2}+r_{21}^{2}+r_{31}^{2}=1 \\
& r_{12}^{2}+r_{22}^{2}+r_{32}^{2}=1 \\
& r_{13}^{2}+r_{23}^{2}+r_{33}^{2}=1
\end{aligned}
$$

$\mathrm{e}$

$$
\begin{aligned}
& r_{11} r_{12}+r_{21} r_{22}+r_{31} r_{32}=0 \\
& r_{11} r_{13}+r_{21} r_{23}+r_{31} r_{33}=0 \\
& r_{12} r_{13}+r_{22} r_{23}+r_{32} r_{33}=0
\end{aligned}
$$

Assim a equação (3.13) pode ser simplificada para 


$$
\begin{aligned}
l_{i}^{2}=x^{2}+y^{2}+ & z^{2}+a_{i x}^{2}+a_{i y}^{2}+a_{i z}^{2}+b_{i x}^{2}+b_{i y}^{2}+b_{i z}^{2} \\
& +2\left(r_{11} a_{i x}+r_{12} a_{i y}+r_{13} a_{i z}\right)\left(x-b_{i x}\right) \\
& +2\left(r_{21} a_{i x}+r_{22} a_{i y}+r_{23} a_{i z}\right)\left(y-b_{i y}\right) \\
& +2\left(r_{31} a_{i x}+r_{32} a_{i y}+r_{33} a_{i z}\right)\left(z-b_{i z}\right) \\
& -2\left(x b_{i x}+y b_{i y}+z b_{i z}\right) \quad \text { para } i=1,2, \ldots 6 .
\end{aligned}
$$

Então dada uma posição ${ }^{B} \boldsymbol{b}_{0}=(x y z)^{T}$ e uma orientação $(\alpha \beta \gamma)$ pode-se determinar o comprimento $l_{i}$ dos atuadores que levam a plataforma à configuração desejada. Este comprimento $l_{i}$ deverá ser alcançado pelo acionamento do $i$-ésimo atuador. 


\section{MATERIAIS E MÉTODOS}

\subsection{Determinação das Características Inerciais de Corpos Rígidos}

\subsubsection{Experimentos para Determinação do Centro de Massa e dos Momentos de Inércia em Relação aos Eixos Principais de Corpos Rígidos}

Uma das condições para se conseguir um modelo matemático próximo do modelo real é fazer uma identificação dos parâmetros físicos do sistema que se deseja modelar. Quando se fala de modelos de sistemas multicorpos, onde os elos são considerados corpos rígidos, unidos por juntas com determinadas restrições, o modelo matemático será formado por um sistema de equações diferenciais e por equações cinemáticas oriundas das restrições de movimento das juntas. Para que se alcance uma determinada precisão no modelo matemático é necessário que se tenha valores precisos para as dimensões dos elos, pontos de fixação das juntas, valores de massa, posição dos centros de massa e para os momentos de inércia em relação aos eixos principais dos elos. Devido ao fato do problema dimensional ser uma constante em todos os projetos mecânicos e suas soluções e acuracidades serem conhecidas, vamos tratar da solução dada para a determinação de momentos principais de inércia e centro de massa de forma experimental. A base para elaboração dessa parte do trabalho pode ser encontrada em Mucheroni (2000).

\subsubsection{Experimento para Determinação do Centro de Massa}

Encontra-se na literatura diversas formas de determinação de centro de massa desde soluções mais simples como determinação do centro de massa através do centro geométrico através de fórmulas matemáticas de volumes e considerando o material homogêneo, utilizando sistemas CAD modelando os elementos de forma tridimensional ou ainda utilizando-se do estudo de equilíbrio estático de corpos rígidos sujeitos à ação gravitacional. Quando se trata de um conjunto de elementos de materiais diferentes e que não podem ser considerados homogêneos, então as duas primeiras opções se tornam imprecisas ou impraticáveis, pois, muitas vezes, não se pode desmontar muitos dos elementos como 
sensores ou motores elétricos para transformá-los em um conjunto de partes homogêneas. Então, optou-se por utilizar a terceira opção por acreditar ser a que daria maior acuracidade e menor trabalho. Mas para isso é preciso determinar uma metodologia de trabalho e um instrumental a ser utilizado para que se possa garantir uma determinada precisão, que forneça um sistema de controle adequado, já que o mesmo é baseado no modelo matemático obtido através das leis da física e da identificação dos parâmetros físicos. Duas formas de se determinar experimentalmente o centro de massa de corpos rígidos são: “Através da suspensão do corpo por algum ponto, em torno do qual está livre para oscilar. Repete-se este procedimento para dois ou três pontos e o centro de massa é obtido no cruzamento das linhas verticais traçadas a partir do ponto de suspensão” (MUCHERONI, 2000).
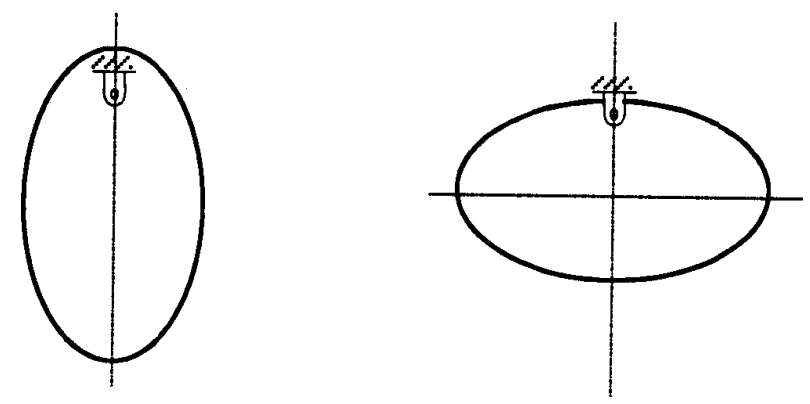

Figura 4.1 - Determinação experimental do centro de massa (MUCHERONI, 2000).

- Através da medida das reações estáticas conforme mostra a Figura 4.2.

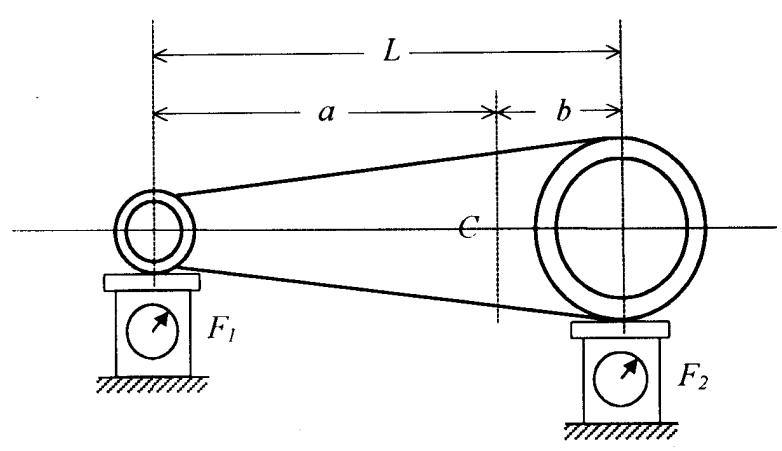

Figura 4.2 - Métodos das reações estáticas (MUCHERONI, 2000).

A segunda opção foi escolhida por parecer mais fácil de ser implementada e de se obter um resultado mais preciso através de técnicas convencionais. Seria necessário apenas medir as reações e isso pode ser feito de várias formas. 
A idéia inicial foi suspender a peça por duas células de carga, fazendo duas medições com uma defasagem de $90^{\circ}$ de rotação da primeira para a segunda. Primeiramente adquirimos duas células de carga de fabricação no Brasil tipo S-5 indicando que a mesma suporta uma carga máxima de $5 \mathrm{~kg}$ e os extensômetros são montados em ponte de Wheatstone em um suporte em forma de $\mathrm{S}$ em alumínio anodizado. Notou-se que a maioria dos fabricantes de células de cargas, as produz para cargas máximas acima de $20 \mathrm{~kg}$. Muito embora a maioria das balanças para estabelecimentos comerciais trabalhem utilizando células de carga e muitas com carga máxima de 5 a $10 \mathrm{~kg}$, essas não são muito fáceis de serem encontradas. Acreditava-se que com estas se estaria utilizando boa parte da sua faixa de medição sem causar sobre carga. Entretanto percebeu-se nos testes iniciais para verificar o tipo de sinal de saída para, então, determinar qual o tipo de circuito condicionador e amplificador seria necessário utilizar, que as mesmas eram bem sensíveis sendo muito fácil passar de sua capacidade máxima comprimindo-as com as mãos, sendo, portanto, sensíveis a choques durante a colocação das cargas o que poderia causar um offset permanente e considerável ao valor de saída do sinal da célula de carga com a mesma descarregada. Uma queda da célula de carga de alguns centímetros sobre uma superfície rígida é o suficiente para inutilizá-la para medições precisas. Decidiu-se trocar as células de carga e adquirir células que suportassem uma carga máxima de $10 \mathrm{~kg}$ para minimizar os efeitos anteriormente citados, sem correr o risco de perder sensibilidade.

Como não se adquiriu o indicador juntamente com a célula de carga, por ser um equipamento industrial e não possuir a precisão desejada, então, necessitava-se determinar um circuito condicionador e um indicador para leitura do valor medido com a célula de carga ou, se possível, um único equipamento que fizesse as duas coisas. Conseguiu-se o resultado desejado de duas formas. Uma delas foi através do condicionador de sinal MGC Plus do fabricante alemão $H B M$, Inc., equipamento que combina facilidade de parametrização, com versatilidade e acuracidade. A outra foi através de um circuito condicionador utilizando um amplificador operacional de instrumentação com ganho de 100 e um filtro RC de segunda ordem com freqüência de corte em $3 \mathrm{~Hz}$ e uma placa de aquisição da National Instruments com amplificação programável e um computador com o software LabVIEW instalado. Devido à praticidade e o número menor de equipamentos utilizados, optou-se pelo primeiro caso onde o MGC Plus faz todas as tarefas desde a alimentação da célula de carga, condicionamento, ou seja, amplificação e filtragem do sinal e a apresentação do valor em $\mathrm{mV}$ ou $\mathrm{Kg}$, conforme seja desejado. No segundo caso, precisa-se de uma fonte de alimentação linear, um circuito 
condicionador para cada célula de carga, uma placa de aquisição de dados, vários cabos com terminais diferentes para conexão dos equipamentos, de um computador e da necessidade de se programar um instrumento virtual utilizando o software LabVIEW que tornaria mais trabalhosa a montagem do experimento.

Definido o equipamento a ser utilizado passa-se para a fase de calibração da célula de carga e do condicionador de sinal que será feita através de pesos calibrados com precisão de décimo de grama. Com isso, se levantando-se a curva de calibração do experimento. Para tanto, será utilizada uma haste de aproximadamente $500 \mathrm{~g}$, uma anilha de $500 \mathrm{~g}$ e quatro anilhas de $1 \mathrm{~kg}$, totalizando $5 \mathrm{~kg}$.

Pode-se ver através da Figura 4.3 a curva de calibração obtida para uma das células de carga. A mesma foi obtida através de dez conjuntos de medições sendo cinco ascendentes e cinco descendentes. E os valores relativos a $0 ; 0,5 ; 1 ; 2 ; 3 ; 4$ e $5 \mathrm{~kg}$ foram obtidos através de média aritmética dos valores nas medições ascendentes e descendentes.

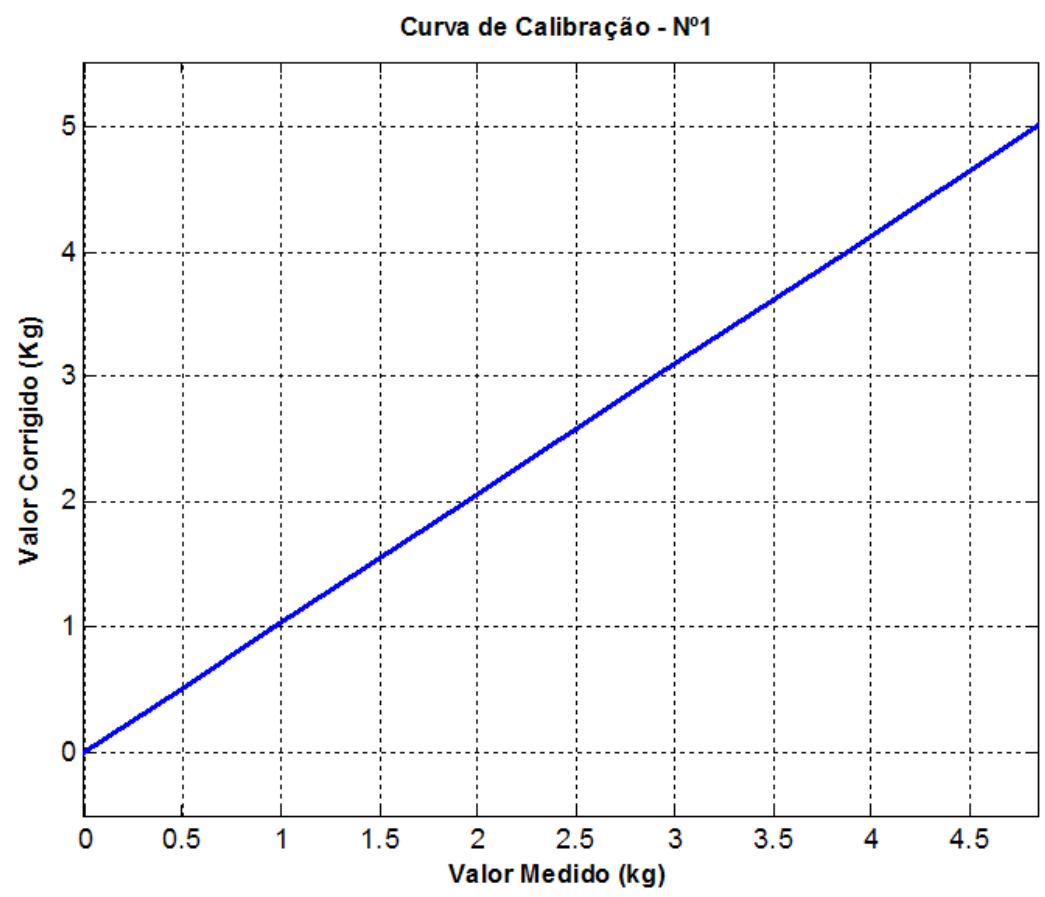

Figura 4.3 - Curva de calibração do sistema de aquisição e da célula de carga.

Pode-se observar que a célula de carga possui uma boa linearidade, embora o coeficiente angular da mesma esteja um pouco fora do valor desejado, o ideal seria que o valor corrigido correspondesse ao mesmo valor medido. Caso isso ocorra não há necessidade de se utilizar a curva de calibração, pois o valor medido é o próprio valor real da massa. $\mathrm{O}$ 
mais importante durante a calibração é observar a repetibilidade da medição, a histerese e a linearidade do elemento sensor. Observou-se que o experimento não sofreu alteração sensível à temperatura e que os valores para repetibilidade, histerese e linearidade, podem ser considerados satisfatórios. A histerese não chegou a um grama. Não se quantificou a linearidade, pois tal fator será amenizado com a utilização de um polinômio de sexta ordem para aproximar a função de calibração. Foi escolhido um polinômio de sexta ordem por se ter sete pontos no gráfico.

As equações para a determinação do centro de massa a partir das reações estáticas, resultam da aplicação das equações de equilíbrio de corpo rígido, ou seja

$\sum F=0$

$\sum M_{o}=0$

De acordo com a Figura 4.4, pode-se definir um procedimento de cálculo.

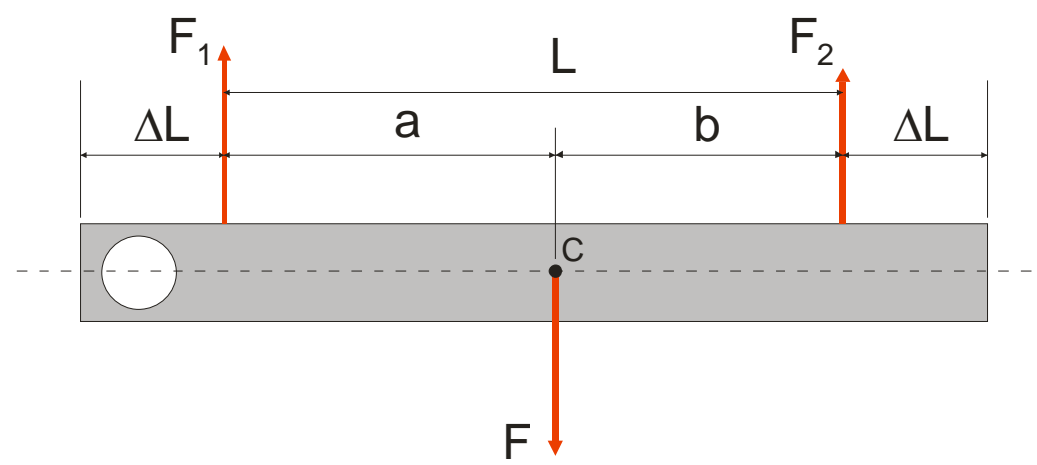

Figura 4.4 - Determinação do centro de massa utilizando reações estáticas.

$$
\begin{aligned}
& \sum M_{2}=-F_{1} L+m g b=0 \\
& b=\frac{F_{1} L}{m g} \\
& \sum F=F_{1}+F_{2}-m g=0 \\
& m g=F_{1}+F_{2} .
\end{aligned}
$$

Substituindo a equação (4.6) na (4.4), resulta em 
$b=\frac{F_{1} L}{F_{1}+F_{2}}$

o mesmo procedimento vale para calcular

$a=\frac{F_{2} L}{F_{1}+F_{2}}$

Para determinar o centro de massa, basta somar a medida $\Delta L$ aos valores de $a$ ou $b$.

É necessário verificar a possibilidade de se obter o centro de massa quando se tem elos que não podem ser separados para serem ensaiados. Neste caso o método proposto é que se façam duas medições do centro de massa para duas posições relativas diferentes entre os elos (Figura 4.5), ou seja, no caso do atuador faz-se a medição do centro de massa para duas posições diferentes de curso.

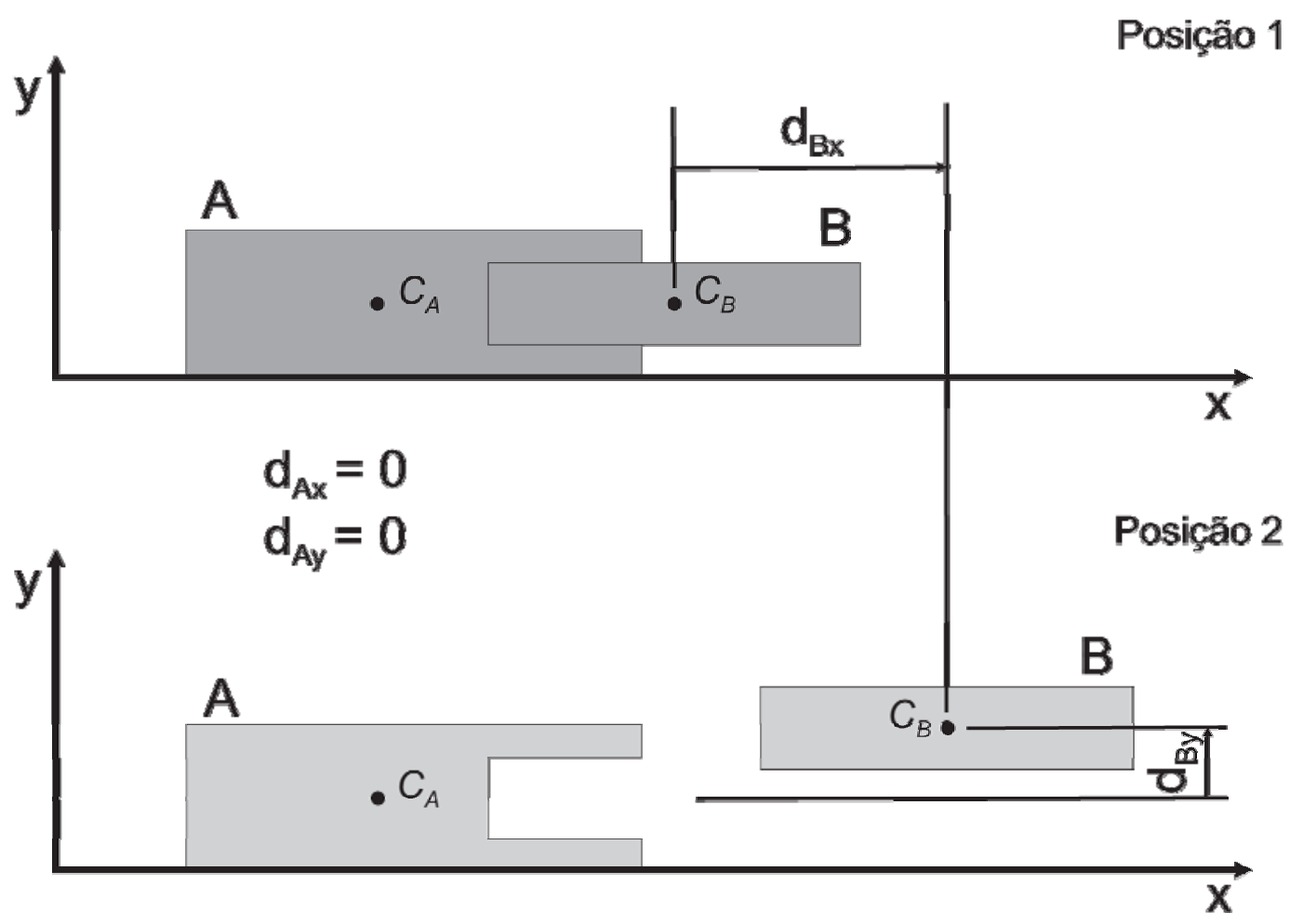

Figura 4.5 - Movimento relativo entre os elos.

Através dos valores conhecidos de $\bar{x}_{1}, \bar{y}_{1}, \bar{x}_{2}, \bar{y}_{2}, d_{A x}, d_{A y}, d_{B x}, d_{B y}, m$ onde

$\bar{x}_{i}=$ coordenada $x$ do centro de massa para a posição $i$

$\bar{y}_{i}=$ coordenada $y$ do centro de massa para a posição $i$; 
$d_{x 1-2}=$ distância entre as coordenadas em $x$ da posição 1 e 2 do centro de massa;

$d_{y 1-2}=$ distância entre as coordenadas em $y$ da posição 1 e 2 do centro de massa;

$m=$ massa da parte $A+$ da parte $B$;

parte $N$;

$d_{N x}=$ diferença de posição do centro de massa na direção $x$ da posição 1 para 2 da parte $N$.

$d_{N y}=$ diferença de posição do centro de massa na direção $y$ da posição 1 para 2 da

$\bar{x}_{N i}=$ coordenada $x$ do centro de massa da parte $N$ para a posição $i$;

$\bar{y}_{N i}=$ coordenada $y$ do centro de massa da parte $N$ para a posição $i$.

$d_{x 1-2}=\bar{x}_{2}-\bar{x}_{1}$ e $d_{y 1-2}=\bar{y}_{2}-\bar{y}_{1}$

$m \bar{x}_{i}=m_{A} \bar{x}_{A i}+m_{B} \bar{x}_{B i}$

$m \bar{y}_{i}=m_{A} \bar{y}_{A i}+m_{B} \bar{y}_{B i}$

$d_{N x}=\bar{x}_{N(i+1)}-\bar{x}_{N i}$

$d_{N y}=\bar{y}_{N(i+1)}-\bar{y}_{N i}$

onde $N=A, B ; i=1,2$.

A partir das equações acima e da condição de equilíbrio dada pela primeira Lei de Newton podemos verificar que não é possível determinar os centros de massa para dois corpos acoplados por uma junta de translação. As equações linearmente independentes, para uma análise na direção $x$, são

$F=F_{1}+\mathrm{F}_{2}$

$m \bar{x}_{i}=m_{A} \bar{x}_{A i}+m_{B} \bar{x}_{B i}$

como temos quatro incógnitas, $m_{A}, m_{B}, \bar{x}_{A i}, \bar{x}_{B i}$, e apenas duas equações, não é possível determinar os centros de massa das partes. Se forem realizadas duas medições das reações 
estáticas para posições diferentes do corpo $B$, conhecendo-se o curso do deslocamento, e se mantiver a posição do corpo $A$, ter-se-á

$$
\begin{aligned}
& m \bar{x}_{1}=m_{A} \bar{x}_{A 1}+m_{B} \bar{x}_{B 1} \\
& m \bar{x}_{2}=m_{A} \bar{x}_{A 2}+m_{B} \bar{x}_{B 2}
\end{aligned}
$$

como o corpo $A$ não se moveu

$$
\bar{x}_{A 1}=\bar{x}_{A 2}
$$

resulta em

$$
\begin{aligned}
& m \bar{x}_{1}=m_{A} \bar{x}_{A 1}+m_{B} \bar{x}_{B 1} \\
& m \bar{x}_{2}=m_{A} \bar{x}_{A 1}+m_{B} \bar{x}_{B 2}
\end{aligned}
$$

subtraindo a eq. (4.20) da eq. (4.19), tem-se

$m d_{x 1-2}=m_{B} d_{B x}$

$m_{B}=m d_{x 1-2} / d_{B x}$

Conclui-se que a medição das reações estáticas para corpos ligados por junta de translação, fornece o centro de massa do conjunto. A realização de outra medição com a variação da posição das peças fornece as massas dos corpos, mas não a posição dos centros de massa, que ficarão indeterminados através das equações (4.19) e (4.20), que são linearmente dependentes. A única solução é ter o centro de massa do conjunto e o de uma das partes conhecido, para, então, se obter o outro.

Para peças com um plano de simetria, onde seria necessário dois ensaios para a obtenção do centro de massa, um na direção $x$ e outro na direção $y$, pelo primeiro método, apresenta-se uma formulação para através de três reações estáticas da peça, definir, em um plano, duas coordenadas que representam o ponto por onde passa a reta perpendicular ao 
plano e que contém o centro de massa (Figura 4.6). De posse disso e do plano de simetria fica definido o centro de massa da peça com um único ensaio, na intersecção da reta com o plano de simetria.

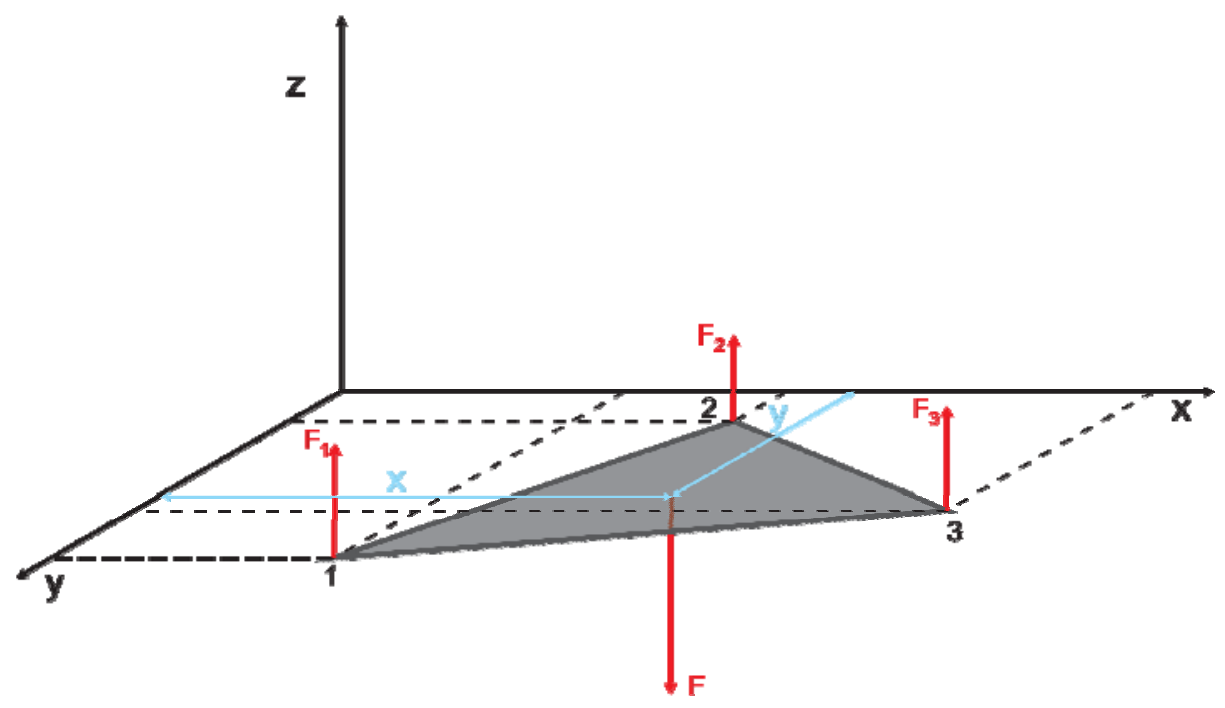

Figura 4.6 - Solução para determinação do centro de massa para três reações estáticas.

As equações para a determinação do centro de massa a partir das três reações estáticas, também, resultam da aplicação das equações de equilíbrio de corpo rígido, ou seja

$\sum F=0$

$\sum M_{o}=0$

Da aplicação da equação (4.23), tem-se

$F=F_{1}+F_{2}+F_{3}$

e da aplicação da equação (4.24), resulta

$F x=F_{1} x_{1}+F_{2} x_{2}+F_{3} x_{3}$

$F y=F_{1} y_{1}+F_{2} y_{2}+F_{3} y_{3}$

Como temos três equações e três incógnitas e o sistema é não homogêneo e linearmente independente, então a solução do sistema é possível e determinada. 
4.1.3 Experimento para Determinação dos Momentos de Inércia em Relação aos Eixos Principais de Corpos Rígidos

Apresenta-se dois métodos experimentais para determinação de momento de inércia. Sendo um dos mais comuns, o da pendulação, onde a peça é colocada de forma tal que possa oscilar em torno de um eixo, o valor do ângulo de oscilação deve ser pequeno e é necessário medir o período de oscilação (Figura 4.7).

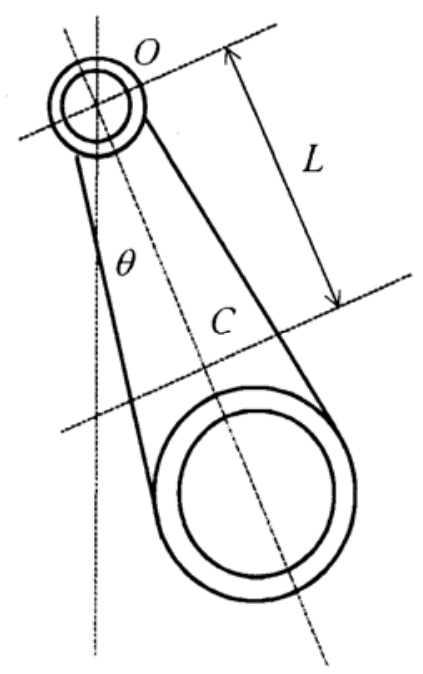

Figura 4.7 - Método da pendulação (MUCHERONI, 2000).

Noutra forma, utiliza um dispositivo de vibração. Neste caso as oscilações poderão ocorrer com grandes amplitudes, desde que a mola esteja na sua faixa linear de trabalho.

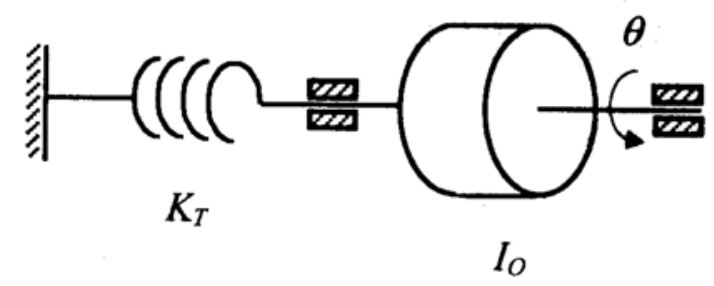

Figura 4.8 - Método da vibração (MUCHERONI, 2000).

Escolheu-se o Método da Pendulação, por parecer mais fácil de serem desenvolvidos dispositivos de fixação para que se possam determinar os momentos de inércia em três eixos perpendiculares entre si, que esses eixos sejam principais de inércia e que sejam baricentrais. Para a medição do período usa-se um encoder em quadratura com um drive RS-422, por ser 
padrão para a maioria das placas de aquisição e para eliminar ruído na transmissão do sinal do encoder até a placa de aquisição. Embora em alguns casos, isso não seja necessário, o fabricante recomenda o uso do driver. O sinal do encoder é transmitido para uma placa de aquisição de dados (DAQ - Data Acquisition), PCI-6251 série M, fabricada pela National Instruments. Um instrumento virtual (VI - Virtual Instrument) foi programado utilizando a linguagem gráfica LabVIEW ${ }^{\mathrm{TM}}$ para controlar a aquisição dos dados e armazená-los em um arquivo tipo texto, que pode ser lido por um programa, desenvolvido no Matlab ${ }^{\circledR}$, para determinar o período de oscilação da peça e através deste, determinar o momento de inércia. A Figura 4.9 ilustra as etapas do experimento para identificação de momento de inércia.

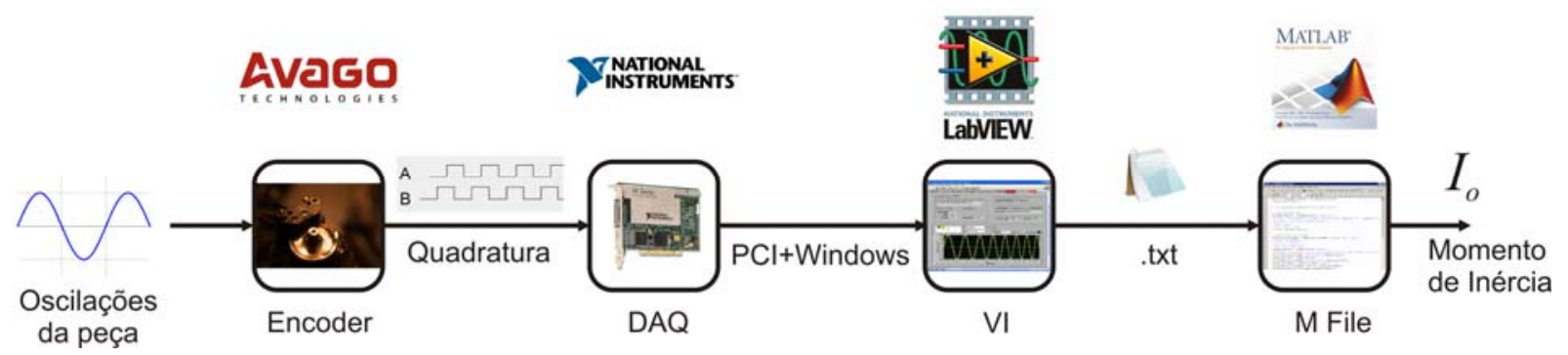

Figura 4.9 - Etapas do ensaio de identificação de momento de inércia.

Para se realizar esse experimento foi desenvolvido um cavalete, onde são fixados os dispositivos tanto para o experimento de determinação do centro de massa, como para o de momento de inércia. Esse cavalete foi confeccionado em metalon 60x60x3mm, perfis de alumínio 60×60×900mm e 30×30x900mm, pés com ajustagem de altura anti-vibração e pintura eletrostática. Os dispositivos para realização dos experimentos foram confeccionados em alumínio ou aço inox (Figura 4.10).

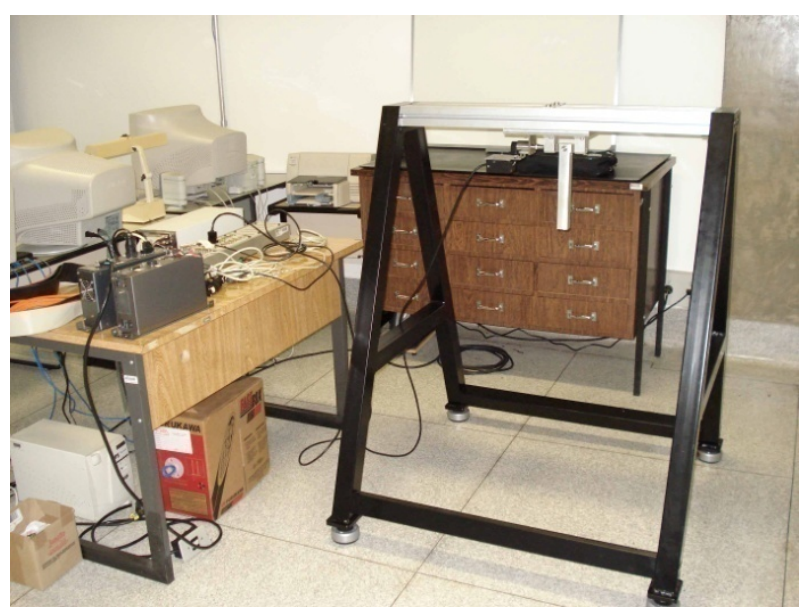

Figura 4.10 - Cavalete para determinação experimental de centro de gravidade e momentos principais de inércia. 
Embora a maioria das pessoas leigas acredite que o movimento de um pêndulo seja um movimento harmônico, isso não é verdade, o que se pode dizer é que o período pode ser considerado constante para pequenos valores do ângulo de oscilação. Se for utilizado um encoder de alta resolução e uma placa de aquisição, pode se observar que mesmo para ângulos pequenos o período varia à medida que varia o ângulo de oscilação, mas nesse caso a variação do período pode ser desprezada.

Aplicando a equação do movimento à peça da Figura 4.7 em relação a $O$, obtém-se

$-M g L \operatorname{sen} \theta=I_{o} \frac{d^{2} \theta}{d t^{2}}$

onde

$L=$ distância entre o ponto $O$ e o centro de massa $C$;

$\theta$ = ângulo de rotação da peça em relação a posição vertical;

$I_{O}=$ momento de inércia em relação ao eixo $z$ que passa por $O$.

Considerando que a peça da Figura 4.7 sofrerá pequenas oscilações, pode-se adotar $\operatorname{sen} \theta=\theta$ a fim de se obter uma equação diferencial linear, ou seja

$\frac{d^{2} \theta}{d t^{2}}+\frac{M g L}{I_{o}} \theta=0$

sendo a solução dessa equação conhecida e dada por

$\theta=A \operatorname{sen}(\omega t)+B \operatorname{sen}(\omega t)$

ou

$\theta=\theta_{o} \operatorname{sen}(\omega t+\alpha)$

onde $A$ e $B$ ou $\theta_{o}$ e $\alpha$ dependem das condições iniciais e $\omega$ é a freqüência de oscilação.

$\omega=\sqrt{\frac{M g L}{I_{o}}}$ 
sendo o período de uma oscilação

$T=\frac{2 \pi}{\omega}$

tem-se

$T=2 \pi \sqrt{\frac{I_{o}}{M g L}}$

onde o momento de inércia de $I_{o}$ pode ser dado por

$I_{o}=M g L \frac{T^{2}}{4 \pi^{2}}$

e o momento de inércia $I_{C}$ em relação ao eixo que passa pelo centro de massa $C$ é

$I_{C}=I_{o}-M L^{2}=M L^{2}\left(\frac{T^{2} g}{4 \pi^{2} L}-1\right)$

Uma formulação parecida será útil para determinação dos momentos de inércia dos elos que necessitarão de um suporte para serem fixados ao eixo do encoder do cavalete. Este método é uma variação do anterior, onde se coloca a peça, cujo momento de inércia em relação ao eixo $y$ que passa por $C$ deseja-se determinar, para oscilar junto com o suporte. No exemplo dado, o suporte é suspenso por fios (Figura 4.11), o que não altera a formulação do problema para o caso estudado, que será mostrado na parte referente à validação do experimento. 

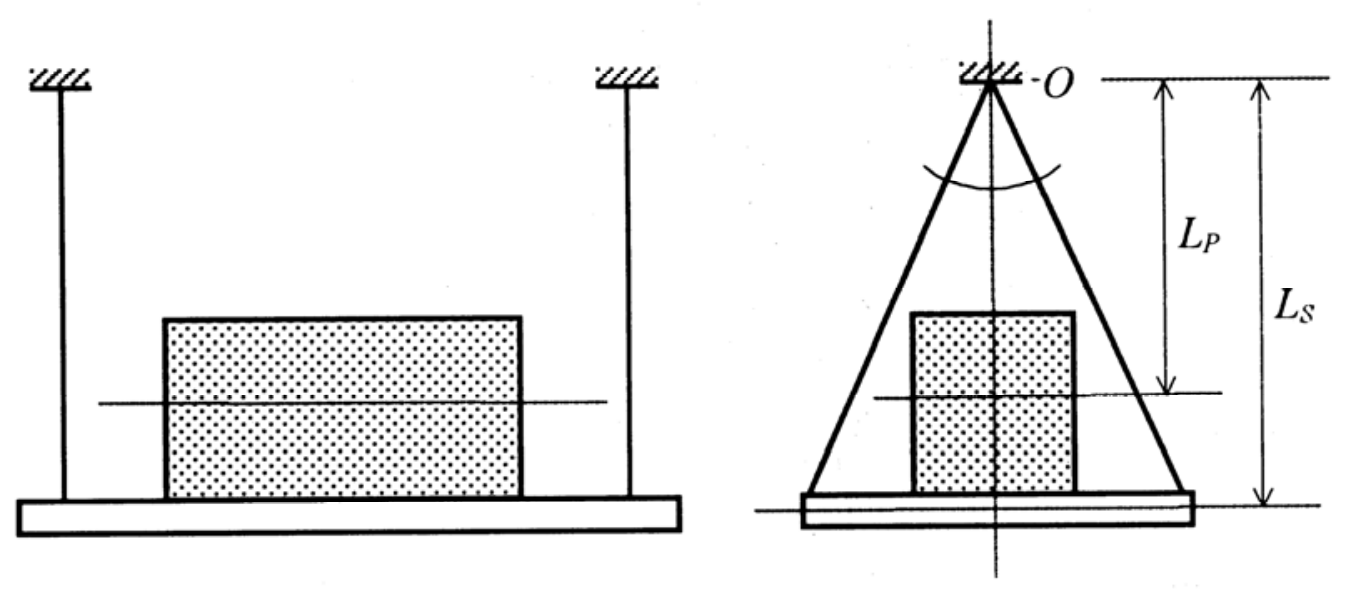

Figura 4.11 - Peça sobre suporte oscilatório (MUCHERONI, 2000).

Primeiramente deve-se determinar a posição do centro de massa do sistema todo, composto pelo suporte mais a peça da qual se deseja determinar o momento de inércia. Esta posição é dada por

$L_{s p}=\frac{M_{P} L_{P}+M_{S} L_{S}}{M_{P}+M_{S}}$

onde

$M_{P}=$ massa da peça;

$M_{S}=$ massa do suporte;

$L_{P}=$ distância entre o eixo de rotação e o centro de massa da peça;

$L_{S}=$ distância entre o eixo de rotação e o centro de massa do suporte.

Aplicando a equação (4.25) para o sistema composto pelo suporte mais a peça resulta em

$T_{S P}=2 \pi \sqrt{\frac{I_{P O}+I_{S O}}{\left(M_{P}+M_{S}\right) g L_{S P}}}$

onde

$T_{S P}=$ período de oscilação do suporte com a peça; 
$I_{P O}=$ momento de inércia da peça em relação ao eixo de rotação;

$I_{S O}=$ momento de inércia do suporte em relação ao eixo de rotação.

Substituindo a equação (4.28) na (4.29), obtém-se

$T_{S P}=2 \pi \sqrt{\frac{I_{P O}+I_{S O}}{\left(M_{P} L_{P}+M_{S} L_{S}\right) g}}$.

Isolando-se $I_{P O}$ na equação anterior, tem-se

$I_{P O}=\frac{T_{S P}^{2}}{4 \pi}\left(M_{P} L_{P}+M_{S} L_{S}\right) g-I_{S O}$

E aplicando a equação (4.25) para o suporte sem a peça, resulta em

$T_{S P}=2 \pi \sqrt{\frac{I_{S O}}{M_{S} L_{S} g}}$

e

$I_{S O}=\frac{T_{S}^{2}}{4 \pi^{2}} M_{S} L_{S} g$

Substituindo (4.33) na equação (4.31), tem-se

$I_{P O}=\frac{T_{S P}^{2}}{4 \pi^{2}}\left(M_{P} L_{P}+M_{S} L_{S}\right) g-\frac{T_{S}^{2}}{4 \pi^{2}} M_{S} L_{S} g$

$\mathrm{ou}$

$I_{P O}=\frac{T_{S P}^{2}}{4 \pi^{2}} M_{P} L_{P} g-\frac{T_{S P}^{2}-T_{S}^{2}}{4 \pi^{2}} M_{S} L_{S} g$

Usando o teorema dos eixos paralelos, dado por $I_{P C}=I_{P O}-M_{P} L_{P}^{2}$, obtém-se

$I_{P C}=M_{P} L_{P}^{2}\left(\frac{T_{S P}^{2} g}{4 \pi^{2} L_{P}}-1\right)+M_{S} L_{S}^{2}\left(\frac{T_{S P}^{2} g}{4 \pi^{2} L_{S}}-\frac{T_{S}^{2}}{4 \pi^{2} L_{S}}\right)$ 
Para a determinação experimental de $I_{P C}$ são necessárias as seguintes medidas: os períodos de oscilação do suporte sem a peça $T_{S}$ e com a peça $T_{S P}$, as massas do suporte $M_{S}$ e a da peça $M_{P}$ e as distâncias do centro de massa do suporte $L_{S}$ e da peça $L_{P}$ até o eixo de rotação.

Agora precisam ser determinados os eixos principais de inércia. Com a ajuda de dispositivos varia-se a posição da peça até que a direção do eixo principal seja paralelo ao eixo de rotação. Para poder determinar os eixos principais partiu-se do conceito de elipse de inércia, do conceito de círculo de Mohr e sabe-se que o momento será máximo quando o período for máximo. Se conseguir se medir o ângulo $\psi$ onde o momento de inércia for máximo, sabe-se que o momento de inércia mínimo está defasado deste de $90^{\circ}$ e vice versa. Outra forma seria utilizar a expressão

$I_{O L}=I_{x} \lambda_{x}^{2}+I_{y} \lambda_{y}^{2}+I_{z} \lambda_{z}^{2}-2 I_{x y} \lambda_{x} \lambda_{y}-2 I_{y z} \lambda_{y} \lambda_{z}-2 I_{z x} \lambda_{z} \lambda_{x}$

onde as peças possuam pelo menos um plano de simetria. Se considerar que os eixos pertencentes a ele sejam os eixos $x$ e $y$, o eixo $z$ será perpendicular ao plano de simetria. Portanto, o cosseno diretor $\lambda_{z}$ será sempre igual a zero para qualquer momento de inércia cuja direção esteja contida no plano. Então a equação (4.37) se reduz a

$I_{O L}=I_{x} \lambda_{x}^{2}+I_{y} \lambda_{y}^{2}-2 I_{x y} \lambda_{x} \lambda_{y}$

Faz se a medição do momento de inércia para dois eixos quaisquer $I_{x}$ e $I_{y}$ perpendiculares entre si, e em relação a um terceiro eixo $I_{O L}$, com direção diferente dos anteriores, contida no plano dos mesmos e do qual se conheça os ângulos formados com os eixos medidos anteriormente e por conseqüência os seus cossenos diretores $\lambda_{x}$ e $\lambda_{y}$. De posse desses valores é possível calcular o produto de inércia $I_{x y}$. 


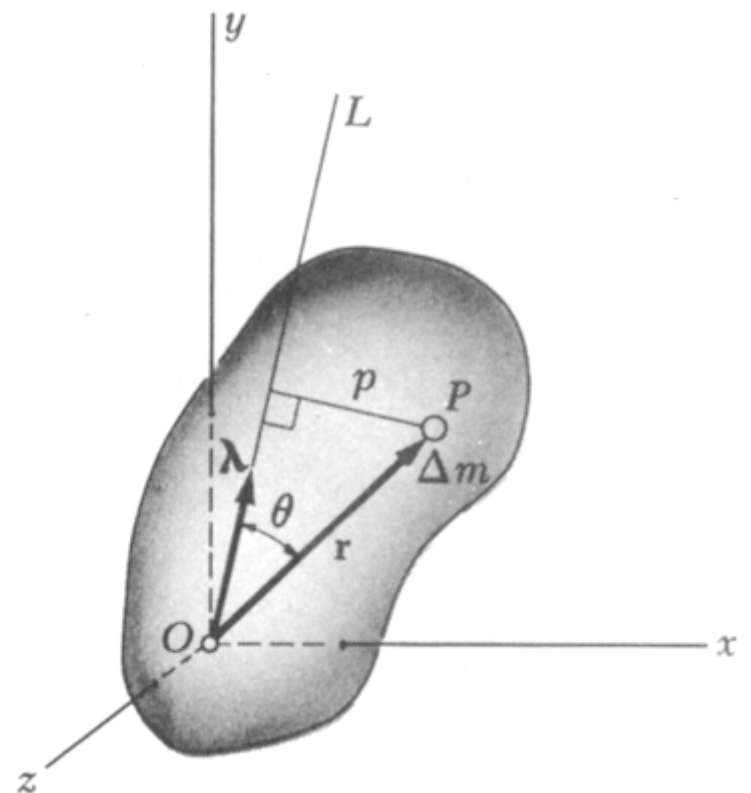

Figura 4.12 - Eixo $O L$ e sua direção representada pelo versor $\lambda$ (BEER; JOHNSTON, 1980).

Aplicando-se os valores de $I_{x}, I_{y}$ e $I_{x y}$ à teoria do círculo de Mohr podesse determinar a direção dos eixos principais de inércia através da fórmula

$\tan (2 \alpha)=\frac{-2 I_{x y}}{I_{x}-I_{y}}$

e os valores máximo e mínimo dos momentos principais de inércia através de

$I_{\text {máx }}=\frac{I_{x}+I_{y}}{2} \pm \sqrt{\left(\frac{I_{x}-I_{y}}{2}\right)^{2}+I_{x y}^{2}}$

A relação entre os momentos de inércia principais, em um plano, e a sua relação com os demais dada a variação do ângulo $\alpha$, pode ser visualizada através do círculo de Mohr. 


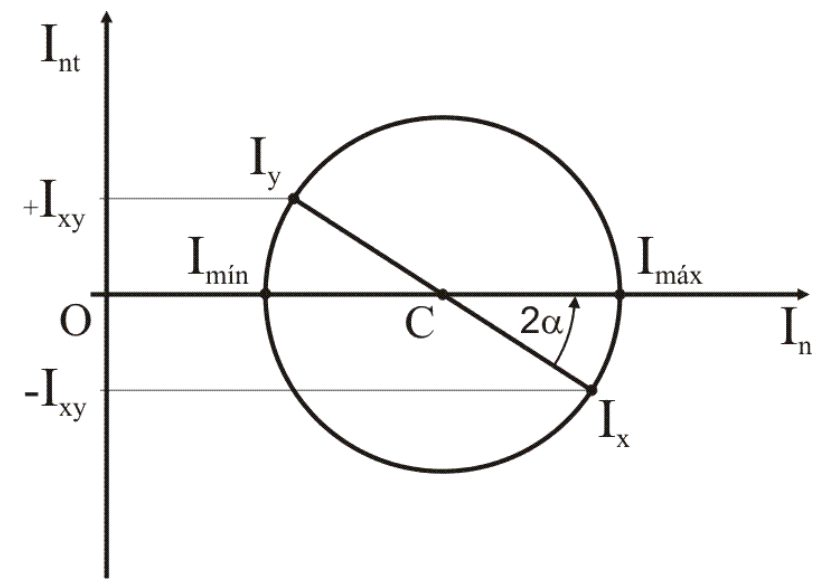

Figura 4.13 - Círculo de Mohr.

É necessário verificar a possibilidade de se obter os momentos principais de inércia quando se tem elos que não podem ser separados para serem ensaiados. Neste caso o método proposto e já mencionado atrás, é que se façam duas medições de momentos principais de inércia para duas posições relativas diferentes entre os elos, ou seja, no caso do atuador faz-se a medição dos momentos principais de inércia para duas posições diferentes de curso utilizando o procedimento descrito anteriormente através dos valores conhecidos de $I_{x 1}, I_{y 1}$, $I_{x y 1}, \bar{x}_{1}, \bar{y}_{1}, I_{x 2}, I_{y 2}, I_{x y 2}, \bar{x}_{2}, \bar{y}_{2}, \bar{x}_{A 1}, \bar{y}_{A 1}, \bar{x}_{A 2}, \bar{y}_{A 2}, \bar{x}_{B 1}, \bar{y}_{B 1}, \bar{x}_{B 2}, \bar{y}_{B 2}, m_{A}, m_{B}$ onde posição $i$.

$I_{x i}=$ momento de inércia em relação ao eixo $x$ que passa pelo centro de massa, para a

$I_{y i}=$ momento de inércia em relação ao eixo $y$ que passa pelo centro de massa, para a posição $i$.

$I_{x y i}=$ produto de inércia em relação ao eixo $y$ que passa pelo centro de massa, para a posição $i$.

$I_{N x i}=$ momento de inércia em relação ao eixo $x$ que passa pelo centro de massa da parte $N$, para a posição $i$.

$I_{N y i}=$ momento de inércia em relação ao eixo $y$ que passa pelo centro de massa da parte $N$, para a posição $i$.

$I_{N x y i}=$ produto de inércia em relação ao eixo $y$ que passa pelo centro de massa da parte $N$, para a posição $i$.

$\bar{x}_{i}=$ coordenada $x$ do centro de massa para a posição $i$.

$\bar{y}_{i}=$ coordenada $x$ do centro de massa para a posição $i$. 
$\bar{x}_{N i}=$ coordenada $x$ do centro de massa da parte $N$, para a posição $i$.

$\bar{y}_{N i}=$ coordenada $y$ do centro de massa da parte $N$, para a posição $i$.

Através do teorema dos eixos paralelos, temos

$$
\begin{aligned}
& d_{N x i}=\bar{x}_{i}-\bar{x}_{N i} \\
& d_{N y i}=\bar{y}_{i}-\bar{y}_{N i} \\
& I_{N x i}=I_{N x c i}+m_{N} d_{N x i}^{2} \\
& I_{N y i}=I_{N y c i}+m_{N} d_{N y i}^{2} \\
& I_{N x y i}=I_{N x y c i}+m_{N} d_{N x i} d_{N y i} \\
& I_{x i}=I_{A x i}+I_{B x i} \\
& I_{y i}=I_{A y i}+I_{B y i} \\
& I_{x y i}=I_{A x y i}+I_{B x y i}
\end{aligned}
$$

onde $N=A, B ; i=1,2$ e o índice $c$ indica que o momento de inércia passa pelo centro de massa, mas que não necessariamente é principal. Conhecendo-se $I_{N x c}, I_{N y c}$ e $I_{N x y c}$ para cada parte, basta aplicar as equações do círculo de Mohr para determinar os eixos principais das partes. O que se verificou é que não é possível determinar os momentos de inércia das partes através da medição do momento de inércia do conjunto para duas posições relativas diferentes, pois as equações resultantes são linearmente dependentes. Para se ter um sistema com solução possível e determinada é necessário que se conheça os momentos de inércia e os produtos de inércia do conjunto e de uma das partes. 
4.2 Validação dos Experimentos para Determinação do Centro de Massa e dos Momentos de Inércia em Relação aos Eixos Principais de Corpos Rígidos

\subsubsection{Validação dos Experimentos para Determinação do Centro de Massa}

Para a validação do experimento de determinação do centro de massa e momento de inércia, foram confeccionadas peças de formas geométricas simples e de material que pode ser considerado homogêneo. Assim, de posse das dimensões e da massa específica é possível determinar, de forma algébrica, o centro de massa e os momentos de inércia, em relação aos eixos que sejam necessários. Para o levantamento das dimensões reais das peças, depois de submetidas aos processos de fabricação, foram utilizados paquímetros convencionais da marca Mitutoyo com resolução de $0,05 \mathrm{~mm}$ e paquímetros digitais da marca Starrett com resolução de $0,01 \mathrm{~mm}$, para dimensões de até $200 \mathrm{~mm}$. Acima desse valor foi utilizada uma trena digital da marca Mitutoyo com resolução de 0,1 mm. Podem-se utilizar outras formas mais sofisticadas e de maior precisão para determinação das dimensões, mas acredita-se que isso não acrescentaria melhora significativa nesse primeiro momento, onde se deseja obter uma referência inicial para acuracidade do método.

Para o primeiro ensaio foram escolhidas quatro peças padrão com dimensões máximas variando de 250 a $400 \mathrm{~mm}$ aproximadamente.

Procedimento de ensaio:

$1^{\circ}$ - Pesagem das peças utilizando a célula de carga $\mathrm{n}^{\circ} 1$.

$2^{\circ}$ - Definir e marcar as duas secções por onde as barras serão suspensas através de fios.

$3^{0}$ - Suspender as peças pelas secções determinadas e obter as reações estáticas para cada secção.

$4^{\circ}$ - Corrigir os valores obtidos através da curva de calibração de cada célula de carga.

$5^{\circ}$ - Realizar os cálculos para a determinação dos centros de massa de cada peça a partir das reações estáticas.

A Tabela 4.1 mostra os valores obtidos de forma experimental e os obtidos de forma analítica, onde podemos observar qual a magnitude do erro que estamos trabalhando ao utilizar este procedimento para determinação do centro de massa. 
Tabela 4.1 - Dados do primeiro experimento para determinação do centro de massa.

\begin{tabular}{l|r|r|r|r|r|c}
\hline F1 & \multicolumn{1}{c|}{ F2 } & \multicolumn{1}{c|}{$\Delta \mathrm{L}$} & \multicolumn{1}{c|}{$\mathrm{L}$} & cg_experim & cg analítico & erro \\
\hline 272,6 & 326,8 & 45 & 200,3 & 136,09 & 135,50 & 0,438421 \\
\hline 282,7 & 342,3 & 25 & 200,1 & 115,51 & 115,85 & 0,295014 \\
\hline 182,1 & 196,9 & 25 & 200,2 & 121,19 & 121,21 & 0,01561 \\
\hline 331,0 & 355,7 & 100 & 200,6 & 196,69 & 196,52 & 0,087674 \\
\hline
\end{tabular}

Embora o processo tenha se mostrado preciso para os padrões de ensaios experimentais, optou-se por melhorar a precisão da calibração das células de carga. Calibrouse as células de carga com uma resolução de décimo de grama, e se refez o experimento anterior e os resultados estão mostrados na Tabela 4.2.

Tabela 4.2 - Dados do segundo experimento para determinação do centro de massa.

\begin{tabular}{c|c|r|r|r|r|c}
\hline F1 & F2 & \multicolumn{1}{c|}{$\Delta$ L } & \multicolumn{1}{c|}{ L } & cg_experim & cg analítico & erro \\
\hline 267,724 & 327,324 & 45 & 200,3 & 135,12 & 135,50 & 0,2812 \\
\hline 279,769 & 339,574 & 25 & 200,1 & 115,39 & 115,85 & 0,399543 \\
\hline 180,283 & 194,889 & 25 & 200,2 & 121,20 & 121,21 & 0,005809 \\
\hline 325,970 & 355,019 & 100 & 200,6 & 196,02 & 196,52 & 0,25367 \\
\hline
\end{tabular}

Constata-se que a magnitude do erro permaneceu praticamente constante e as variações de valores do centro de massa entre o primeiro e o segundo experimento é devido ao posicionamento das células de carga que acabaram gerando diferenças nas reações estáticas. O processo de posicionamento das células de carga na secção da peça é feita de forma visual o que torna o procedimento mais rápido e mais impreciso também. Como o erro obtido é suficientemente pequeno considerou-se o método para determinação do centro de massa satisfatório.

4.2.2 Validação do Experimento para Determinação dos Momentos de Inércia em Relação aos Eixos Principais de Corpos Rígidos

Considerando a equação não linear de movimento de um pêndulo simples 
$-M g L \operatorname{sen} \theta=I_{o} \frac{d^{2} \theta}{d t^{2}}$

onde

$L=$ distância entre o ponto $O$ e o centro de massa $C$;

$\theta=$ ângulo de rotação da peça em relação a posição vertical;

$I_{O}=$ momento de inércia em relação ao eixo $z$ que passa por $O$.

A solução desta equação pode ser útil devido ao fato do encoder apresentar uma resolução limitada a 8.000 pontos por volta e a taxa de amostragem adotada para a placa de aquisição ser de $1.000 \mathrm{Sa} / \mathrm{s}$. Para deslocamentos angulares muito pequenos acontece que a placa adquire vários valores iguais, pois a velocidade angular decai significativamente à medida que se diminui a amplitude de oscilação e assim a placa acaba por amostrar várias vezes antes do encoder sofrer um incremento ou decremento.

Deseja-se, então, determinar quanto maior é o período para o sistema não linear em relação ao linear. E assim, corrigir o valor do período sem que seja necessário colocar a peça para oscilar com uma amplitude muito pequena.

A solução não linear da equação (4.49) é bem conhecida e pode ser encontrada em Greenwood (1988).

$\ddot{\theta}=\frac{d \dot{\theta}}{d \theta} \frac{d \theta}{d t}$

Substituindo (4.50) na equação (4.49), tem-se

$$
\begin{aligned}
& \frac{d \dot{\theta}}{d \theta} \frac{d \theta}{d t} I_{o}=-M g L \operatorname{sen} \theta \\
& \dot{\theta} d \dot{\theta}=-\frac{M g L}{I_{o}} \operatorname{sen} \theta d t
\end{aligned}
$$


$\int_{0}^{\dot{\theta}} \dot{\theta} d \dot{\theta}=-\frac{M g L}{I_{o}} \int_{\theta}^{\theta_{o}} \operatorname{sen} \theta d t$

$\frac{\dot{\theta}^{2}}{2}=\frac{M g L}{I_{o}}\left(\cos \theta-\cos \theta_{o}\right)$

$\dot{\theta}=\sqrt{\frac{2 M g L\left(\cos \theta-\cos \theta_{o}\right)}{I_{o}}}$

$\int_{t_{o}}^{t} d t=\sqrt{\frac{I_{o}}{2 M g L}} \int_{0}^{\theta} \frac{d \theta}{\sqrt{\cos \theta-\cos \theta_{o}}}$

onde $t-t_{o}$ é o intervalo de tempo da passagem da peça por $\theta=0$ no sentido positivo até alcançar $\theta$. Essa é uma integral elíptica. E a equação (4.56) pode ser colocada na forma padrão fazendo-se as seguintes substituições

$k=\operatorname{sen} \frac{\theta_{o}}{2}$

e

$\operatorname{sen} \phi=\frac{\operatorname{sen} \frac{\theta}{2}}{\operatorname{sen} \frac{\theta_{o}}{2}}$

notando-se que

$\cos \theta_{o}=1-2 \operatorname{sen}^{2} \frac{\theta_{o}}{2}=1-2 k^{2}$

e

$\cos \theta=1-2 \operatorname{sen}^{2} \frac{\theta}{2}=1-2 k^{2} \operatorname{sen}^{2} \phi$

então 
$d \theta=\frac{2 k \cos \phi d \phi}{\sqrt{1-k^{2} \operatorname{sen}^{2} \phi}}$

Como conseqüência pode se escrever a equação (4.56) da seguinte forma

$t-t_{o}=\sqrt{\frac{I_{o}}{M g L}} \int_{0}^{\phi} \frac{d \phi}{\sqrt{1-k^{2} \operatorname{sen}^{2} \phi}}$

ou

$t-t_{o}=\sqrt{\frac{I_{o}}{M g L}} F(\phi, k)$

onde

$F(\phi, k)=\int_{0}^{\phi} \frac{d \phi}{\sqrt{1-k^{2} \operatorname{sen}^{2} \phi}}$

Essa integral é conhecida como integral elíptica de Legendre de primeiro tipo. Pode se perceber que o tempo requerido para alcançar certo ângulo $\theta$, ou seu correspondente valor de $\phi$, depende da máxima amplitude $\theta_{o}$ que é expresso em termos do quadrado de $k$.

O período $T$ de oscilação é quatro vezes o intervalo requerido para o movimento de $\theta=0$ a $\theta=\theta_{o}$, ou de $\phi=0$ a $\phi=\frac{\pi}{2}$ (GREENWOOD, 1988).

$T=4 \sqrt{\frac{I_{o}}{M g L}} \int_{0}^{\frac{\pi}{2}} \frac{d \phi}{\sqrt{1-k^{2} \operatorname{sen} \phi}}=4 \sqrt{\frac{I_{o}}{M g L}} K(k)$

onde $K(k)=F\left(\frac{\pi}{2}, k\right)$ é chamado de integral elíptica completa de primeiro tipo. Por exemplo, se $\theta_{o}=\frac{\pi}{2}$, então $k=1 / \sqrt{2}$ e encontra-se a partir de tabelas que $K=1,8541$, resultando em um período 
$T=7,4164 \sqrt{\frac{I_{o}}{M g L}}$.

Isso é aproximadamente $18 \%$ maior que o período

$2 \pi \sqrt{\frac{I_{o}}{M g L}}$

que seria o valor obtido para pequenas oscilações de movimento. Para que não haja dúvida quanto ao valor de $18 \%$ acima citado, a peça deve ser posicionada a $90^{\circ}$ da posição vertical de repouso e, então, deve ser solta. De posse do valor de $\theta_{o}$ e do período $T$ é possível saber quanto o período não linear é maior que o linear, assim, pode-se corrigir o valor $T$ e achar o correspondente para pequenas oscilações de movimento, sem que se corra o risco de perder precisão no encoder com amplitudes de oscilação muito pequenas. Embora se tenha tentado reduzir bastante o atrito, este ainda permanece e, aparentemente, parece influenciar mais quando se reduz muito a amplitude de oscilação devido às velocidades serem muito baixas. $\mathrm{O}$ que se percebeu, também, é que amplitudes de oscilações muito grandes, mesmo corrigidas, ainda inserem um determinado erro, maior do que quando oscilam com amplitude de $\pm 5^{\circ} \mathrm{a} \pm$ $20^{\circ}$.

Nos ensaios preliminares de validação do experimento para determinação dos momentos de inércia, foram testados alguns tipos de encoders. Primeiramente, utilizou se um encoder HEDS-5540\#A02, com 3 canais $A, B$ e $I$ e com resolução de 500 CPR (Counts per Revolution), fabricado por Avago Technologies, que para uma taxa de aquisição de $1 \mathrm{kSa} / \mathrm{s}$ e uma amplitude de $\pm 10^{\circ}$ de oscilação do pêndulo pode se verificar que no momento de inversão no sentido do movimento a placa de aquisição amostra várias vezes o mesmo valor do encoder. $\mathrm{O}$ encoder configurado para trabalhar em quadratura 4x possui uma resolução de $0,18^{\circ}$. Embora esse problema pudesse ser contornado, através de métodos computacionais, optou-se por utilizar um encoder com maior resolução. 


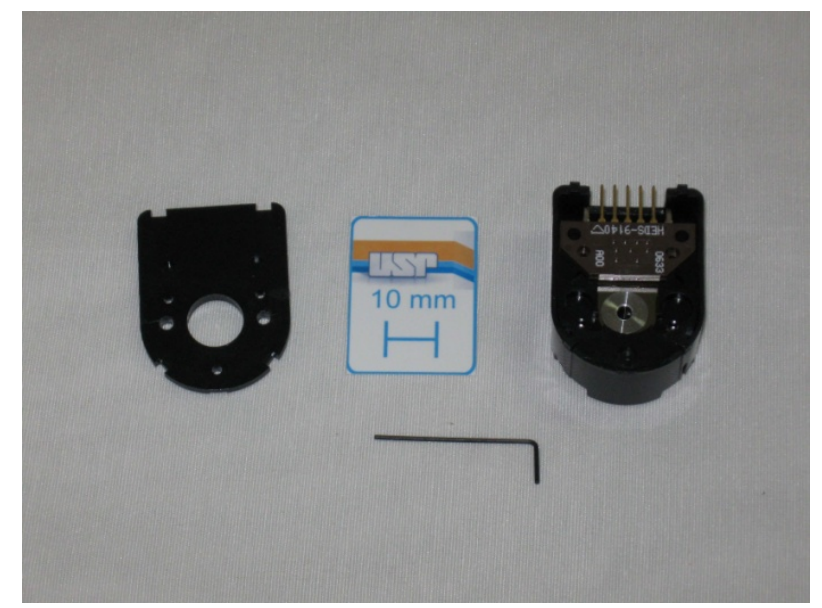

Figura 4.14 - Encoder HEDS-5540\#A02, Avago Technologies.

Resolveu-se, então, testar utilizando o elemento sensor HEDS-9040\#B00, com 3 canais $A, B$ e $I$ e com resolução para até 1000 CPR em conjunto com o disco HEDS6140\#B06, ambos fabricado por Avago Technologies. Com isso aumentou-se a resolução do encoder para $0,09^{\circ}$. Embora tenha melhorado o problema ainda não foi solucionado completamente, pois para amplitudes de oscilação entre $\pm 5^{\circ}$ e $\pm 10^{\circ}$, ainda ocorria o problema para oscilações próxima de $\pm 5^{\circ}$. Optou-se novamente por utilizar um sensor HEDS-9000\#T00 em conjunto com o disco HEDM-6040\#T12, o encoder possui dois canais $A$ e $B$, com capacidade de $2000 \mathrm{CPR}$ que aumentou a resolução para $0,045^{\circ}$ em quadratura 4x. Assim resolveu-se o problema para a faixa de amplitudes de oscilação que se deseja.

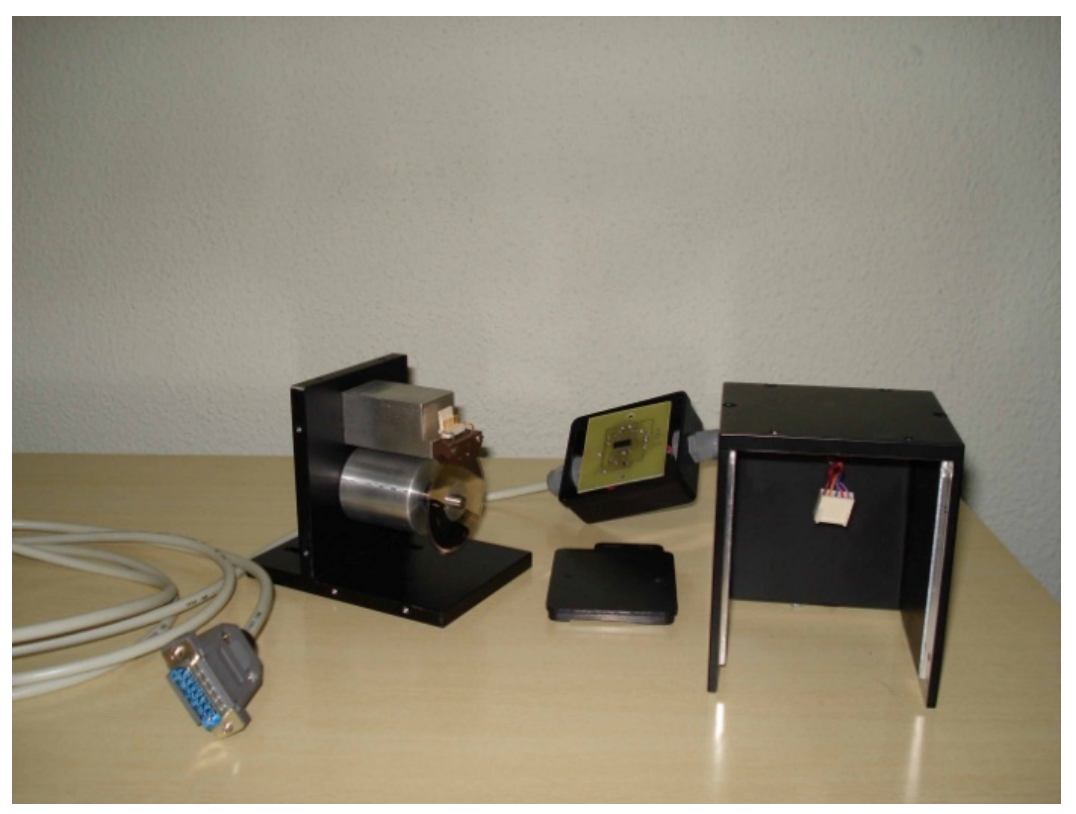

Figura 4.15 - Encoder com resolução de 1000 CPR. 
Para o primeiro encoder utilizado construiu-se um dispositivo mecânico para se fixar o encoder e poder acoplá-lo à plataforma. Esse dispositivo foi confeccionado em aço inox 304, conforme Figura 4.16.

(a)

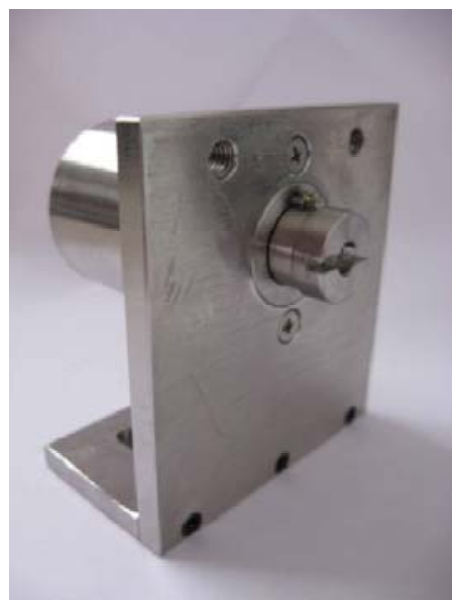

(b)

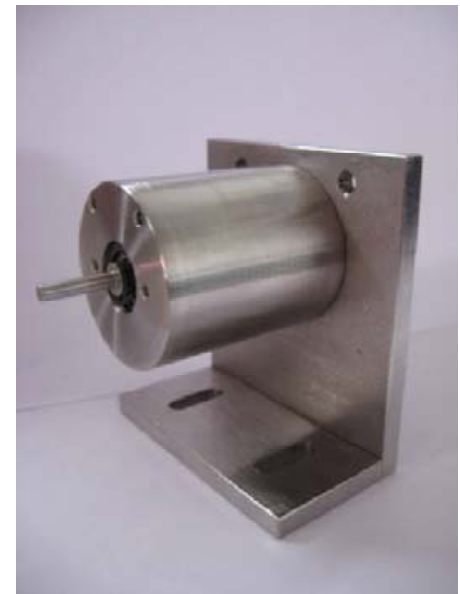

Figura 4.16 - Dispositivo em inox para fixação do encoder HEDS-5540\#A02.

Para os dois outros encoders foram confeccionados dispositivos em alumínio e aço inox com pintura eletrostática na cor preta. Para todos os casos foram desenvolvidos uma interface RS-422 para supressão de ruídos na transmissão do sinal até à placa de aquisição, por recomendação do fabricante do sensor, conforme Figura 4.17.

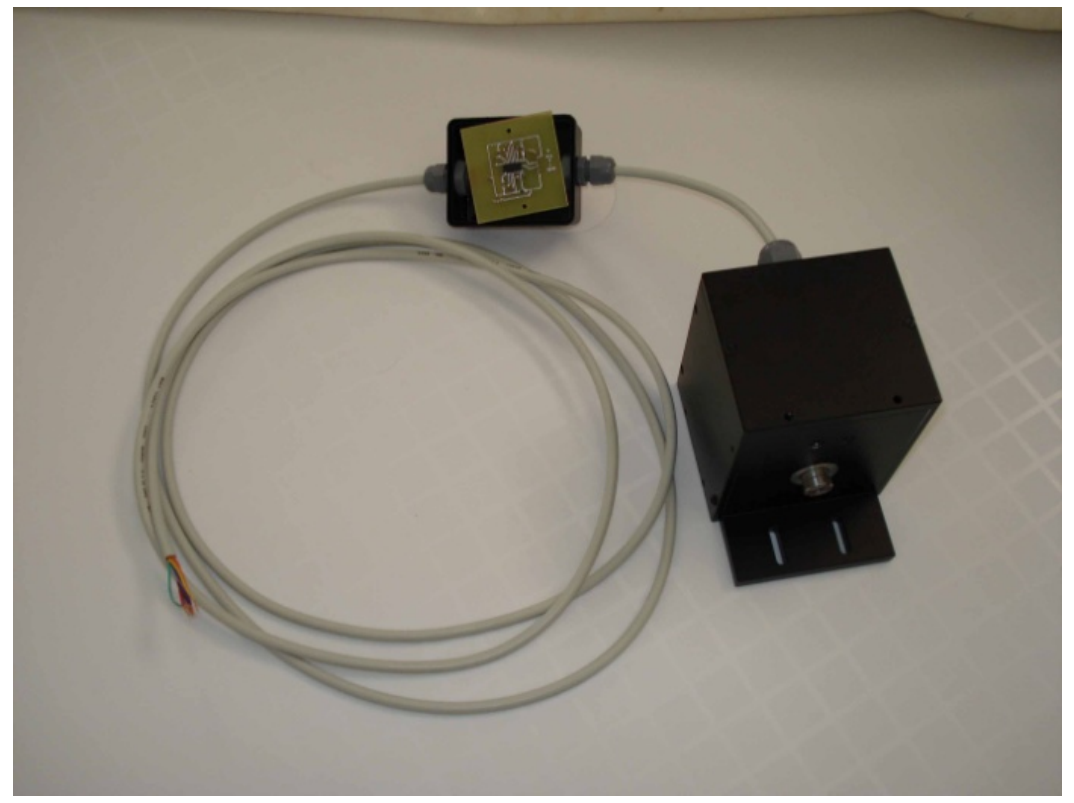

Figura 4.17 - Dispositivo para proteção, alinhamento e fixação do encoder.

Como há algumas influências que alteram a medição correta do período de oscilação, embora não de forma significativa, mas cujos fatores reais não puderam ser identificados, 
resolveu-se ainda procurar outras soluções, com encoders com maior resolução que num trabalho futuro poderia ajudar a esclarecer os fatores que afetam o período de oscilação para amplitudes pequenas. Existem várias soluções para isso, encontradas em catálogos dos fabricantes. O problema maior é encontrar soluções satisfatórias, com um custo adequado e que possa ser adquirido através de importação. Chega-se a dois encoders com tecnologias de aplicação bem diferentes, mas capazes de fornecer resultados precisos. O primeiro encoder é o AEAS-7000-1GSG0, encoder absoluto, com 16 bits de resolução, fabricado pela Avago Technologies, com capacidade de comunicação digital através de uma interface SPI (Serial Peripheral Interface) e, também, através de uma saída analógica de voltagem (Figura 4.18).

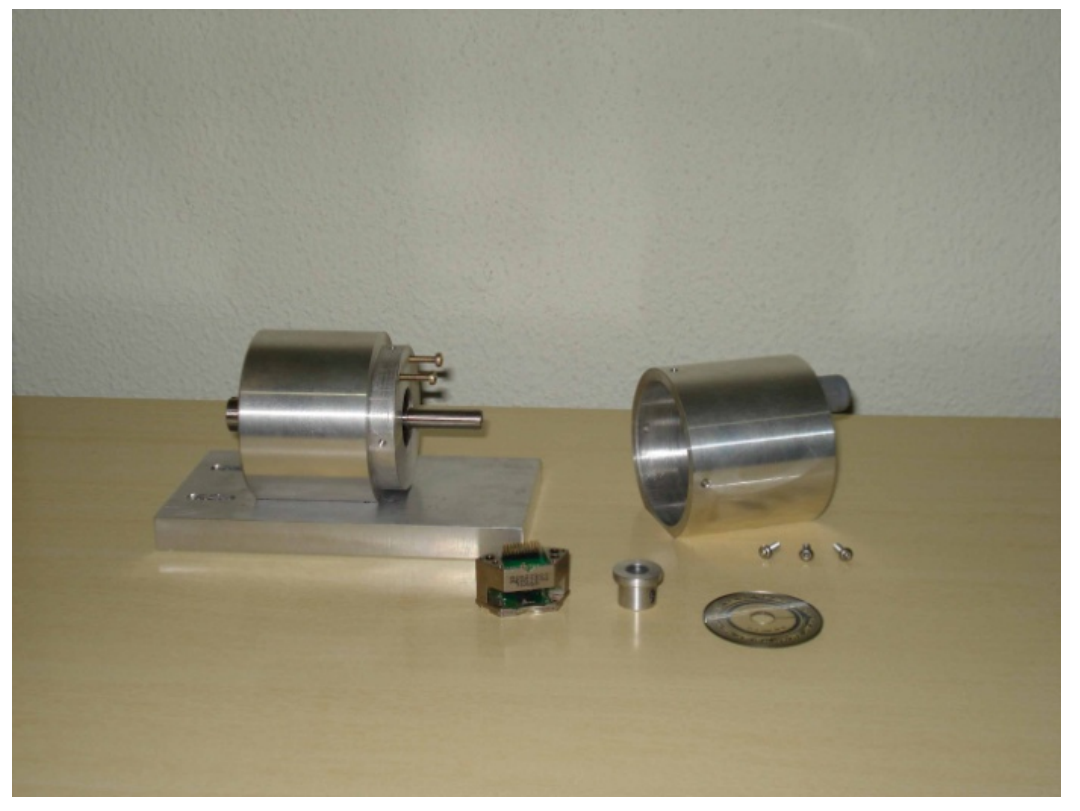

Figura 4.18 - Encoder AEAS-7000-1GSG0, Avago Technologies.

A segunda opção, aparentemente bem mais fácil de ser implementada, é através do encoder AEDA-3200-TBJ, tipo incremental, com resolução de 7200 CPR, com 3 canais, fabricado pela Avago Technologies, que utilizado em quadratura 4x nos forneceria uma resolução de $0,0125^{\circ}$ (Figura 4.19). Pretende-se utilizar ambos os encoders para testar a facilidade de implementação e verificar os resultados obtidos, para identificar o problema em amplitudes pequenas de oscilação e também para conhecer a tecnologia. Esta pode ser utilizada em outras áreas como para instrumentação em sistemas de controle. 


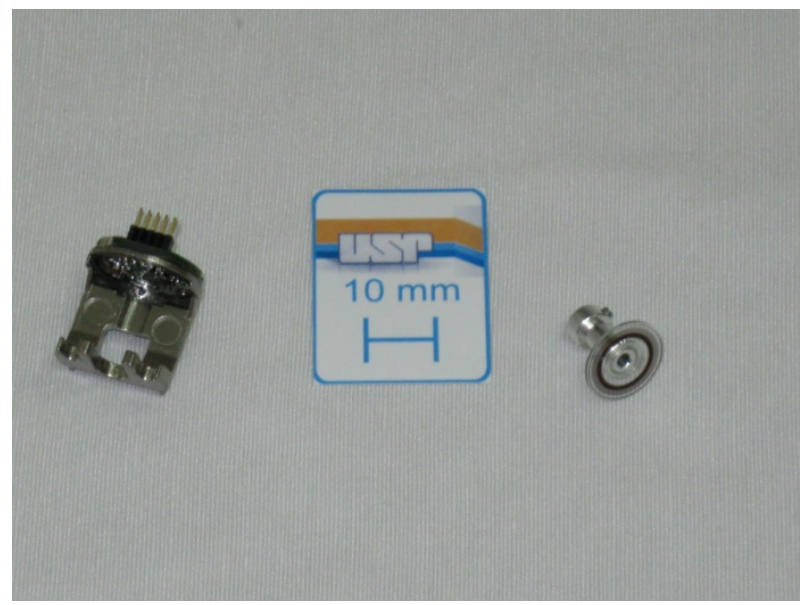

Figura 4.19 - Encoder AEDA-3200-TBJ, Avago Technologies.

Para o experimento de momento de inércia foram desenvolvidos vários dispositivos: para realizar a medição do período de oscilação, para diminuição do atrito, suportes para fixação das peças a serem medidas e peças padrão cujos momentos de inércia podem ser determinados através das dimensões e da massa considerando o material homogêneo.

Os dispositivos para medição do período de oscilação foram descritos anteriormente juntamente com os encoders utilizados. Para que o objeto suspenso pudesse oscilar com pouca influência do atrito seco, optou-se por utilizar mancais de rolamento. No entanto foram confeccionados dois tipos de mancais. Um para peças pequenas e leves e outro com uma capacidade de carga maior, para peças grandes (Figura 4.20).

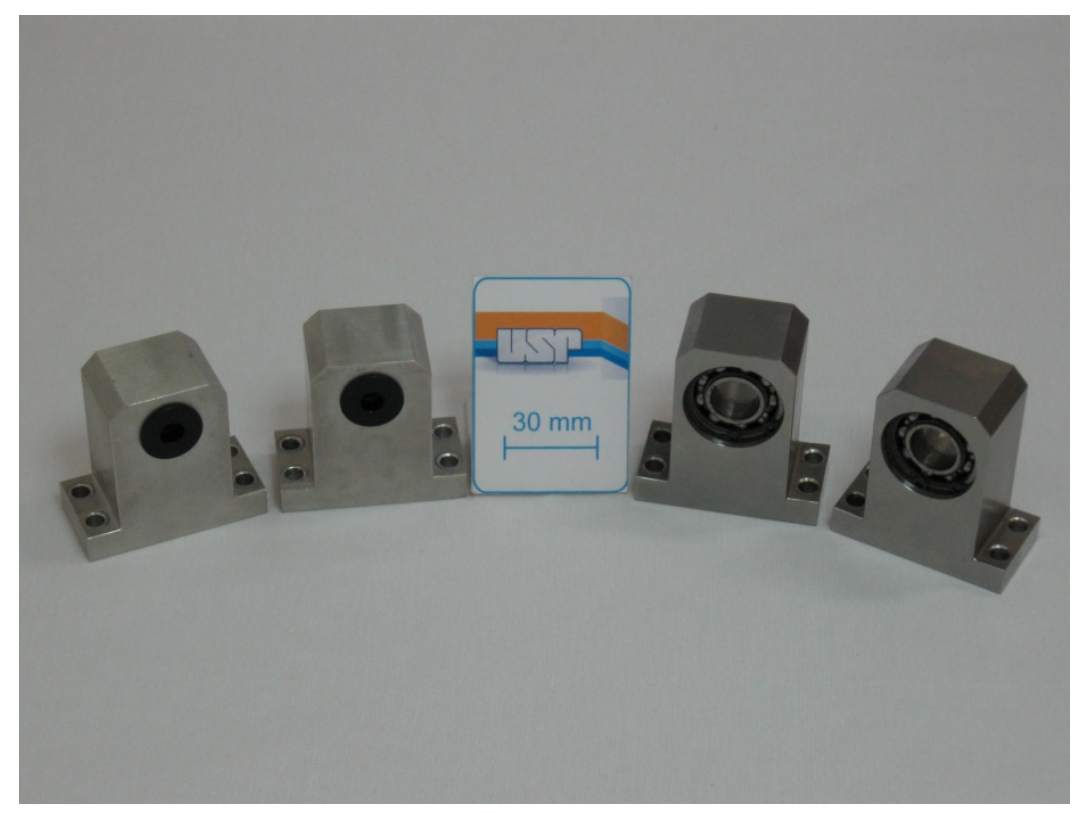

Figura 4.20 - Mancais de rolamento. 
Para a transmissão do movimento do eixo bi-apoiado nos mancais de rolamento para o enconder, compensando possíveis desalinhamentos, desenvolveu-se um acoplamento rígido com rasgos a $90^{\circ}$ e para evitar parte da perda por atrito, utilizou-se um elemento de ligação confeccionado em teflon, conforme Figura 4.21.

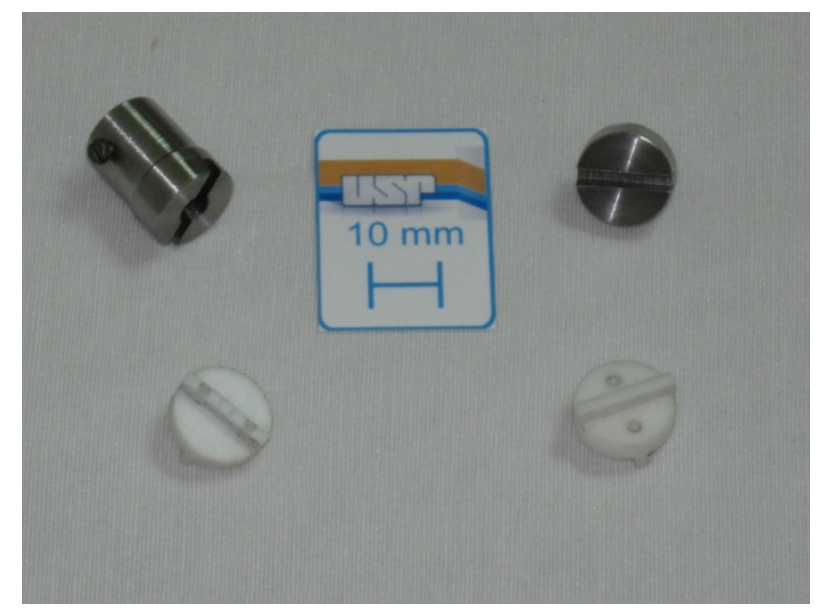

Figura 4.21 - Acoplamento rígido para compensação de desalinhamento.

Para que fosse possível determinar os momentos principais de inércia nos eixos $x, y$ e $z$ dos atuadores fez-se necessário a confecção de dois tipos de eixos além de um suporte auxiliar, com a finalidade de permitir mudar o ângulo de inclinação da peça que irá oscilar a fim de se determinar o ângulo onde o momento de inércia é máximo ou mínimo (Figura 4.22).

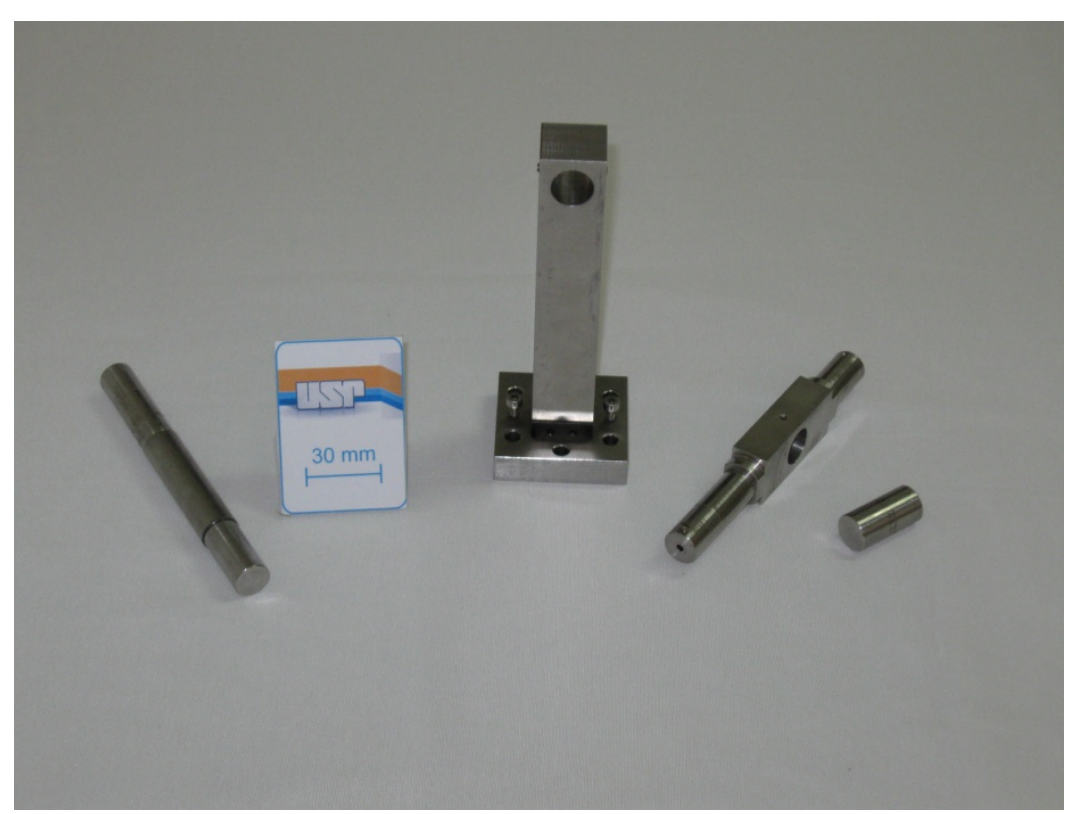

Figura 4.22 - Eixos e suporte auxiliar.

Com o objetivo de verificar a acuracidade do experimento foram confeccionadas algumas peças padrão, de tal forma, que seja possível obter analiticamente os momentos de 
inércia da peça, através das suas dimensões e da sua massa considerando o material homogêneo, e compará-los com os valores obtidos experimentalmente (Figura 4.23).

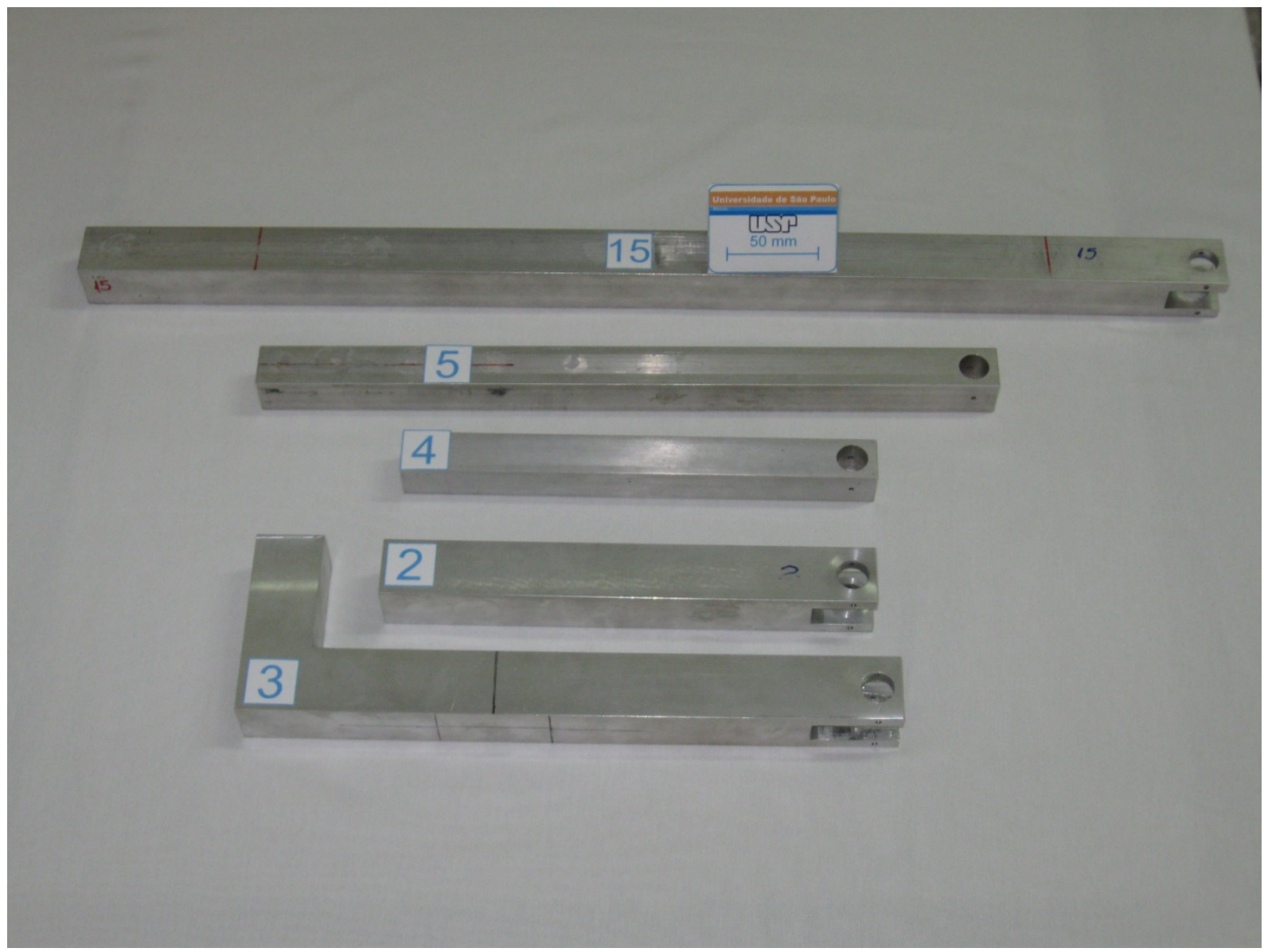

Figura 4.23 - Peças padrão.

Quando colocamos a peça para oscilar no dispositivo, estamos medindo o momento de inércia da peça em relação ao eixo de rotação que passa pelo centro do eixo que gira apoiado nos mancais de rolamento, para alguns casos esse eixo pode ser paralelo ao eixo principal de inércia que se deseja determinar, bastando, então, aplicar o teorema dos eixos paralelos para determinar o seu valor. Nos casos em que isso não ocorra deve-se variar a inclinação da peça, de tal forma que se possa determinar através de alguns ensaios o momento principal de inércia. 


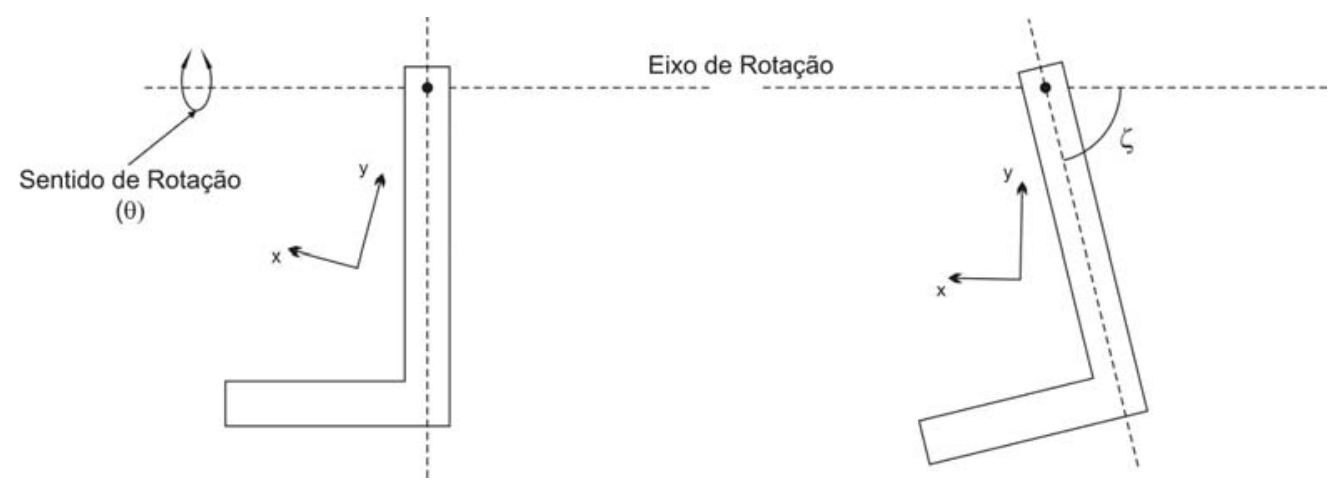

Figura 4.24 - Eixo principal de inércia da peça paralelo ao eixo de rotação.

Para que se possa medir esse ângulo será utilizado um medidor de inclinação, PRO 3600 , fabricado pela Mitutoyo com resolução de $0,01^{\circ}$ para medições de 0 a $\pm 10^{\circ}$ e $0,1^{\circ}$ de $\pm 10^{\circ} \mathrm{a} \pm 90^{\circ}$. Se houver a necessidade de trabalhar com a resolução mais precisa em ângulos maiores que $10^{\circ} \mathrm{o}$ aparelho pode ser zerado em um determinado ângulo e trabalhar com uma resolução de $0,01^{\circ}$ numa faixa de $\pm 10^{\circ}$ em torno do valor zerado. $\mathrm{O}$ aparelho também possui um procedimento para calibração automática sem a necessidade de outro medidor de inclinação como referência. Possui saída RS-232 para conexão com microcomputador, mas o conector não é um DB-9 ou DB-25, e sim, um conector padrão da Mitutoyo, cujo cabo de comunicação deve ser adquirido separadamente.

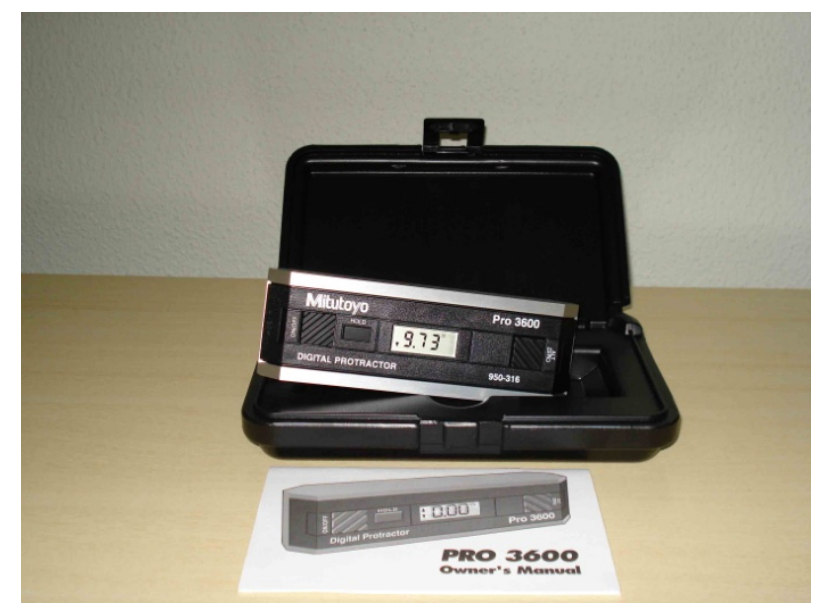

Figura 4.25 - Medidor de Inclinação PRO 3600, Mitutoyo.

Em alguns casos não é possível colocar a peça para oscilar com o eixo $y$, da Figura 4.24, paralelo ao eixo de rotação com os eixos confeccionados até o momento. Por isso desenvolveu-se um suporte para possibilitar essa medição, Figura 4.26, e também comparar com o valor obtido através da elipse de inércia para o seu correspondente momento de inércia principal defasado de $90^{\circ}$. Sempre que se determina a equação da elipse de inércia podem ser obtidos os valores dos semi-eixos maior e menor da elipse de inércia. 


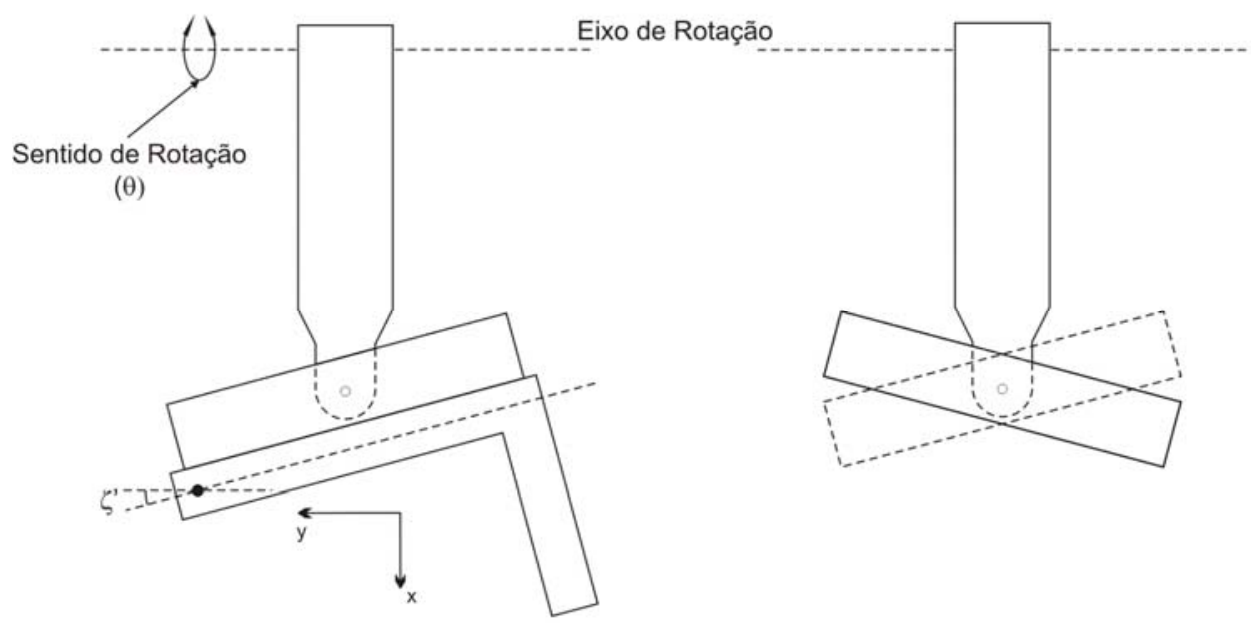

Figura 4.26 - Eixo principal de inércia da peça paralelo ao eixo de rotação.

Foram realizados vários ensaios para determinação de momento de inércia utilizando apenas uma única peça, ou seja, sem a utilização de suportes auxiliares. Para realização do experimento a taxa de amostragem foi de $2 \mathrm{kSa} / \mathrm{s}$ e o ângulo de oscilação das peças por volta de $\pm 20^{\circ}$. O que se pôde observar é que em nenhum dos casos o erro passou de 1,2\% para o momento de inércia em relação ao centro de massa e de $0,29 \%$ para o momento de inércia em relação ao eixo de rotação da peça. Chegou-se a estes valores comparando o valor calculado analiticamente e o obtido experimentalmente. Também não se pode dizer que esse valor seja o erro real, pois existem erros em determinadas grandezas que afetam tanto a medida experimental quanto a analítica, como no caso da massa e do centro de massa para as peças padrão utilizadas. Acredita-se que devido aos testes realizados até o momento que a medição da massa de uma peça, com o procedimento adotado, está com um erro pequeno, abaixo de $0,5 \%$, e considera-se o procedimento adequado e os valores que mais influenciam a medida final são os do centro de massa e o comprimento total da peça. Qualquer variação mesmo que pequena nessas grandezas afetam de formam significativa o valor do momento principal de inércia. A tabela 4.3 apresenta os resultados dos ensaios realizados com quatro peças em relação ao eixo que passa por $O$ e pelo centro de massa da peça como representado na Figura 4.7. 
Tabela 4.3 - Comparação dos momentos de inércia obtidos de forma experimental e analítica para peças padrão com dois planos de simetria.

\begin{tabular}{c|c|c|c|c|c|c|c}
\hline Peça & Período & $\begin{array}{c}\text { Analítico } \\
I_{0} \cdot 10^{-2} \\
\left(\mathrm{~kg} \cdot \mathrm{m}^{2}\right)\end{array}$ & $\begin{array}{c}\text { Experim. } \\
I_{0} \cdot 10^{-2} \\
\left(\mathrm{~kg} \cdot \mathrm{m}^{2}\right)\end{array}$ & Erro $I_{0}$ & $\begin{array}{c}\text { Analítico } \\
I_{c} \cdot 10^{-3} \\
\left(\mathrm{~kg} \cdot \mathrm{m}^{2}\right)\end{array}$ & $\begin{array}{c}\text { Experim. } \\
I_{c} \cdot 10^{-3} \\
\left(\mathrm{~kg} \cdot \mathrm{m}^{2}\right)\end{array}$ & Erro $I_{c}$ \\
\hline 2 & 0,8039 & 1,2179 & 1,2101 & 0,9982 & 2,8849 & 2,9072 & 0,9923 \\
\hline 4 & 0,8007 & 6,9610 & 6,9626 & 0,9998 & 1,8846 & 1,8862 & 0,9992 \\
\hline 5 & 1,0219 & 3,3833 & 3,3884 & 0,9985 & 8,8715 & 8,9219 & 0,9943 \\
\hline 15 & 1,3009 & 2,2256 & 2,2321 & 0,9971 & 54,040 & 54,690 & 0,9881 \\
\hline
\end{tabular}

Resolveu-se realizar mais um conjunto de ensaios a fim de melhorar os resultados dos ensaios para as peças com maior comprimento. Como pode se observar na Tabela 4.3 e na Tabela 4.4, a peça 15 foi a que apresentou um erro significativo em relação às demais ensaiadas.

As alterações realizadas foram: o aumento da taxa de aquisição, de $2 \mathrm{kSa} / \mathrm{s}$ para 10 $\mathrm{kSa} / \mathrm{s}$. Partindo do princípio que se deseja uma resolução de décimo de milisegundos, então definiu-se a taxa de amostragem igual à resolução. Embora o desejado seja 10 vezes, utilizouse este valor para evitar sobrecarregar o sistema de aquisição. Para tanto, foi necessário alterar o algoritmo do programa que calcula o período de oscilação, pois haverá zeros repetidos quando o pêndulo estiver passando pela origem devido à resolução do encoder digital. $\mathrm{O}$ programa considera como o ponto zero, o tempo central dos conjuntos de zeros amostrados em seqüência; e a mudança da faixa de oscilação do pêndulo que passou de $\pm 20^{\circ}$ para $\pm 5^{\circ} \mathrm{com}$ o intuito de diminuir a diferença entre a oscilação do pêndulo que é não linear e o modelo adotado que é linear. Foram realizados quatro ensaios para cada peça com o intuito de verificar além do erro o desvio padrão dos resultados. 
Tabela 4.4 - Comparação dos momentos de inércia obtidos de forma experimental e analítica, para peças padrão com dois planos de simetria, com análise de repetibilidade.

\begin{tabular}{c|c|c|c|c|c|c|c}
\hline Peça & Período & $\begin{array}{c}\text { Analítico } \\
I_{0} \cdot 10^{-2} \\
\left(\mathrm{~kg} \cdot \mathrm{m}^{2}\right)\end{array}$ & $\begin{array}{c}\text { Experim. } \\
I_{0} \cdot 10^{-2} \\
\left(\mathrm{~kg} . \mathrm{m}^{2}\right)\end{array}$ & Erro $I_{0}$ & $\begin{array}{c}\text { Analítico } \\
I_{c} \cdot 10^{-3} \\
\left(\mathrm{~kg} . \mathrm{m}^{2}\right)\end{array}$ & $\begin{array}{c}\text { Experim. } \\
I_{c} \cdot 10^{-3} \\
\left(\mathrm{~kg} \cdot \mathrm{m}^{2}\right)\end{array}$ & Erro $I_{c}$ \\
\hline 2 & 0,8039 & 1,2179 & 1,2201 & 0,9982 & 2,8849 & 2,9072 & 0,9923 \\
\hline 2 & 0,8040 & 1,2179 & 1,2204 & 0,9979 & 2,8849 & 2,9103 & 0,9913 \\
\hline 2 & 0,8040 & 1,2179 & 1,2204 & 0,9979 & 2,8849 & 2,9103 & 0,9913 \\
\hline 2 & 0,8039 & 1,2179 & 1,2201 & 0,9982 & 2,8849 & 2,9072 & 0,9923 \\
\hline 4 & 0,8004 & 6,9610 & 6,9574 & 1,0005 & 1,8846 & 1,8809 & 1,0019 \\
\hline 4 & 0,8002 & 6,9610 & 6,9539 & 1,0010 & 1,8846 & 1,8775 & 1,0038 \\
\hline 4 & 0,8003 & 6,9610 & 6,9556 & 1,0008 & 1,8846 & 1,8792 & 1,0029 \\
\hline 4 & 0,8002 & 6,9610 & 6,9539 & 1,0010 & 1,8846 & 1,8775 & 1,0038 \\
\hline 5 & 1,0214 & 3,3833 & 3,3851 & 0,9995 & 8,8715 & 8,8888 & 0,9981 \\
\hline 5 & 1,0214 & 3,3833 & 3,3851 & 0,9995 & 8,8715 & 8,8888 & 0,9981 \\
\hline 5 & 1,0217 & 3,3833 & 3,3870 & 0,9989 & 8,8715 & 8,9086 & 0,9958 \\
\hline 5 & 1,0216 & 3,3833 & 3,3864 & 0,9991 & 8,8715 & 8,9020 & 0,9966 \\
\hline 15 & 1.3013 & 22,256 & 22,335 & 0,9965 & 5,4040 & 54,828 & 0,9856 \\
\hline 15 & 1,3012 & 22,256 & 22,331 & 0,9966 & 5,4040 & 54,793 & 0,9862 \\
\hline 15 & 1,3012 & 22,256 & 22,331 & 0,9966 & 5,4040 & 54,793 & 0,9862 \\
\hline 15 & 1,3011 & 22,256 & 22,328 & 0,9968 & 5,4040 & 54,759 & 0,9869 \\
\hline
\end{tabular}

Pode-se declarar que os valores obtidos para a determinação do centro de massa ou para determinação do momento de inércia, de peças com dois planos de simetria, estão acima das expectativas iniciais, e a opção por utilizar métodos experimentais, para determinação dessas grandezas, se mostrou precisa e prática.

Os próximos ensaios visam verificar a acuracidade da medição de momento de inércia para peças com somente um plano de simetria. Para tanto, utiliza-se uma peça em forma de "L" onde é possível calcular as características inerciais da mesma através das dimensões medidas com um paquímetro digital. As características inerciais calculadas serão consideradas como valores padrão para análise do erro em relação aos valores obtidos experimentalmente. Serão realizadas três medições com ângulos diferentes, sendo um deles coincidente com um eixo principal. Para a medição do ângulo de inclinação da peça será utilizado o inclinômetro mostrado na Figura 4.25. O ângulo $\theta$ apresentado na Tabela 4.5 é medido como indicado na Figura 4.24, onde se adota o sentido horário como positivo. 
Tabela 4.5 - Comparação dos momentos de inércia obtidos de forma experimental e analítica, para peças padrão com um plano de simetria, com análise de repetibilidade

\begin{tabular}{c|c|c|c|c|c|c|c}
\hline $\begin{array}{c}\text { Ângulo } \\
\theta\end{array}$ & Período & $\begin{array}{c}\text { Analítico } \\
I_{0} \cdot 10^{-2} \\
\left(\mathrm{~kg} \cdot \mathrm{m}^{2}\right)\end{array}$ & $\begin{array}{c}\text { Experim. } \\
I_{0} \cdot 10^{-2} \\
\left(\mathrm{~kg} \cdot \mathrm{m}^{2}\right)\end{array}$ & Erro $I_{0}$ & $\begin{array}{c}\text { Analítico } \\
I_{c} \cdot 10^{-3} \\
\left(\mathrm{~kg} \cdot \mathrm{m}^{2}\right)\end{array}$ & $\begin{array}{c}\text { Experim. } \\
I_{c} \cdot 10^{-3} \\
\left(\mathrm{~kg} \cdot \mathrm{m}^{2}\right)\end{array}$ & Erro $I_{c}$ \\
\hline $90^{\mathbf{0}}$ & 0,9737 & 4,6654 & 4,6699 & 0,9990 & 9,6249 & 9,6695 & 0,9954 \\
\hline $90^{\mathbf{0}}$ & 0,9736 & 4,6654 & 4,6689 & 0,9992 & 9,6249 & 9,6599 & 0,9964 \\
\hline $90^{\mathbf{0}}$ & 0,9735 & 4,6654 & 4,6679 & 0,9995 & 9,6249 & 9,6503 & 0,9974 \\
\hline $83,5^{\mathbf{o}}$ & 0,9744 & 4,6698 & 4,6718 & 0,9996 & 9,7448 & 9,7645 & 0,9980 \\
\hline $83,5^{\mathbf{0}}$ & 0,9744 & 4,6698 & 4,6718 & 0,9996 & 9,7448 & 9,7645 & 0,9980 \\
\hline $83,5^{\mathbf{o}}$ & 0,9745 & 4,6698 & 4,6728 & 0,9994 & 9,7448 & 9,7740 & 0,9970 \\
\hline $100,9^{\mathbf{0}}$ & 0,9585 & 4,3966 & 4,4027 & 0,9986 & 8,9153 & 8,9758 & 0,9933 \\
\hline $100,9^{\mathbf{o}}$ & 0,9585 & 4,3966 & 4,4027 & 0,9986 & 8,9153 & 8,9758 & 0,9933 \\
\hline $100,9^{\mathbf{o}}$ & 0,9587 & 4,3966 & 4,4045 & 0,9982 & 8,9153 & 8,9941 & 0,9912 \\
\hline
\end{tabular}

Os momentos de inércia medidos experimentalmente foram considerados satisfatórios. Os momentos de inércia medidos com um ângulo de $83,5^{\circ}$ estão muito próximos do eixo $x$ apresentado na Figura 4.24 como principal de inércia. O valor exato do ângulo é de $83,4558^{\circ}$.

O ensaio utilizado para determinação de momento de inércia através de pendulação não apresentou variação de acuracidade com relação à simetria da peça ensaiada. Portanto, como era de se esperar, é possível medir momentos de inércia de qualquer tipo de peça. Para peças que necessitem de um suporte para oscilarem em torno de um eixo serão analisadas durante o ensaio do atuador na secção 5.1.1 e 5.1.2.

\subsubsection{Protótipo Real de uma Plataforma de Movimento com 2 G.D.L.}

Devido ao elevado custo de se construir um simulador de vôo com seis graus de liberdade optou-se, primeiramente, por construir um com dois graus de liberdade sendo estes de rolagem (roll) e arfagem (pitch), assim se teria noção dos problemas para construção, identificação e controle do sistema.

Optou-se por uma configuração original tipo 6-6, devido à dificuldade de se colocar duas juntas esféricas no mesmo ponto como acontece com a configuração cúbica. Para se obter os graus de liberdade desejados, ou seja, 2 G.D.L., colocou-se uma coluna fixando o centro da plataforma móvel com uma junta universal. 
A plataforma de movimento de 2 G.D.L. é constituída pelos seguintes itens:

- uma plataforma móvel, confeccionada em metalon 60x60x1,5mm, cobertura em chapa de aço 1020 de \#1/8", reforços para os mancais em chapa de aço 1020 de \#1/4”, pintura eletrostática e dois mancais de rolamentos;

- uma plataforma fixa confeccionada em metalon 60x60x3mm, cobertura em chapa de aço 1020 de \#3/16", reforços para os mancais em chapa de aço 1020 de \#1/4", fuso roscado com diâmetro externo de $80 \mathrm{~mm}$, pés anti-vibração, pintura eletrostática e dois mancais de rolamento;

- dois atuadores lineares D24-20B5-08 da marca Warner Electric com fusos de esferas e curso de 8"; trocou-se o sistema de engrenagens com uma redução de 20:1, por um sistema de correia sincronizada com uma redução de $2: 1$ e os motores de corrente contínua de $24 \mathrm{~V}$ por servomotores brushless da marca Thomson Industries, Inc. modelo BLD2315B10200 com encoder integrado da marca Agilent de 1000 linhas (4000 pontos em quadratura) com driver RS-422 para redução de ruído;

- dois drivers de potência para os motores modelo TD502315B da marca Thomson Industries, Inc. com entrada analógica de $\pm 10 \mathrm{~V}$, Tensão do motor de $160 \mathrm{~V}$, freqüência do PWM de $20 \mathrm{kHz}$ e tensão de alimentação de $115 \mathrm{~V}$;

- dois sensores de posição BTL5-G11-M0225 da linha micropulse transducer da marca $B A L L U F F$, atuando sob o princípio da magnetostricção, com curso de medida de 225 $\mathrm{mm}$, com sinal de saída $\pm 10 \mathrm{~V}$, medida absoluta e medição sem contato através de um captador magnético;

- uma coluna de elevação em aço 1020;

- duas juntas esféricas e três juntas universais.

A plataforma, já confeccionada, com todas as adaptações necessárias para acomodar diversos equipamentos que foram adquiridos, e que, originalmente, eram para outras finalidades, pode ser vista na Figura 4.27. Na figura, os motores não estão montados. 


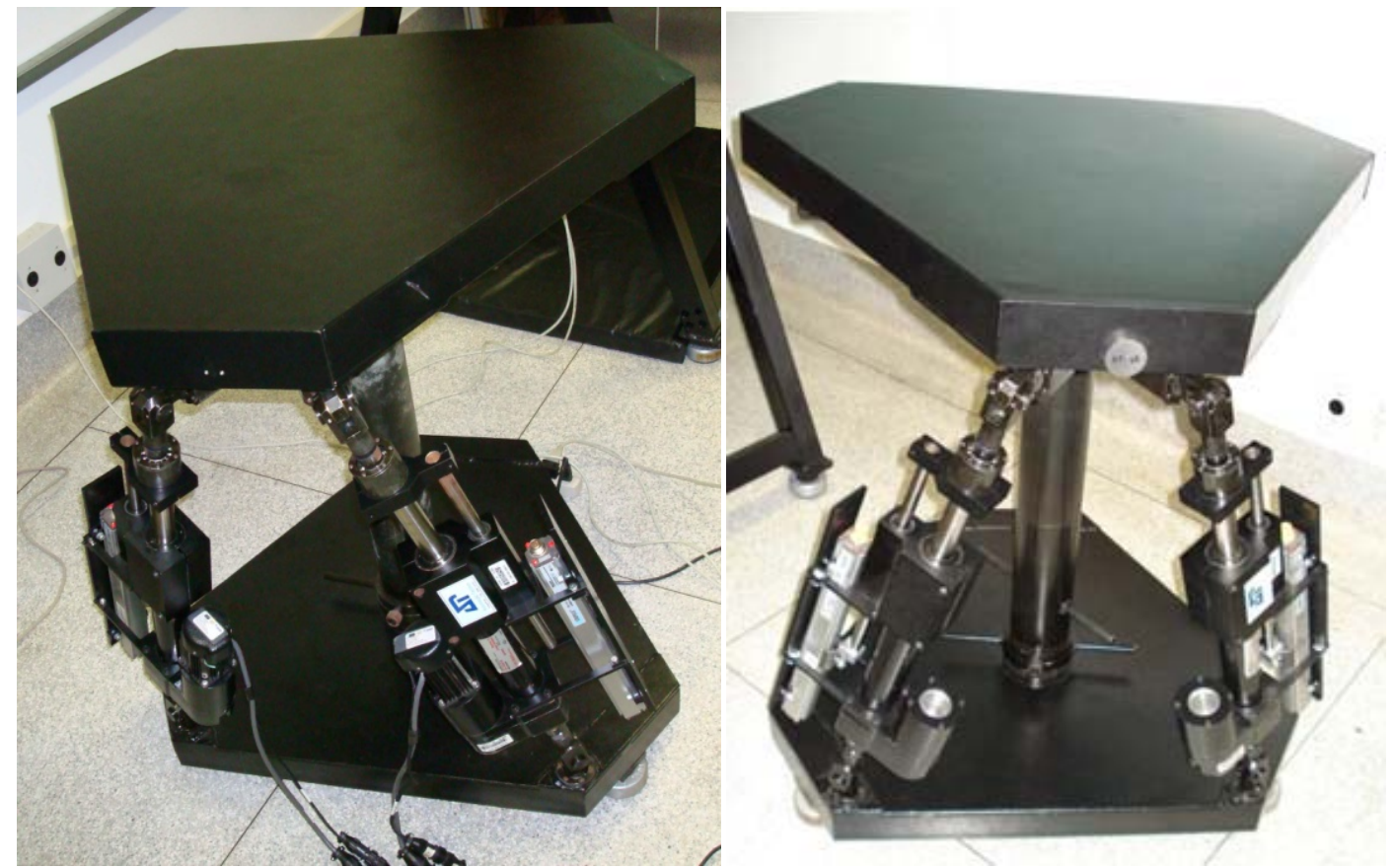

Figura 4.27 - Protótipo da plataforma de movimento com 2 G.D.L.

Foram montados diversos cabos para interligação de sensores, fontes de alimentação e placa de aquisição.

\subsubsection{Sistema de Aquisição de Dados e Controle}

O próximo passo foi terminar de validar os experimentos de identificação, para então identificar o protótipo e elaborar o sistema de controle do mesmo que deverá ser implementado utilizando a placa de aquisição DS1103 PPC Controller Board cujo fabricante é a $d S P A C E$, Inc. 


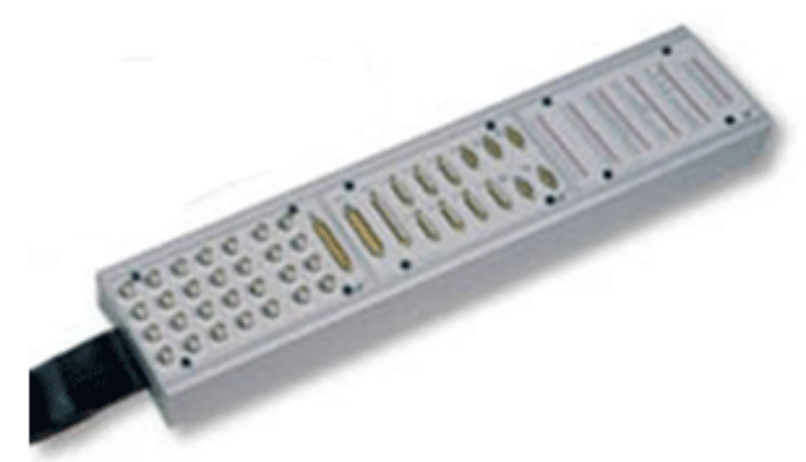

Figura 4.28 - Conectores da placa de aquisição e controle DS1103, dSPACE, Inc.

Através de um software control desk desenvolvido pela fabricante da placa e que trabalha juntamente com o MATLAB/Simulink foi implementado o sistema de controle, que pode ser feito através do modelo contínuo sem a necessidade de realizar a discretização. Além do mais é muito prático desenvolver instrumentos virtuais utilizando a placa DS1103 e o Control Desk, uma aplicação desta pode ser vista na Figura 4.29.

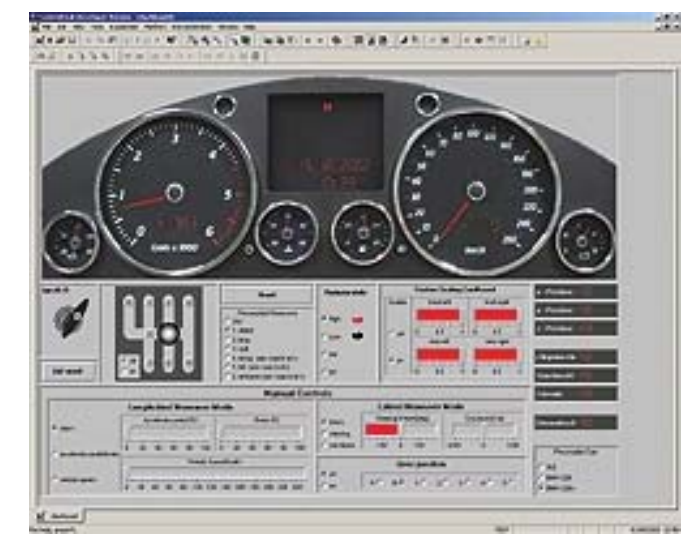

Figura 4.29 - Exemplo de painel de controle elaborado utilizando o Control Desk desenvolvido pela $d S P A C E$, Inc. 


\section{IDENTIFICAÇÃO DAS CARACTERÍSTICAS INERCIAIS DOS ELOS DA PLATAFORMA DE MOVIMENTO}

\subsection{Identificação das Características Inerciais dos Elos que Compõem o Atuador}

O atuador é formado, principalmente, por duas partes unidas por um fuso de esferas, que não podem ser desacopladas para determinação de suas características inerciais de forma independente. Uma vez, que a utilização de duas medições, em posições relativas diferentes, dos elos se mostrou uma solução indeterminada, optou-se por separar um elo do outro. O atuador será desmontado, separando a haste, do corpo do atuador sem danificar o equipamento.

Verificou-se que a única parte do corpo que não pode ser separada da haste é o eixo do fuso de esferas. Portanto, serão realizados os ensaios da haste com o eixo do fuso de esferas e, posteriormente, o mesmo será modelado através das suas características dimensionais, de forma aproximada, e da sua massa. A partir daí, pode-se determinar as características inerciais da haste. De posse, destas e das características do atuador, como um todo, é possível determinar as características inerciais do corpo do atuador. Finalizando, assim, a identificação dos elos que compõem o atuador.

A haste está ligada ao garfo através de uma junta de rotação no modelo virtual no $A D A M S^{\circledR}$ representando um mancal de rolamentos no modelo real. $\mathrm{O}$ mancal da plataforma está ligado ao eixo do mancal, também por uma junta de rotação no protótipo virtual e por rolamentos na plataforma real. O eixo do mancal da plataforma se conecta ao garfo da haste no $A D A M S^{\circledR}$ através de uma junta de rotação e na plataforma por uma bucha de bronze, devido à impossibilidade de se utilizar rolamentos, e ao espaço disponível. Considerando os três graus de rotação e a configuração das juntas de rotação, o conjunto equivale a uma junta esférica ligando a haste ao mancal da plataforma. O corpo do atuador está ligado à plataforma fixa por uma junta universal no modelo virtual e por um sistema parecido com o descrito anteriormente, só que, com um mancal de rolamento e outro de bucha de bronze de rotação que equivalem a uma junta universal no modelo real. 


\subsubsection{Identificação das Características Inerciais da Haste do Atuador}

O primeiro procedimento é determinar as coordenadas $x$ e $y$ do centro de massa do conjunto haste mais eixo do fuso de esferas, através de duas medições das reações estáticas, defasadas de $90^{\circ}$ uma da outra (Figura 5.1). Com mais uma medição das reações estáticas para uma posição relativa diferente entre os elos que compõem o conjunto, pode-se determinar as massas das partes. Utilizar-se-á a denominação de parte " $E$ " para o eixo do fuso de esferas e parte " $H$ " para a haste do atuador.

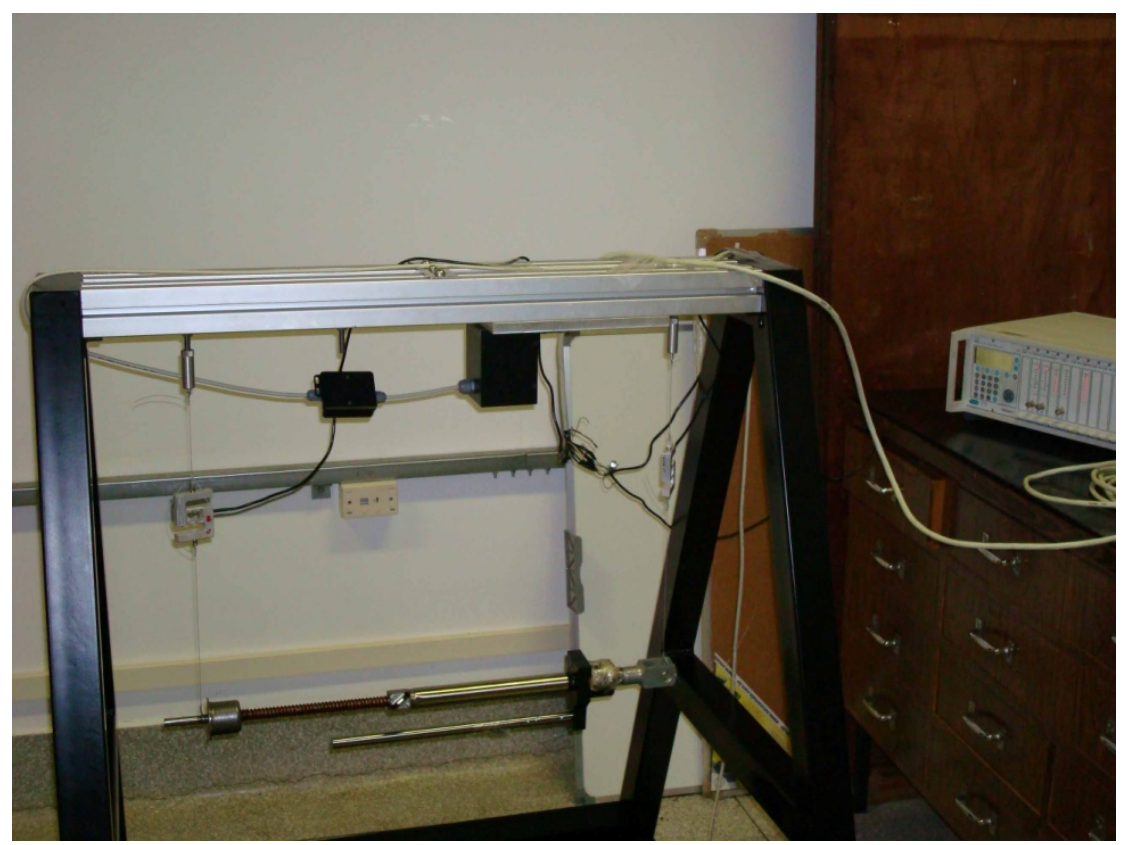

Figura 5.1 - Ensaio para determinação do centro de massa da haste, coordenada $y$, através de reações estáticas

Tabela 5.1 - Resultados do ensaio de reações estáticas.

\begin{tabular}{c|c|c|c|c}
\hline Posição & P1 $(\mathrm{kg})$ & P2 $(\mathrm{kg})$ & $\mathrm{d}(\mathrm{m})$ & Medida obtida \\
\hline 1 & 1,4496 & 1,4701 & 0,460 & $y=0,2316 \mathrm{~m}$ \\
\hline 2 & 2,3748 & 0,5282 & 0,0733 & $x=0,0133 \mathrm{~m}$ \\
\hline 3 & 1,6498 & 1,2646 & 0,6584 & $m_{H}=2,1239 \mathrm{~kg}$ \\
\hline
\end{tabular}

A determinação do centro de massa do atuador pode ser definido, através do sistema de coordenadas adotado, como

$\bar{x}_{H}=0,0133 m$ 
$\bar{y}_{H}=-0,2316 m$

Para a determinação dos momentos de inércia baricentrais realizam-se dois ensaios para se obter os períodos de oscilação da peça, um em relação ao eixo $x$, e outro em relação ao eixo $z$. Os eixos $x$ e $y$ estão contidos no plano de simetria da peça e o eixo $z$ é perpendicular ao plano de simetria (Figura 5.2).

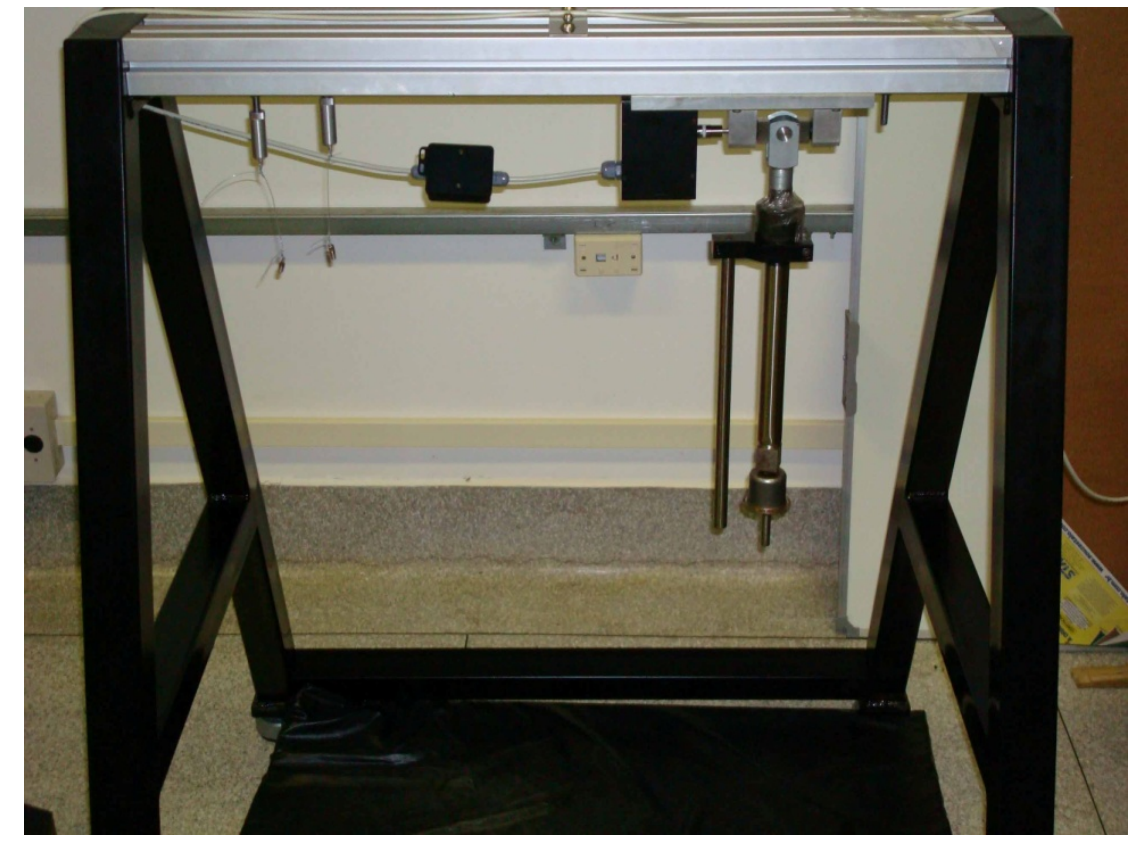

Figura 5.2 - Ensaio da haste do atuador para determinação do momento de inércia em $x$.

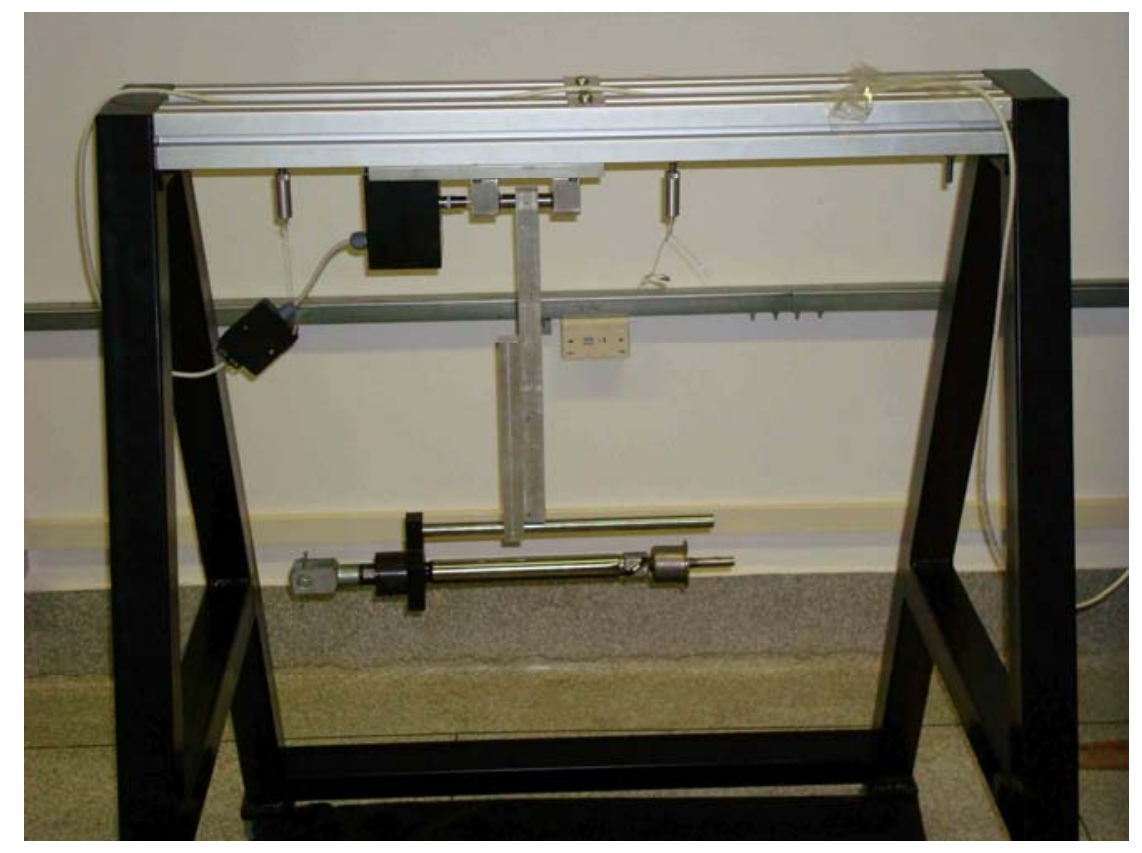

Figura 5.3 - Ensaio da haste do atuador para determinação do momento de inércia em $y$ 
Tabela 5.2 - Resultados dos ensaios de momento de inércia.

\begin{tabular}{c|c|c|c}
\hline Eixo & Período $(s)$ & $I_{o}\left(\mathrm{~kg}^{2} \mathrm{~m}^{2}\right)$ & $I_{\text {eixo }}\left(\mathrm{kg} \cdot \mathrm{m}^{2}\right)$ \\
\hline$x$ & 1,1441 & 0,219241 & 0,063080 \\
\hline$z$ & 1,1493 & 0.221603 & 0,064927 \\
\hline$y$ & -- & -- & 0,005600 \\
\hline
\end{tabular}

Dado o valor determinado para o momento de inércia em $y$, da haste do atuador, utilizando o suporte mostrado na Figura 5.3, resolveu-se investigar melhor, já que tal ensaio não havia sido validado no capítulo 4 . O resultado de tal investigação será mostrado mais adiante.

Para determinação dos eixos principais baricentrais de inércia é necessário realizar uma medição de momento de inércia do conjunto, para um eixo $O L$ contido no plano de simetria, e com um ângulo conhecido em relação às medições anteriores. Assim, conhecendose $I_{O L}, I_{x}, I_{y}$ e os cossenos diretores $\lambda_{x}, \lambda_{y}$, aplicando-os à equação (4.38) é possível determinar o produto de inércia, e pela teoria do círculo de Mohr determina-se os momentos principais e a sua orientação $\alpha$.

Tabela 5.3 - Resultados dos ensaios de momento de inércia, da haste, em relação a um ângulo.

\begin{tabular}{c|c|c|c|c|c}
\hline Âng. & $I_{O L}\left(\mathrm{~kg} \cdot \mathrm{m}^{2}\right)$ & $I_{x y}\left(\mathrm{~kg} \cdot \mathrm{m}^{2}\right)$ & $I_{\operatorname{máx}}\left(\mathrm{kg} \cdot \mathrm{m}^{2}\right)$ & $I_{\min }\left(\mathrm{kg} \cdot \mathrm{m}^{2}\right)$ & $\alpha\left(^{\circ}\right)$ \\
\hline $58,4^{\circ}$ & 0,044946 & $-0,002635$ & 0,063201 & 0,005479 & 2,6197 \\
\hline $63,3^{\circ}$ & 0,049699 & $-0,002212$ & 0,063165 & 0,005515 & 2,2007 \\
\hline $116,9^{\circ}$ & 0,051467 & $-0,000189$ & 0,063081 & 0,005599 & 0,0188 \\
\hline $120,7^{\circ}$ & 0,048033 & 0,000073 & 0,063085 & 0,005599 & $-0,0729$ \\
\hline
\end{tabular}

Pode-se observar que as medições à direita e à esquerda da posição vertical da haste, convergiram para valores diferentes. Ou seja, as medições à direita convergiram para um ângulo em torno de $2,4^{\circ}$ e as medições à esquerda convergiram para um valor em torno de $0,04^{\circ}$. Acredita-se que a imprecisão esteja relacionada ao valor obtido para o momento de inércia da haste em $y$. Com o intuito solucionar tal questão, resolveu-se utilizar uma aproximação através do erro quadrático mínimo do ângulo $\alpha$, para determinar o valor do momento de inércia da haste em $y$. Para isso usaremos uma medição à esquerda e uma à direita considerando que o valor de $\alpha$ resultante para ambos deva ser o mais próximo possível.

Realizando o procedimento descrito anteriormente, e utilizando os valores obtidos através das medições com os ângulos de $63,3^{\circ}$ e $116,9^{\circ}$ chegou-se ao gráfico mostrado na 
Figura 5.4. O valor de $I_{y}$, encontrado para a haste, foi de $0,001596 \mathrm{~kg} \cdot \mathrm{m}^{2}$ e o valor do ângulo $\alpha$ de $1,1225^{\circ}$.

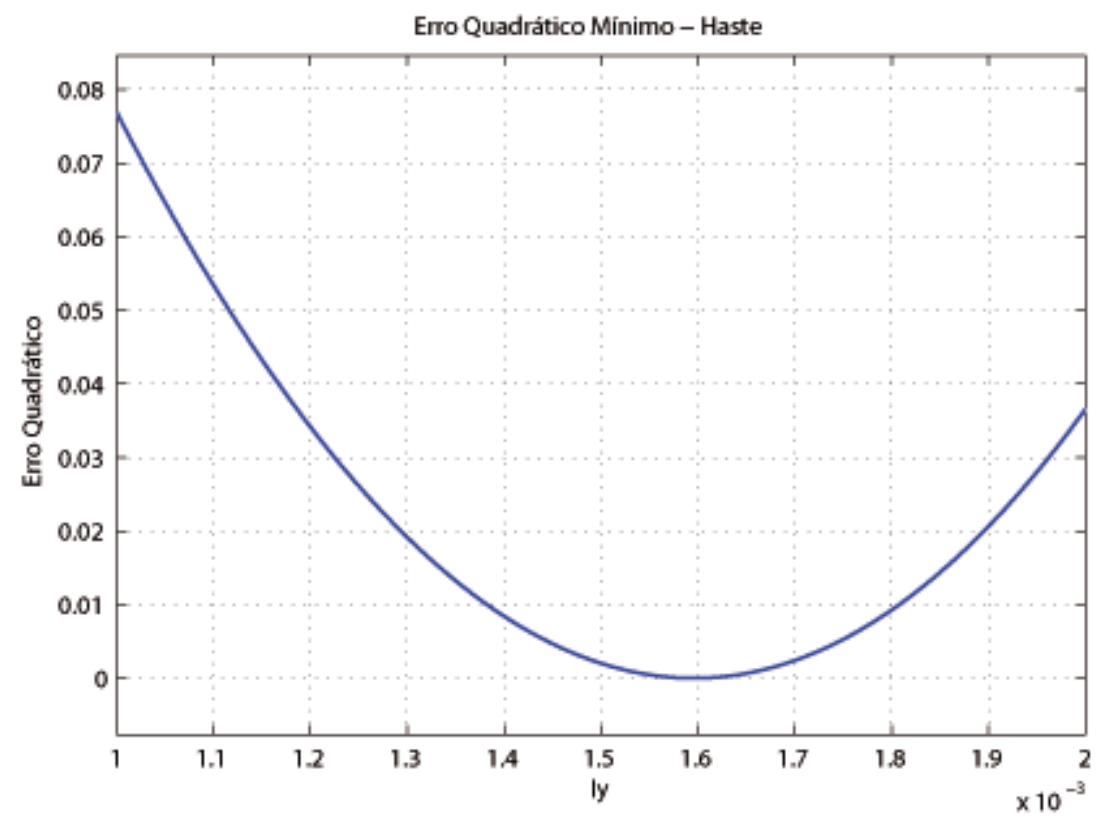

Figura 5.4 - Gráfico do erro quadrático mínimo para determinação do momento de inércia em $y$ da haste.

Tabela 5.4 - Resultados dos ensaios de momento de inércia, da haste, em relação a um ângulo.

\begin{tabular}{c|c|c|c|c|c}
\hline$\hat{A} n g$. & $I_{O L}\left(\mathrm{~kg} \cdot \mathrm{m}^{2}\right)$ & $I_{x y}\left(\mathrm{~kg} \cdot \mathrm{m}^{2}\right)$ & $I_{\text {máx }}\left(\mathrm{kg} \cdot \mathrm{m}^{2}\right)$ & $I_{\min }\left(\mathrm{kg} \cdot \mathrm{m}^{2}\right)$ & $\alpha\left(^{\circ}\right)$ \\
\hline 58,4 & 0,044946 & $-0,0014039$ & 0,063112 & 0,001563 & 1,3073 \\
\hline $63,3^{\mathrm{o}}$ & 0,049699 & $-0,0012052$ & 0,063104 & 0,001572 & 1,1225 \\
\hline 116,9 & 0,051467 & $-0,0012052$ & 0,063104 & 0,001572 & 1,1225 \\
\hline 120,7 & 0,048033 & $-0,0011155$ & 0,063101 & 0,001575 & 1,0391 \\
\hline
\end{tabular}

Obtiveram-se valores próximos para os produtos de inércia em todas as medições com ângulos de inclinação próximos. Os resultados foram considerados satisfatórios e a variação de aproximadamente $0,18^{\circ}$ entre as medições, pouco significativa. Serão adotados os valores médios para $I_{m a ́ x}, I_{m i ́ n}$ e $\alpha$, como correspondentes aos valores e orientação dos eixos dos momentos principais baricentrais de inércia para o conjunto da haste mais o eixo do fuso de esferas como mostrado na Tabela 5.5.

Tabela 5.5 - Características inerciais da haste no plano $x y$.

\begin{tabular}{c|c|c|c|c|c|c}
\hline$m(\mathrm{~kg})$ & $\bar{x}_{H}(\mathrm{~m})$ & $\bar{y}_{H}(\mathrm{~m})$ & $I_{x y}\left(\mathrm{~kg} \cdot \mathrm{m}^{2}\right)$ & $I_{\operatorname{máx}}\left(\mathrm{kg} \cdot \mathrm{m}^{2}\right)$ & $I_{\min }\left(\mathrm{kg} \cdot \mathrm{m}^{2}\right)$ & $\alpha\left(^{\circ}\right)$ \\
\hline 2,91135 & 0,0133 & $-0,2316$ & $-0,0012052$ & 0,063104 & 0,001572 & 1,1225 \\
\hline
\end{tabular}




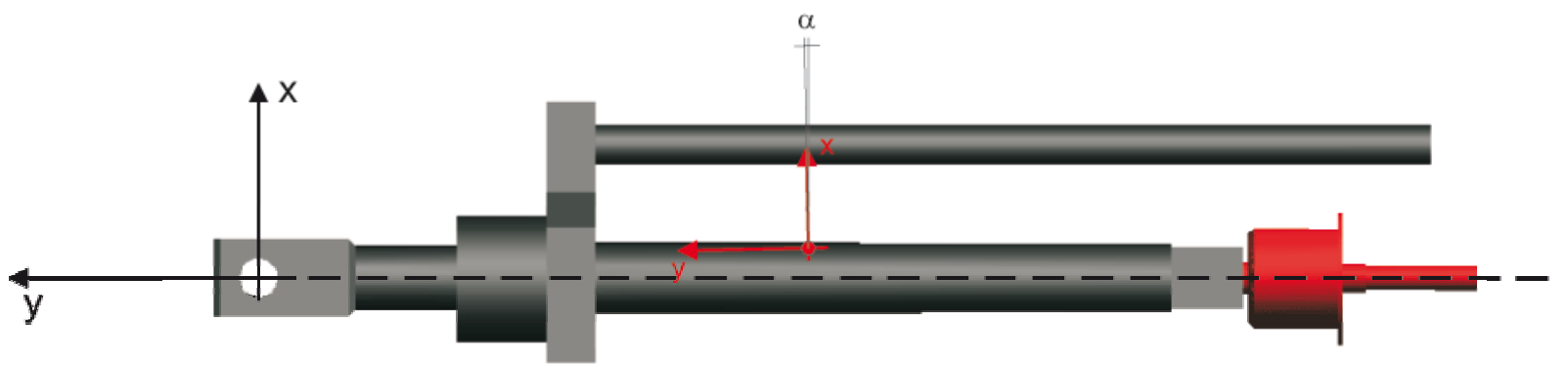

Figura 5.5 - Posicionamento do centro de massa e dos eixos principais de inércia da haste mais o eixo do fuso de esferas.

Tabela 5.6 - Características inerciais do eixo do fuso de esferas obtidas através do $A D A M S^{\circledR}$.

\begin{tabular}{c|c|c|c|c|c|c}
\hline$m(\mathrm{~kg})$ & $\bar{x}_{E}(m)$ & $\bar{y}_{E}(m)$ & $I_{x y}\left(\mathrm{~kg} \cdot \mathrm{m}^{2}\right)$ & $I_{x}\left(\mathrm{~kg} \cdot \mathrm{m}^{2}\right)$ & $I_{y}\left(\mathrm{~kg} \cdot \mathrm{m}^{2}\right)$ & $I_{z}\left(\mathrm{~kg} \cdot \mathrm{m}^{2}\right)$ \\
\hline 0,7958 & 0,0 & 0,1318 & 0,0 & 0,006056 & 0,000120 & 0,006056 \\
\hline
\end{tabular}

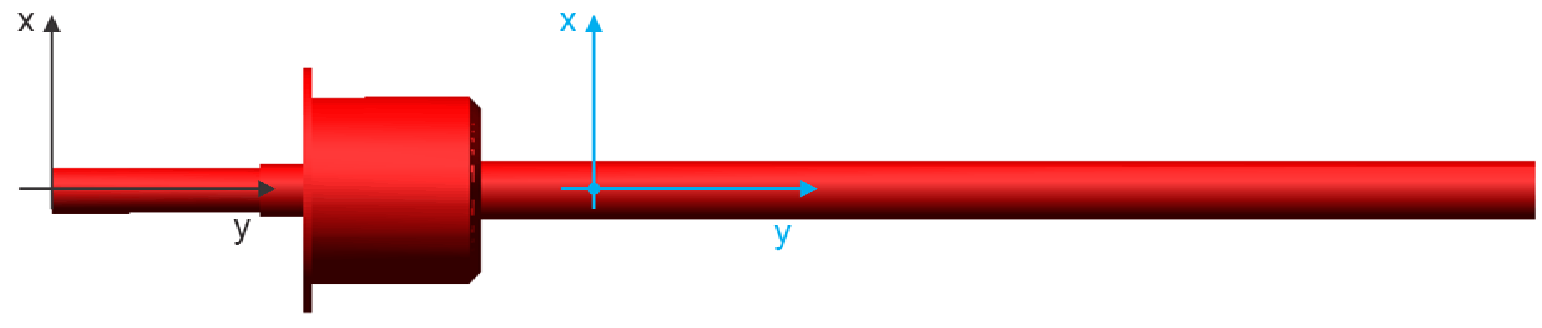

Figura 5.6 - Posicionamento do centro de massa e dos eixos principais de inércia do eixo do fuso de esferas

Tabela 5.7 - Características inerciais do garfo da haste obtidas através do $A D A M S^{\circledR}$.

\begin{tabular}{c|c|c|c|c|c|c}
\hline$m(\mathrm{~kg})$ & $\bar{x}_{G}(\mathrm{~m})$ & $\bar{y}_{G}(\mathrm{~m})$ & $I_{x y}\left(\mathrm{~kg} \cdot \mathrm{m}^{2}\right)$ & $I_{x}\left(\mathrm{~kg} \cdot \mathrm{m}^{2}\right)$ & $I_{y}\left(\mathrm{~kg} \cdot \mathrm{m}^{2}\right)$ & $I_{z}\left(\mathrm{~kg} \cdot \mathrm{m}^{2}\right)$ \\
\hline 0,4630 & 0,0 & $-0,0423$ & 0,0 & 0,0005512 & 0,000070 & 0,0005419 \\
\hline
\end{tabular}

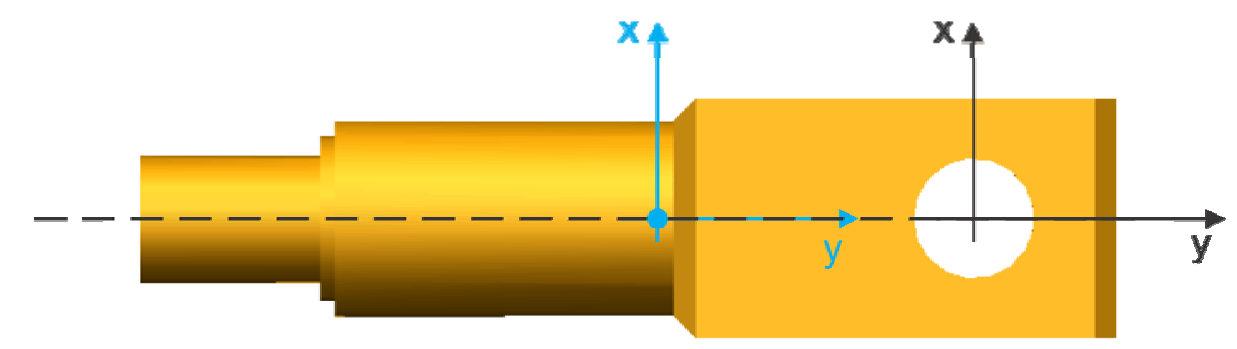

Figura 5.7 - Posicionamento do centro de massa e dos eixos principais de inércia do garfo da haste. 


\subsubsection{Identificação das Características Inerciais do Atuador}

Assim como no caso da haste, o procedimento para identificação do atuador começa pela determinação das coordenadas $x$ e $y$ do centro de massa, através de duas medições das reações estáticas, defasadas de $90^{\circ}$ uma da outra (Figura 5.5). Todos os ensaios serão realizados para o atuador com um curso de $-91,125 \mathrm{~mm}$.

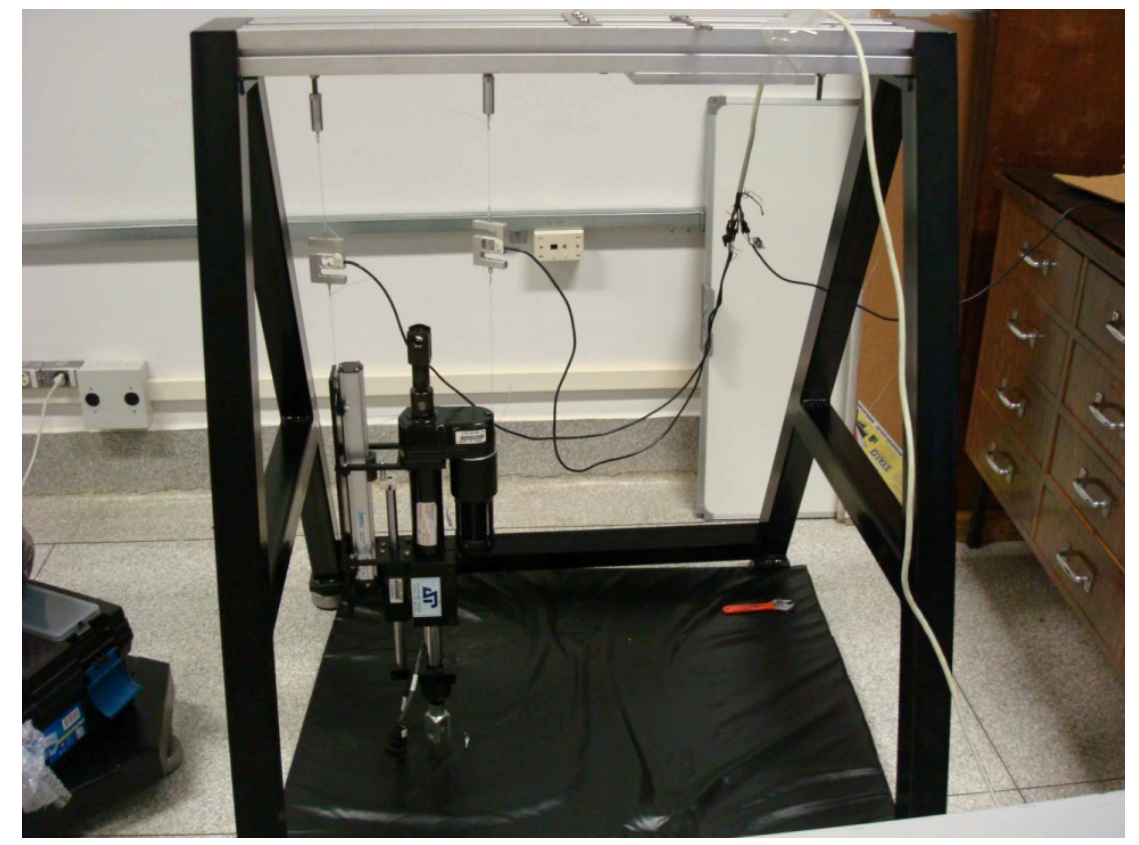

Figura 5.8 - Ensaio para determinação do centro de massa do atuador, coordenada $x$, através de reações estáticas.

Tabela 5.8 - Resultados dos ensaios de reações estáticas

\begin{tabular}{c|c|c|c|c}
\hline Posição & P1 $(\mathrm{kg})$ & P2 $(\mathrm{kg})$ & $\mathrm{d}(\mathrm{m})$ & Medida obtida \\
\hline 1 & 5,1089 & 5,9525 & 0,2290 & $x=0,1773$ \\
\hline 2 & 5,2155 & 5,7408 & 0,3724 & $y=0,1058$ \\
\hline
\end{tabular}

A posição do centro de massa do atuador pode ser encontrada, através do sistema de coordenadas adotado, sendo

$\bar{x}_{A}=x-0,10922 \therefore \bar{x}_{A}=-0,0035 m$

$\bar{y}_{A}=-(y+0,117) \therefore \bar{y}_{A}=-0,2943 m$ 
Para a determinação dos momentos de inércia baricentrais realizam-se dois ensaios para se obter os períodos de oscilação da peça, um em relação ao eixo $x$, e outro em relação ao eixo $z$, como no caso da haste. Os eixos $x$ e $y$ estão contidos no plano de simetria da peça e o eixo $z$ é perpendicular ao plano de simetria (Figura 5.6).

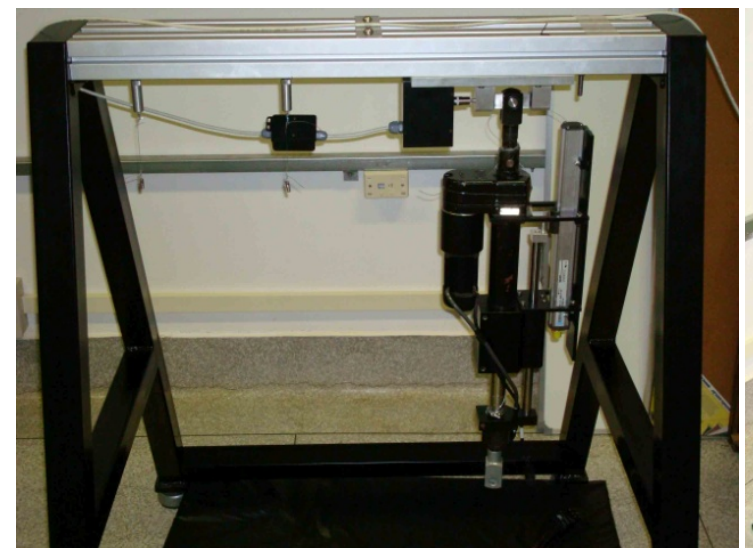

(a)

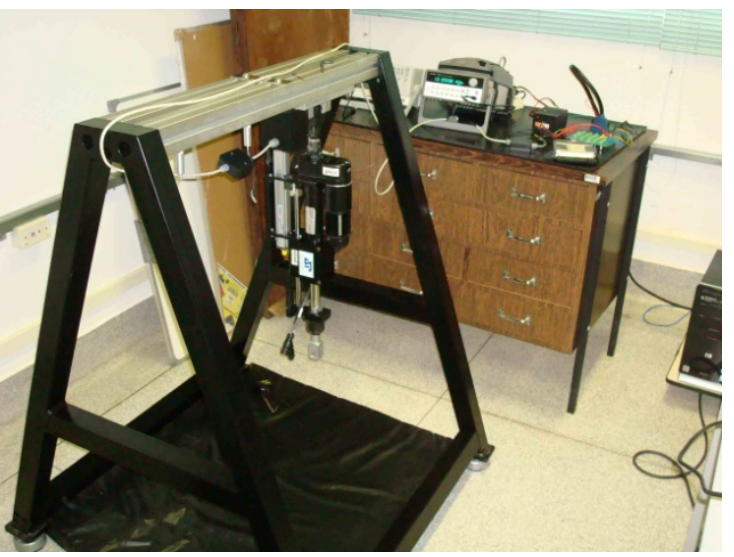

(b)

Figura 5.9 - Ensaio do atuador (a) para determinação do momento de inércia em $x$, (b) para determinação do momento de inércia em $z$.

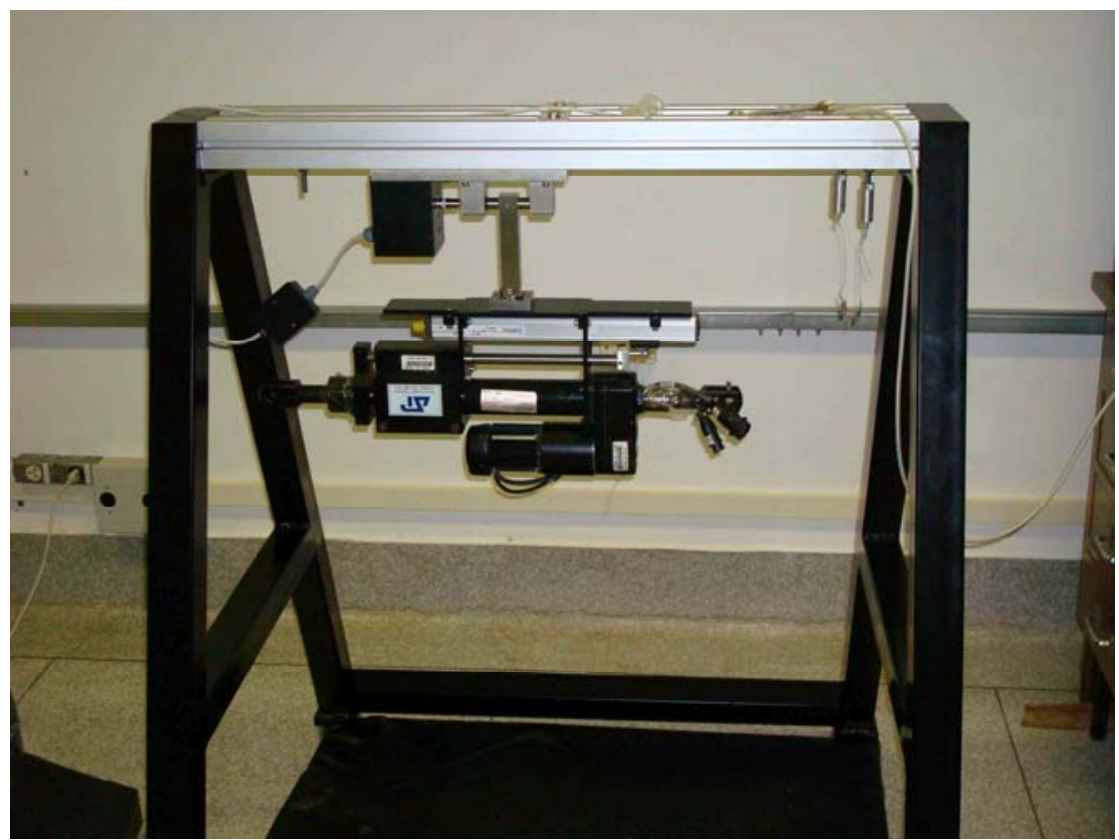

Figura 5.10 - Ensaio do atuador para determinação do momento de inércia em y

Para determinação dos eixos principais baricentrais de inércia será necessário realizar uma medição de momento de inércia do atuador, para um eixo $O L$ contido no plano de simetria e que possua um ângulo conhecido em relação às medições anteriores. Assim, conhecendo-se os momentos de inércias $I_{O L}, I_{x}, I_{y}$, os cossenos diretores $\lambda_{x}, \lambda_{y}$, aplicados à 
equação (4.38) é possível determinar o produto de inércia, e pela teoria do círculo de Mohr determinam-se os momentos principais e a sua orientação $\alpha$.

Tabela 5.9 - Resultados dos ensaios de momento de inércia.

\begin{tabular}{c|c|c|c}
\hline Eixo & Período $(\mathrm{s})$ & $I_{o}\left(\mathrm{~kg} \cdot \mathrm{m}^{2}\right)$ & $I_{\text {eixo }}\left(\mathrm{kg} \cdot \mathrm{m}^{2}\right)$ \\
\hline$x$ & 1,2210 & 1,199843 & 0,246339 \\
\hline$z$ & 1,2365 & 1,230586 & 0,276947 \\
\hline$y$ & -- & -- & 0,041200 \\
\hline
\end{tabular}

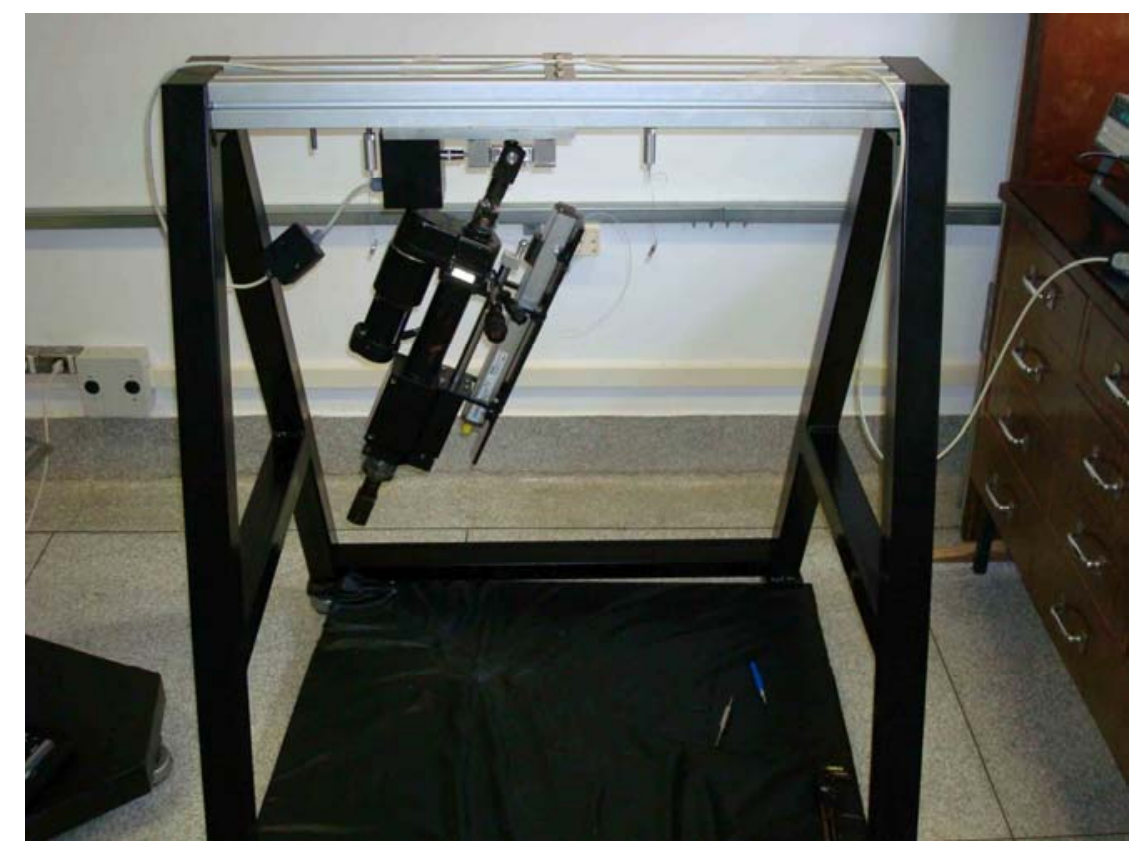

Figura 5.11 - Ensaio do atuador para determinação do momento de inércia para o eixo OL.

Tabela 5.10 - Resultados dos ensaios de momentos de inércia em relação a um ângulo.

\begin{tabular}{c|c|c|c|c|c}
\hline Âng. & $I_{O L}\left(\mathrm{~kg} \cdot \mathrm{m}^{2}\right)$ & $I_{x y}\left(\mathrm{~kg} \cdot \mathrm{m}^{2}\right)$ & $I_{\operatorname{máx}}\left(\mathrm{kg} \cdot \mathrm{m}^{2}\right)$ & $I_{\min }\left(\mathrm{kg} \cdot \mathrm{m}^{2}\right)$ & $\alpha\left(^{\circ}\right)$ \\
\hline $59,7^{\circ}$ & 0,182193 & $-0,013746$ & 0,247322 & 0,040283 & 3,8155 \\
\hline $113^{\circ}$ & 0,224111 & $-0,012559$ & 0,247170 & 0,040434 & 3,4894 \\
\hline
\end{tabular}

Embora as medições, à esquerda e à direita da posição vertical do atuador, tenham resultado em valores de $\alpha$ muito próximos, se realizará o mesmo procedimento utilizado para a determinação do $I_{y}$ da haste, sabendo-se que a inserção de um suporte aumenta significativamente o erro de medição do momento de inércia.

Realizando o procedimento descrito anteriormente, e utilizando os valores obtidos através das medições com os ângulos de 59, $7^{\circ}$ e $113^{\circ}$ chegamos ao gráfico mostrado na Figura 
5.12. O valor de $I_{y}$, encontrado para o atuador, foi de $0,03885 \mathrm{~kg} \cdot \mathrm{m}^{2}$ e o valor do ângulo $\alpha$ de $3,5862^{\circ}$.

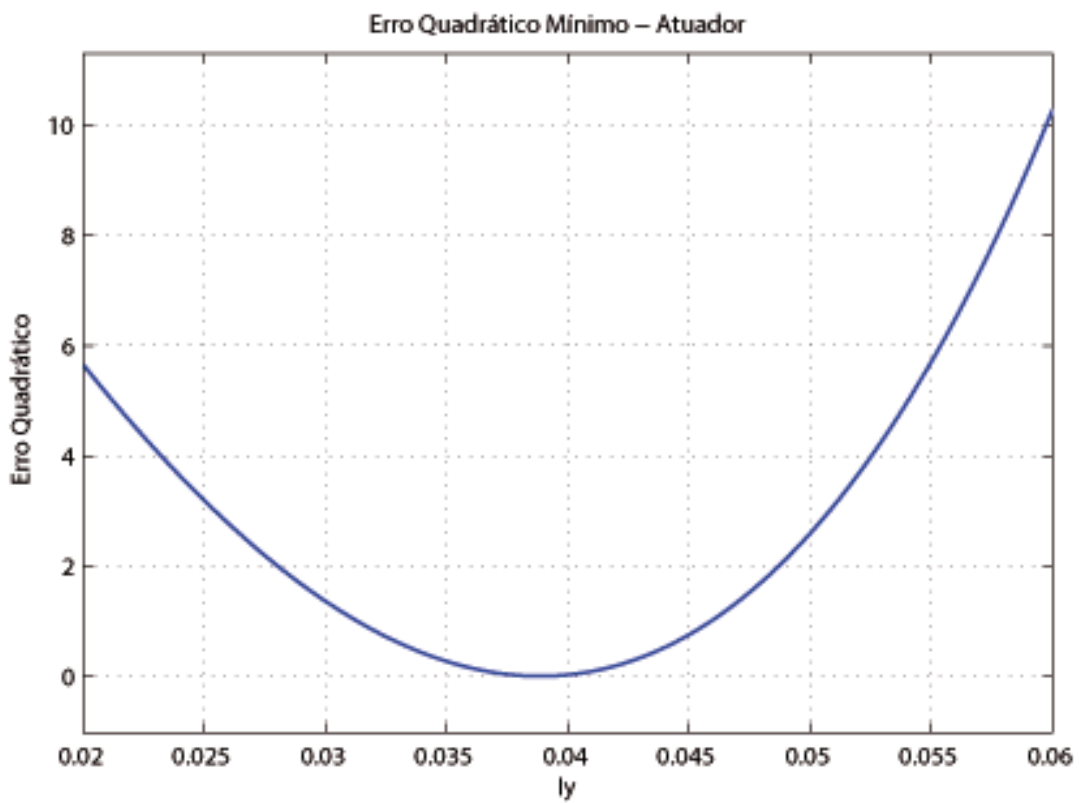

Figura 5.12 - Gráfico do erro quadrático mínimo para determinação do momento de inércia em $y$ do atuador.

Tabela 5.11 - Resultados dos ensaios de momentos de inércia em relação a um ângulo.

\begin{tabular}{c|c|c|c|c|c}
\hline$\hat{\text { Ang. }}$ & $I_{O L}\left(\mathrm{~kg} \cdot \mathrm{m}^{2}\right)$ & $I_{x y}\left(\mathrm{~kg} \cdot \mathrm{m}^{2}\right)$ & $I_{\text {máx }}\left(\mathrm{kg} \cdot \mathrm{m}^{2}\right)$ & $I_{\min }\left(\mathrm{kg} \cdot \mathrm{m}^{2}\right)$ & $\alpha\left(^{\circ}\right)$ \\
\hline $59,7^{\circ}$ & 0,182193 & $-0,013060$ & 0,247224 & 0,038031 & 3,5864 \\
\hline $113^{\circ}$ & 0,224111 & $-0,013059$ & 0,247223 & 0,038032 & 3,5860 \\
\hline
\end{tabular}

Os resultados foram considerados satisfatórios e as variações entre as medições, pouco significativas. Serão adotados os valores médios para $I_{\text {máx }}, I_{\text {mín }}$ e $\alpha$, como correspondentes aos valores e orientação dos eixos dos momentos principais baricentrais de inércia para o atuador como mostrado na Tabela 5.11.

Tabela 5.12 - Características inerciais do atuador no plano $x y$.

\begin{tabular}{c|c|c|c|c|c|c}
\hline$m(k g)$ & $\bar{x}_{A}(m)$ & $\bar{y}_{A}(m)$ & $I_{x y}\left(k g \cdot m^{2}\right)$ & $I_{\max }\left(k g \cdot m^{2}\right)$ & $I_{\min }\left(k g \cdot m^{2}\right)$ & $\alpha\left(^{\circ}\right)$ \\
\hline 11,00885 & $-0,0035$ & $-0,2943$ & $-0,013060$ & 0,247224 & 0,038032 & 3,5862 \\
\hline
\end{tabular}




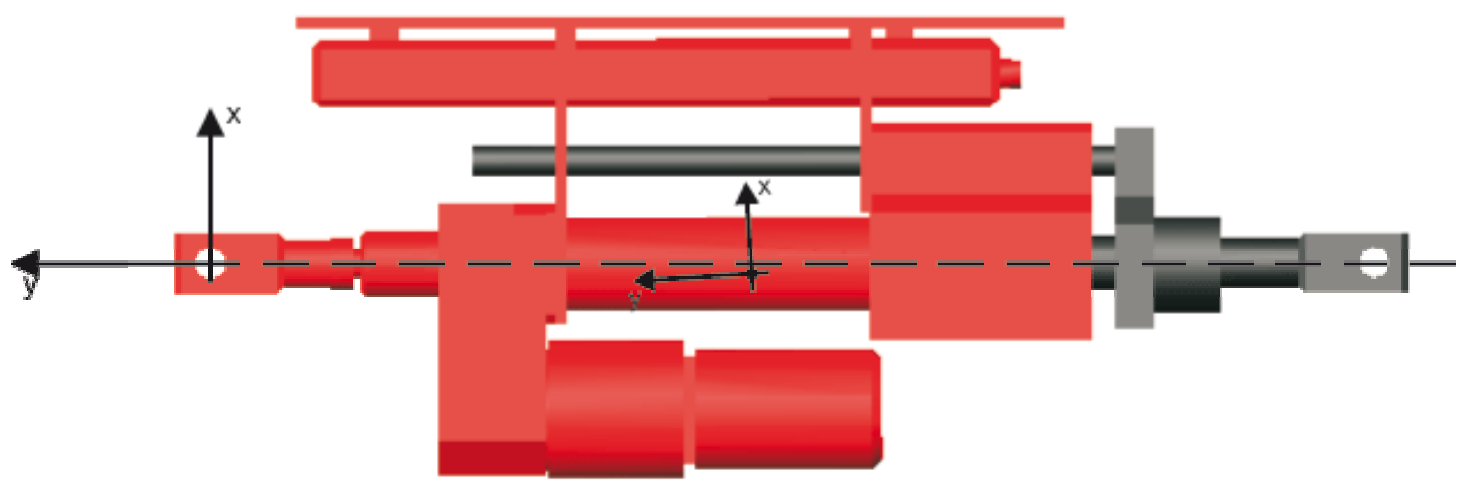

Figura 5.13 - Posicionamento do centro de massa e dos eixos principais de inércia do atuador para o curso utilizado nos ensaios.

\subsubsection{Identificação das Características Inerciais da Plataforma Móvel}

Devido à plataforma móvel possuir formas geométricas simples e ser constituída de um único material, opta-se por determinar suas características inerciais através da utilização de software de CAD, a partir dos desenhos de processo de fabricação. Acredita-se, que essa seja uma ótima aproximação para peças homogêneas e de formas simples. Como alguns materiais possuem significativa variação na sua densidade, o que não é o caso do aço 1020 , recomenda-se uma pesagem da peça para servir de referência e corrigir variações de densidade do material real e o teórico adotado. A plataforma móvel foi modelada no software de sistemas multicorpos $A D A M S^{\circledR}$ que forneceu os momentos de inércia principais baricentrais, assim como a posição do centro de massa.

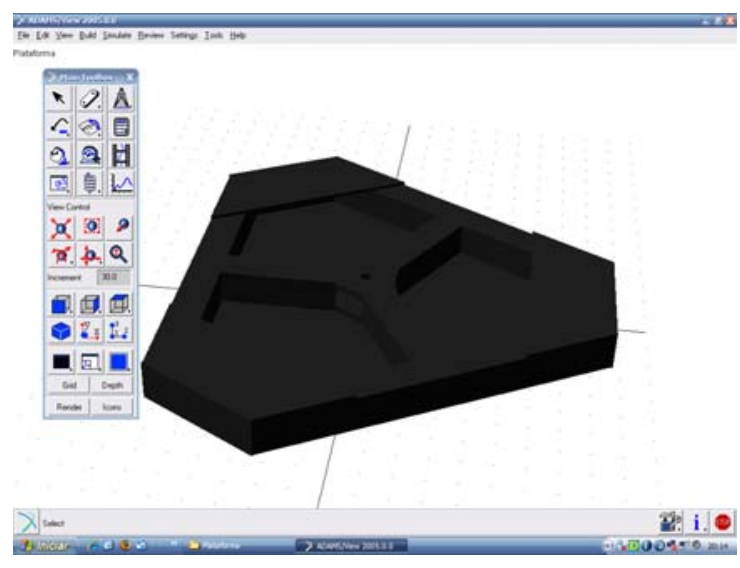

(a)

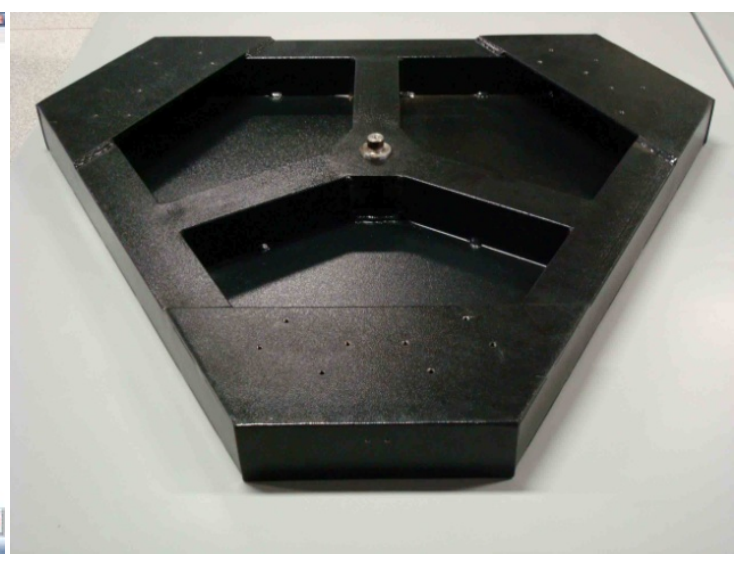

(b)

Figura 5.14 - Plataforma: (a) modelada no $A D A M S^{\circledR}$ (b) real. 
Tabela 5.13 - Momentos e produtos de inércia da plataforma móvel, obtidos através do $A D A M S^{\circledR}$ em $\left(k g \cdot m^{2}\right)$.

\begin{tabular}{c|c|c|c|c|c}
\hline$I_{x}$ & $I_{y}$ & $I_{z}$ & $I_{x y}$ & $I_{z x}$ & $I_{y z}$ \\
\hline 3,063311 & 1,556486 & 1,556463 & 0,0 & 0,0 & 0,0 \\
\hline
\end{tabular}

Pode-se observar, para este tipo de peça, que a utilização da geometria para a obtenção das características inerciais é uma excelente aproximação. A peça, da Figura 5.14(b), foi pesada numa balança eletrônica, com resolução de $10 \mathrm{~g}$ e capacidade máxima de $100 \mathrm{~kg}$, e a massa obtida foi de $30,140 \mathrm{~kg}$. Muito próximo do valor de $30,070 \mathrm{~kg}$ calculado pelo $A D A M S^{\circledR}$ considerando o material como sendo aço (TABELA 5.13).

Tabela 5.14 - Grandezas físicas da plataforma móvel.

\begin{tabular}{c|c|c|c|c|c}
\hline$\rho\left(\mathrm{kg} / \mathrm{m}^{3}\right)$ & Massa $(\mathrm{kg})$ & Volume $\left(\mathrm{m}^{3}\right)$ & $\bar{x}(\mathrm{~mm})$ & $\bar{y}(\mathrm{~mm})$ & $\bar{z}(\mathrm{~mm})$ \\
\hline 7801 & 30,070 & $3,854684.10^{-3}$ & 0,0 & 25,771317 & 0,0 \\
\hline
\end{tabular}




\section{SISTEMA DE CONTROLE}

\subsection{Sistema de Controle Seguidor com Realimentação de Estados}

O sistema linearizado de malha aberta é representado abaixo pelas equações de estado de $n$-ésima ordem e as equações de saída de $p$-ésima ordem.

$\dot{\boldsymbol{x}}=\boldsymbol{A x}+\boldsymbol{B u}$

$y=C x=\left[\begin{array}{l}E \\ F\end{array}\right] x$

onde $\boldsymbol{y}$ é um vetor $p \times 1$ e $\boldsymbol{w}=\boldsymbol{E} \boldsymbol{x}$ é um vetor $m \times 1$ representando as saídas que são requeridas para seguir o vetor de entrada $\boldsymbol{r}$.

O controle por realimentação de estados é projetado com o intuito de que o vetor $\boldsymbol{w}$ siga o comando de entrada $\boldsymbol{r}$ no sentido de que a resposta em regime seja

$\lim _{t \rightarrow \infty} \boldsymbol{w}(t)=\boldsymbol{r}(t)$

quando $\boldsymbol{r}$ é um comando de entrada constante por partes. Segundo D'Azzo e Houpis (1988) o método de projeto consiste em adicionar um vetor comparador e integrador que satisfaça a equação

$\dot{\mathbf{z}}=\boldsymbol{r}-\boldsymbol{w}=\boldsymbol{r}-\boldsymbol{E x}$.

O sistema de malha aberta composto é então governado pelas equações aumentadas de estado e saída formadas a partir das equações (6.1) a (6.4)

$\left[\begin{array}{c}\dot{x} \\ \dot{z}\end{array}\right]=\left[\begin{array}{cc}A & 0 \\ -E & 0\end{array}\right]\left[\begin{array}{l}x \\ z\end{array}\right]+\left[\begin{array}{l}B \\ 0\end{array}\right] u+\left[\begin{array}{l}0 \\ I\end{array}\right] r=\bar{A} x^{\prime}+\bar{B} u+\bar{B}^{\prime} r$

$y=\left[\begin{array}{ll}C & 0\end{array}\right]\left[\begin{array}{l}x \\ z\end{array}\right]=\bar{C} x^{\prime}$

onde 
$\bar{A}=\left[\begin{array}{cc}A & 0 \\ -E & 0\end{array}\right] ; \bar{B}=\left[\begin{array}{l}B \\ 0\end{array}\right] ; \bar{B}^{\prime}=\left[\begin{array}{l}0 \\ I\end{array}\right] ; \bar{C}=\left[\begin{array}{ll}C & 0\end{array}\right]$

D’Azzo e Houpis (1988) mostram que a lei de controle a ser usada é

$\boldsymbol{u}=\boldsymbol{K}_{1} \boldsymbol{x}+\boldsymbol{K}_{2} \boldsymbol{z}=\left[\begin{array}{ll}\boldsymbol{K}_{1} & \boldsymbol{K}_{2}\end{array}\right]\left[\begin{array}{l}\boldsymbol{x} \\ z\end{array}\right]$

$\overline{\boldsymbol{K}}=\left[\begin{array}{ll}\boldsymbol{K}_{1} & \boldsymbol{K}_{2}\end{array}\right]$

O diagrama que representa o sistema de controle por realimentação, consistindo das equações de estado e de saída dadas pelas equações (6.1) e (6.2) e a lei de controle dada pela equação (6.8), é mostrado na Figura 6.1.

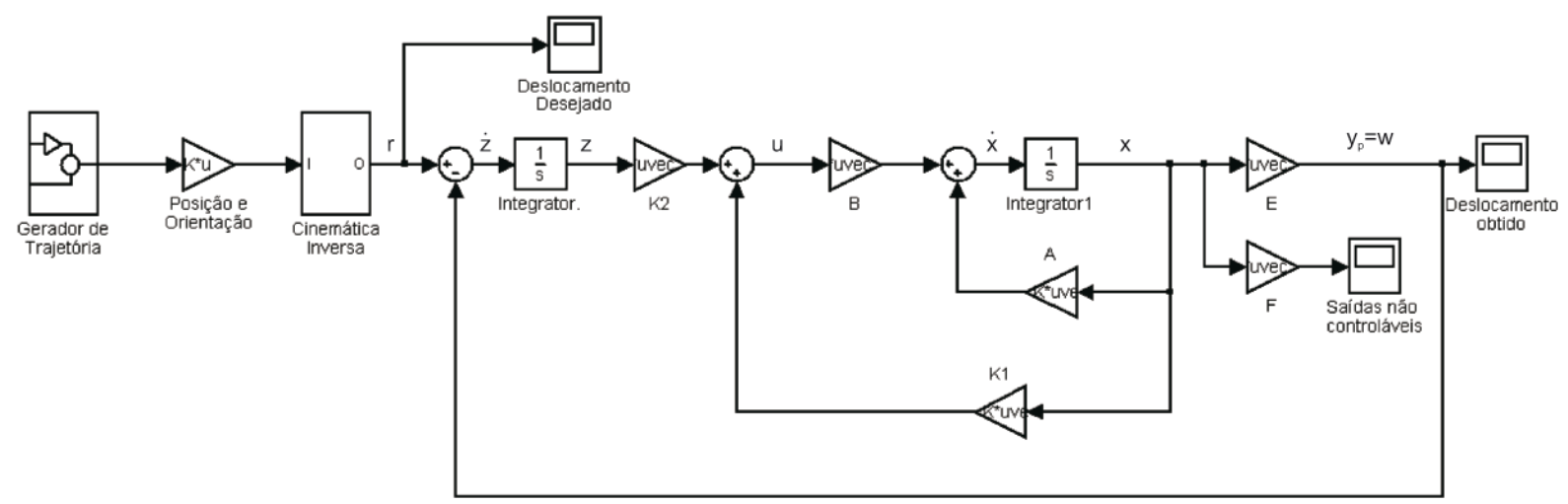

Figura 6.1 - Sistema de controle seguidor.

Esta lei de controle atribui o espectro de autovalores de malha fechada, se e somente se, a planta aumentada e o par de matrizes de controle $(\bar{A}, \bar{B})$ é controlável (D'AZZO; HOUPIS, 1988). Esta condição é satisfeita se $(\boldsymbol{A}, \boldsymbol{B})$ for um par controlável e o

posto $\left[\begin{array}{cc}\boldsymbol{B} & \boldsymbol{A} \\ \mathbf{0} & -\boldsymbol{E}\end{array}\right]=n+m$.

Para que $(\boldsymbol{A}, \boldsymbol{B})$ seja controlável é necessário que satisfaça a seguinte condição de controlabilidade

posto $\boldsymbol{M}_{c}=$ posto $\left[\boldsymbol{B} \quad \boldsymbol{A} \boldsymbol{B} \quad \boldsymbol{A}^{2} \boldsymbol{B} \ldots \boldsymbol{A}^{n-m} \boldsymbol{B}\right]=n$. 
As condições das equações (6.10) e (6.11) garantem que a lei de controle pode ser sintetizada tal que a saída da malha fechada $\boldsymbol{w}$ segue o comando de entrada $\boldsymbol{r}$. E neste caso a equação de malha fechada é

$\dot{\boldsymbol{x}}^{\prime}=\left[\begin{array}{c}\dot{\boldsymbol{x}} \\ \dot{\mathbf{z}}\end{array}\right]=\left[\begin{array}{cc}\boldsymbol{A}+\boldsymbol{B} \boldsymbol{K}_{2} & \boldsymbol{B} \boldsymbol{K}_{2} \\ -\boldsymbol{E} & \mathbf{0}\end{array}\right]\left[\begin{array}{l}\boldsymbol{x} \\ \boldsymbol{z}\end{array}\right]+\left[\begin{array}{l}\mathbf{0} \\ \boldsymbol{I}\end{array}\right] \boldsymbol{r}=\boldsymbol{A}_{c l}^{\prime} \boldsymbol{x}^{\prime}+\boldsymbol{B}^{\prime} \boldsymbol{r}$

A matriz de realimentação deve ser selecionada tal que os autovalores da matriz da planta de malha fechada estejam todos no semiplano complexo esquerdo.

A obtenção da matriz $\overline{\boldsymbol{K}}$ é realizada a partir da seleção dos autovalores a serem atribuídos à matriz da planta de malha fechada $\boldsymbol{A}_{c l}^{\prime}$ na equação (6.12)

$\sigma(\overline{\boldsymbol{A}}+\overline{\boldsymbol{B}} \overline{\boldsymbol{K}})=\left\{\lambda_{1}, \lambda_{2}, \ldots \lambda_{n+m}\right\}$

e um conjunto associado de autovetores

$\boldsymbol{v}(\overline{\boldsymbol{A}}+\overline{\boldsymbol{B}} \overline{\boldsymbol{K}})=\left\{\boldsymbol{v}_{1}, \quad \boldsymbol{v}_{2}, \ldots \boldsymbol{v}_{n+m}\right\}$

que são selecionados a fim de se obter as características de resposta no tempo desejadas. Os autovalores e autovetores são relacionados pela equação

$[\bar{A}+\bar{B} \bar{K}] v_{i}=\lambda_{i} v_{i}$

que pode ser colocada na forma

$\left[\begin{array}{ll}\overline{\boldsymbol{A}}-\lambda_{i} \boldsymbol{I} & \overline{\boldsymbol{B}}\end{array}\right]\left[\begin{array}{l}\boldsymbol{v}_{i} \\ \boldsymbol{g}_{i}\end{array}\right]=\mathbf{0} \quad$ para $i=1,2, \ldots n+m$

onde $\boldsymbol{v}_{\boldsymbol{i}}$ é o autovetor e

$\boldsymbol{g}_{i}=\overline{\boldsymbol{K}} \boldsymbol{v}_{i}$

Para satisfazer a equação (6.16), o vetor $\left[\boldsymbol{v}_{i}^{T} \boldsymbol{g}_{i}^{T}\right]^{T}$ deve pertencer ao kernel de

$\overline{\boldsymbol{S}}\left(\lambda_{i}\right)=\left[\begin{array}{ll}\overline{\boldsymbol{A}}-\lambda_{i} \boldsymbol{I} & \overline{\boldsymbol{B}}\end{array}\right] \quad$ para $i=1,2, \ldots n+m$.

A notação $\operatorname{ker} \boldsymbol{S}\left(\lambda_{i}\right)$ é usada para definir o espaço chamado de nulo que contém todos os vetores $\left[\boldsymbol{v}_{i}^{T} \boldsymbol{g}_{i}^{T}\right]^{T}$ para que a equação (6.16) seja satisfeita (D’AZZO; HOUPIS, 1988). A equação (6.17) pode ser usada para formar a igualdade matricial 
$\left[\begin{array}{llll}\boldsymbol{g}_{1} & \boldsymbol{g}_{2} & \ldots & \boldsymbol{g}_{n+m}\end{array}\right]=\left[\begin{array}{lllll}\overline{\boldsymbol{K}} \boldsymbol{v}_{1} & \overline{\boldsymbol{K}} \boldsymbol{v}_{2} & \ldots & \overline{\boldsymbol{K}} \boldsymbol{v}_{n+m}\end{array}\right]$

donde se obtém a matriz $\overline{\boldsymbol{K}}$ como segue:

$\overline{\boldsymbol{K}}=\left[\begin{array}{llll}\boldsymbol{g}_{1} & \boldsymbol{g}_{2} & \ldots & \boldsymbol{g}_{n+m}\end{array}\right]\left[\begin{array}{llll}\boldsymbol{v}_{1} & \boldsymbol{v}_{2} & \ldots & \boldsymbol{v}_{n+m}\end{array}\right]^{-1}=\boldsymbol{Q} \boldsymbol{V}^{-1}$

Observa-se que os autovalores podem ter valores repetidos de número igual às entradas do sistema. Isso se deve ao fato do espaço nulo ter dimensão igual ao número de entradas. Assim associa-se um autovalor repetido a um vetor da base do espaço nulo. Com isso, todas as colunas da matriz $\boldsymbol{V}$ continuam sendo linearmente independentes e, por isso, a matriz $\boldsymbol{V}^{-1}$ existe.

$\mathrm{Na}$ síntese do controle por realimentação de estados, apresentada anteriormente assume-se que todos os estados $\boldsymbol{x}$ são mensuráveis ou que possam ser gerados a partir da saída. Na prática em muitos sistemas de controle é impossível fisicamente ou economicamente impraticável instalar todos os sensores que seriam necessários para medir os estados. Para que se possam reconstruir os estados da planta, a partir das saídas, requer-se que todos os estados sejam observáveis. A condição necessária para observabilidade completa é dada pela equação (6.21) (D’AZZO; HOUPIS, 1988).

posto $\boldsymbol{M}_{o}=$ posto $\left[\boldsymbol{C}^{T} \quad \boldsymbol{A}^{T} \boldsymbol{C}^{T} \quad\left(\boldsymbol{A}^{T}\right)^{2} \boldsymbol{C}^{T} \ldots\left(\boldsymbol{A}^{T}\right)^{n-l} \boldsymbol{C}^{T}\right]=n$.

O objetivo no momento é apresentar uma forma de reconstruir os estados a partir das saídas medidas de um sistema dinâmico, à qual se dá o nome de observador. $\mathrm{O}$ vetor de estados estimados $\widehat{\boldsymbol{x}}$ pode, então, ser usado para implementar a lei de controle com realimentação de estados $\boldsymbol{u}=\boldsymbol{K} \widehat{\boldsymbol{x}}$ (D’AZZO; HOUPIS, 1988).

Um método básico de reconstrução dos estados é simular às equações de estado e de saída da planta. Essas equações serão simuladas utilizando a mesma entrada $\boldsymbol{u}$ que é aplicada ao sistema físico. Os estados do sistema simulado e do sistema físico deverão ser identicos, somente se as condições iniciais de simulação e do sistema físico forem iguais (D’AZZO; HOUPIS, 1988).

Como a planta física pode estar sujeita a distúrbios não mensuráveis que não podem ser aplicados na simulação, então, a diferença entre a saída atual da planta $\boldsymbol{y}$ e a saída 
simulada $\widehat{\boldsymbol{y}}$ é usada como outra entrada na equação da simulação. Assim, as equações de estado e de saída do observador se tornam

$\dot{\hat{x}}=A \widehat{x}+B u+L(y-\widehat{y})$

$\widehat{y}=C \widehat{x}$

onde $\boldsymbol{L}$ é a matriz de ganho $n \times p$ do observador (D'AZZO; HOUPIS, 1988).

Um método para sintetizar $\boldsymbol{L}$ usa a reconstrução do erro do observador definido por

$e \equiv \boldsymbol{x}-\widehat{x}$

Subtraindo a equação (6.22) da equação (6.1) e usando as equações (6.2), (6.23) e (5.24) resulta na equação de estado do erro do observador

$\dot{e}=(\boldsymbol{A}-\boldsymbol{L C}) \boldsymbol{e}$

Para uma escolha apropriada da matriz $\boldsymbol{L}$ do observador, todos os autovalores de $(\boldsymbol{A}-\boldsymbol{L C})$ atribuidos devem estar no semiplano complexo esquerdo, de tal forma que o valor em regime do erro $\boldsymbol{e}(t)$ para qualquer condição inicial seja zero:

$\lim _{t \rightarrow \infty} \boldsymbol{e}(t)=\mathbf{0}$

A equação (6.25) indica que a equação do erro do observador não possui entrada e é excitada somente pela condição inicial, assim o erro do observador independe da entrada do sistema. O valor do erro em regime é desta forma igual a zero. A importância disto é que haverá a convergência dos estados do observador para os da planta, em regime, independentemente de quais sejam as entradas (D’AZZO; HOUPIS, 1988).

Os autovalores de $(\boldsymbol{A}-\boldsymbol{L} \boldsymbol{C})$ são usualmente escolhidos de tal modo que fiquem a esquerda dos autovalores de $\boldsymbol{A}$. Assim se o observador de estados tiver um erro inicial em relação à planta física, este rapidamente tenderá para zero.

A representação da planta física dada pelas equações (6.1) e (6.2) e o observador pelas equações (6.22) e (6.23) são mostrados na Figura 6.2. 


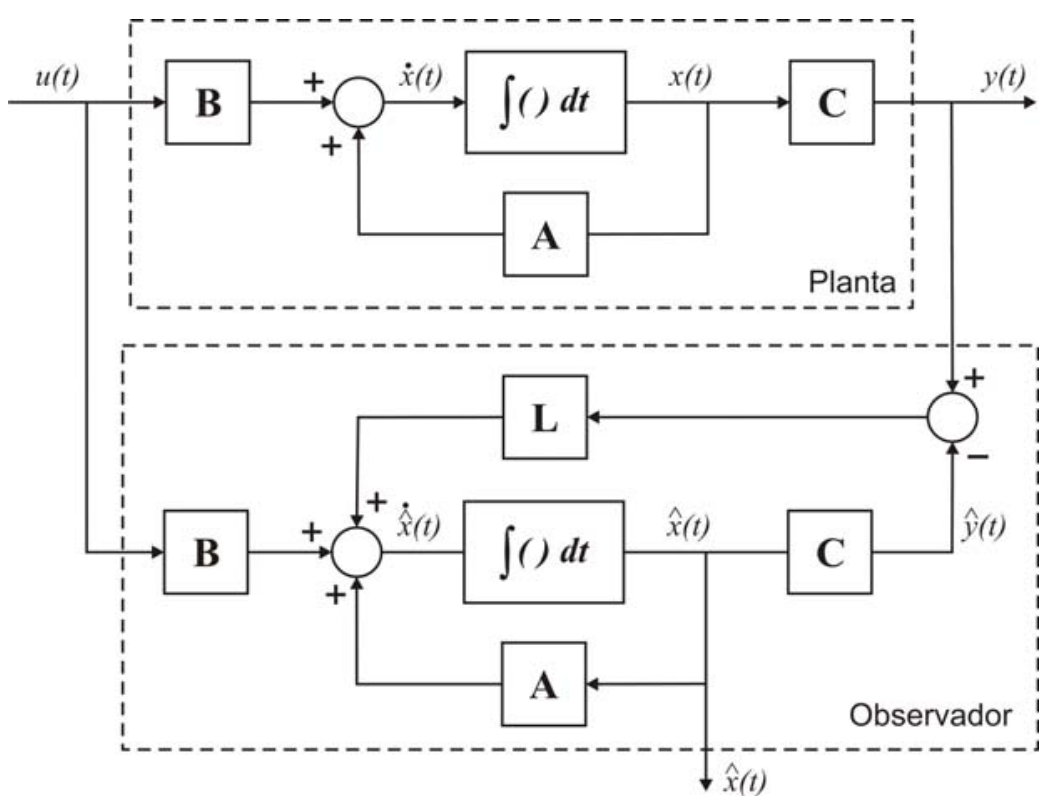

Figura 6.2 - Planta física e um observador para reconstruir os estados. 


\section{SIMULAÇÃO USANDO SIMULINK/ADAMS ${ }^{\circledR}$}

\subsection{SIMULINK}

SIMULINK é um software que faz parte do MATLAB desenvolvido pela Mathworks Inc. que permite modelar, simular e analisar sistemas cujas saídas variam no tempo. Tais sistemas são freqüentemente sistemas dinâmicos podendo ser lineares ou não lineares modelados em tempo contínuo ou discreto. O SIMULINK pode ser usado para explorar o comportamento de uma ampla faixa de sistemas dinâmicos reais incluindo circuitos elétricos, sistemas de freios, de absorção de choques e muito outros sistemas elétricos, mecânicos e termodinâmicos.

O processo de simulação usando o SIMULINK consiste de duas etapas. Primeiro criase um modelo gráfico (diagrama de blocos) do sistema a ser simulado usando-se o editor de modelos do SIMULINK. O modelo representa as relações matemáticas dependentes no tempo entre os sistemas de entradas, estados e saídas. Então, simula-se o comportamento do sistema durante um determinado período de tempo, que no caso é o modelo ou a planta do sistema gerado pelo $A D A M S^{\circledR}$ e exportado para o SIMULINK no formato de matrizes das equações de estado e de saída. O controle e a modelagem do sistema de acionamento, se necessário, serão realizados no próprio SIMULINK.

\subsection{Ambiente de Sistemas Multicorpos $A D A M S^{\circledR}$}

A simulação por computador vem sendo, atualmente, muito utilizada no processo de desenvolvimento de projetos de engenharia. O advento do computador digital trouxe uma nova dimensão na solução destes problemas. Não somente tornou possível a solução de sistemas de equações matemáticas, mas também tornou acessível a formulação automática das equações de movimento que governam os sistemas definidos pelos analistas e projetistas. Uma das técnicas empregadas em sistemas mecânicos é a técnica de Sistemas Multicorpos ou Multibody Systems (MBS), implementada em vários sistemas de software disponíveis comercialmente (RYAN, 1990). 
Esta secção tem o objetivo de apresentar a modelagem da plataforma de movimento utilizada neste trabalho para a determinação de suas características dinâmicas. A modelagem proposta engloba todos os aspectos do movimento da plataforma. Tal modelo foi construído utilizando o software de simulação de sistemas $A D A M S^{\circledR}$, que utiliza técnicas de modelagem de sistemas multicorpos para a obtenção de equações dinâmicas do movimento. Este software oferece uma interface gráfica para auxiliar na criação do modelo matemático e para a visualização dos resultados da simulação, onde os parâmetros desejados são fornecidos de uma maneira simples e rápida. Utilizou-se juntas universais ligando o corpo do atuador à plataforma fixa, um conjunto de três juntas de rotação que equivalem a uma junta esférica ligando a haste do atuador ao mancal, juntas de translação ligando o corpo à haste do atuador e junta screw para representar o comportamento do fuso de esferas.

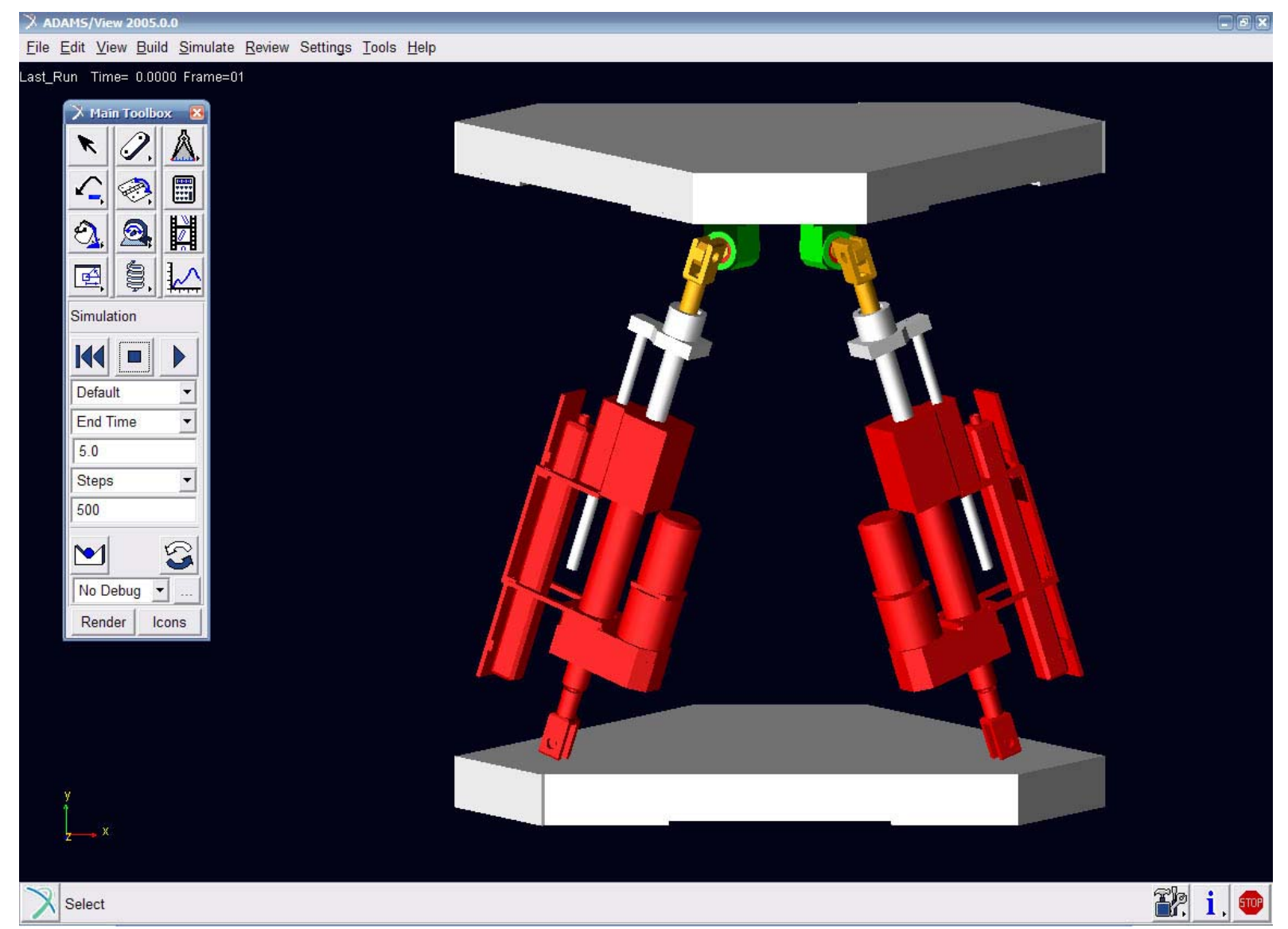

Figura 7.1 - Modelo dinâmico da plataforma de movimento desenvolvida no $A D A M S^{\circledR}$. 


\subsection{Simulação e Controle Usando SIMULINK/ADAMS ${ }^{\circledR}$}

O sistema de controle será montado através de um diagrama de blocos que represente a planta e a lei de controle desejadas. São utilizados dois modelos da plataforma de movimento como planta, um gerado a partir do software de modelagem dinâmica $A D A M S^{\circledR} \mathrm{e}$ exportado para o SIMULINK, que é o modelo linear. Este será utilizado para o projeto do sistema de controle que deverá ser testado no modelo real, que por natureza é não linear.

O modelo matemático linearizado em termos de variáveis de estado é utilizado para realizar o controle em torno da posição de linearização. É representado por quatro matrizes: $\boldsymbol{A}, \boldsymbol{B}, \boldsymbol{C}$ e $\boldsymbol{D}$. A matriz $\boldsymbol{A}$ possui dimensões $n \times n$ onde $n$ é o número de estados que no caso é igual a duas vezes o número de graus de liberdade do sistema. Como a plataforma de movimento possui dois graus de liberdade $n$ é igual a quatro. A matriz $\boldsymbol{B}$ possui dimensões $n \times m$ onde $m$ é igual a dois que é o número de entradas do sistema. A matriz $C$ é $p \times n$ onde $p$ é o número de saídas do sistema e a matriz $\boldsymbol{D}$ é $p \times m$ que no caso tem todos os seus elementos nulos.

O modelo matemático não linear é utilizado para simular o comportamento da plataforma real e testar a eficiência do controle utilizado, isto é, verificar se o controle gerado a partir do modelo linear é capaz de controlar o modelo não linear de forma adequada em torno do ponto de linearização. Nesta aplicação utilizaremos a planta real instrumentada e a técnica hardware-in-the-loop para verificar se o controle obtido através do modelo linear é capaz de controlar a plataforma real.

$\mathrm{Na}$ utilização do modelo não linear, para que os estados possam ser realimentados, estes devem ser medidos e colocados como saídas do sistema. O modelo em questão possui duas saídas controláveis que são os deslocamentos dos atuadores e se forem acrescentados mais quatro, uma para cada estado, resultaria num sistema com seis saídas. Isto se faz necessário, pois os estados são definidos internamente durante o processo de linearização realizado pelo $A D A M S^{\circledR}$ e nem sempre coincidem com as saídas que se deseja controlar. Nas versões mais atuais do software já é possível selecionar os estados que se deseja na realização das matrizes da planta, mas isso não garante que se tenha um bom condicionamento das matrizes do sistema. Outra opção é acrescentar mais duas saídas, pois assim a matriz $\boldsymbol{C}$ passa a ter dimensão quadrada $4 x 4$. Então, com as saídas do modelo real e a inversa da matriz $C$ 
consegue-se reconstruir os estados e realizar a realimentação a partir do sistema construído no SIMULINK. Optou-se pela solução mais tradicional de se desenvolver um observador para reconstruir os estados como demonstrado no capítulo anterior.

Na Figura 7.2 a planta do sistema é o modelo real da plataforma de movimento. A entrada de controle $\boldsymbol{r}$ é o vetor formado pelos deslocamentos dos atuadores lineares, calculados através da cinemática inversa, que levam a plataforma a uma orientação $(\alpha \beta)^{T}$ desejada.

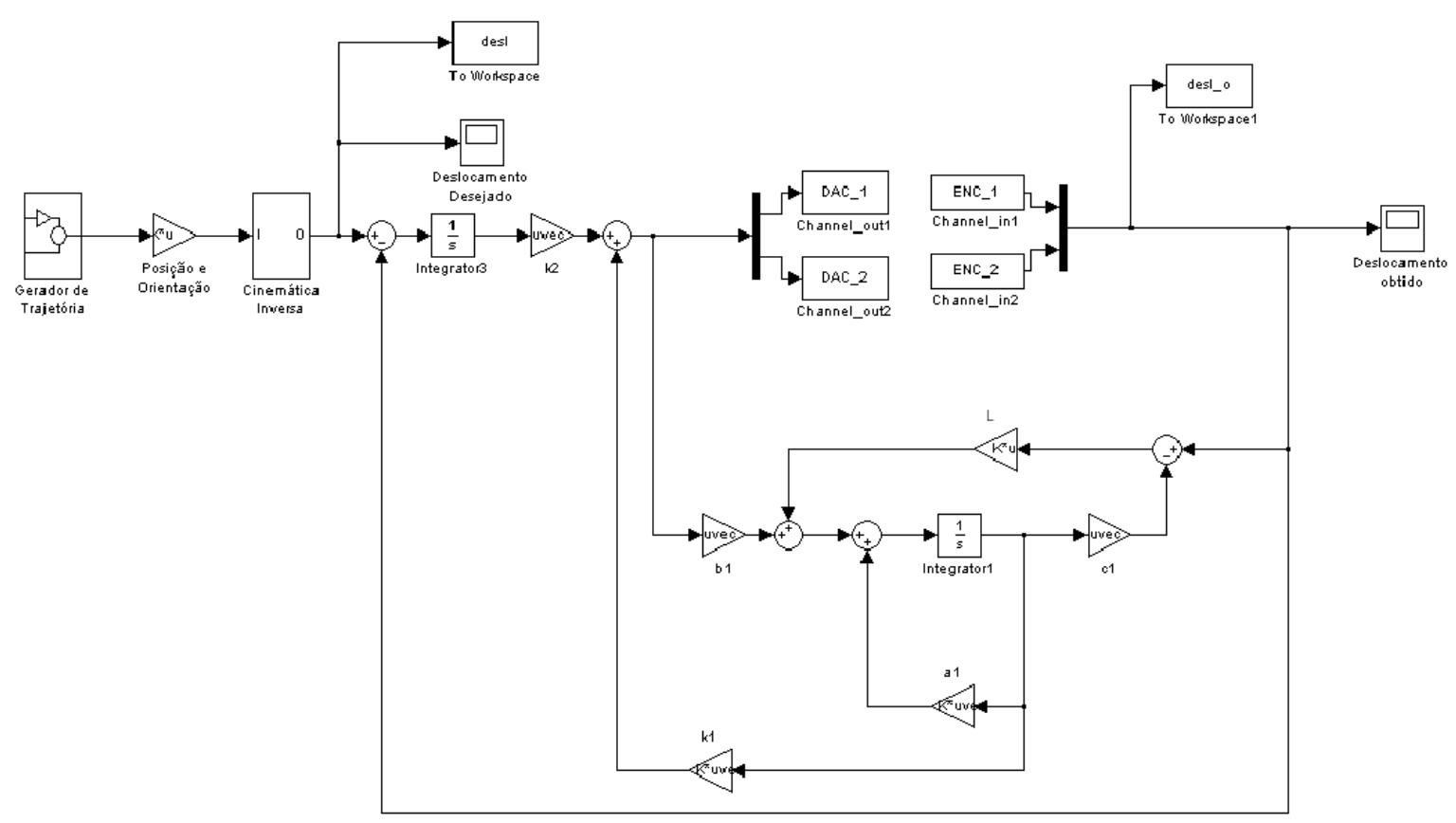

Figura 7.2 - Sistema de controle seguidor com observador.

\subsection{Resultados da Simulação}

As simulações realizadas têm o objetivo de verificar as características de resposta, no tempo, do sistema de controle baseado no modelo. Com base nessa resposta, espera-se que aplicando o controle à plataforma real, o desempenho e as características de reposta sejam semelhantes à simulação.

Primeiramente realiza-se a simulação utilizando o modelo de plataforma mostrado na Figura 7.1. O objetivo é verificar se o procedimento de cálculo para a obtenção das matrizes de ganhos $\boldsymbol{K}_{\mathbf{1}}$ e $\boldsymbol{K}_{\mathbf{2}}$, a partir do modelo linear gerado pelo $A D A M S^{\circledR}$, está correto. O sistema 
deve ser capaz de estabilizar a planta e atribuir as características de desempenho no tempo dadas pelos autovalores. Algumas regras, antes de se escolher os autovalores, devem ser observadas. Como se tem duas saídas controladas, o espaço vetorial nulo, ou seja, aquele que representa as soluções para as equações matriciais que representam a planta mais o sistema de controle pertencem ao $R^{2}$. Portanto, os autovalores repetidos não poderão ultrapassar a dimensão do espaço nulo. Como a planta de malha fechada possui dimensão seis, sendo quatro da planta normal mais duas do sistema de controle, deve se definir seis autovalores que deverão ser atribuídos. Então, os autovalores serão atribuídos em pares e em um total de seis autovalores. Autovalores complexos devem ser atribuídos através de seus complexos conjugados e tendem a tornar a resposta oscilatória dependendo dos valores da parte real e imaginária que os compõem. Autovalores reais, distantes entre si, tendem a apresentar uma resposta superamortecida e se todos os autovalores forem reais e iguais a resposta é crítica, lembrando que todo autovalor deve estar no semi-plano complexo esquerdo, e que temos seis autovalores para serem atribuídos e só podem ser iguais aos pares, ou seja, dois a dois. Devem, então, ser escolhidos três valores o mais próximo possível, para serem atribuídos aos pares e formarem o conjunto de autovalores que se precisa. Valores muito próximos podem tornar o sistema mal condicionado. Utilizam-se dois conjuntos de autovalores para as simulações $[-9,-9,-10,-10,-11,-11]$ e $[-19,-19,-20,-20,-21,-21] \mathrm{em} \mathrm{rad} / \mathrm{s}$.

Utilizam-se três tipos, muito comuns, de entradas para demonstrar o desempenho do sistema de controle, sendo estas, a entrada degrau, a senoidal e a entrada rampa (ou trapezoidal).

Para o teste de simulação utilizam-se os modelos de entradas:

Entrada Degrau:

$\delta(t)=\left\{\begin{array}{c}0, \quad \text { para } 0 \leq t<1 \\ 1, \text { para } t \geq 1\end{array}\right\}$

Entrada senoidal:

$\delta(t)=\{\operatorname{sen}(\omega t)$, para $t \geq 0\}$

Entrada Rampa: 
$\delta(t)=\left\{\begin{array}{c}0, \text { para } 0 \leq t<1 \\ t-1, \text { para } 1 \leq t<2 \\ 1, \text { para } t \geq 2\end{array}\right\}$

que multiplica o vetor orientação $(\alpha \beta)^{T}$.

Estes valores serão transformados em comprimentos dos atuadores, através da cinemática inversa, usados como entrada de comando $\boldsymbol{r}$ que deverá ser seguida pela saída $\boldsymbol{w}$ que é a parte controlável da resposta do sistema dinâmico.

Os autovalores atribuídos ao sistema devem ser determinados de tal forma que a plataforma de movimento responda mais rápido do que o sistema que se deseja simular, como por exemplo, um avião, um carro, um robô ou uma máquina ferramenta. No caso de um avião o modo mais rápido, o de período curto, varia de $4,0 \mathrm{~Hz}$ para aviões de acrobacias a $0,1 \mathrm{~Hz}$ para grandes aviões comerciais (McLEAN, 1990). Por outro lado, a matriz de ganhos $\bar{K}$ não deve possuir elementos com valores muito elevados que inviabilizem a implementação física do sistema, devido à questão de amplificação de ruídos e/ou à necessidade de altas energias que são limitadas pelas características dos sistemas de atuação. Determina-se, então, por exemplo, o seguinte conjunto de autovalores para a planta de malha fechada $\boldsymbol{A}_{c l}^{\prime}$

$\sigma(\overline{\boldsymbol{A}}+\overline{\boldsymbol{B}} \overline{\boldsymbol{K}})=\{-9,-9,-10,-10,-11,-11\}$

$9 \frac{\mathrm{rad}}{\mathrm{s}}=1,43 \mathrm{~Hz}, 10 \frac{\mathrm{rad}}{\mathrm{s}}=1,59 \mathrm{~Hz}, 11 \frac{\mathrm{rad}}{\mathrm{s}}=1,75 \mathrm{~Hz}$

que satisfaz os critérios anteriormente estabelecidos para aviões, além de estarem próximos uns dos outros de tal forma que se esteja próximo o suficiente de um sistema criticamente amortecido.

Para os autovalores do observador foram atribuídos valores apresentados na equação (7.6).

$\sigma(\boldsymbol{A}+\boldsymbol{L C})=\{-40,-40,-41,-41\}$ 
Considerando as matrizes das equações de estado e saída geradas pelo $A D A M S^{\circledR}$, os autovalores $\sigma(\overline{\boldsymbol{A}}+\overline{\boldsymbol{B}} \overline{\boldsymbol{K}})=\{-9,-9,-10,-10,-11,-11\}$ para a planta mais o controle e os autovalores do observador como sendo $\sigma(\boldsymbol{A}+\boldsymbol{L} \boldsymbol{C})=\{-40,-40,-41,-41\}$, obtêm-se as matrizes de ganho $\boldsymbol{K}_{\mathbf{1}}, \boldsymbol{K}_{\mathbf{2}}$ e $\boldsymbol{L}$ que serão utilizadas nas simulações seguintes.

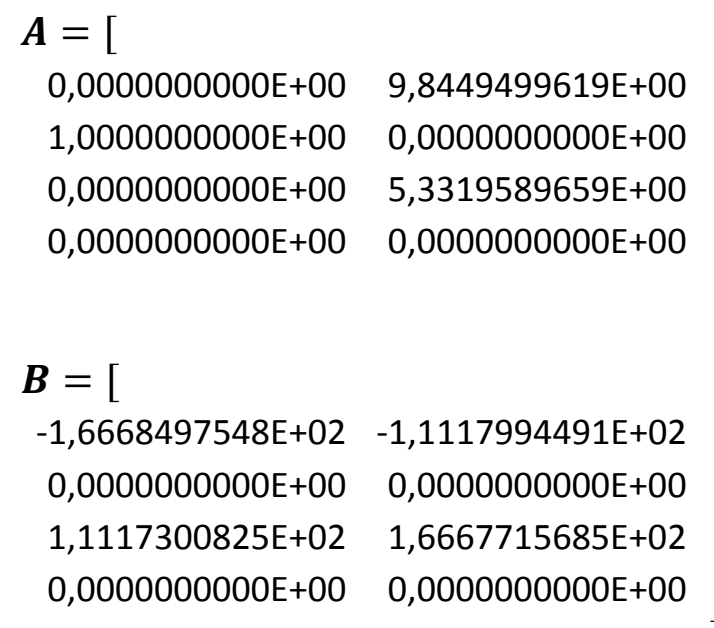

$\boldsymbol{B}=[$

$\begin{array}{rr}-1,6668497548 E+02 & -1,1117994491 E+02 \\ 0,0000000000 E+00 & 0,0000000000 E+00 \\ 1,1117300825 E+02 & 1,6667715685 E+02 \\ 0,0000000000 E+00 & 0,0000000000 E+00\end{array}$

\section{$\boldsymbol{C}=[$}

$0,0000000000 E+00 \quad-4,0424558260 E-01$

0,0000000000E+00 -2,8115598372E-06

$0,0000000000 E+00 \quad-2,7188636985 E-06$

$0,0000000000 E+00 \quad 4,0426235197 E-01$
$\boldsymbol{D}=[$

$0,0000000000 E+00 \quad 0,0000000000 E+00$

$0,0000000000 E+00 \quad 0,0000000000 E+00$

$K_{1}=[$
$3,2422481579 \mathrm{E}-01$
$-2,1625667730 \mathrm{E}-01$
$3,3762780229 \mathrm{E}+00$
2,1627017068E-01 2,2840957643E+00
$-2,1625667730 \mathrm{E}-01$
$-2,2839539062 E+00$
$-3,2424002480 \mathrm{E}-01 \quad-3,3764379023 \mathrm{E}+00$

$K_{2}=[$

2,6467743908E+01 -1,7653990374E+01

$-1,7653983305 \mathrm{E}+01 \quad 2,6467645991 \mathrm{E}+01$

$$
\begin{aligned}
& \boldsymbol{L}=[ \\
& -4,0812937926 \mathrm{E}+03 \quad 1,3162665199 \mathrm{E}+01 \\
& -2,0037324706 \mathrm{E}+02 \quad-1,3476089110 \mathrm{E}-03 \\
& -1,3218284932 \mathrm{E}+01 \quad 4,0811251124 \mathrm{E}+03 \\
& -1,3935538913 \mathrm{E}-03 \quad 2,0036493530 \mathrm{E}+02
\end{aligned}
$$


Pode-se observar através do gráfico de deslocamento dos atuadores que estes convergiram para os valores desejados, inclusive no caso de deslocamentos consideravelmente grandes (Figuras 7.3, 7.5, 7.7 e 7.9).

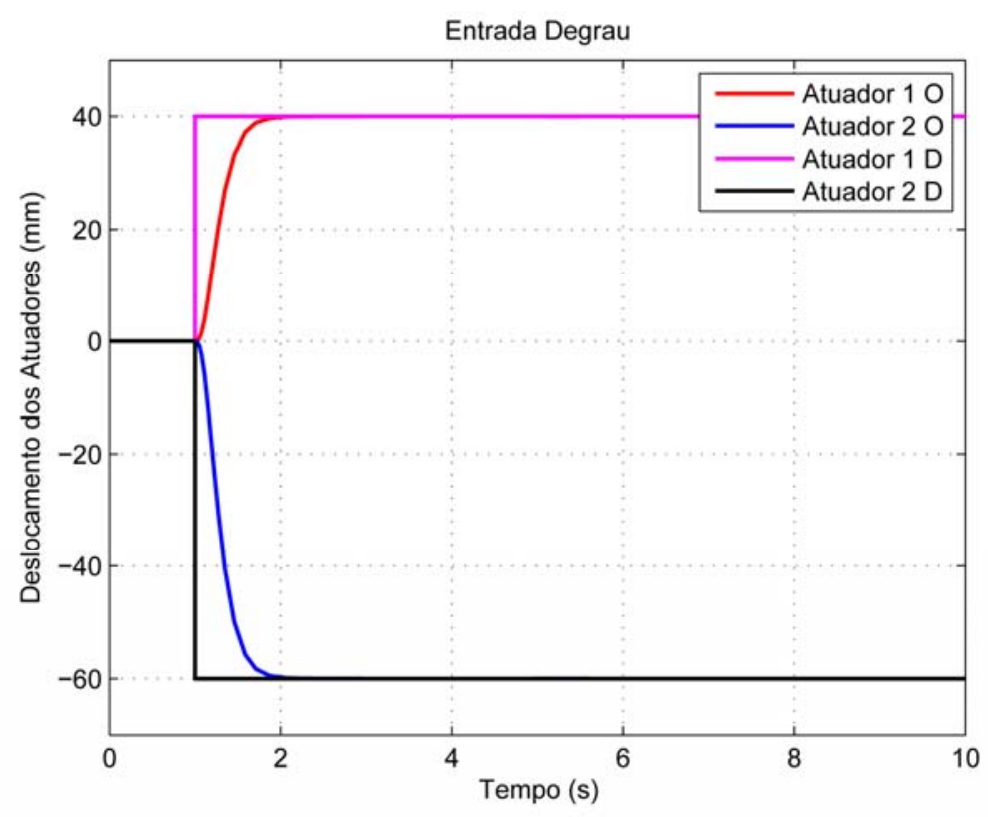

Figura 7.3 - Deslocamento dos atuadores para uma entrada degrau.

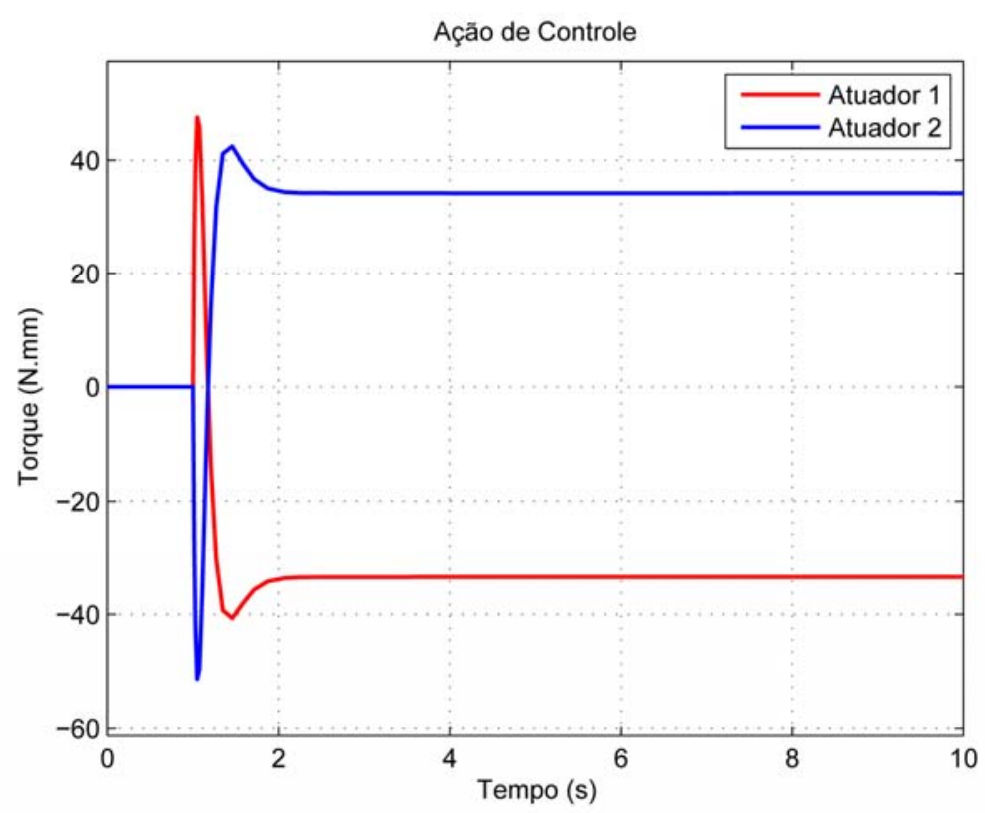

Figura 7.4 - Ação de controle para uma entrada degrau. 


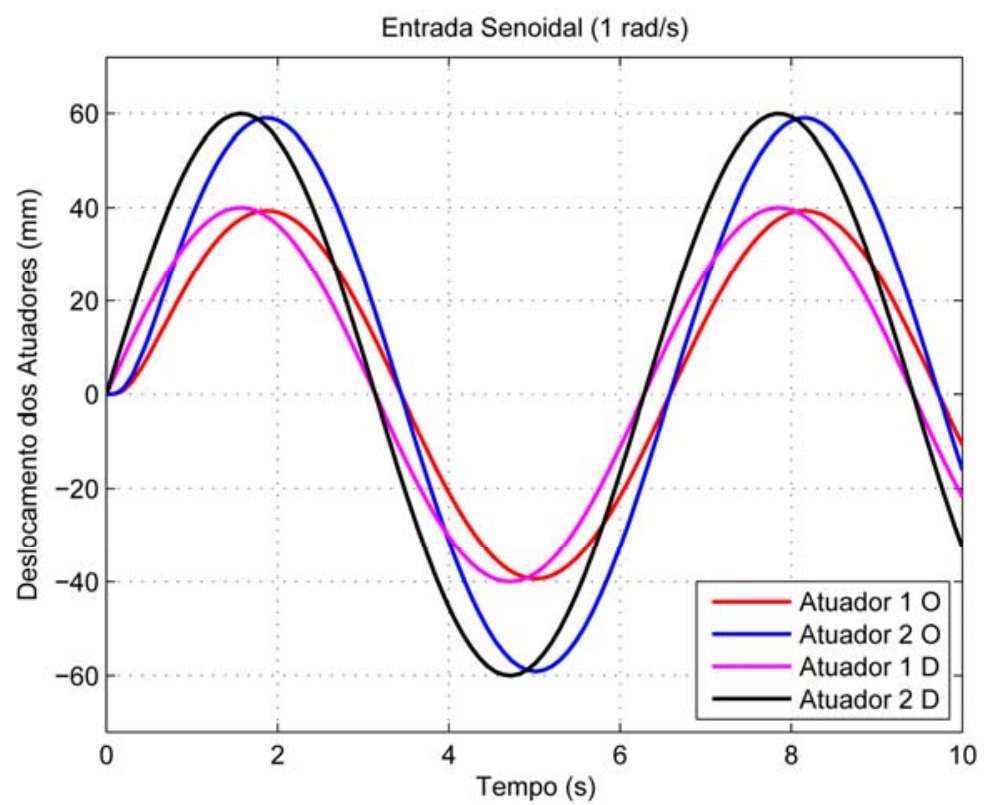

Figura 7.5 - Deslocamentos dos atuadores para uma entrada senoidal de $1 \mathrm{rad} / \mathrm{s}$, deslocamentos diferentes para os atuadores em fase.

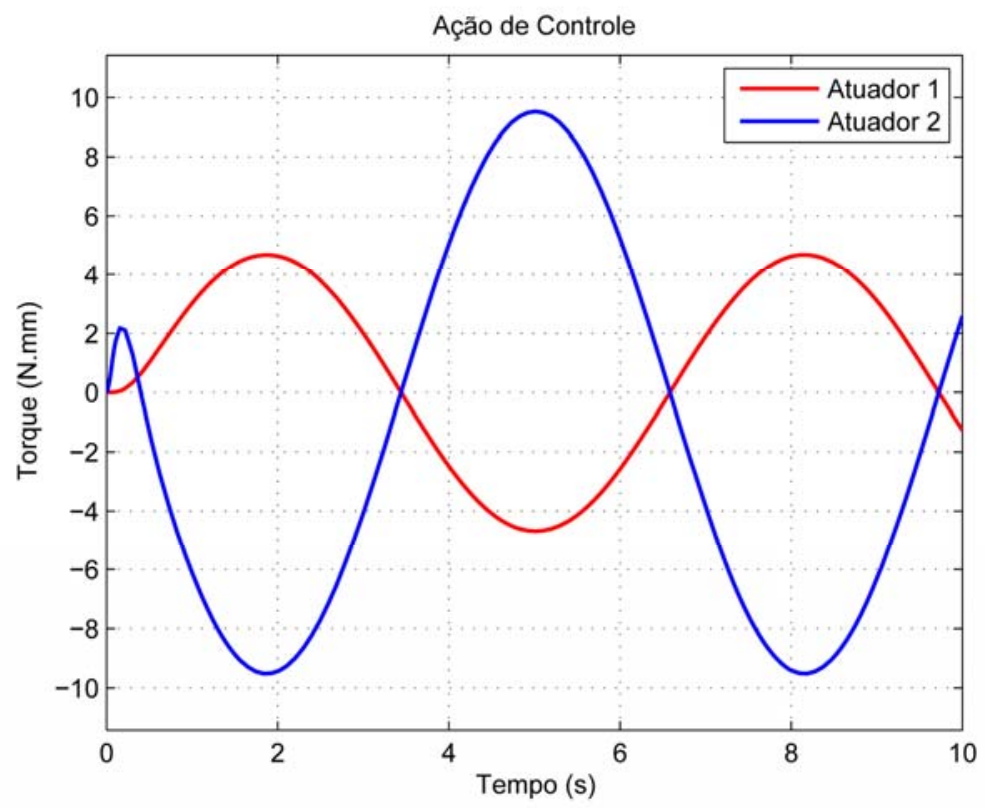

Figura 7.6 - Ação de controle para uma entrada senoidal de $1 \mathrm{rad} / \mathrm{s}$, deslocamentos diferentes para os atuadores em fase. 


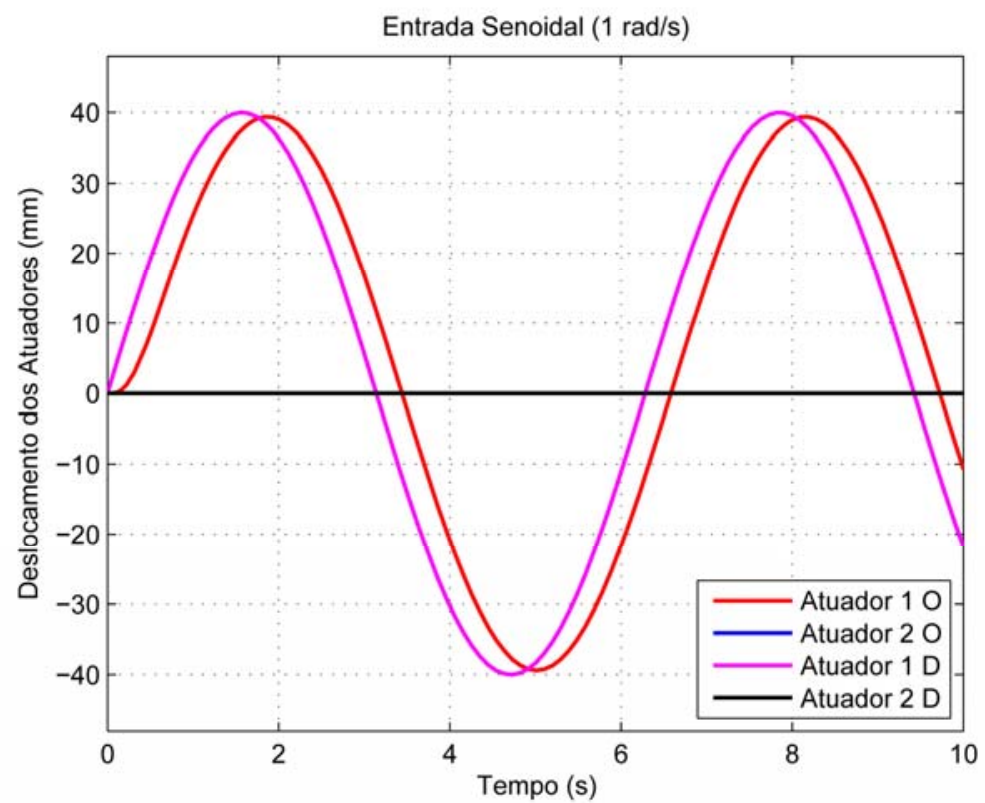

Figura 7.7 - Deslocamentos dos atuadores para uma entrada senoidal de $1 \mathrm{rad} / \mathrm{s}$, deslocamentos diferentes para os atuadores.

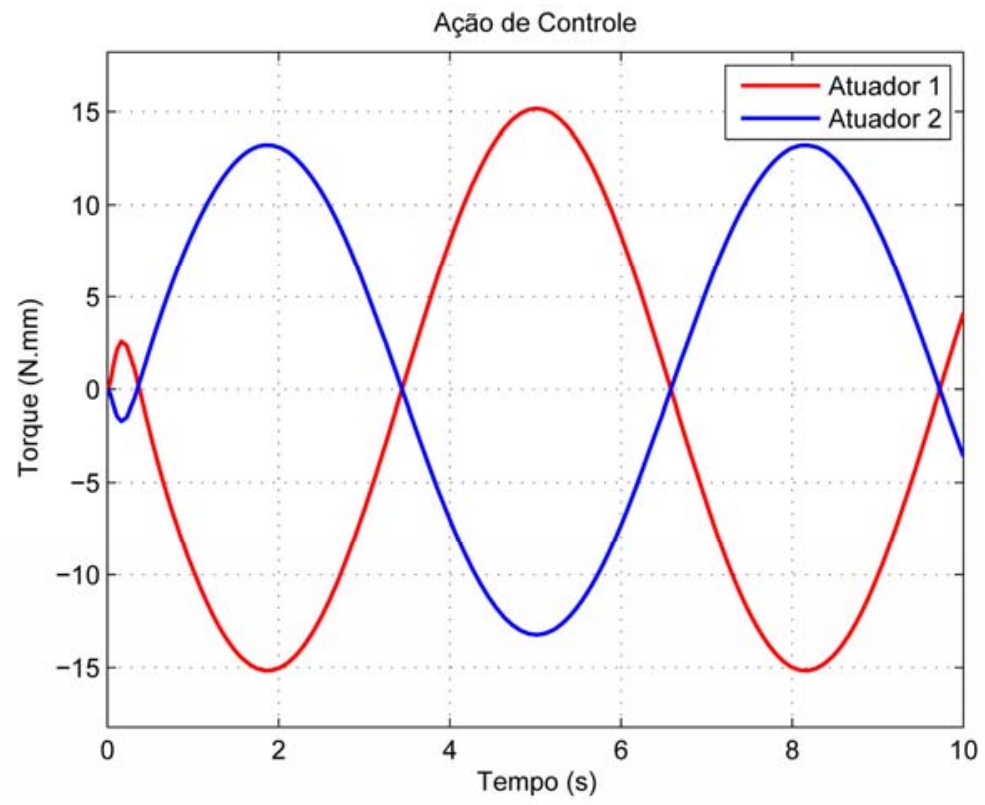

Figura 7.8 - Ação de controle para uma entrada senoidal de $1 \mathrm{rad} / \mathrm{s}$, deslocamentos diferentes para os atuadores. 


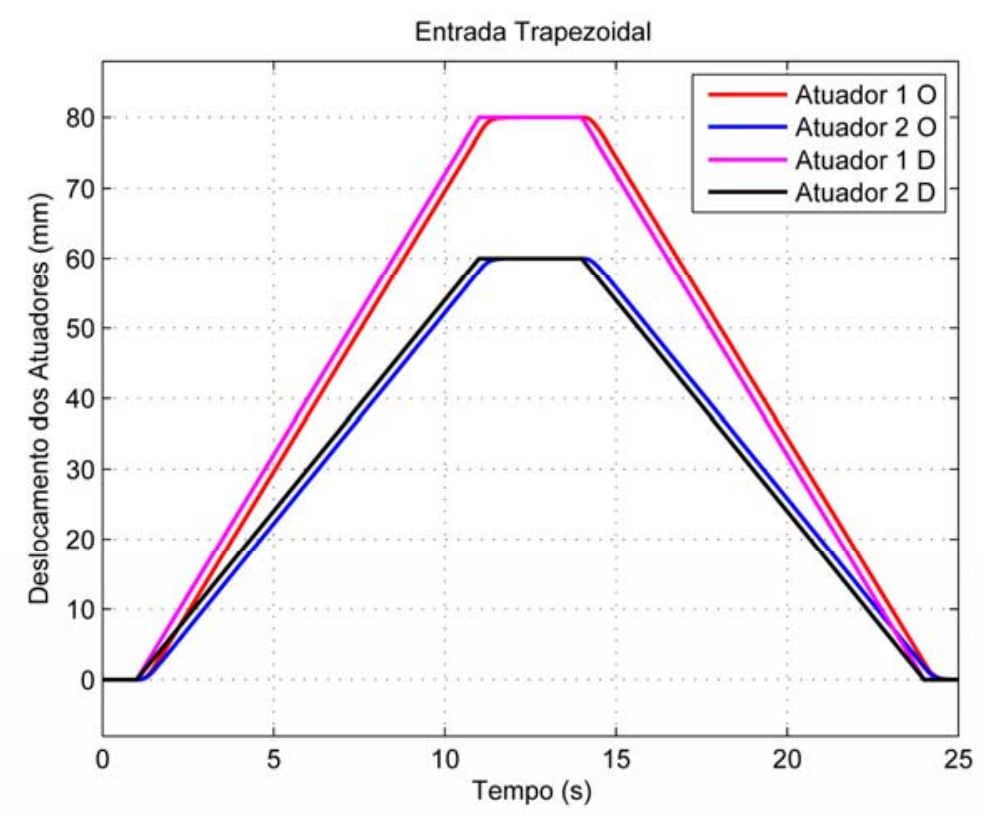

Figura 7.9 - Deslocamentos dos atuadores para uma entrada trapezoidal.

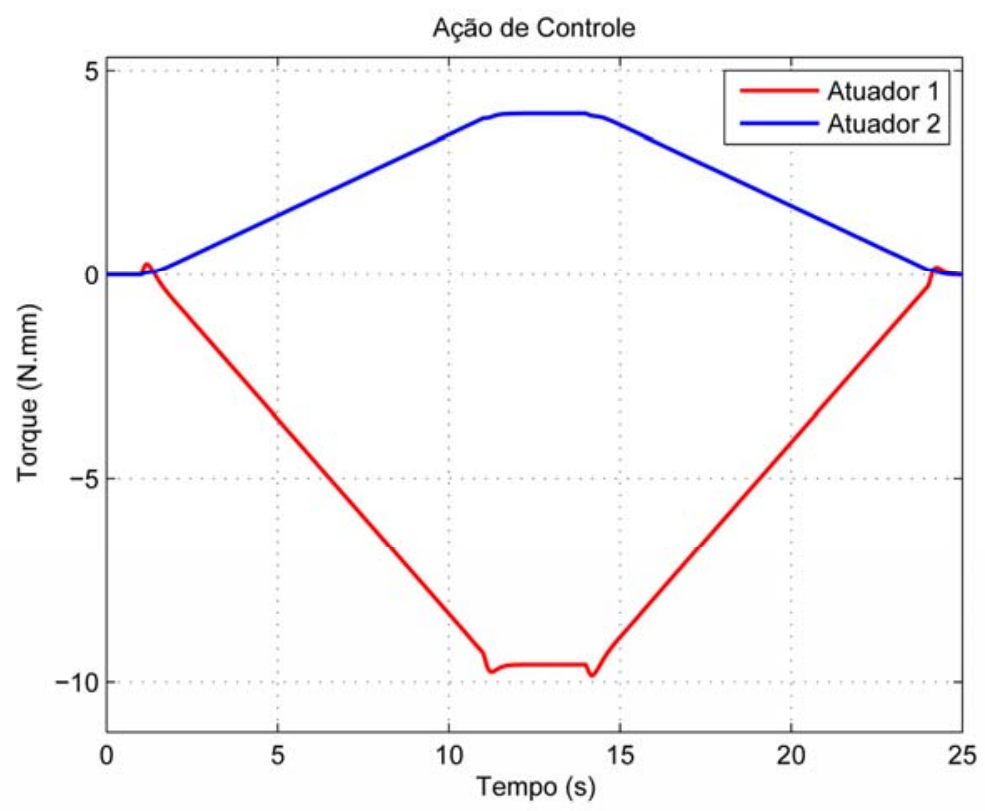

Figura 7.10 - Ação de controle para uma entrada trapezoidal.

Como se pode observar nos gráficos de ação de controle, principalmente o da Figura 7.8, os comportamentos do torque dos motores não apresentam uma resposta que intuitivamente se pareça com o esperado para os atuadores. Tentou-se implementar esse sistema de controle na plataforma real. Utilizou-se o caso da Figura 7.7 e o que se observou é que o atuador 2 que deveria ficar parado acabava tendo um deslocamento contrário do atuador 1, mesmo que a entrada não pedisse esse deslocamento. Algo que realmente aparece na Figura 7.8 , através da ação de controle do atuador 2 , mas que não faz sentido devido ao fato dos 
atuadores reais terem um comportamento não linear, ou seja, não se consegue avançar os atuadores puxando-os através das hastes e, não se consegue recuar os atuadores empurrandoos através das hastes.

Após vários testes no modelo montado no $A D A M S^{\circledR}$, verificamos que a modelagem que utilizamos permite que se avance ou recue a haste através de uma força, o que não é condizente com o modelo real. Não foi encontrada uma forma eficiente de aplicar este comportamento, dos atuadores reais, ao modelo virtual.

Para que se possa entender melhor, devido aos acoplamentos gerados pelas interligações dos elos por juntas móveis, determinadas forças são transmitidas através das ligações que formam a cadeia cinemática da plataforma. Assim quando um atuador avança, tende a puxar o outro consigo, então, este é obrigado a realizar uma ação contrária para permanecer no mesmo lugar. É isso que observamos nas Figuras 7.7 e 7.8.

$\mathrm{Na}$ realidade só se consegue avançar e recuar as hastes dos atuadores através da aplicação de torque nos motores. Talvez, se for aplicada uma força alta, se consiga mover a haste, mas acredita-se que tal atitude possa danificar o atuador. Devido à configuração física do mesmo o avanço e recuo só é possível através da ação dos motores.

Talvez, algumas das ações de controle possam parecer incoerentes, independentemente da não linearidade do atuador, discutida até aqui, mas isso é devido ao fato da linearização excluir a ação da gravidade. Nas simulações realizadas os sistemas não estão sujeitos à ação da gravidade. Embora isso seja comum, e não afete a utilização do modelo linear e do sistema de controle no modelo real, onde haja ação da gravidade, é algo que deve ser ressaltado.

Outro ponto importante é o fato de em nenhum ponto do gráfico da entrada senoidal o valor de saída se iguala ao valor desejado. Isso realmente é uma deficiência deste tipo de controle, que considera a entrada $\boldsymbol{r}$ constante por partes. A entrada senoidal não se aplica a esta categoria, pois em nenhum momento um seno tem valor constante. A resposta do controle pode ser melhorada aumentando-se os autovalores atribuídos ao sistema, sendo mais rápido, o atraso na resposta do controle será menor quanto maiores forem os autovalores. Isso será mostrado mais adiante neste capítulo.

A solução encontrada para solucionar a diferença entre o atuador real e o protótipo virtual, foi abrir a cadeia cinemática e considerar apenas a dinâmica dos atuadores, como 
mostrado na Figura 7.11. A idéia é identificar as características dinâmicas principais do modelo real e procurar deixar o modelo virtual funcionando de forma semelhante. Quanto à plataforma, esta será considerada um distúrbio, assim como as forças transmitidas através das juntas no modelo real. Se se pensar no atuador com tais características não lineares, é fácil de verificar que ele será a dinâmica principal, já que o mesmo depende apenas da potência do motor, e as forças externas que atuam na haste, apenas uma parte pequena é transmitida ao motor. Outro fator importante verificado, é que o fuso de esferas utilizado é dimensionado para baixas velocidades, e aumentar sua velocidade gera determinadas vibrações que poderão ser observados nos resultados experimentais. Para manter os atuadores na posição, como se estivessem ligados à plataforma, substituem-se as juntas universais, ligando o corpo do atuador à plataforma estática, por juntas fixas.

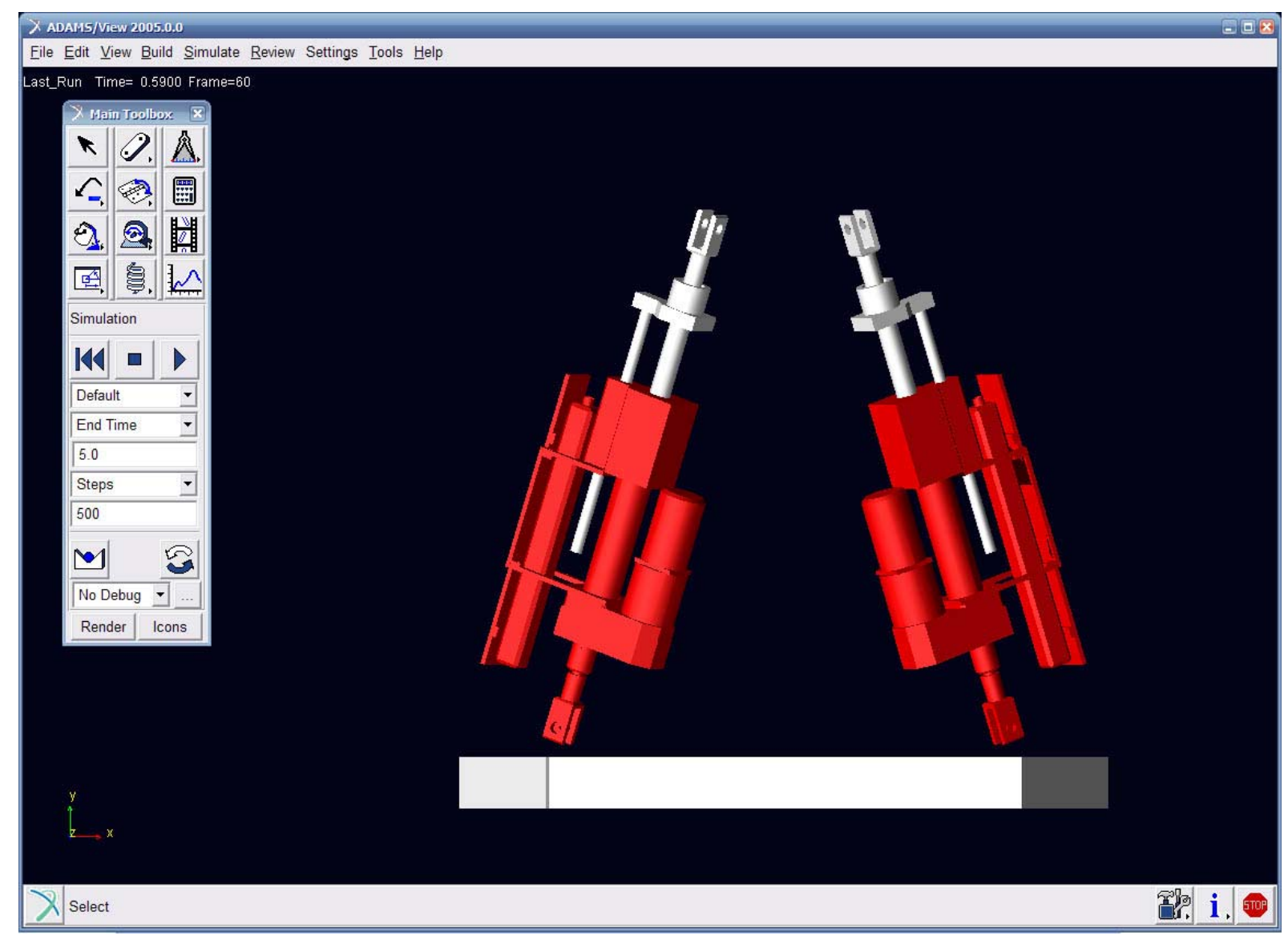

Figura 7.11 - Protótipo virtual dos atuadores na configuração que estariam na plataforma de movimento modelados no $A D A M S^{\circledR}$.

Considerando as matrizes das equações de estado e saída geradas pelo $A D A M S^{\circledR}$ para o caso apresentado na Figura 7.11, mantendo os autovalores utilizados nas simulações anteriores $\sigma(\overline{\boldsymbol{A}}+\overline{\boldsymbol{B}} \overline{\boldsymbol{K}})=\{-9,-9,-10,-10,-11,-11\}$ para a planta mais o controle e os 
autovalores do observador como sendo $\sigma(\boldsymbol{A}+\boldsymbol{L} \boldsymbol{C})=\{-40,-40,-41,-41\}$, obtêm-se as matrizes de ganho $\boldsymbol{K}_{\mathbf{1}}, \boldsymbol{K}_{\mathbf{2}}$ e $\boldsymbol{L}$ que serão utilizadas nas simulações seguintes.

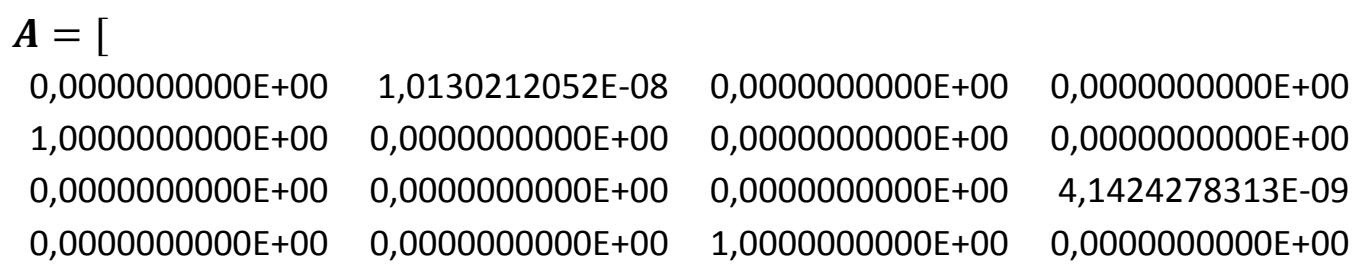


Realizam-se as simulações, para as mesmas entradas utilizadas, anteriormente, para a plataforma completa e as respostas dos deslocamentos e das ações de controle, para o modelo apenas com os atuadores, podem ser vistas nas figuras a seguir. As letras “ $O$ " e " $D$ " nas legendas querem dizer, respectivamente, obtido e desejado.

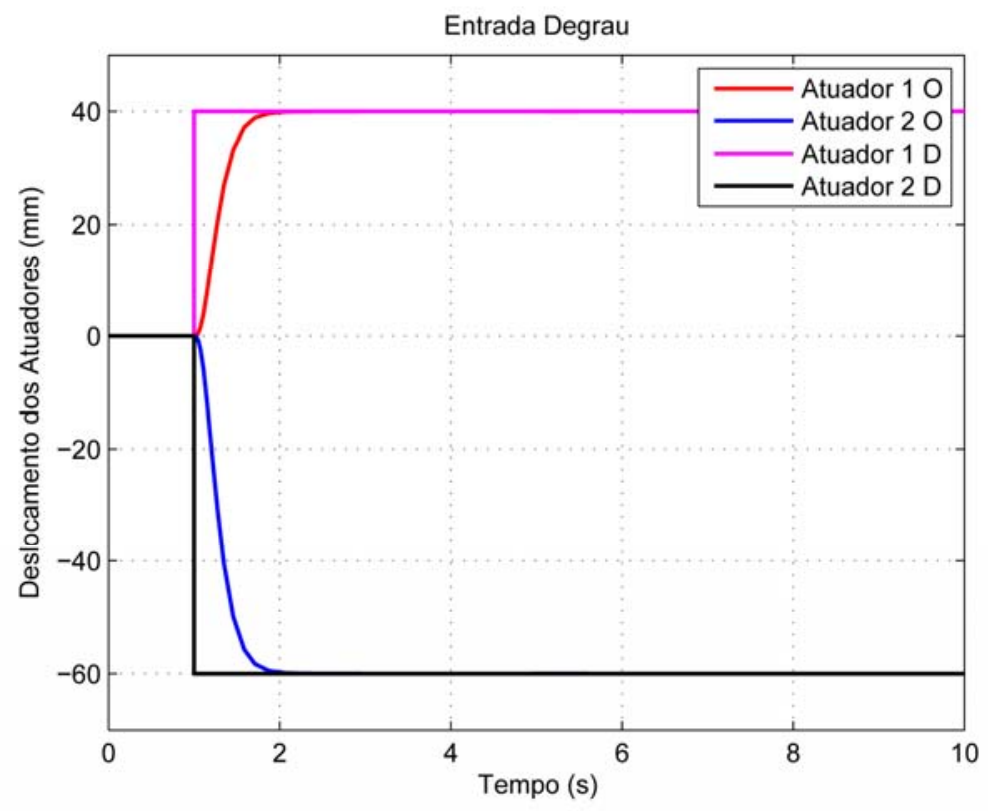

Figura 7.12 - Deslocamento dos atuadores para uma entrada degrau.

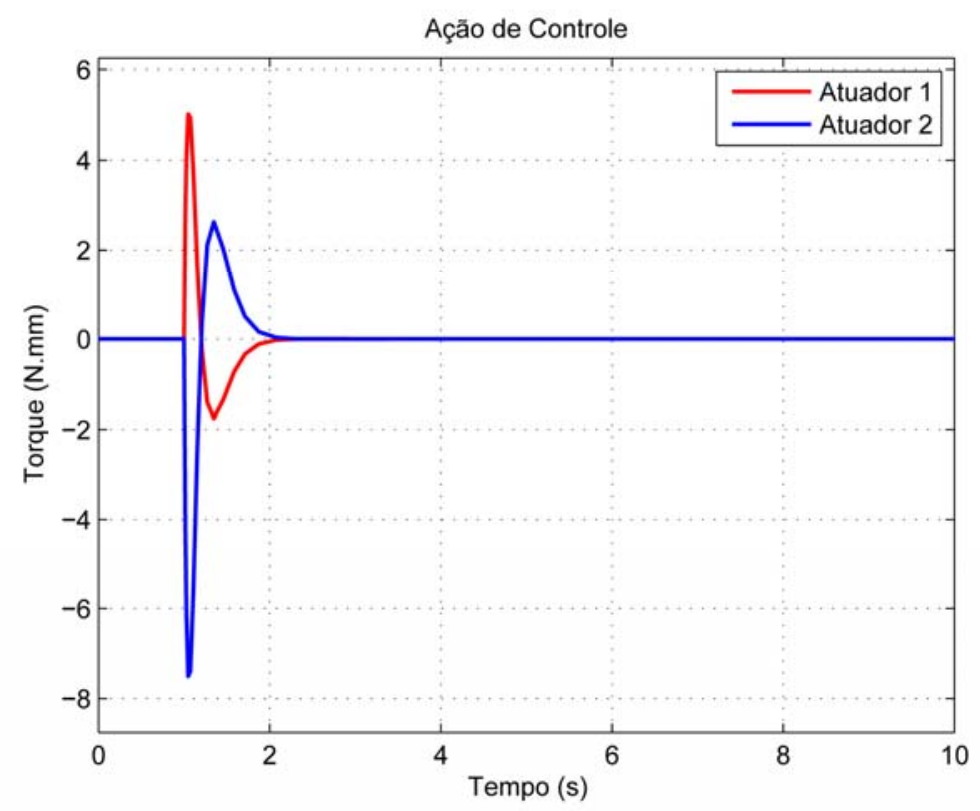

Figura 7.13 - Ação de controle para uma entrada degrau. 


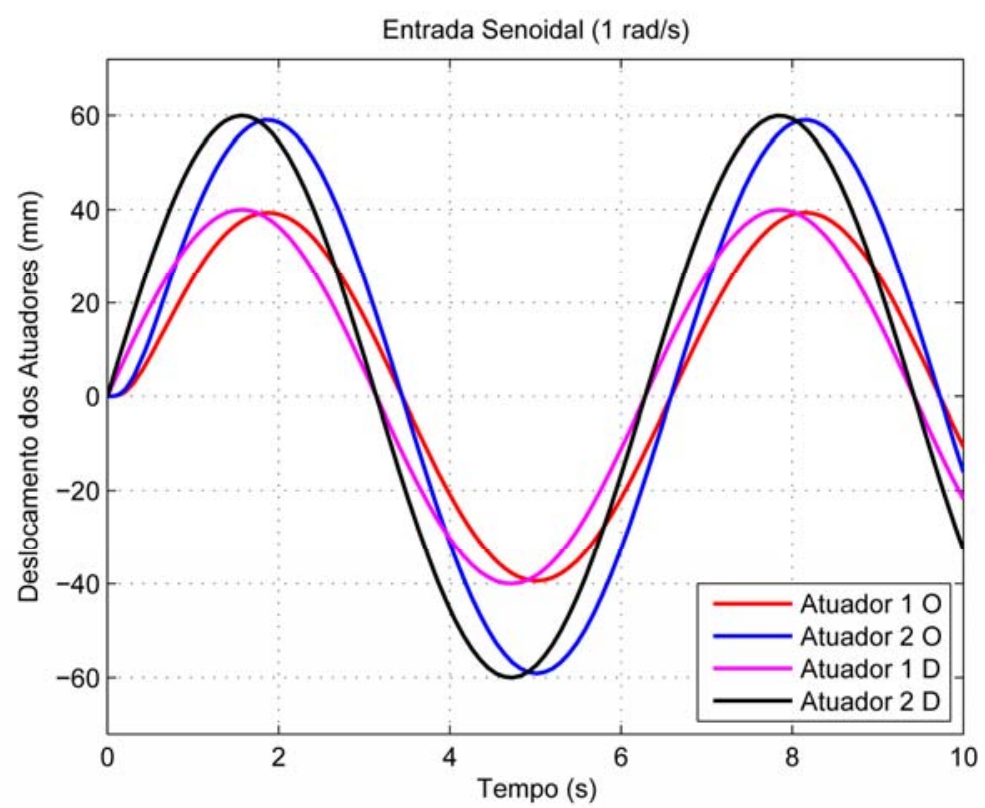

Figura 7.14 - Deslocamentos dos atuadores para uma entrada senoidal de $1 \mathrm{rad} / \mathrm{s}$, deslocamentos diferentes para os atuadores em fase.

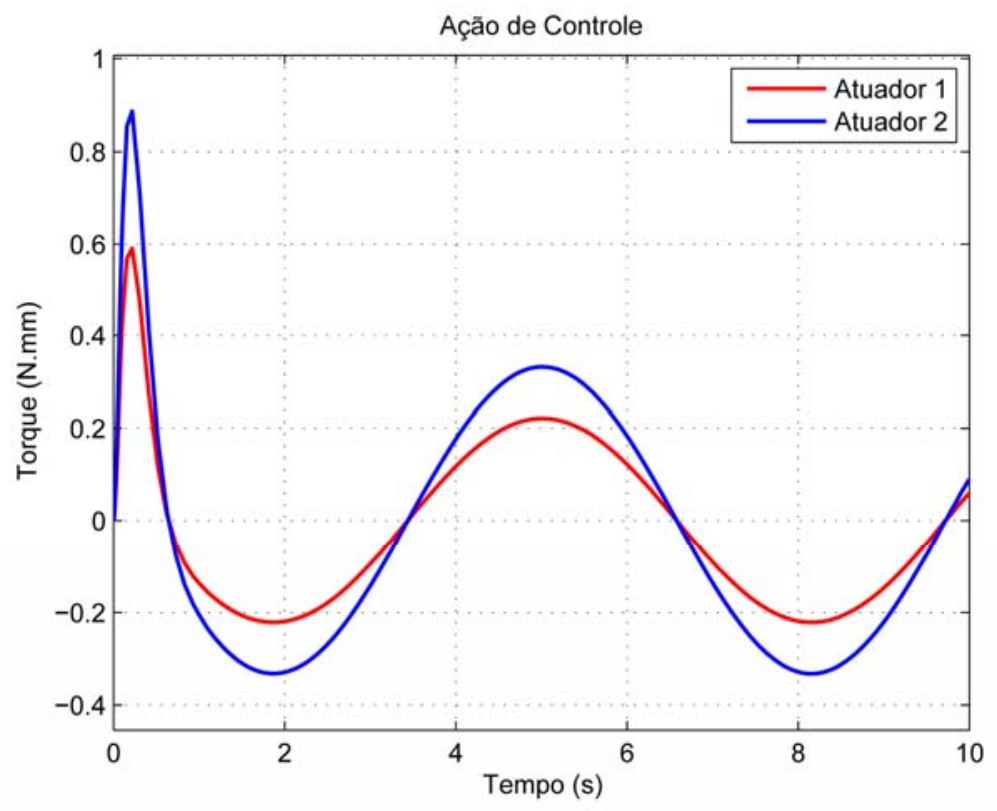

Figura 7.15 - Ação de controle para uma entrada senoidal de $1 \mathrm{rad} / \mathrm{s}$, deslocamentos diferentes para os atuadores em fase. 


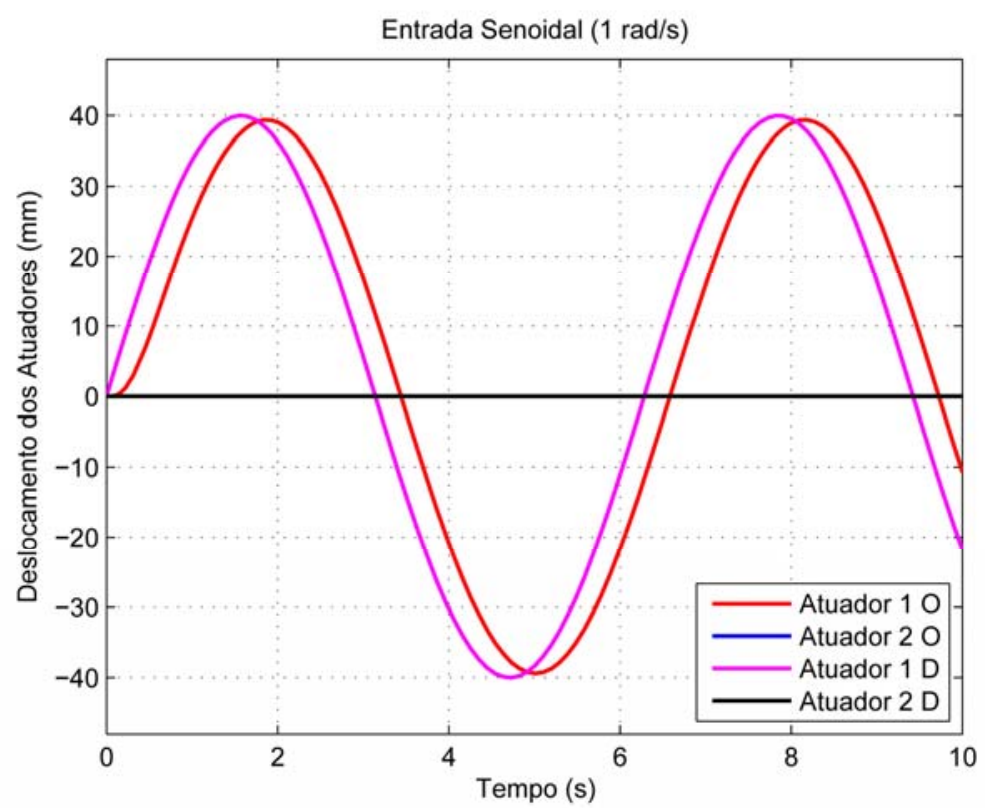

Figura 7.16 - Deslocamentos dos atuadores para uma entrada senoidal de $1 \mathrm{rad} / \mathrm{s}$, deslocamentos diferentes para os atuadores.

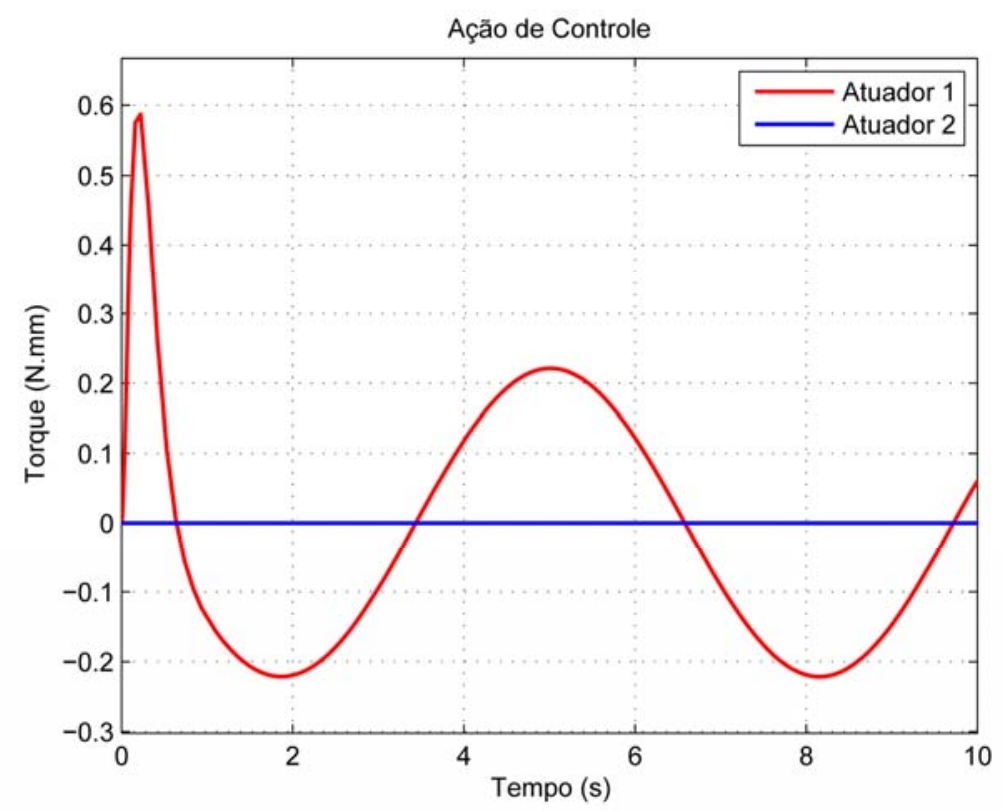

Figura 7.17 - Ação de controle para uma entrada senoidal de $1 \mathrm{rad} / \mathrm{s}$, deslocamentos diferentes para os atuadores. 


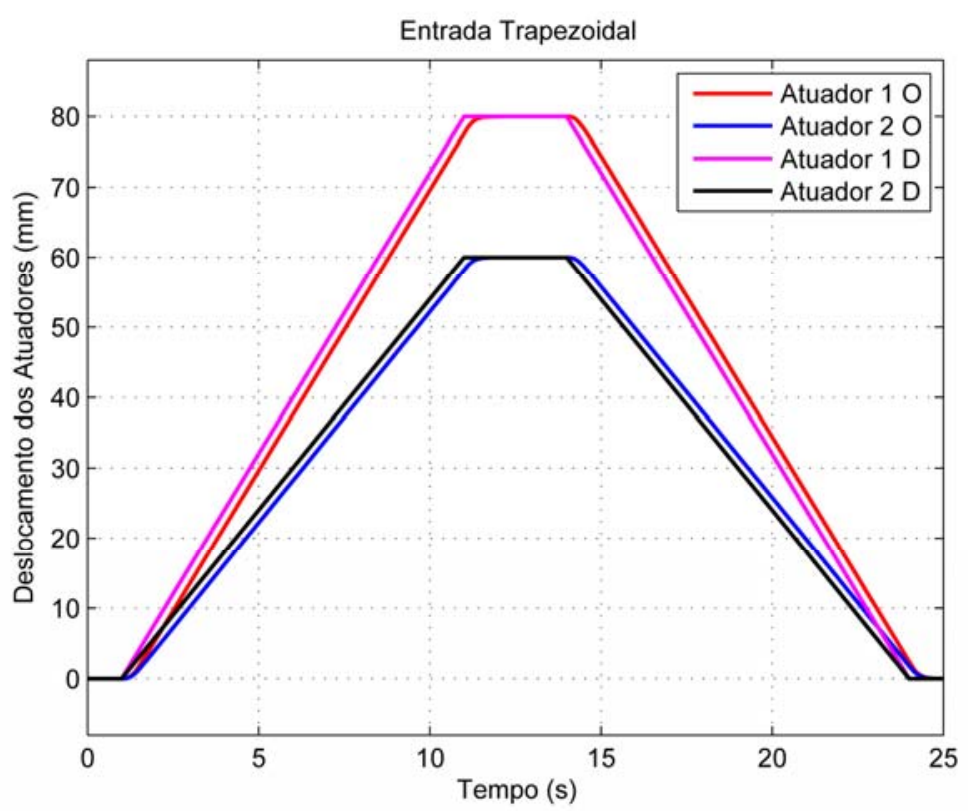

Figura 7.18 - Deslocamentos dos atuadores para uma entrada trapezoidal.

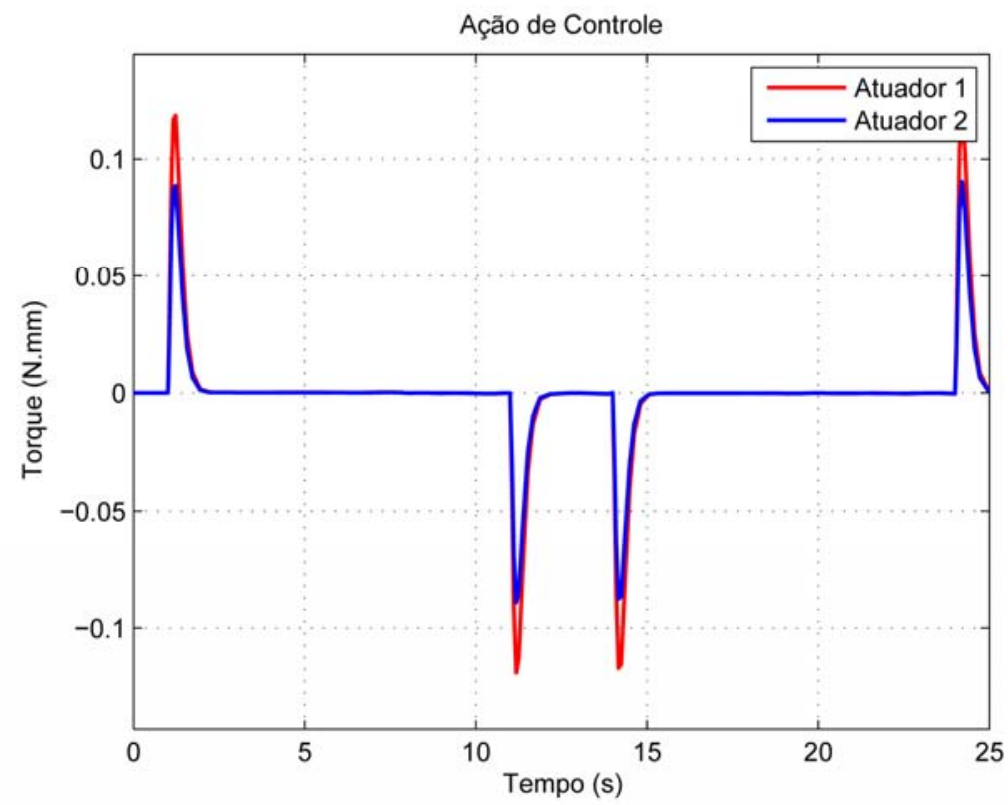

Figura 7.19 - Deslocamento dos atuadores para uma entrada trapezoidal.

Observando os gráficos das simulações do modelo somente com os atuadores, verifica-se que, agora, o modelo tem um comportamento mais próximo do real e com características de desacoplamento exigido pelo modelo real.

Na simulação apresentada na Figura 7.18, tanto o atuador 1 como o atuador 2 tiveram um erro de regime de $0,0001 \mathrm{~mm}$ no patamar superior e da ordem de $10^{-5}$ no retorno dos atuadores à posição zero. 
Pode-se observar que os valores de ação de controle máximos estão bem abaixo das simulações anteriores, mas o fator predominante para isso é o desacoplamento do sistema e em parcela menor o peso e a inércia da plataforma.

Embora, acredita-se ter chegado a um modelo que possa ser utilizado para a obtenção do sistema de controle da plataforma de movimento real, vamos antes verificar $o$ comportamento da simulação para autovalores maiores. Serão utilizadas as mesmas entradas, já utilizadas, com o seguinte conjunto de autovalores $[-19,-19,-20,-20,-21,-21]$ em $\mathrm{rad} / \mathrm{s}$.

Alterando os autovalores utilizados nas simulações anteriores para $\sigma(\overline{\boldsymbol{A}}+\overline{\boldsymbol{B}} \overline{\boldsymbol{K}})=$ $\{-19,-19,-20,-20,-21,-21\}$ para a planta mais o controle e os autovalores do observador como sendo $\sigma(\boldsymbol{A}+\boldsymbol{L C})=\{-40,-40,-41,-41\}$, obtêm-se as matrizes de ganho $\boldsymbol{K}_{1}, \boldsymbol{K}_{2}$ e $\boldsymbol{L}$ que serão utilizadas nas simulações seguintes. Como as matrizes $\boldsymbol{A}, \boldsymbol{B}, \boldsymbol{C}$ e $\boldsymbol{D}$, são as mesmas apresentadas na simulação anterior e os autovalores do observador não se alteraram, as matrizes de ganhos que se alteram são apenas $\boldsymbol{K}_{\mathbf{1}}$ e $\boldsymbol{K}_{\mathbf{2}}$ a matriz de ganhos do observador $\boldsymbol{L}$ permanece igual como se observa abaixo.

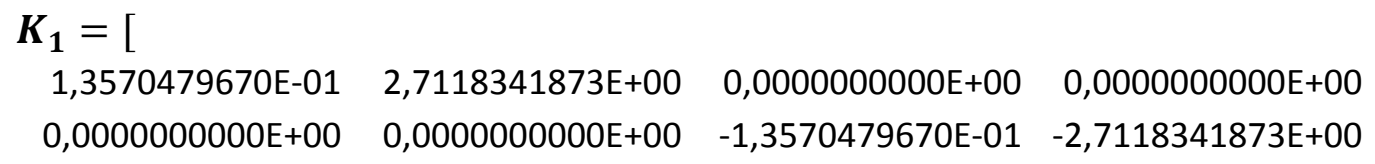


As figuras com as simulações podem ser vistas a seguir.

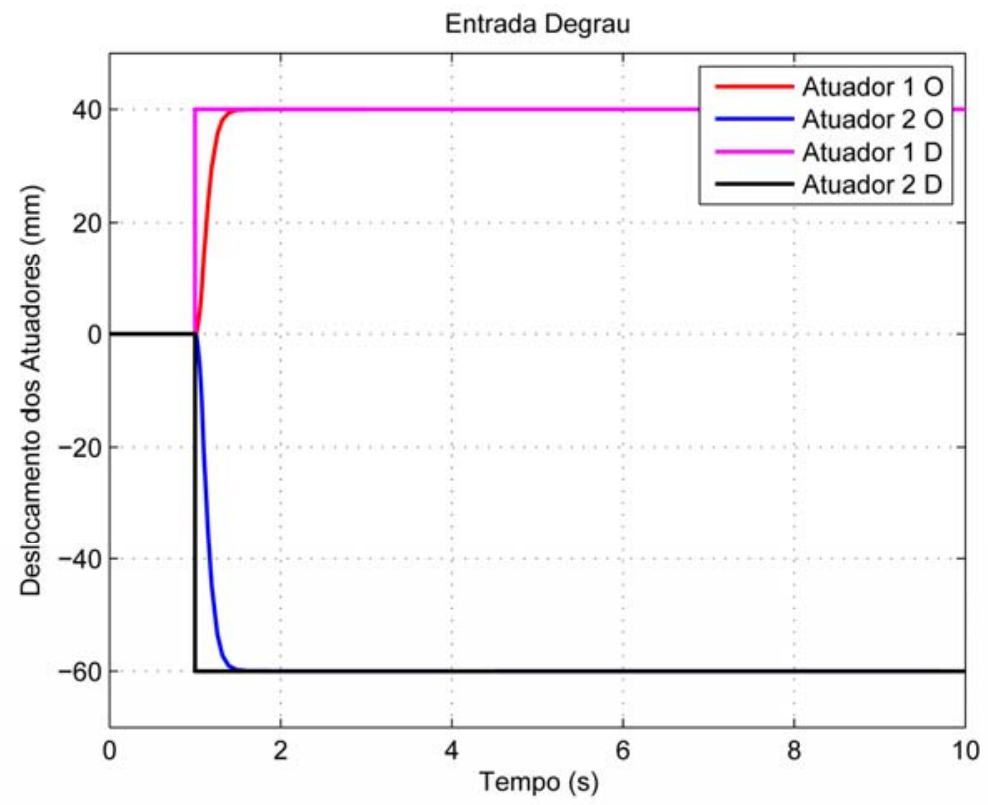

Figura 7.20 - Deslocamentos dos atuadores para uma entrada degrau.

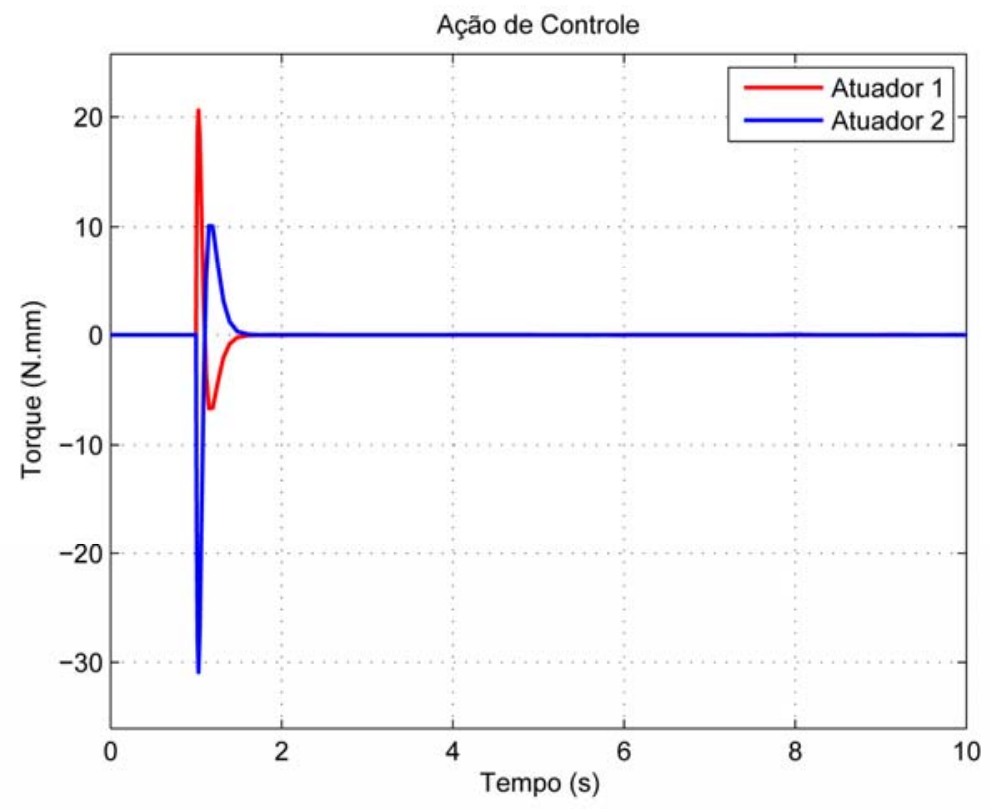

Figura 7.21 - Ação de controle para uma entrada degrau. 


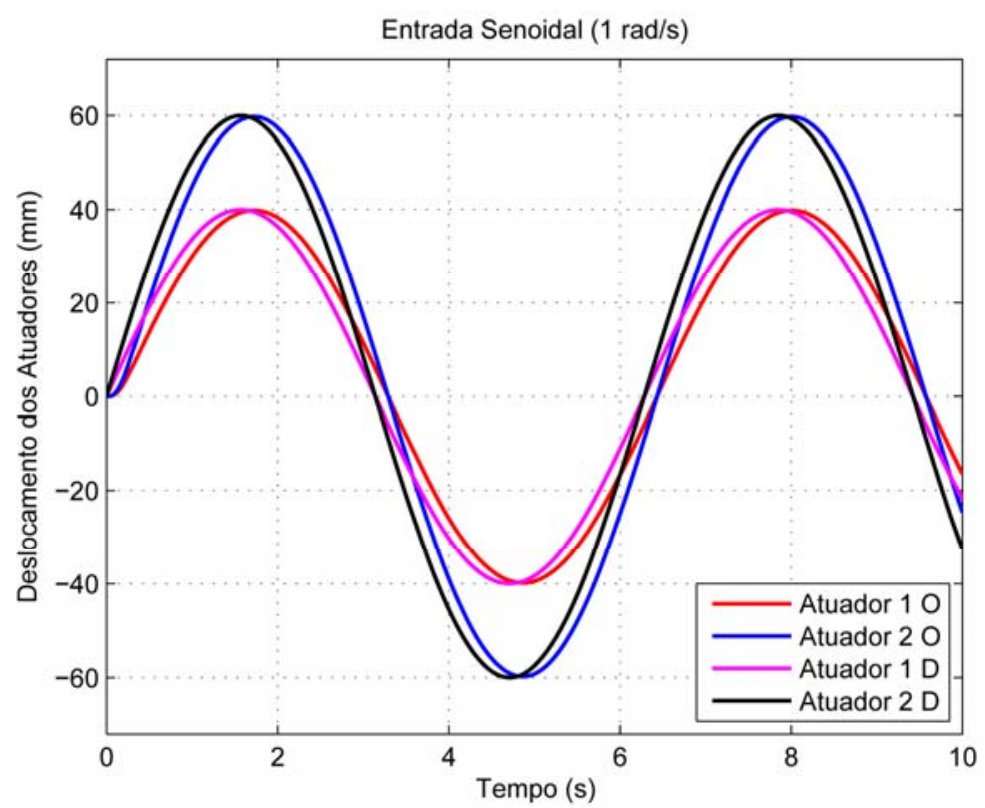

Figura 7.22 - Deslocamentos dos atuadores para uma entrada senoidal de $1 \mathrm{rad} / \mathrm{s}$, deslocamentos diferentes para os atuadores em fase.

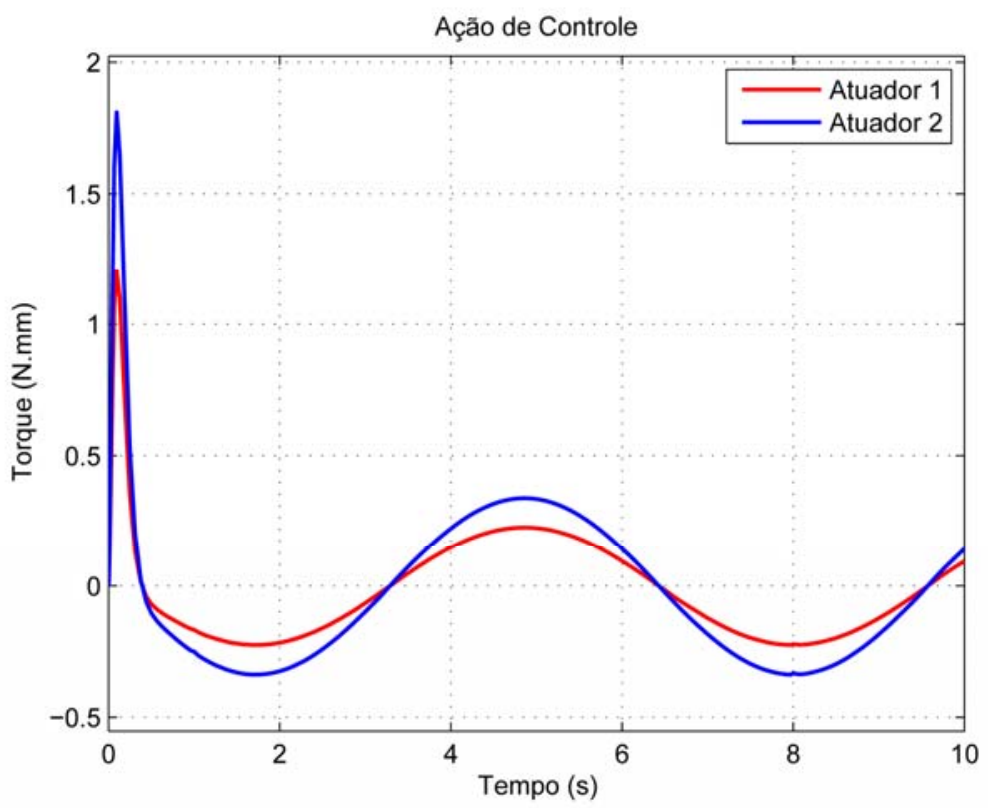

Figura 7.23 - Ação de controle para uma entrada senoidal de $1 \mathrm{rad} / \mathrm{s}$, deslocamentos diferentes para os atuadores em fase. 


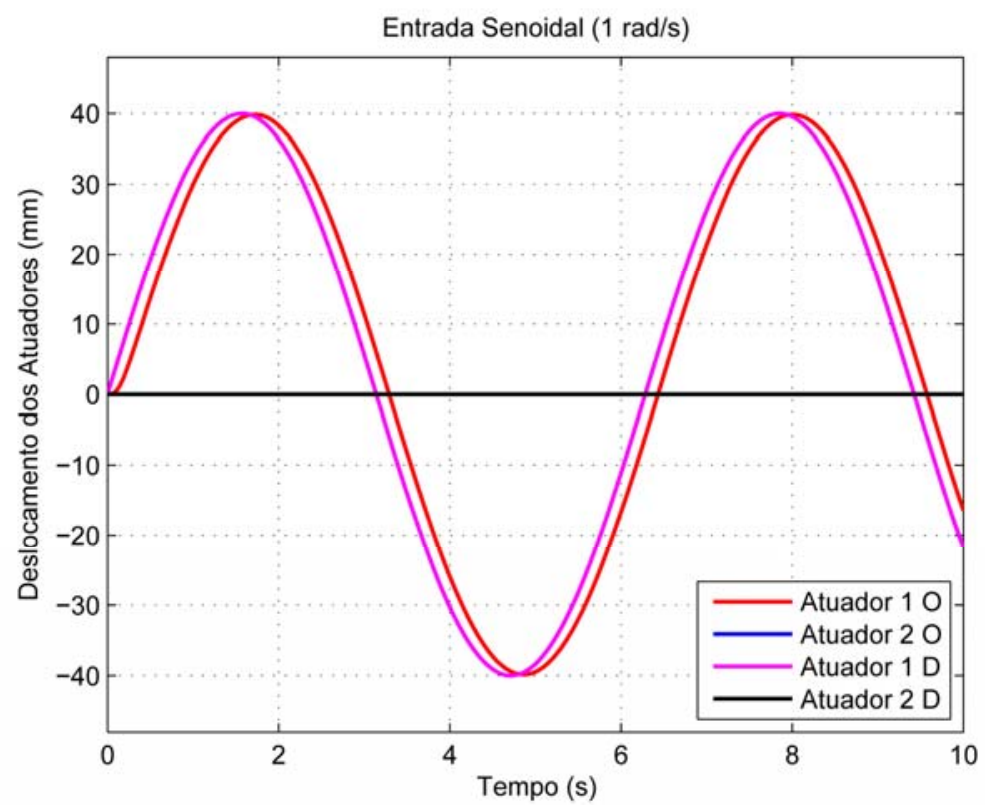

Figura 7.24 - Deslocamentos dos atuadores para uma entrada senoidal de $1 \mathrm{rad} / \mathrm{s}$, deslocamentos diferentes para os atuadores.

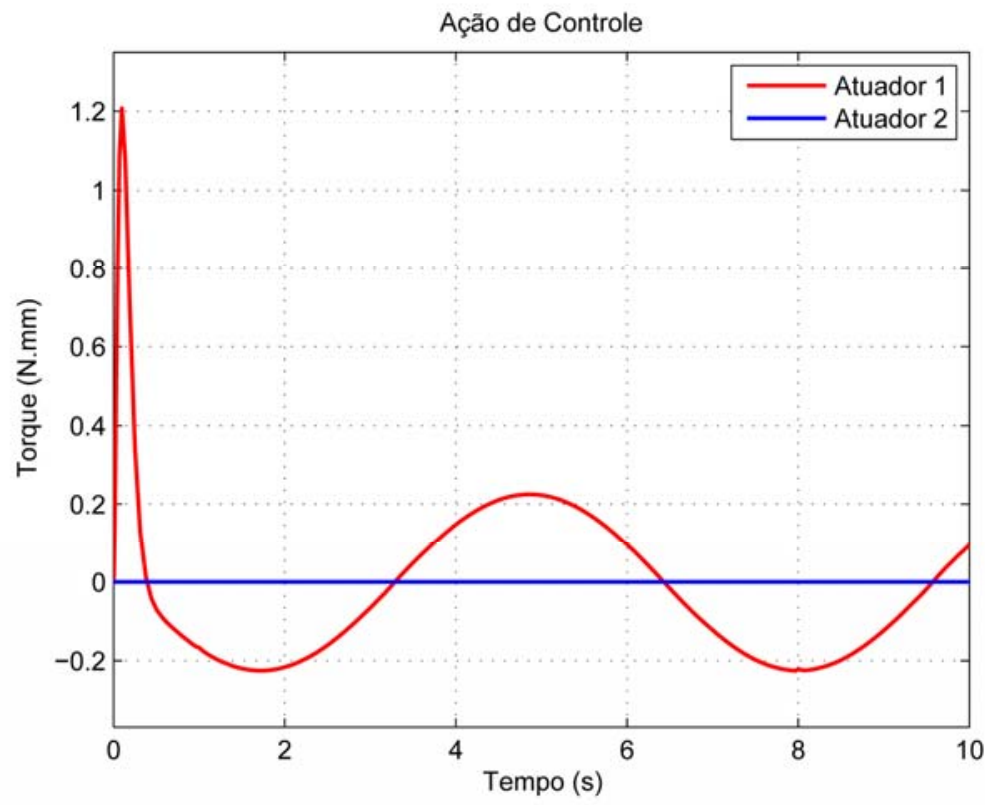

Figura 7.25 - Deslocamentos dos atuadores para uma entrada senoidal de $1 \mathrm{rad} / \mathrm{s}$, deslocamentos diferentes para os atuadores. 


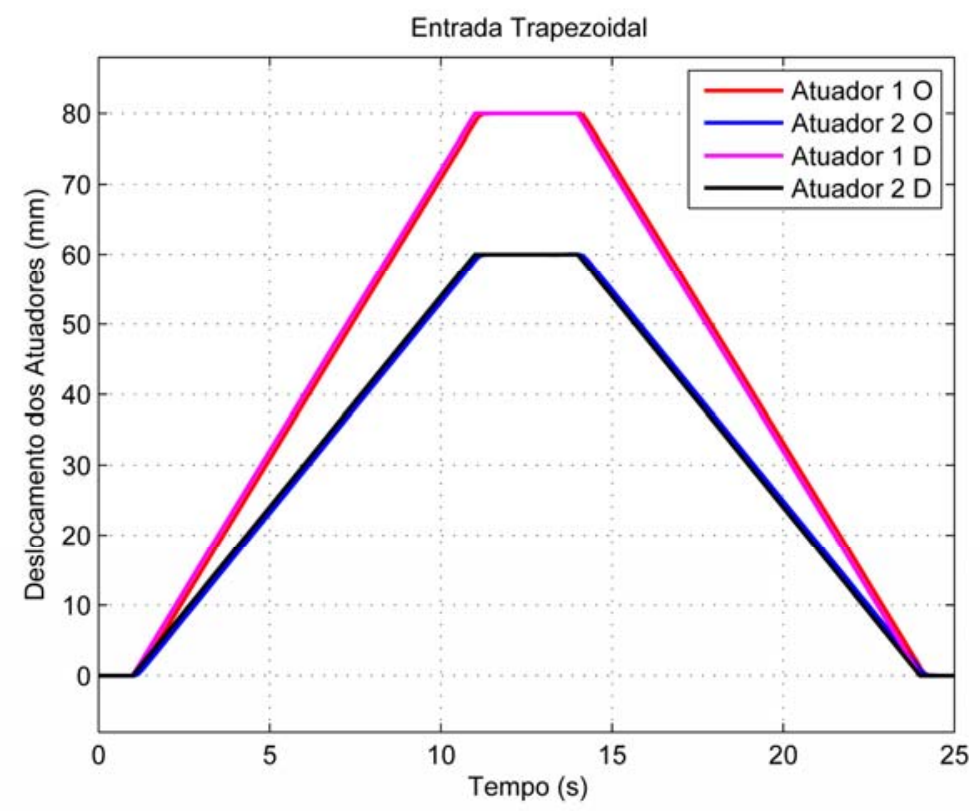

Figura 7.26 - Deslocamentos dos atuadores para uma entrada trapezoidal.

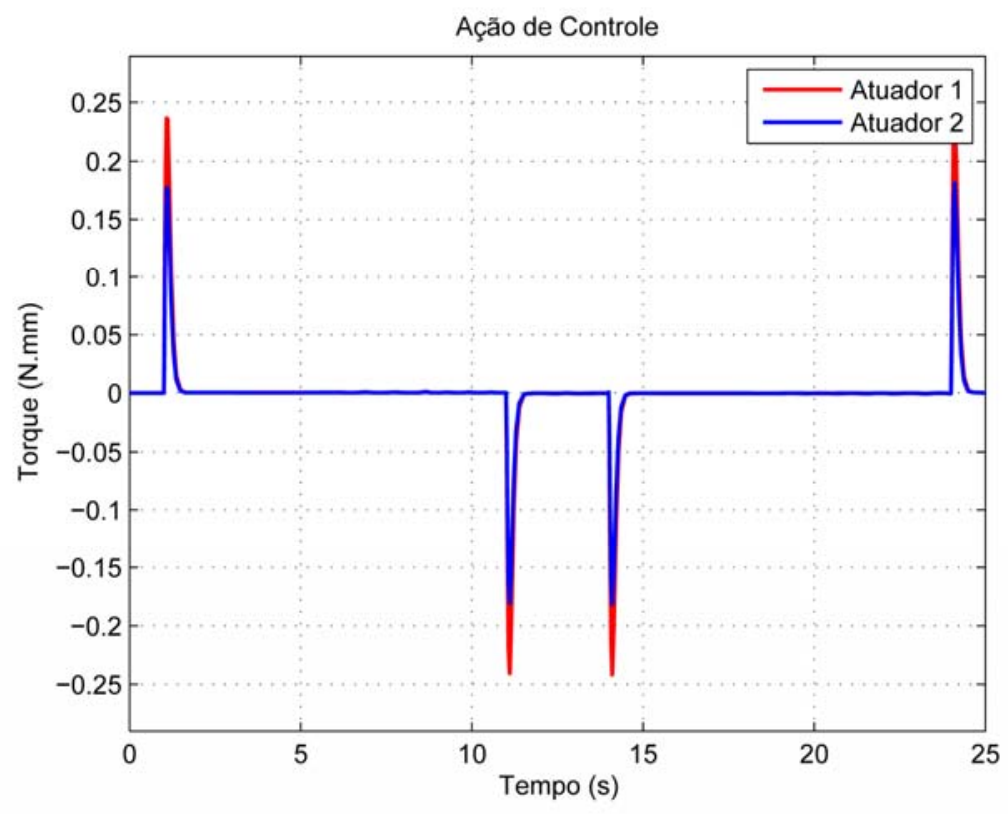

Figura 7.27 - Ação de controle para uma entrada trapezoidal.

Na simulação apresentada na Figura 7.26, tanto o atuador 1 como o atuador 2 tiveram um erro de regime de $-0,0002 \mathrm{~mm}$ no patamar superior e da ordem de $10^{-5}$ no retorno dos atuadores a posição zero.

As simulações com autovalores maiores apresentaram duas características importantes, um menor tempo de atraso da resposta e valores maiores para a ação de controle, conforme já se esperava. 


\section{RESULTADOS EXPERIMENTAIS}

Foram realizados vários ensaios experimentais com o intuito de validar a metodologia apresentada. A partir do modelo desenvolvido no $A D A M S^{\circledR}$, apresentado na Figura 8.1, foram geradas as matrizes do modelo linear usado para determinar as matrizes de ganhos do sistema de controle seguidor apresentado no capítulo 6.

Montou-se o experimento para realizar os ensaios necessários para validação da metodologia (Figura 8.1).

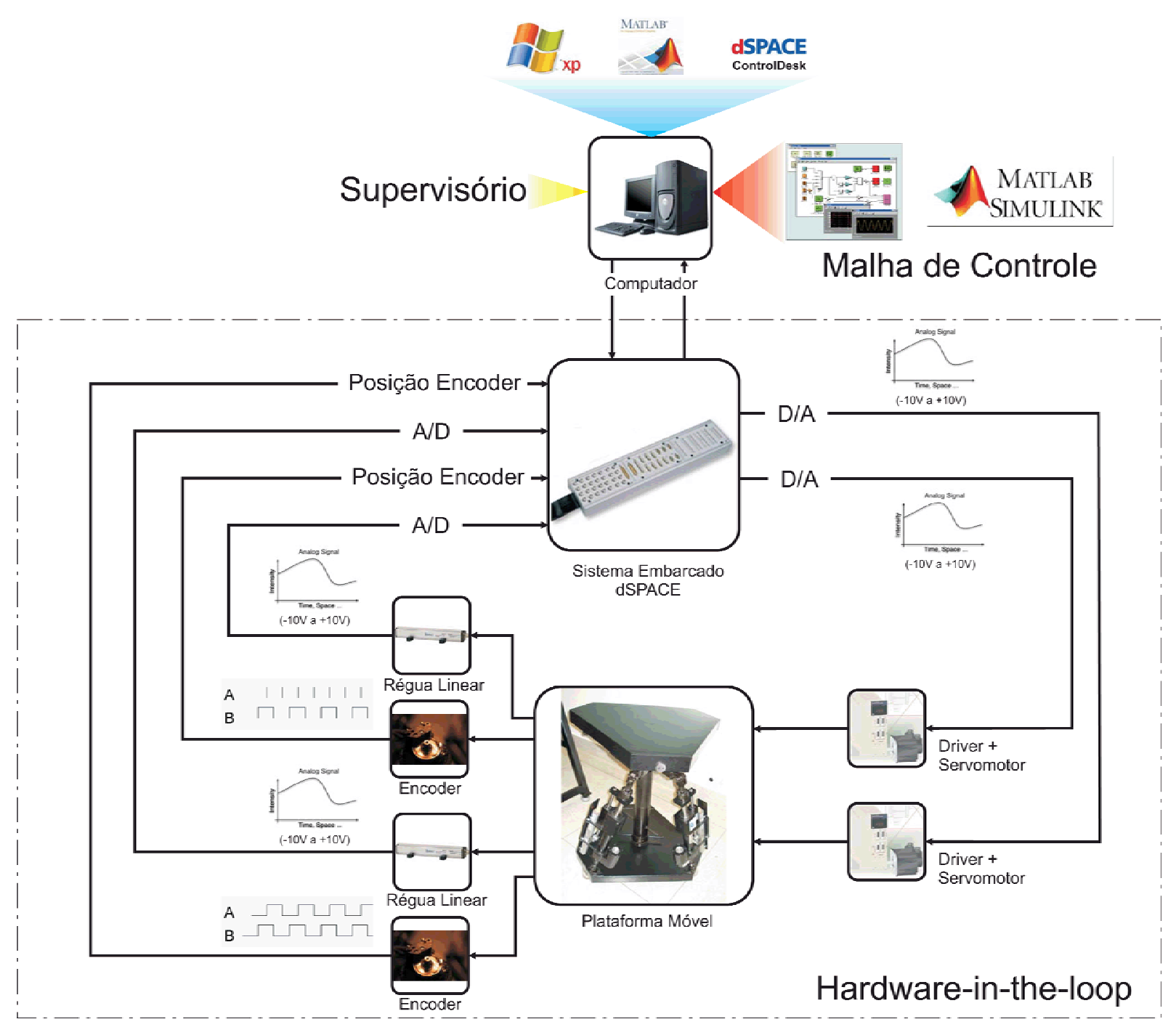

Figura 8.1 - Imagem ilustrativa do sistema hardware-in-the-loop do experimento.

O experimento montado pode ser observado na Figura 8.2. 


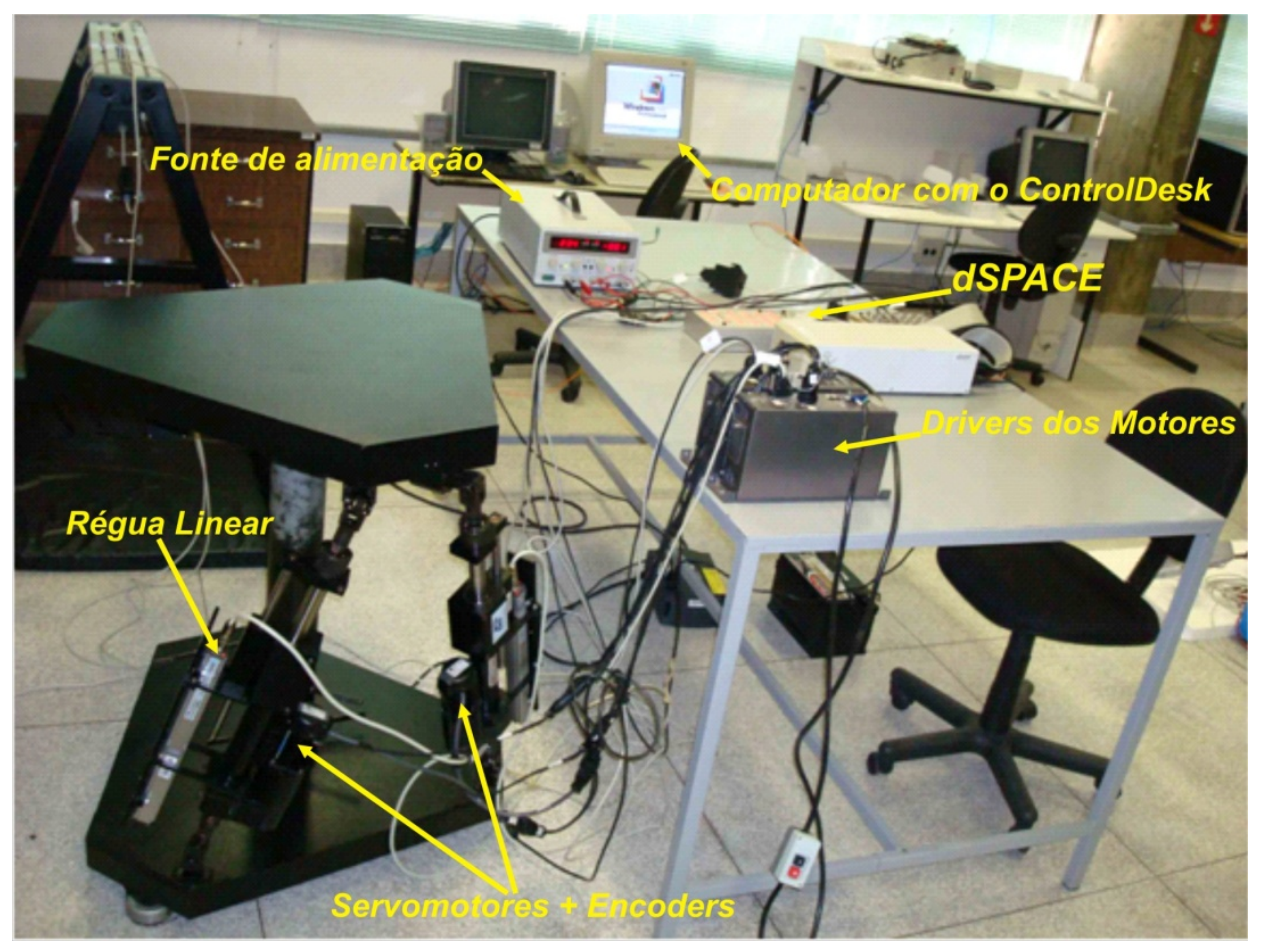

Figura 8.2 - Experimento montado para validação da metodologia.

Os resultados apresentados a seguir, possuem os autovalores $\left(2 x\left[-10 \frac{\mathrm{rad}}{\mathrm{s}},-11 \frac{\mathrm{rad}}{\mathrm{s}}\right.\right.$, $\left.-12 \frac{\mathrm{rad}}{\mathrm{s}}\right]$ ) para o conjunto, planta mais sistema de controle. Exceto onde houver uma indicação contrária.

Levando-se em conta as matrizes das equações de estado e saída geradas pelo $A D A M S^{\circledR}$, para o caso apresentado na Figura 7.11 , alterando os autovalores utilizados anteriormente para $\sigma(\overline{\boldsymbol{A}}+\overline{\boldsymbol{B}} \overline{\boldsymbol{K}})=\{-10,-10,-11,-11,-12,-12\}$ considerando a planta mais o controle, $\mathrm{e}$ os autovalores do observador como sendo $\sigma(\boldsymbol{A}+\boldsymbol{L C})=\{-40,-40,-41,-41\}$, obtêm-se as matrizes de ganho $\boldsymbol{K}_{\mathbf{1}}, \boldsymbol{K}_{\mathbf{2}}$ que faltam para os experimentos seguintes.

$$
\begin{aligned}
& K_{1}=[ \\
& 7,4637638183 \mathrm{E}-02 \quad 8,1875227342 \mathrm{E}-01 \quad 0,0000000000 \mathrm{E}+00 \quad 0,0000000000 \mathrm{E}+00 \\
& K_{2}=[ \\
& 7,3852301039 \mathrm{E}+00 \quad 0,0000000000 \mathrm{E}+00 \\
& 0,0000000000 \mathrm{E}+00 \quad 7,3852301039 \mathrm{E}+00
\end{aligned}
$$$$
0,0000000000 E+00 \quad 0,0000000000 E+00 \quad-7,4637638183 E-02 \quad-8,1875227341 E-01
$$ 


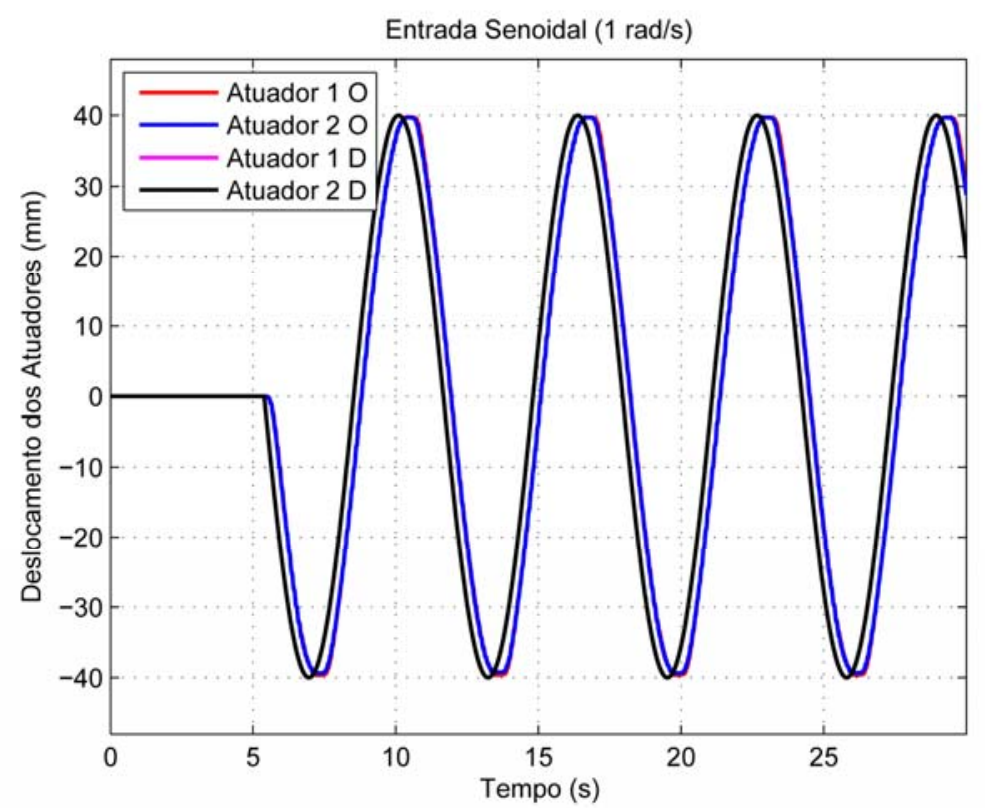

Figura 8.3 - Deslocamentos dos atuadores para uma entrada senoidal de $1 \mathrm{rad} / \mathrm{s}$.

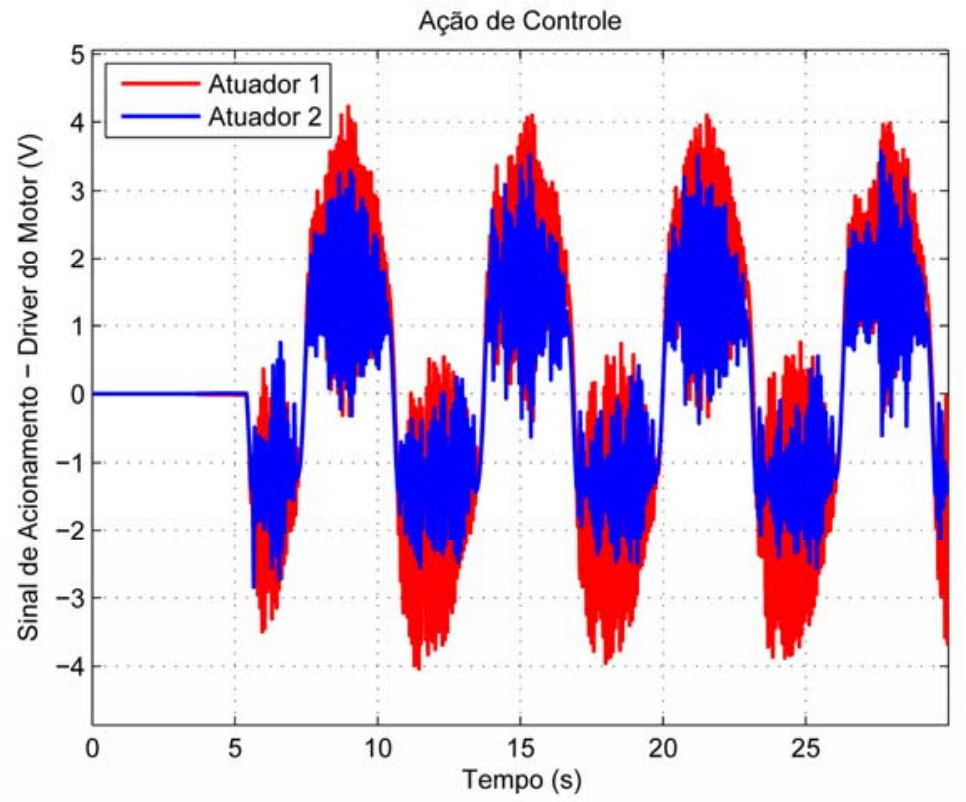

Figura 8.4 - Ação de controle para uma entrada senoidal de $1 \mathrm{rad} / \mathrm{s}$.

Podemos observar através da Figura 8.3 que o controle respondeu de maneira satisfatória, com o mesmo comportamento das simulações, onde podemos observar um atraso na resposta, e como já foi citado, esse atraso pode ser diminuído aumentando-se os autovalores, desde que, se tenha potência necessária no sistema de acionamento. Pode-se observar, algo como, um ruído na ação de controle, apresentado na Figura 8.4, que possivelmente ocorre por se estar trabalhando com o fuso de esferas em velocidades maiores que a especificada. 
Quanto ao torque aplicado pelos motores, o catálogo do fabricante do motor diz que o valor máximo de torque é de 267 oz.in ou aproximadamente 1,88 N.m quando o sinal de acionamento for de $10 \mathrm{~V}$, tanto positivo quanto negativo.

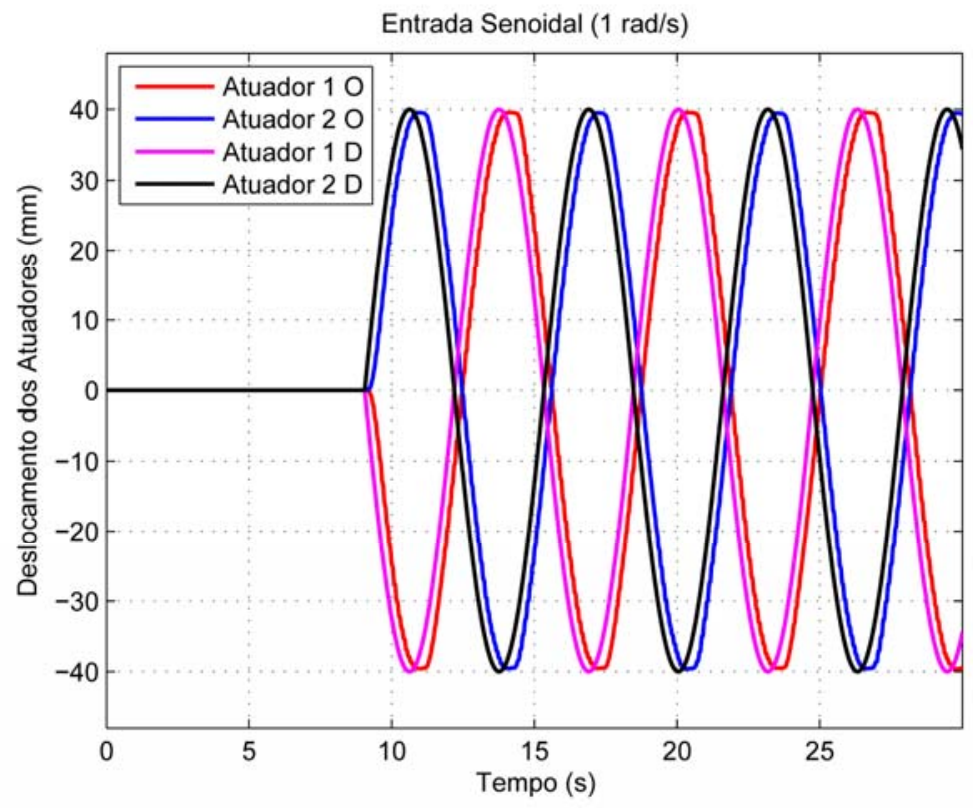

Figura 8.5 - Deslocamentos dos atuadores para uma entrada senoidal de $1 \mathrm{rad} / \mathrm{s}$ com o atuador 2 defasado em $180^{\circ}$ do atuador 1.

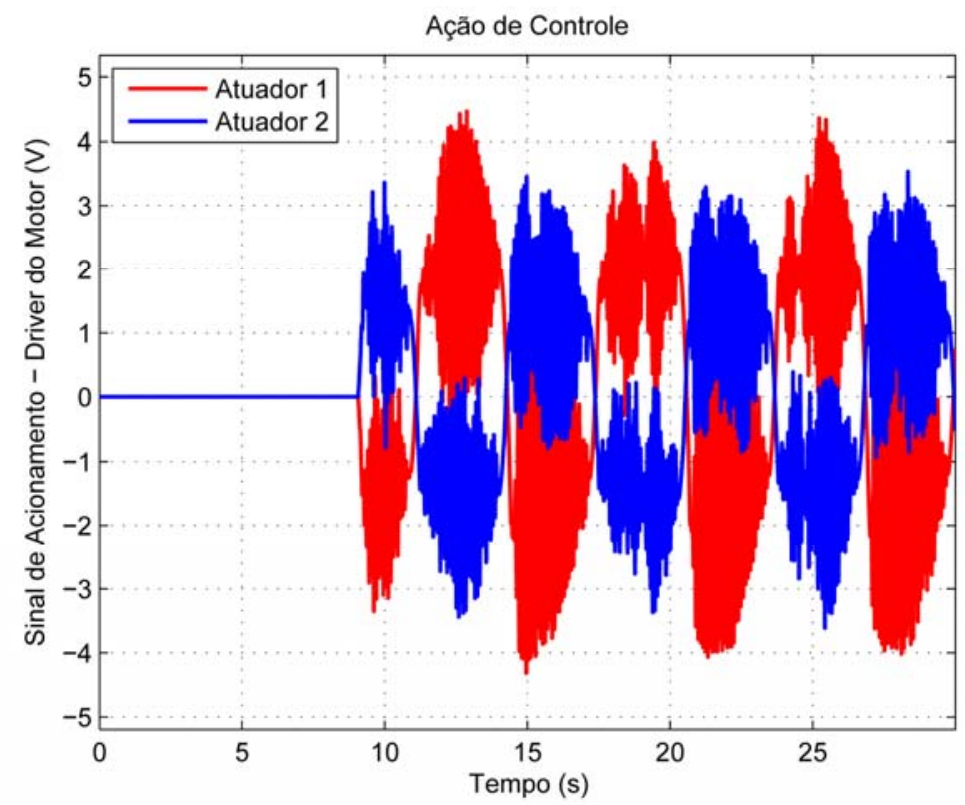

Figura 8.6 - Ação de controle para uma entrada senoidal de $1 \mathrm{rad} / \mathrm{s}$ com o atuador 2 defasado em $180^{\circ}$ do atuador 1 . 


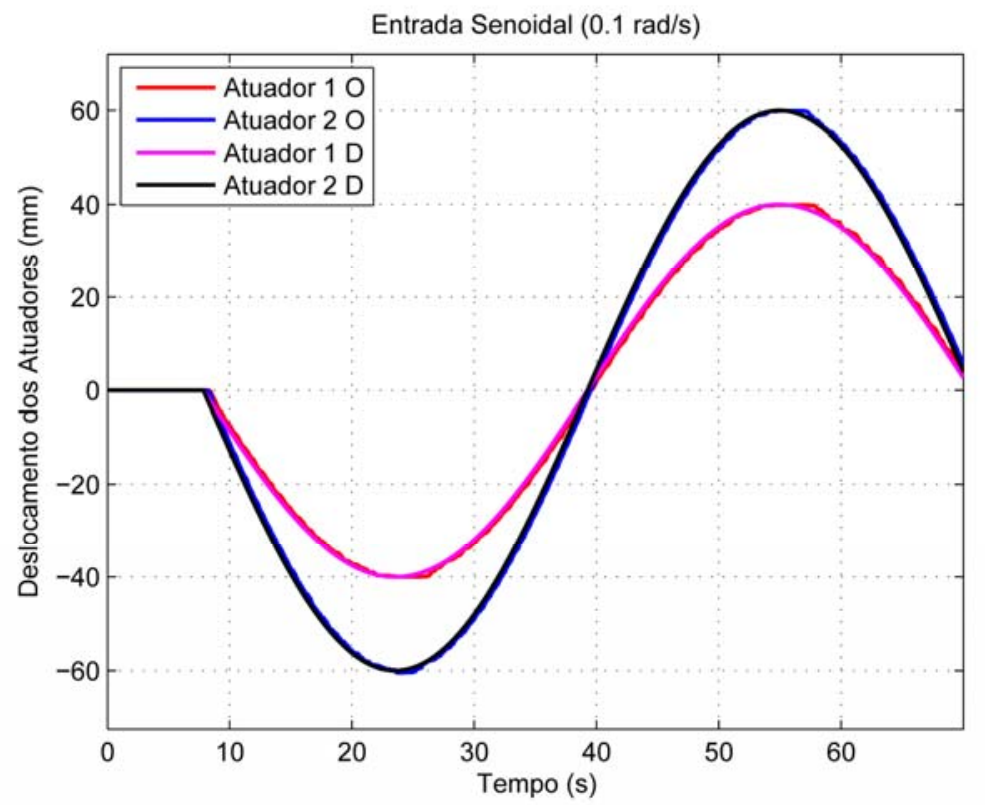

Figura 8.7 - Deslocamentos dos atuadores para uma entrada senoidal de $0,1 \mathrm{rad} / \mathrm{s}$ deslocamento diferente para os atuadores, em fase.

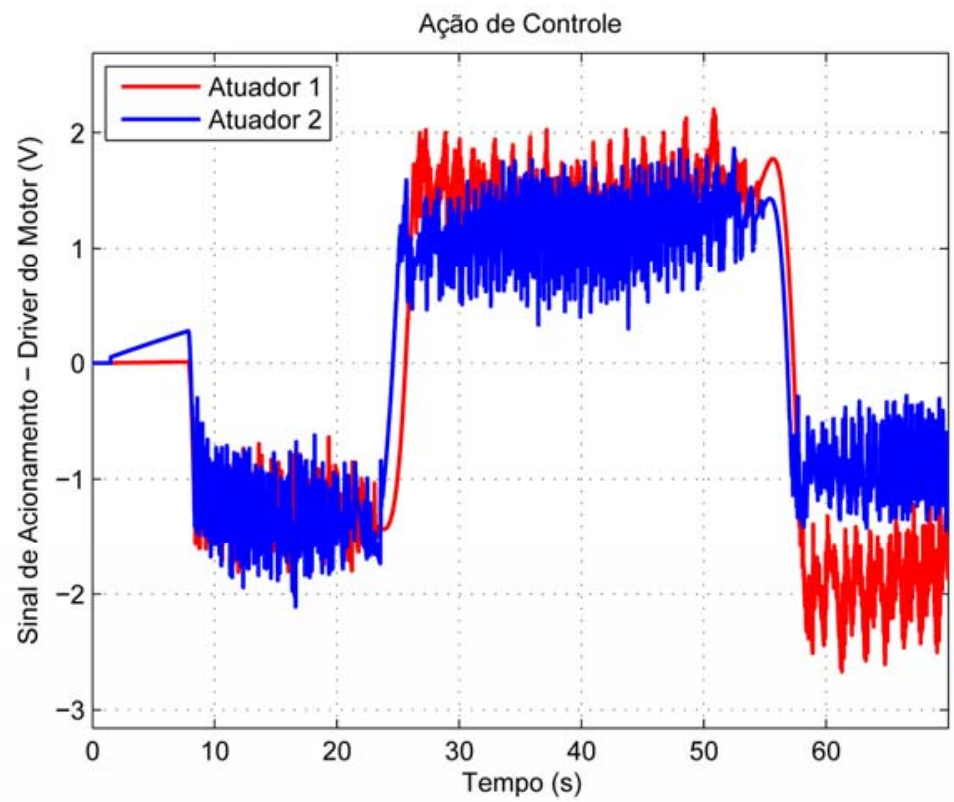

Figura 8.8 - Ação de controle para uma entrada senoidal de $0,1 \mathrm{rad} / \mathrm{s}$ deslocamento diferente para os atuadores em fase.

Para valores muito diferentes entre a freqüência do seno, $0,1 \mathrm{rad} / \mathrm{s}$, a ser seguido e os autovalores atribuídos ao sistema, em torno de $-11 \mathrm{rad} / \mathrm{s}$, o atraso da resposta se torna muito pequeno. 


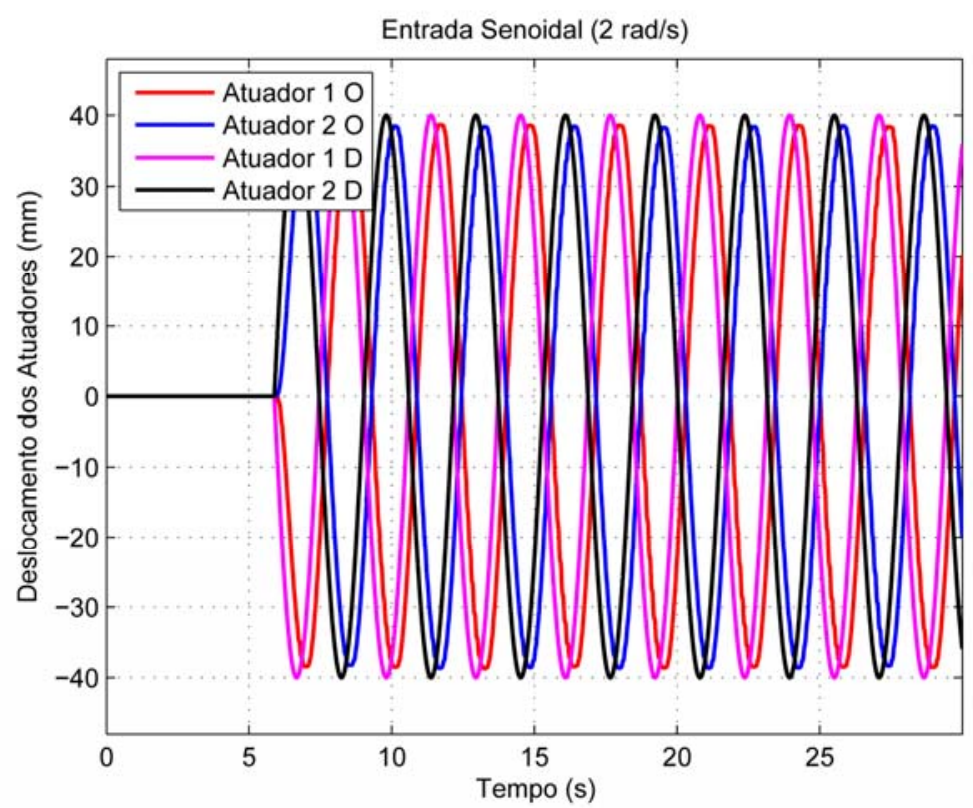

Figura 8.9 - Deslocamentos dos atuadores para uma entrada senoidal de $2 \mathrm{rad} / \mathrm{s}$ com o atuador 2 defasado em $180^{\circ}$ do atuador 1 .

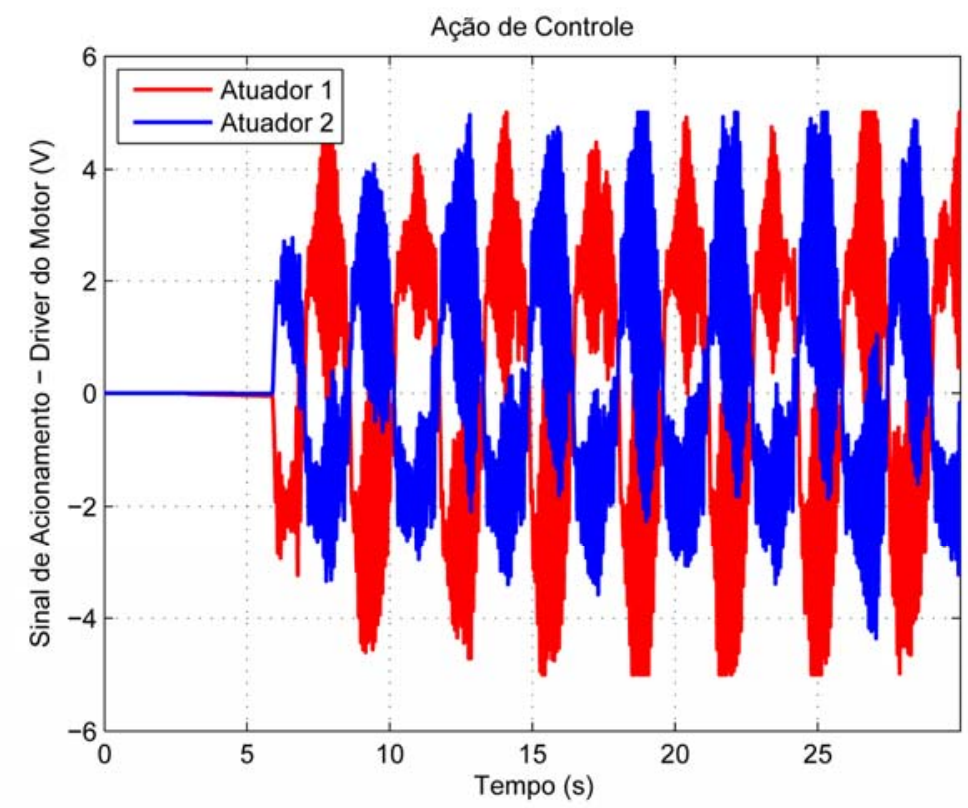

Figura 8.10 - Ação de controle para uma entrada senoidal de $2 \mathrm{rad} / \mathrm{s}$ com o atuador 2 defasado em $180^{\circ}$ do atuador 1.

Como as ações de controle dos motores, por motivo de segurança, estavam com uma saturação de $\pm 5 \mathrm{~V}$, na Figura 8.10 pode-se observar alguns pontos de saturação da ação de controle, mas que não afetaram significativamente a resposta final da plataforma. 


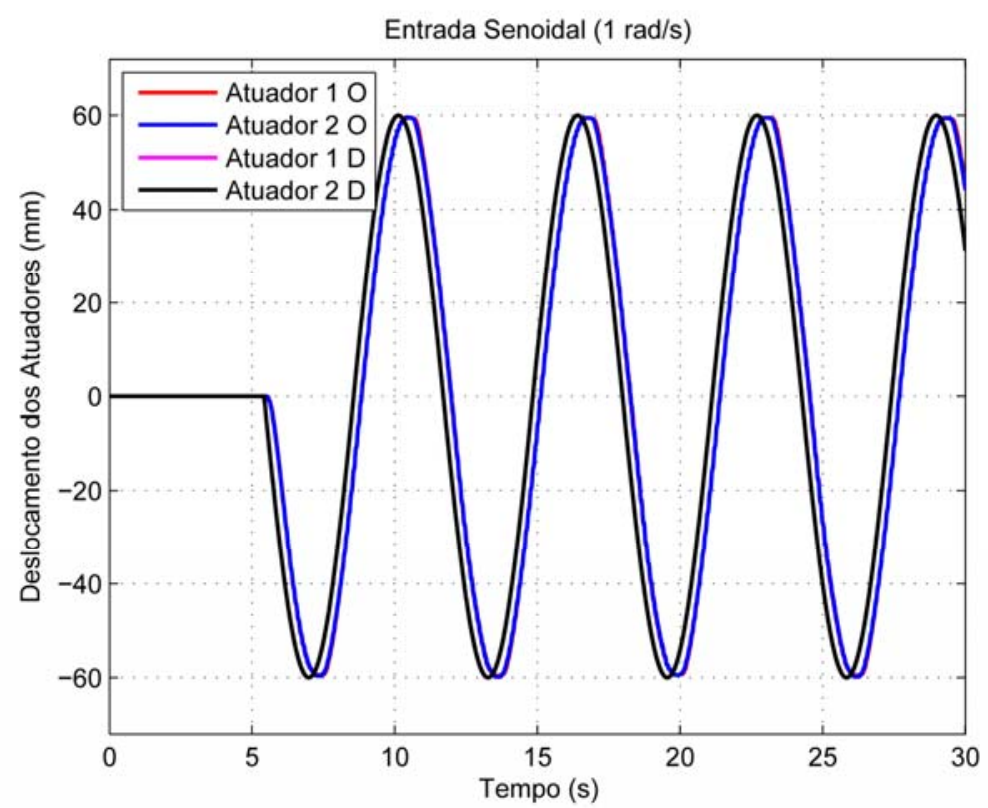

Figura 8.11 - Deslocamentos dos atuadores para uma entrada senoidal de $1 \mathrm{rad} / \mathrm{s}$.

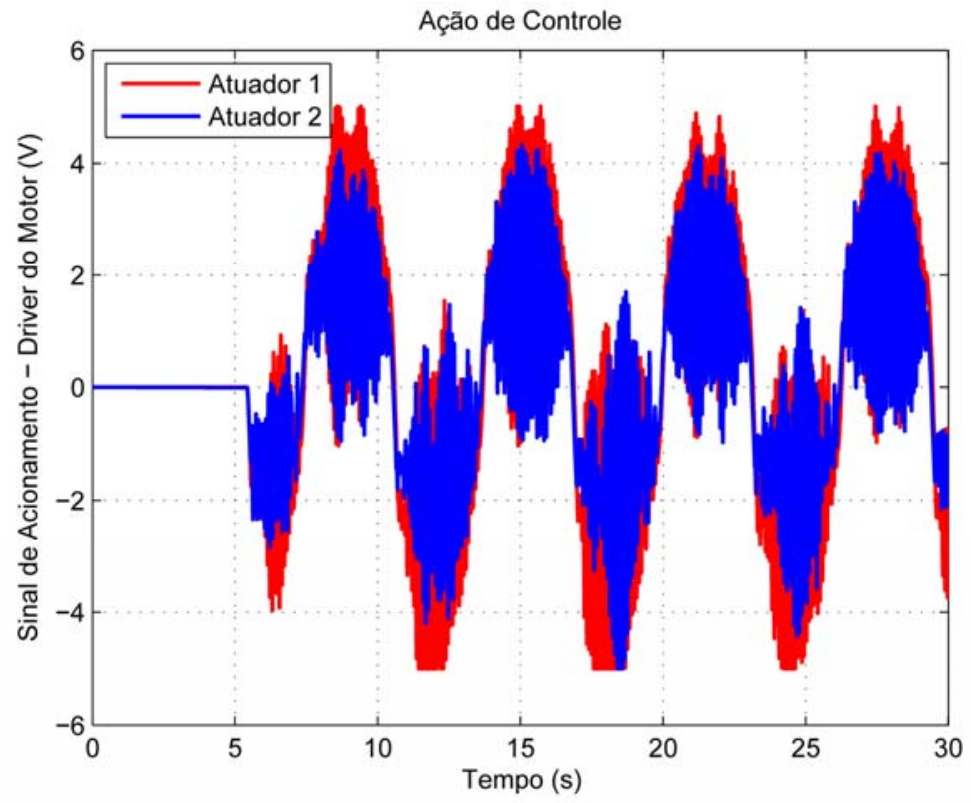

Figura 8.12 - Ação de controle para uma entrada senoidal de $1 \mathrm{rad} / \mathrm{s}$. 


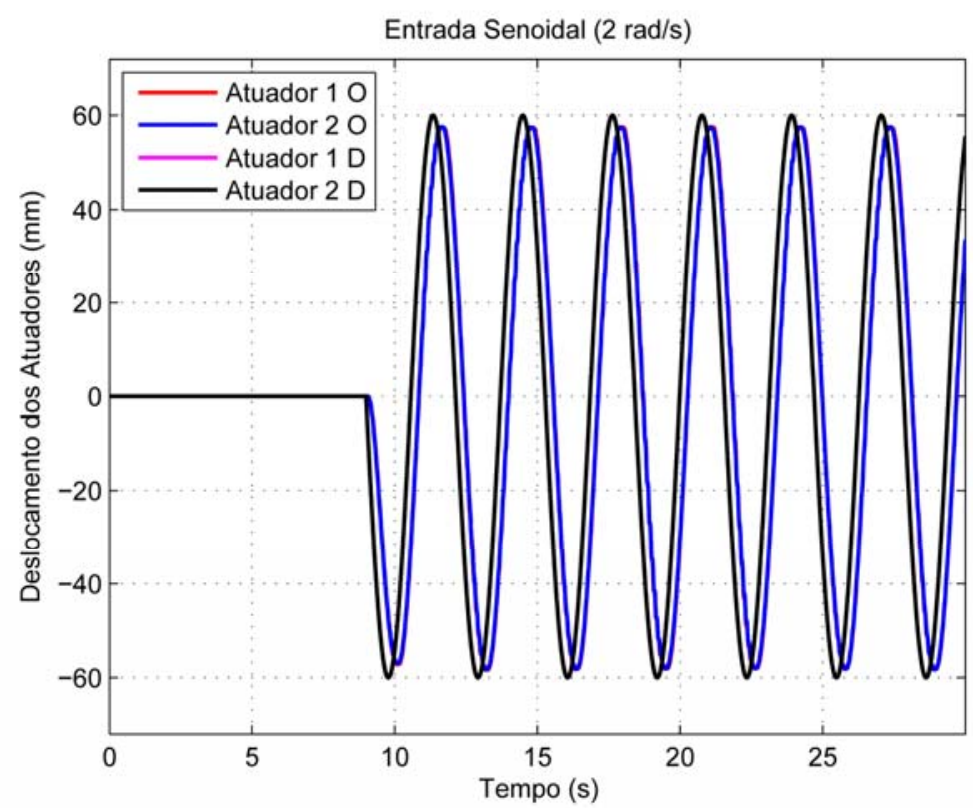

Figura 8.13 - Deslocamentos dos atuadores para uma entrada senoidal de $2 \mathrm{rad} / \mathrm{s}$.

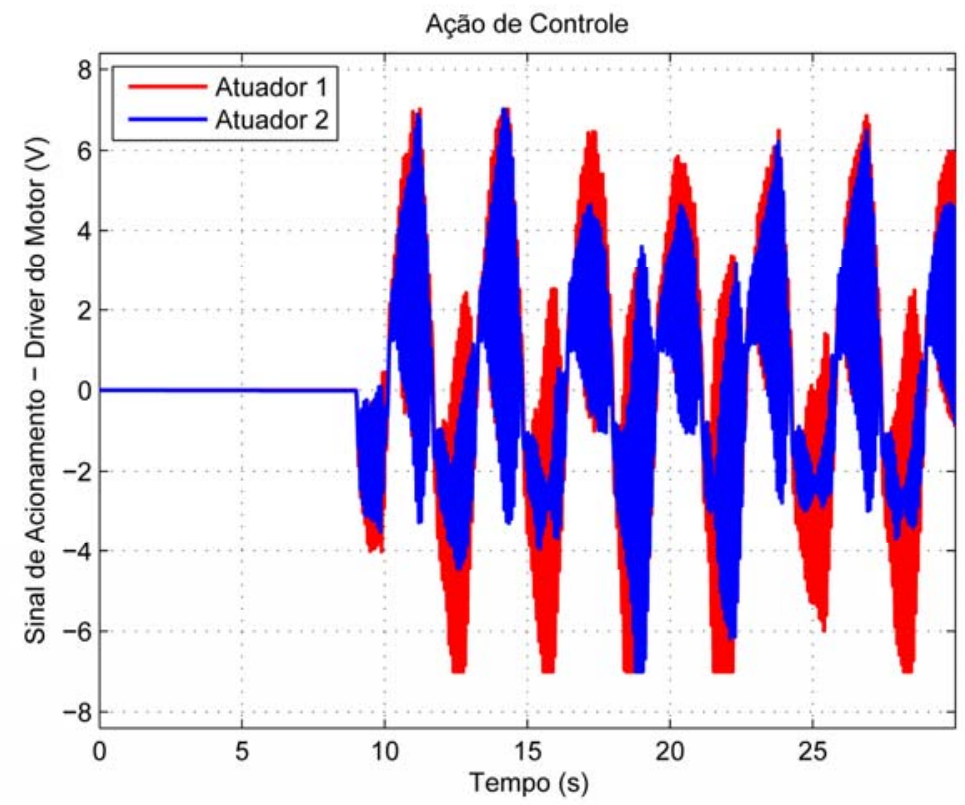

Figura 8.14 - Ação de controle para uma entrada senoidal de $2 \mathrm{rad} / \mathrm{s}$.

Observa-se uma significativa variação nas características da ação de controle à medida que se aumenta a velocidade de resposta da plataforma, tais variações necessitariam de estudos mais aprofundados e de novos ensaios para que se possa caracterizá-las, e podem ser observadas nas Figuras 8.12 e 8.14. 


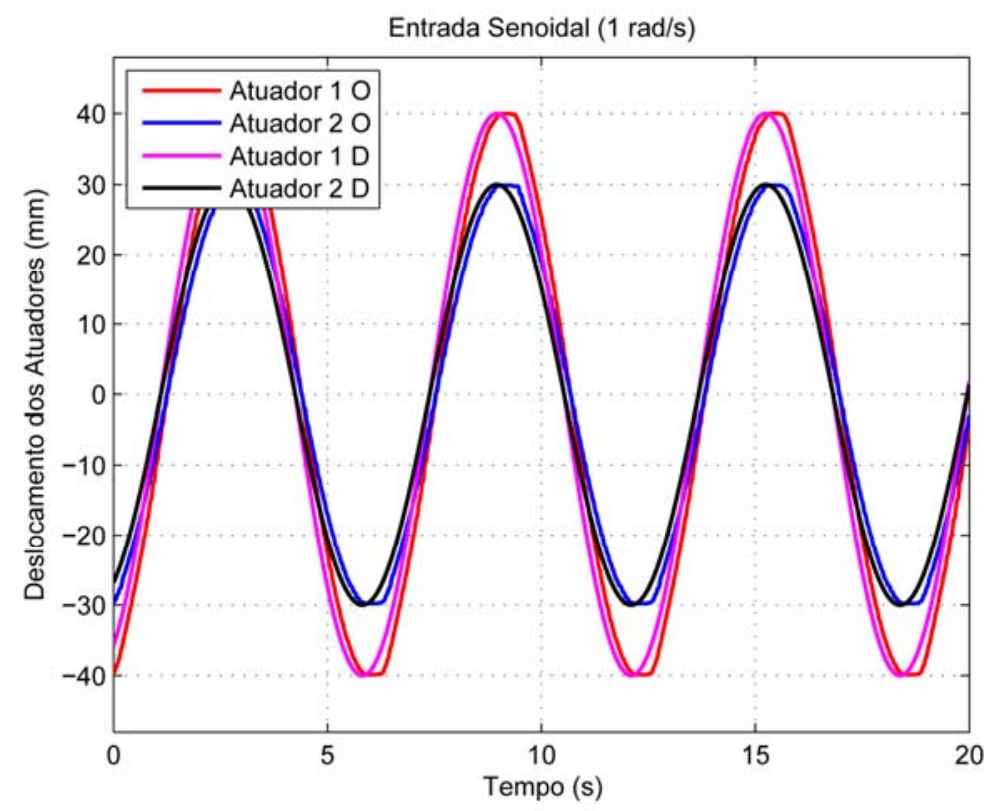

Figura 8.15 - Deslocamentos dos atuadores para uma entrada senoidal de $1 \mathrm{rad} / \mathrm{s}$ deslocamentos diferentes para os atuadores em fase $\left(2 x\left[-19 \frac{\mathrm{rad}}{\mathrm{s}},-20 \frac{\mathrm{rad}}{\mathrm{s}},-21 \frac{\mathrm{rad}}{\mathrm{s}}\right]\right)$.

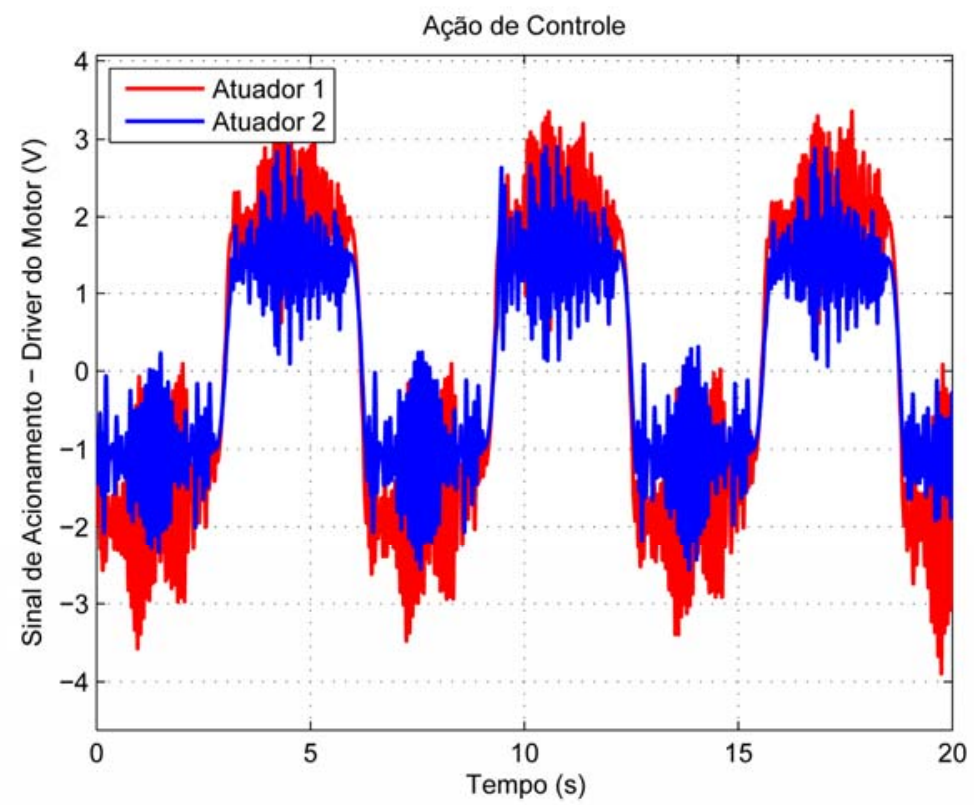

Figura 8.16 - Ação de controle para uma entrada senoidal de $1 \mathrm{rad} / \mathrm{s}$ deslocamentos diferentes para os atuadores em fase $\left(2 x\left[-19 \frac{\mathrm{rad}}{\mathrm{s}},-20 \frac{\mathrm{rad}}{\mathrm{s}},-21 \frac{\mathrm{rad}}{\mathrm{s}}\right]\right)$.

A realização de ensaios da plataforma móvel para conjuntos de autovalores diferentes, tem o objetivo de demonstrar as características de resposta no tempo, que se alteraram, à medida que se mudam os autovalores atribuídos ao sistema. Os principais, mais uma vez, são o tempo de atraso da resposta que diminui e a ação de controle que aumenta, exigindo mais potência dos motores. 


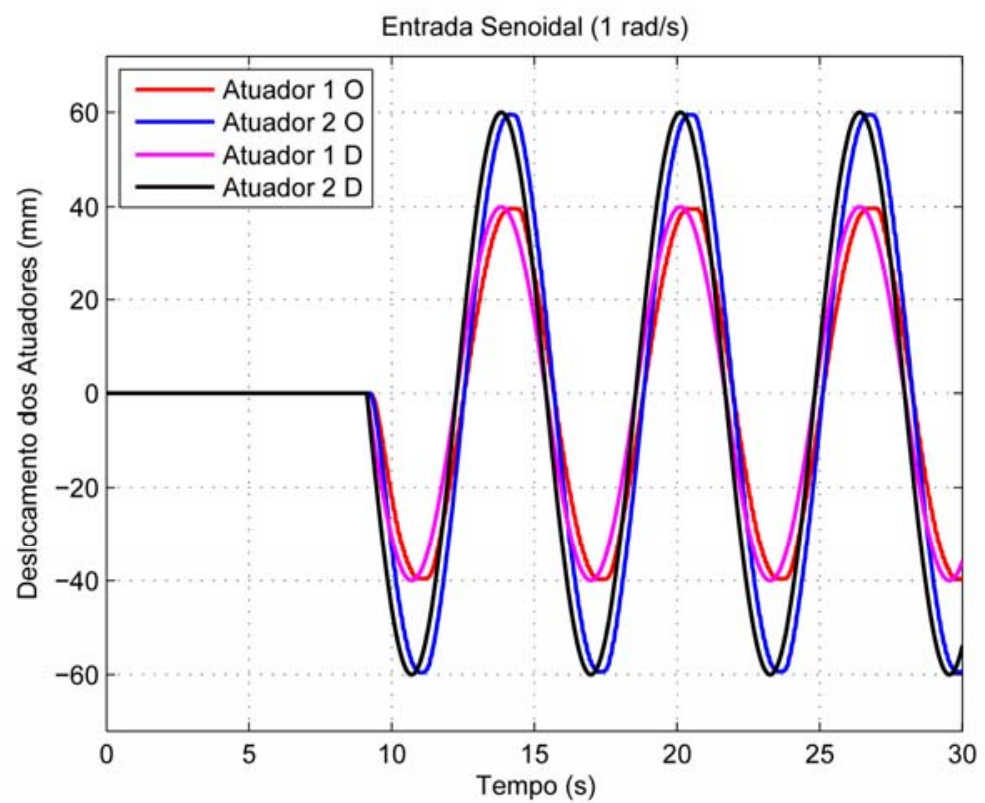

Figura 8.17 - Deslocamentos dos atuadores para uma entrada senoidal de $1 \mathrm{rad} / \mathrm{s}$, deslocamentos diferentes para os atuadores em fase.

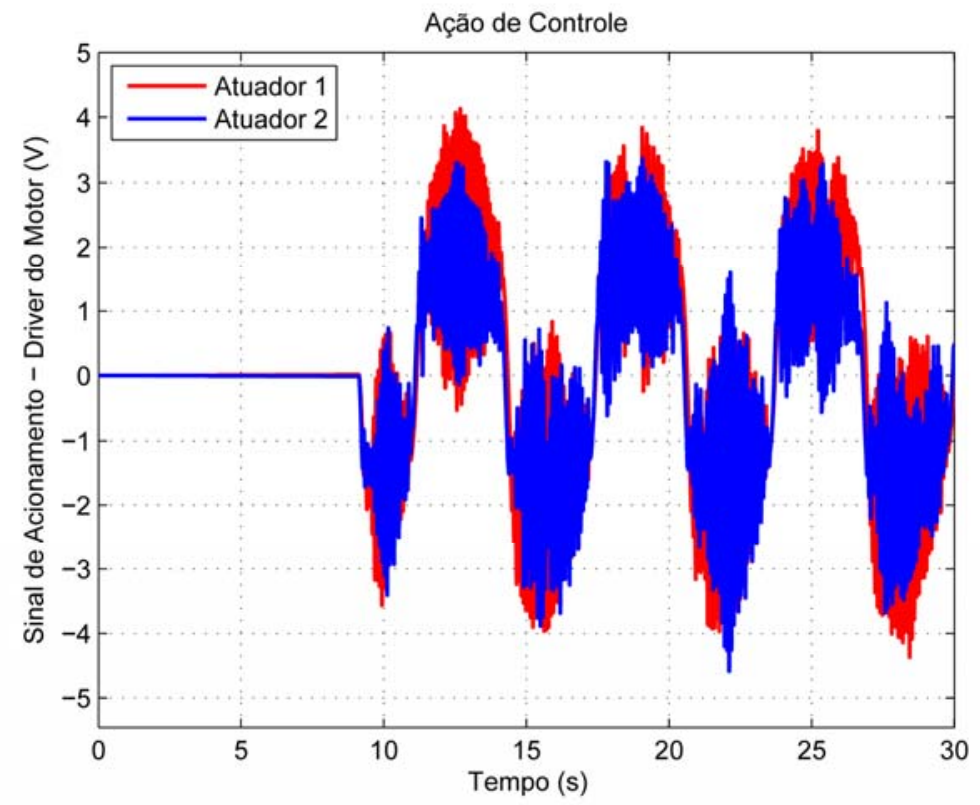

Figura 8.18 - Ação de controle para uma entrada senoidal de $1 \mathrm{rad} / \mathrm{s}$, deslocamentos diferentes para os atuadores em fase. 


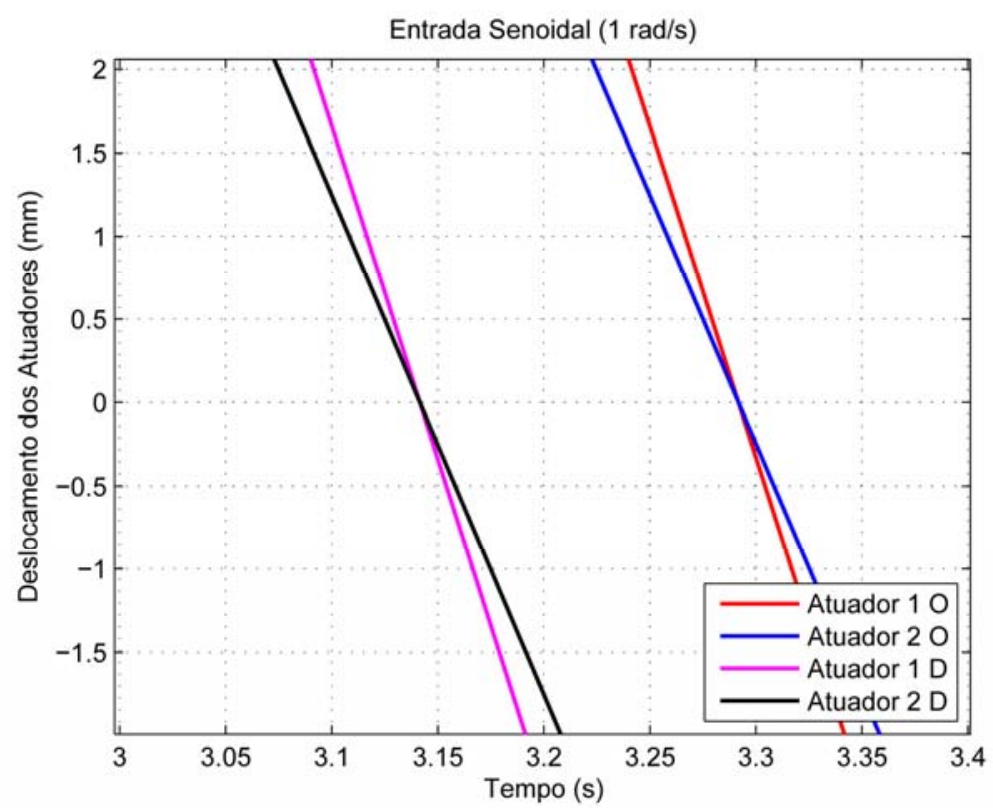

Figura 8.19 - Detalhe do atraso na resposta do controle, na simulação, para deslocamentos máximos de $40 \mathrm{~mm}$ e $30 \mathrm{~mm}$ para os atuadores em fase $\left(2 x\left[-19 \frac{\mathrm{rad}}{\mathrm{s}},-20 \frac{\mathrm{rad}}{\mathrm{s}},-21 \frac{\mathrm{rad}}{\mathrm{s}}\right]\right)$.

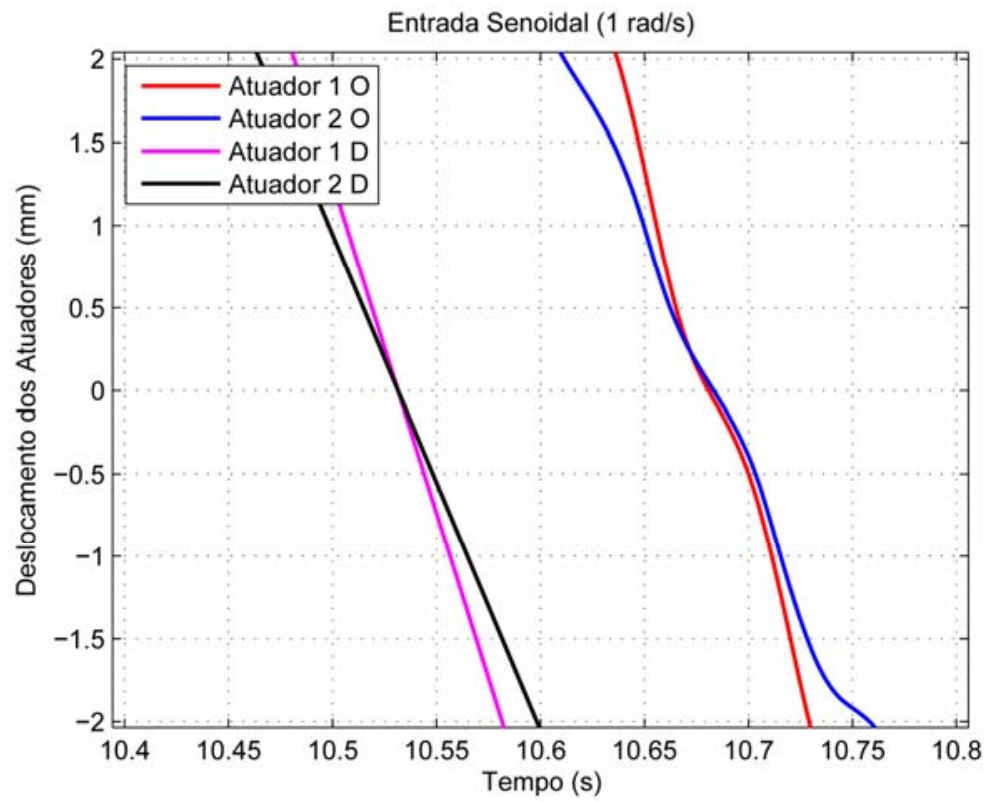

Figura 8.20 - Detalhe do atraso na resposta real do controle para deslocamentos máximos de $40 \mathrm{~mm}$ e $30 \mathrm{~mm}$ para os atuadores em fase $\left(2 x\left[-19 \frac{\mathrm{rad}}{\mathrm{s}},-20 \frac{\mathrm{rad}}{\mathrm{s}},-21 \frac{\mathrm{rad}}{\mathrm{s}}\right]\right)$. 
Pode-se observar que o tempo de atraso tanto na resposta simulada, Figura 8.19, como na resposta real da plataforma, Figuras 8.20 , estão muito próximos de $0,15 \mathrm{~s}$ para o conjunto de autovalores atribuídos.

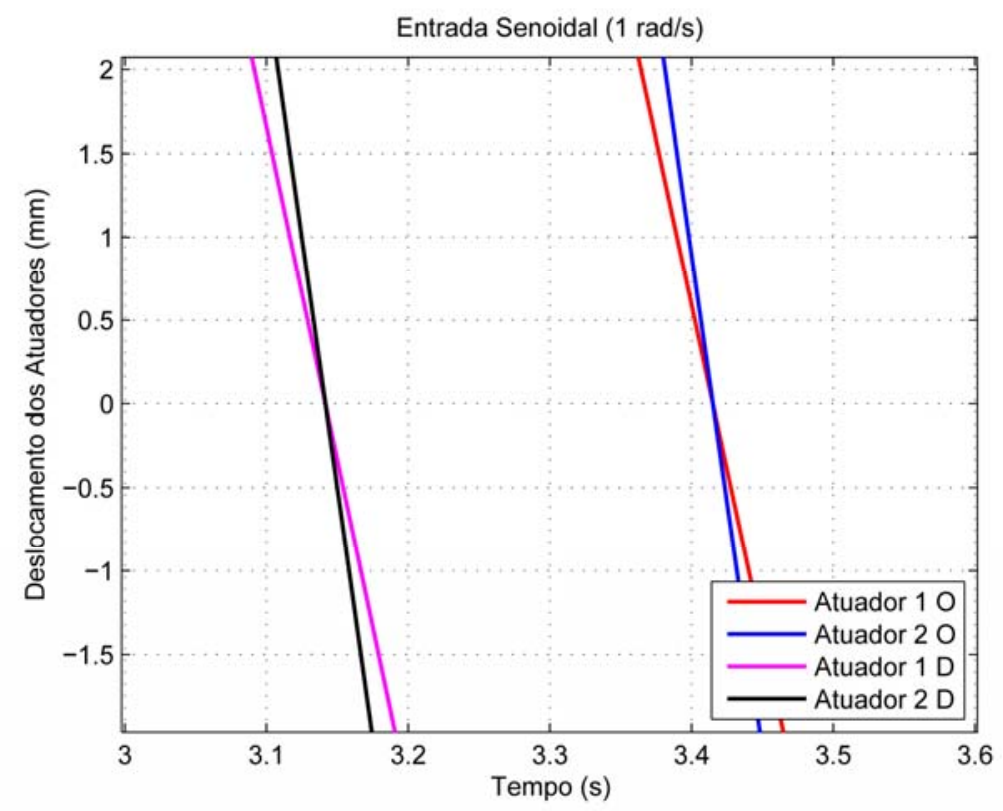

Figura 8.21 - Detalhe do atraso na resposta do controle, na simulação, para deslocamentos máximos de $40 \mathrm{~mm}$ e $60 \mathrm{~mm}$ para os atuadores em fase $\left(2 x\left[-10 \frac{\mathrm{rad}}{\mathrm{s}},-11 \frac{\mathrm{rad}}{\mathrm{s}},-12 \frac{\mathrm{rad}}{\mathrm{s}}\right]\right)$.

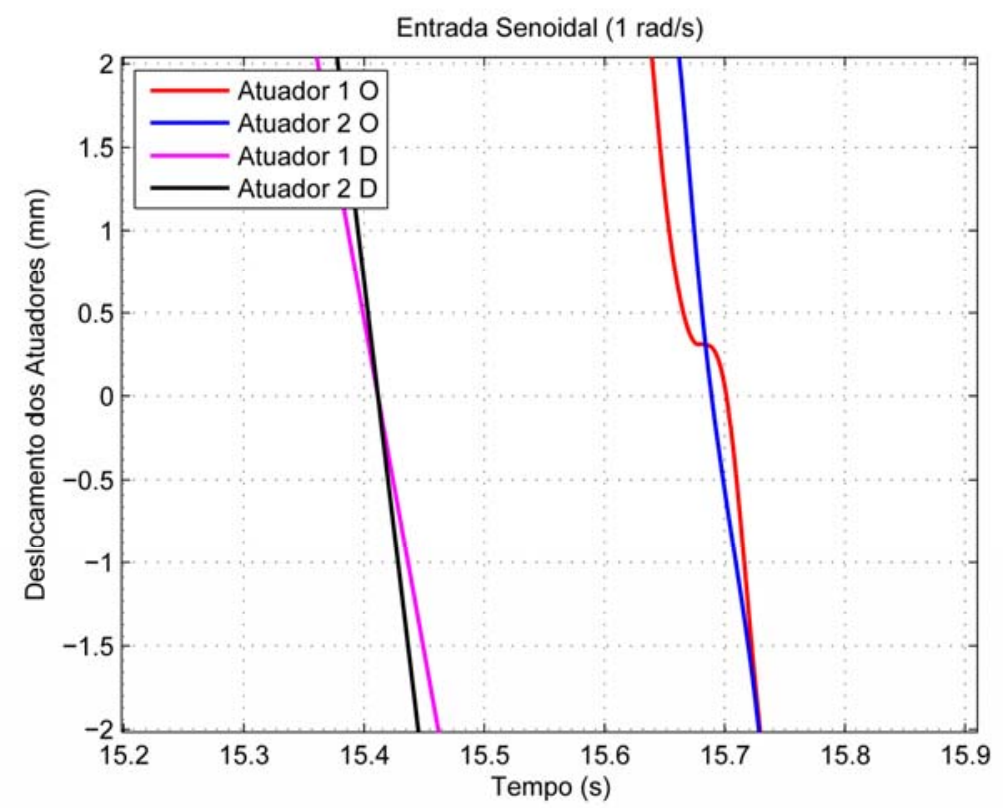

Figura 8.22 - Detalhe do atraso na resposta real do controle para deslocamentos máximos de $40 \mathrm{~mm}$ e $60 \mathrm{~mm}$ para os atuadores em fase $\left(2 x\left[-10 \frac{\mathrm{rad}}{\mathrm{s}},-11 \frac{\mathrm{rad}}{\mathrm{s}},-12 \frac{\mathrm{rad}}{\mathrm{s}}\right]\right)$. 
Pode-se observar que o tempo de atraso tanto na resposta simulada, Figura 8.21, como na resposta real da plataforma, Figuras 8.22 , estão muito próximos de $0,28 \mathrm{~s}$ para o conjunto de autovalores atribuídos.

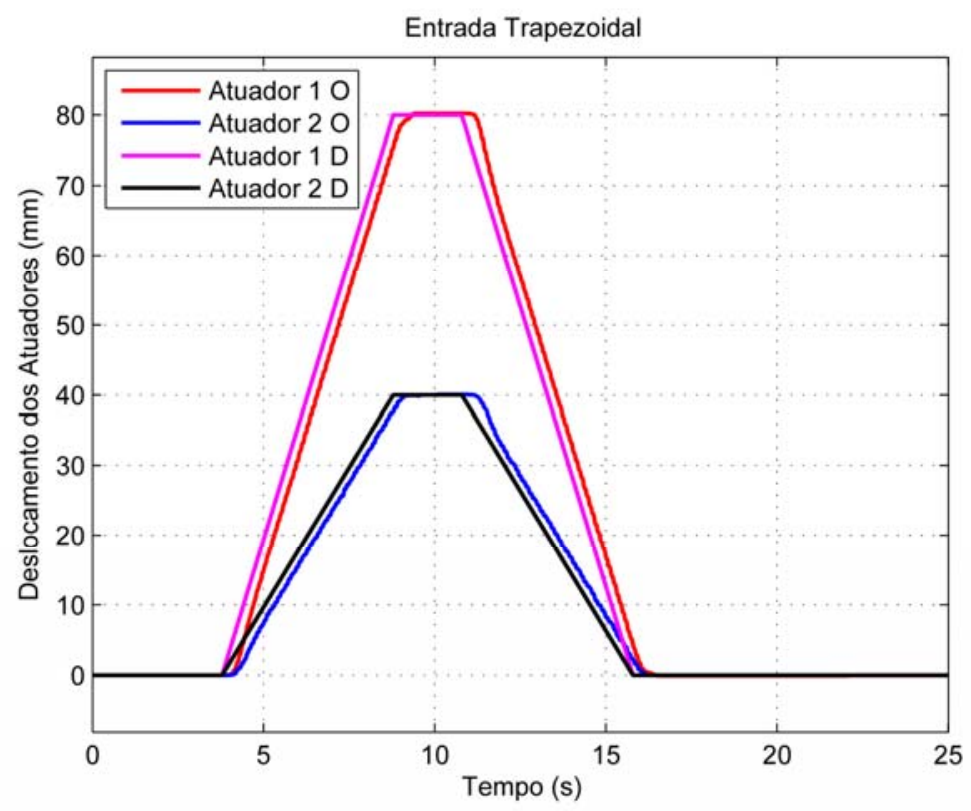

Figura 8.23 - Deslocamento dos atuadores para uma entrada trapezoidal.

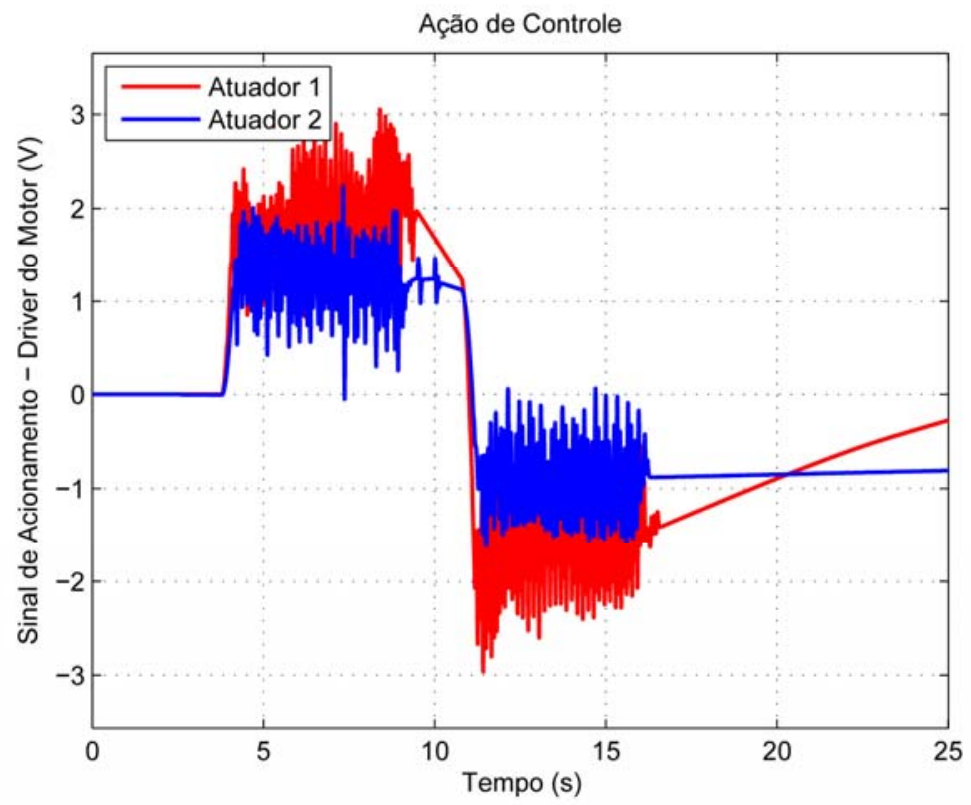

Figura 8.24 - Ação de controle para uma entrada trapezoidal.

Observa-se, na Figura 8.23, que a resposta do sistema converge para o valor desejado desde que a entrada do sistema seja contínua por partes. Como foram atribuídos apenas 
autovalores reais e não houve saturação do sistema e nem ponto de singularidade durante o movimento, então, espera-se uma resposta não oscilatória, sem overshoot. O fato dos autovalores terem sido escolhidos próximos, indica que o comportamento de resposta, mesmo sendo superamortecido, está próximo de um comportamento crítico. Embora não deva ter overshoot, o sistema apresentou 0,2189 mm para o atuador 1 e o erro de regime foi de 0,2170 $\mathrm{mm}$ considerando o deslocamento de $80 \mathrm{~mm}$. Se for desconsiderado o erro de regime o valor do overshoot cai para $0,0019 \mathrm{~mm}$. Para o atuador 2 não houve overshoot, mas somente um erro de regime de $0,0463 \mathrm{~mm}$ considerando um deslocamento de $40 \mathrm{~mm}$. Após retornar ao zero o erro de regime do atuador 1 foi de $-0,0597 \mathrm{~mm}$ e do atuador 2 de $-0,0032 \mathrm{~mm}$, não havendo overshoot.

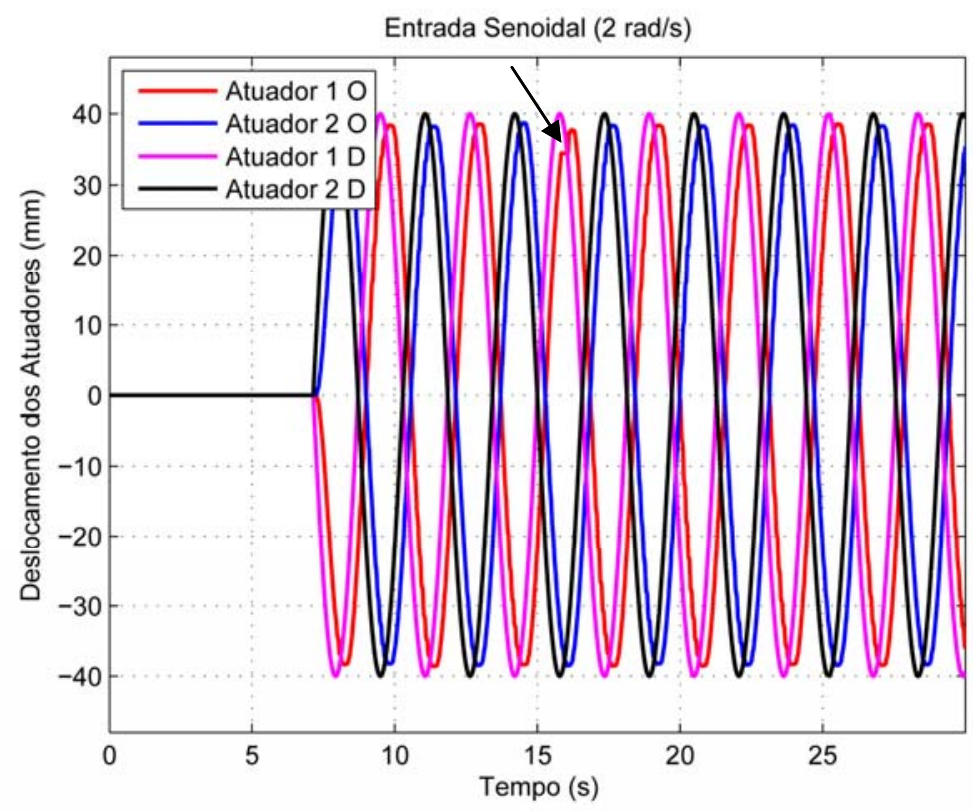

Figura 8.25 - Deslocamento dos atuadores para uma entrada senoidal de $2 \mathrm{rad} / \mathrm{s}$

Durante os ensaios pode-se observar, o que parece ser um breve travamento do atuador quando aumentamos a velocidade de deslocamento do atuador (Figura 8.26). Embora, com esse distúrbio, o sistema continuou a atuar a fim de corrigir o problema sem divergir (Figura $8.25)$. 


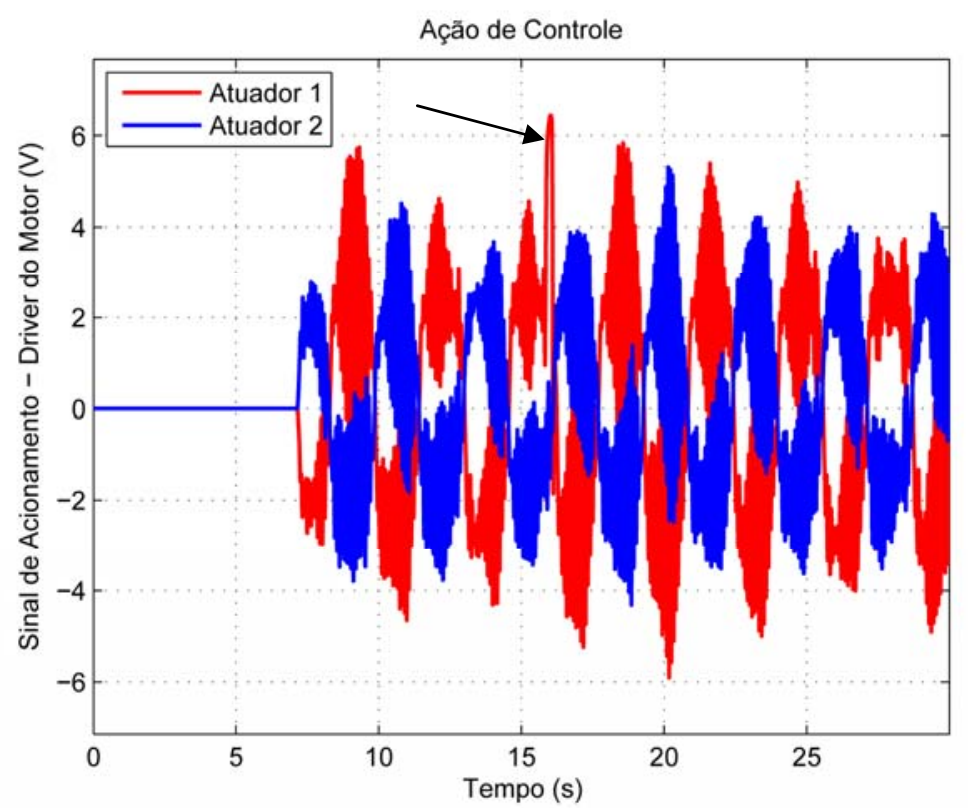

Figura 8.26 - Ação de controle para uma entrada senoidal de $2 \mathrm{rad} / \mathrm{s}$

Pode-se observar que o sistema de controle foi eficiente para vários tipos de entradas e tempos de resposta diferentes, levando-se em consideração as limitações do equipamento. O desempenho do sistema pode ainda ser incrementado, ou seja, podem-se aumentar os autovalores do sistema já que o driver do motor possui entrada analógica, para ação de controle, de $\pm 10 \mathrm{~V}$ e na maioria dos casos utilizou-se $70 \%$ da potência do motor, ou menos. Deve-se observar se o atuador não passará do seu limite de velocidade, pois pode vir a ter um desgaste prematuro. 


\section{CONCLUSÕES E PROPOSTAS PARA TRABALHOS FUTUROS}

\subsection{Conclusões}

Conclui-se, através do demonstrado até aqui, que o método de identificação de características inerciais teve um resultado superior ao esperado. A metodologia mostrou-se fácil, rápida e precisa, podendo ser executada através de procedimentos técnicos bem definidos.

A utilização do software de modelagem dinâmica $A D A M S^{\circledR}$ foi de extrema importância para dar flexibilidade e rapidez na obtenção do modelo dinâmico, e assim, poder fazer vários testes a fim de aproximar o protótipo virtual do modelo real, principalmente quando houver complexidades no modelo como cadeia cinemática fechada, vários graus de liberdade ou não linearidades difíceis de serem modeladas. A interface gráfica do $A D A M S^{\circledR}$ facilita a construção do modelo, embora para geometrias mais complexas seja melhor utilizar um sistema CAD e importar o modelo para o $A D A M S^{\circledR}$. A utilização do $A D A M S^{\circledR}$, reduz bastante o tempo para se obter um novo modelo para ser testado, possibilitando testar várias alternativas de forma rápida e verificar quais opções são mais eficientes.

O sistema seguidor utilizado é eficiente para o controle de orientação do modelo real da plataforma e apresenta boa acuracidade, mesmo para grandes deslocamentos. No entanto, o controle possui um erro durante os períodos de transição, que podem ser minimizados aumentando-se os autovalores do sistema, desde que, para isso, se tenha potência no sistema de acionamento. Demonstrou ser eficiente mesmo na presença de ruídos, na ação de controle, devido a vibrações no fuso de esferas. Pequenos travamentos a alta velocidade, para os atuadores, também não foram suficientes para instabilizar o sistema.

Já que devido à linearização do modelo feita pelo $A D A M S^{\circledR}$; gerando um sistema de matrizes onde a matriz resultante da multiplicação de $\boldsymbol{C}$ por $\boldsymbol{B}$ conhecida como parâmetro de Markov possui posto nulo que impossibilita a utilização de algumas técnicas de controle para sistemas multivariáveis como sistema seguidor com realimentação de saída, então, recomenda-se que se estude a utilização de outras técnicas de controle como $H_{\infty}$, controle 
ótimo ou técnicas de controle não linear como lógica difusa ou redes neurais para obter um controle eficiente e sem erro durante as transições.

Através desta metodologia pode-se testar a plataforma para várias condições de vôo de uma aeronave. Pode-se então dimensionar o sistema de acionamento para que este disponha da energia suficiente para realizar os movimentos com as acelerações desejadas, dando a sensação de se estar pilotando uma aeronave real. E as características de respostas serão determinadas pelos autovalores atribuídos ao sistema no projeto do sistema de controle.

Como já foi dito anteriormente, pode-se testar vários tipos de controles e verificar os que melhor se adaptam às necessidades de forma rápida. Pode-se, também, variar as configurações da plataforma de movimento e realizar os estudos necessários a fim de definir a configuração que melhor se enquadra na aplicação desejada.

Embora esta metodologia tenha sido aplicada a uma plataforma de movimento com o intuito de se estudar o comportamento de um simulador de vôo, o método pode ser usado para modelar e simular outros tipos de sistemas como suspensão ativa, piloto automático de um automóvel, robôs, garras robóticas, trens de pouso de aviões, etc. O objetivo do trabalho foi testar e definir uma metodologia para identificação e controle de sistemas complexos com muitos graus de liberdade de forma rápida e eficiente.

\subsection{Propostas para Trabalhos Futuros}

Para os trabalhos futuros pode-se testar algumas alternativas cujo custo pode variar muito dependendo das escolhas. A instrumentação do atuador e o acionamento do mesmo são duas coisas que podem influenciar significativamente no custo final do projeto. Se o acionamento for feito com um servomotor CA e um driver de potência com entrada analógica de $\pm 10 \mathrm{~V}$, seja o fabricante de origem nacional ou não, o custo desta tecnologia difere em muito se utilizarmos um motor de corrente contínua com um driver de acionamento utilizando tecnologia MOSFET (Metal Oxide Semiconductor Field Effect Transistor) em uma ponte H controlada através de lógica digital para fazer a inversão de sentido e de um PWM (Pulse Width Modulation) pra controlar a potência. Em muitos casos, escolhendo adequadamente a relação de transmissão entre o motor e o fuso de esferas e a potência do motor CC pode-se conseguir um bom desempenho. $\mathrm{O}$ acionamento de um motor de corrente contínua pode ser 
projetado e construído com uma redução significativa de custo sem grandes prejuízos, seja através das proteções contra sobre carga ou de desempenho. Lembrando que um motor de corrente contínua em malha fechada através de um sensor tipo encoder pode ser uma solução precisa e de baixo custo, principalmente se o encoder for adquirido somente o elemento sensor e o disco para o caso de medição angular e elemento sensor e a fita para o caso de medição linear. Cabendo ao projetista definir um invólucro capaz de acomodar os elementos de forma apropriada e de definir uma interface de comunicação imune a ruídos e de fácil implementação, como através de uma interface diferencial RS-422, com o encoder trabalhando em quadratura, sendo possível trabalhar em 1x, 2x ou 4x, quando o mesmo for incremental. Utilizando uma medição indireta através de um encoder óptico angular no motor consegue-se uma alta precisão com baixo custo de forma fácil, sem grandes problemas para adquirir os componentes e adequá-los à aplicação. Já para uma medição direta do deslocamento linear do fuso, não é tão fácil adquirir sensores e fitas com a precisão adequada e de baixo custo. É aconselhável utilizar réguas digitais comerciais. Além do que é mais interessante usar um sensor absoluto para essa medição ao invés de um incremental, isso facilita o controle do simulador de vôo já que a medição não é zerada quando se desenergiza o sensor. Mas a escolha por utilizar um sensor absoluto aumenta os custos da aplicação. Uma solução seria utilizar foto-interruptor com a finalidade de indicar a posição zero do atuador e também como proteção através de fins de curso. Desta forma verifica-se a necessidade de se instrumentar e acionar um atuador para tornar mais econômica, sem perder a eficiência, para construção do simulador de vôo. Como ponto de partida para a escolha do atuador cita-se a linha electrak 2000 que apresenta características que facilitam a instrumentação e garantem a eficiência do simulador de vôo. Existem vários fabricantes que fornecem atuadores com características semelhantes aos desta linha da Warner Electric (Figura 9.1).

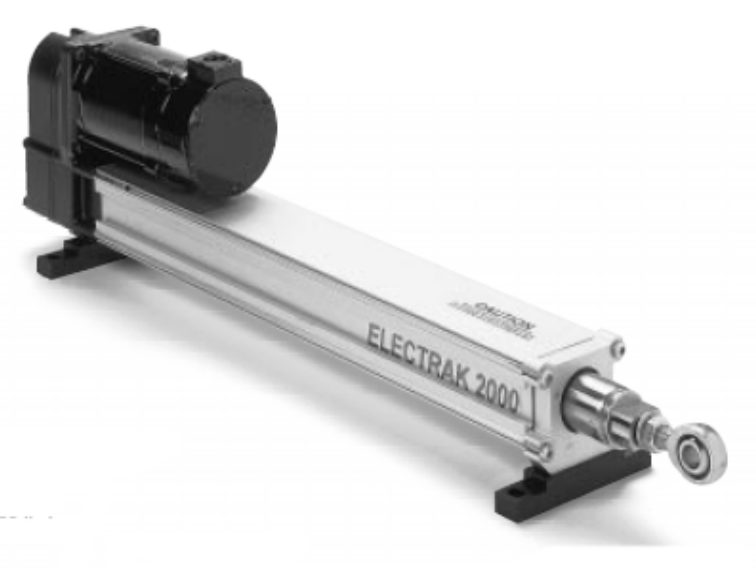

Figura 9.1 - Atuador da linha Electrak 2000, Warner Electric. 
Uma forma prática de simplificar o modelo dinâmico do simulador de vôo é utilizar realimentação de força no sistema de acionamento do atuador, isso faz com que não seja necessário modelar e identificar o sistema de acionamento. O que facilita inclusive quando se deseja variar o tipo de acionamento para analisar as características de resposta do sistema. Para tanto, será necessário medir a força que o atuador está realizando e comparar com a ação de controle determinada pelo controlador e através desse erro e de um sistema PID convencional corrigir a ação do sistema de acionamento. Deve-se observar que as inércias relativas ao sistema de acionamento devem ser levadas em conta, só não sendo necessário modelar o princípio de funcionamento do sistema de acionamento através de leis da física que descrevem o mesmo. Para medir o esforço do qual a haste do atuador está sujeita é necessário utilizar extensômetros colados à própria haste ou ainda através de células de carga que poderão ser adaptadas à haste. Para fechar a malha de controle do sistema de acionamento e implementar um controlador PID pode-se desenvolver uma eletrônica embarcada utilizando um microcontrolador para processar o algoritmo do controlador PID na forma digital com uma eletrônica analógica para condicionar o sinal da célula de carga ou dos extensômetros e compará-lo com o sinal enviado pela placa de controle. Esta eletrônica poderia já estar interligada com a instrumentação do atuador, bem como, com o sistema de fins de curso. Proporcionando um sistema com a entrada sendo a força que o atuador deverá realizar, as saídas podem ser posição ou velocidade do atuador com sinais já condicionados e ainda conter os dispositivos de proteção necessários para interromper o funcionamento quando houver algum risco de dano ao equipamento. 


\section{REFERÊNCIAS ${ }^{12}$}

ABBASI, W. A. et al. Investigation a special 6-6 parallel platform for contour milling. Asme Journal of Manufacturing Science and Engineering, New York, v. 122, n.1, p. 132-139, 2000 .

ADVANI, S. K.; BAARSPUL, M. Design philosophies of the basic research simulator. In: CONGRESS OF THE INTERNATIONAL COUNCIL OF THE AERONAUTICAL

SCIENCES, 18., 1992, Beijing. Proceedings... China, 1992. p. 2134-2143.

BEER, F. P.; JOHNSTON, E. R. Mecânica vetorial para engenheiros: estática. $3^{\text {a }}$ ed. São Paulo: McGraw-Hill do Brasil, 1980.

BEN-HORIN, R.; SHOHAM, M.; DJERASSI S. Kinematics, dynamics and constrution of a planary actuated parallel robot. Robotics and Computer-Integrated Manufacturing, New York, v. 14, n.2, p. 163-172, 1998.

CAPORALI, A. S. Estratégias de controle não-convencional para uma plataforma de Stewart acionada hidraulicamente. 2003. 201 f. Tese (Doutorado em Engenharia Mecânica) - Escola de Engenharia de São Carlos, Universidade de São Paulo, São Carlos, 2003.

CHAE, S. et al. Adaptive control of a 6 d.o.f. Stewart Platform based machine tool. In: MOVIC 98- INTERNATIONAL CONFERENCE ON MOTION AND VIBRATION CONTROL, 4., 1998, Zurich. Proceedings... Switzerland, 1998.

CRAIG, J. J. Introduction to robotics: mechanics and control. Massachusetts: AddisonWesley Publishing Company, 1989.

DASGUPTA, B.; MRUTHYUNJAYA, T.S. The Stewart Platform manipulator: a review. Mechanism and Machine Theory, Elmsford, v. 35, n. 1, p. 15-40, 2000.

D’AZZO, J. J.; HOUPIS, H. C. Linear control system analysis and design: conventional and modern. $3^{\text {th }}$ ed. New York: McGraw Hill Publishing Company, 1988.

DO, W. Q. D.; YANG, D. C. H. Inverse dynamics analysis and simulation of a platform type of robot. Journal of Robotic Systems, New York, v. 5, n. 3, p. 209-227, 1988.

DURFEE, W. K.; IDRIS, H. R.; DUBOWSKY, S. Real time control of the MIT vehicle emulator system. In: AMERICAN CONTROL CONFERENCE. 1991, Boston.

Proceedings... Evanston: American Automatic Control Council, 1991.

FICHTER, E. F. A Stewart Platform-Based manipulator: general theory and practical construction. International Journal of Robotics and Research, Cambridge, v.5, n.2, p.157$182,1986$.

GENG, Z. et al. On the dynamics model and kinematic analysis of a class of Stewart Platform. Robotics and Autonomous Systems, Amsterdam, v.9, p.237-254, 1992.

\footnotetext{
${ }^{12}$ De acordo com Associação Brasileira de Normas Técnicas. NBR 6023.
} 
GENG, Z.; HAYNES, L. Neural network solution for the forward kinematics problem of a Stewart Platform. In: IEEE INTERNATIONAL CONFERENCE ON ROBOTICS AND AUTOMATION, 1991, Sacramento. Proceedings... California: IEEE, 1991. p 2650-2655.

GENG, Z. J.; HAYNES, L. S. Six degree-of-freedom active vibration control using the Stewart Platforms. IEEE Transactions on Control Systems Technology, New York, v.2, n.1, p. 45-53, 1994.

GOGU, G. Structural synthesis of parallel robots: Part 1: methodology. $1^{\text {st }}$ ed. New York: Springer Science + Business Media, 2008. (Solid mechanics and its applications, v. 149).

GRAF, R.; VIERLING, R.; DILLMAN, R. Active acceleration compensation using a Stewart-platform on a mobile robot. In: EUROMICRO WORKSHOP ON A ADVANCED MOBILE ROBOTS, 2., 1997, Brescia. Proceedings... Los Alamitos/CA: IEE Computer Society Press, 1997. p. 59-64.

GRAF, R.; VIERLING, R.; DILLMAN, R. A flexible controller for a Stewart Platform. In: INTERNATIONAL CONFERENCE ON KNOWLEDGE-BASED INTELLIGENT ELECTRONIC SYSTEMS, 2., 1998, Adelaide. Proceedings... Piscataway: IEE, 1998. p. 5259.

GRAF, R.; VIERLING, R.; DILLMAN, R. Acceleration compensation using a Stewartplatform on a mobile robot. In: EUROMICRO WORKSHOP ON ADVANCED MOBILE ROBOTS-EUROBOT 99. 2., 1999, Zurich. Proceedings... Switzerland: IEEE Computer Society Press, 1999. p. 17-24.

GREENWOOD, D. T. Principles of dynamics. $2^{\text {nd }}$ ed. Englewood Cliffs: Prentice Hall, 1988.

HOOTSMANS, N. A. M.; DUBOWSKY, S.; MO, P. Z. Large motion control of an experimental mobile manipula with limited sensing. In: SCIENCE ANNUAL

CONFERENCE, 31., 1992, Kumamoto. Proceedings... Japan, 1992. p. 833-841.

JI, K. Dynamic decomposition for Stewart Platforms. ASME Journal of Mechanical Design, New York, v. 116, n. 1, p. 67-69, 1994.

KANG, J. Y.; KIM, D. H.; LEE, K. I. Robust tracking control of Stewart Platform. In: CONFERENCE ON DECISION AND CONTROL, 35., 1996, Kobe. Proceedings... Japão: IEEE Computer Society Press, 1996. v.3, p. 3014-3019.

KIM, J. H. et al. A design and characteristic analysis of the motion base for vehicle driving simulator. In: IEEE INTERNATIONAL WORKSHOP ON ROBOT AND HUMAN COMMUNICATION, 6., 1997, Sendai. Proceedings... Japan: IEEE Computer Society Press, 1997. p. 290-294.

KOEKEBAKKER, S. H.; TEERHUIS, P. C.; Van der WEIDEN, A. J. J. Alternative parametrization in modelling and analysis of a Stewart Platform. Select Topics in Identification, Modeling and Control, v. 9, p. 59-68, Dec. 1996.

KOEKEBAKKER, S. H.; TEERHUIS, P. C.; Van der WEIDEN, A. J. J. Multiple level control of a hydraulic driven flight simulator motion system. In: IEEE SYSTEMS, MAN 
AND CYBERNETICS IMACS CONFERENCE, 2., 1998, Hammammet. Proceedings... Túnisia: IEEE Computer Society Press, 1998. p 43-49.

KOSUGE, K. et al. Computation of parallel link manipulator dynamics. In: INTERNATIONAL CONFERENCE. ON INDUSTRIAL ELECTRONICS CONTROL AND INSTRUMENTATION IECON'1993, 1993, Mauí. Proceedings... USA: IEEE, 1993. v.3, p. 1672-1677.

KOSUGE, K. et al. Force control of parallel link manipulator with hydraulic actuators. In: IEEE INTERNATIONAL CONFERENCE ON ROBOTICS AND AUTOMATION, 1996, Minneapolis. Proceedings... Minnesota: IEEE, 1996. p 305-310.

LEBRET, G.; LIU, K.; LEWIS, L. Dynamic analysis and control of a Stewart Platform Manipulator. Journal of Robotic Systems, New York, v. 10, n. 5, p. 629-655, 1993.

LEE,S. et al. Position control of a Stewart platform using inverse dynamics control with approximate dynamics. Mechatronics, v.13, n. 6, p. 605-619, Jul. 2003.

LI, D.; SALCUDEAN, S. E. Modeling, simulation, and control of a hydraulic Stewart Platform. In: IEEE INTERNATIONAL CONFERENCE ON ROBOTICS AND

AUTOMATION, 1997, Albuquerque. Proceedings... New Mexico: IEEE, 1997. p. 33603366.

LUO, M. Development of a Stewart platform-based 6-axis force sensor for robot fingers. In: INTERNATIONAL CONFERENCE ON CONTROL, AUTOMATION AND SYSTEM, 2005, Gyeong Gi Do. Proceedings... Korea: ICCAS, 2005.

McLEAN, D. Automatic flight control systems. New York: Prentice Hall International, 1990.

MERLET, J. P. Force-feedback control of parallel manipulators. In: IEEE INTERNATIONAL CONFERENCE ON ROBOTICS AND AUTOMATION, 1988, Philadelphia. Proceedings... Philadelphia: IEEE Computer Society Press, 1988. p. 14841489.

MERLET, J. P. Paralell robots. Dordrecht: Kluwer Academic Publishers, 2000.

MUCHERONI, M. F. Mecânica aplicada às máquinas. São Carlos: EESC - Universidade de São Paulo, 2000.

NANUA, P.; WALDRON, K. J.; MURTHY, V. Direct kinematic solution of a Stewart Platform. IEEE Transactions on Robotics and Automation, New York, v. 6, n. 4, p. 438444, 1990.

NGUYEN, C. C.; POORAN, F. Dynamic analysis of a 6 dof CKCM robot end-effector for dual-arm telerobot systems. Robotics and Autonomous Systems, Amsterdam, v. 5, n. 4, p. 377-394, 1989.

NGUYEN, C. C. et al. Efficient computation of forward kinematic and Jacobian matrix of a Stewart platform-based manipulator. In: IEEE SOUTHEASTCON'1991, 1991, Williamsburg. Proceedings... Virginia: IEEE Computer Society Press, 1991a. p. 869-874. 
NGUYEN, C.C. et al. Experimental study of motion control and trajectory planning for a Stewart Platform robot manipulator. In: IEEE INTERNATIONAL CONFERENCE ON ROBOTICS AND AUTOMATION, 1991, Sacramento. Proceedings... Califórnia: IEEE Computer Society Press, 1991b. p. 1873-1878.

NGUYEN, C. C. et al. Adaptive control of a Stewart Platform-Based manipulator. Journal of Robotic Systems, New York, v. 10, n. 5, p. 657-687, 1993.

PIRLING, T. et al. A new instrument for strain imaging in engineering materials and components. Materials Science \& Engineering A, Lausann, v. 437, n. 1, p. 139-144, 2006.

RYAN, R. R. ADAMS - Multibody systems analysis software. In: SCHIEHLEN, W. (Ed.). Multibody systems handbook. Berlin: New York: Springer-Verlag, 1990.

SILFHOUT, R. G. V. High-precision hydraulic Stewart Platform. Review of Scientific Instruments, v.70, n. 8, p. 3488-3494, 1999.

SILVA, V. R. V. Análise estrutural de uma bicicleta através de simulação conjunta de técnicas de multicorpos e elementos finitos. São Carlos. 1999. 137f. Tese (Doutorado) Escola de Engenharia de São Carlos, Universidade de São Paulo, São Carlos, 1999.

SON, K. et al. A driving simulator of construction vehicles. International Journal of Precision Engineering and Manufacturing, v. 2, n. 4, p. 12-22, 2001.

STEWART, D. A platform with six degrees of freedom. Proceedings of Institution of Mechanical Engineers - Part 1, v.180, n. 15, p.371-386, 1965.

ZANG, C. D.; SONG, S. M. Forward kinematic of a class of parallel (Stewart) Platform with closed-form solutions. In: IEEE INTERNATIONAL CONFERENCE ON ROBOTICS AND AUTOMATION, 1991, Sacramento. Proceedings... Califórnia: IEEE, 1991. p. 2676-281.

ZANG, D. Parallel robotic machine tools. $1^{\text {st }}$ ed. New York: Springer Science Business Media, 2010. 